1.

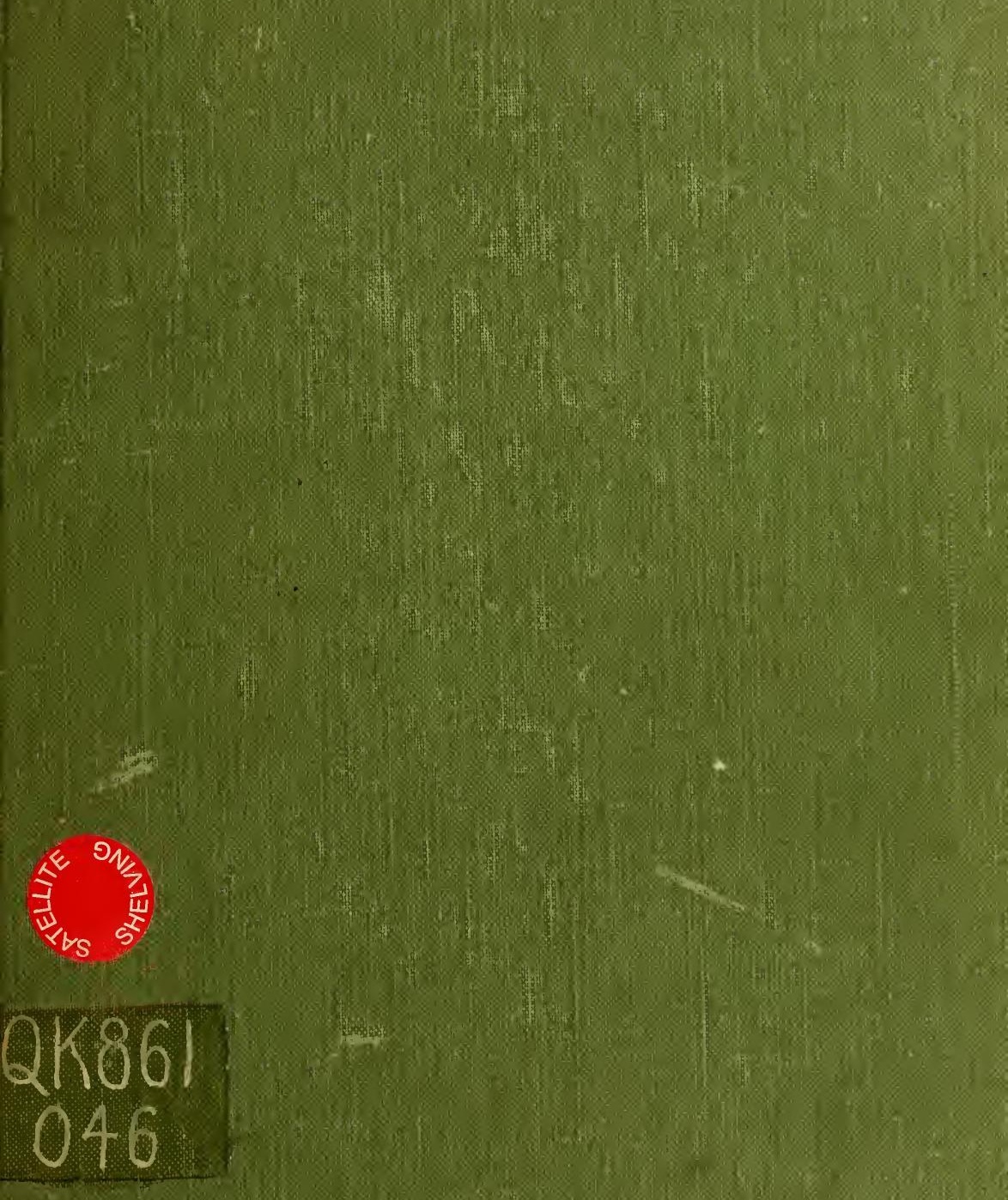




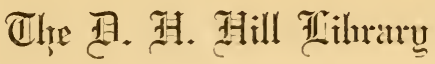

Aurih Carrolinta State College

QK861
O46 


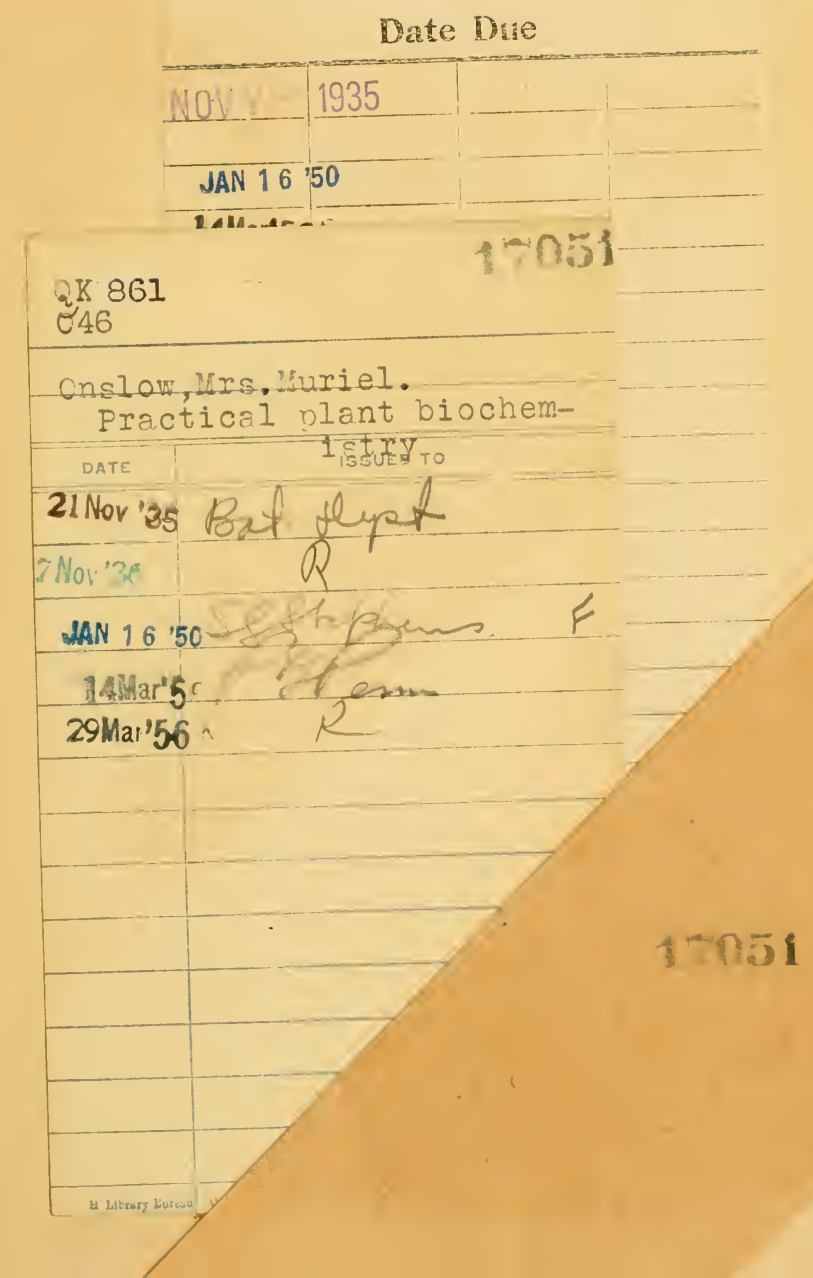





\section{PRACTICAL \\ PLANT BIOCHEMISTRY}


CAMBRIDGE UNIVERSITY PRESS

C. F, Clay, Managek

I.ONDON : FETTER I.ANE, F.C. 4

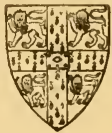

LGNDON : H. K. R.EWIS \& CO., LTD., 136, Gower Street, W. C. I

IONDON : WILLIAM WESLEY \& SON, 28, Essex Street, strand, W.C. ?

NEWYORK : G. P. PUTNAMS SONS BOMBAY

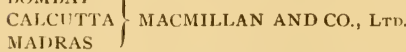

TORONTO: J. M. DENT AND SONS, LTD. TOKY(): MARUZEN-KABUSHIKI-KAISHA

AI.I. RIGHTS RESERVED 


\section{PRACTICAL}

\section{PLANT BIOCHEMISTRY}

BY

\section{MURIEL WHELDALE ONSLOW}

Formerly Fellow of Newnham College, Cambridge, and Research Student at the John Innes Horticultural Institution, Merton, Surrey.

Author of The Anthocyanin Pigments of Plants.

\section{CAMBRIDGE \\ AT THE UNIVERSITY PRESS}

I 920 



\section{PREFACE}

THIS book is intended primarily for students of Botany. Such a student's knowledge of plant products is usually obtained, on the one hand, from Organic Chemistry, on the other hand, from Plant Physiology; between these two standpoints there is a gap, which, it is hoped, the following pages may help to fill. It is essentially a text-book for practical work, an aspect of Plant Biochemistry which has received up to the present time very little consideration in teaching. A number of experiments have been devised ambl have been actually tested in practical classes. These experiments should enable a student to extract from the plant itself the chemical compounds of which it is constituted, and to learn something of their properties. An elementary knowledge of Organic Chemistry on the part of the student has been assumed, as it appeared superfluous to incorporate the material which has already been so amply presented in innumerable text-books.

My sincerest thanks are due to Dr F. F. Blackman, F.K.S., for criticism and many suggestions throughout the writing of the book. I am further indebted to Mr H. Raistrick, M.A., for help in various ways, especially in reading the proof-sheets. I wish, in addition, to express my gratitude to Professor F. G. Hopkins, F.R.S., for the great interest he has always shown in the subject and for his kind and stimulating advice in connexion with the scheme of teaching presented in the following pages.

II. W. O.

Cambridge,

February, 1920.

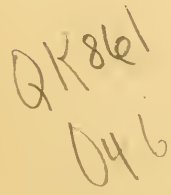





\section{CONTENTS}

CHAP.

PAGE

I. INTRODUCTION . . . . . . . 1

II. THE COLLOIDAL STATE . . . . . 10

III. ENZYME ACTION . . . . . . . 17

IV. CARBON ASSIMLATION . . . . . . 26

V. CARBOHYDRATES AND THEIR HYDROLYZING ENZYMES . . . . . . . 41

VI. THE FATS AND LIPASES . . . . . . 79

VII. AROMATIC COMPOUNDS AND OXIDIZING ENZYMES . . . . . . . 87

VIII. THE PROTEINS AND PROTEASES. . . . 118

IX. GLUCOSIDES AND GLUCOSIDE-SPLITTING ENZYMES . . . . . . . . . 142

X. THE PLANT BASES . . . . . . 154 INDEX . . . . . . . . . . . . 168 



\section{CHAP'TER I}

\section{INTRODUUTION}

This chapter should be re-read after the remaining chapters have been studied.

ALL plants are made up of a complex organized mixture of chemical substances, both organic and inorganic. As a preliminary to the study of plant chemistry, the student should realize that the chemical compounds which make up the living plant may be approximately grouped into the four following classes. Thus, in later chapters, when reference is made to any plant product, it will be understood, broadly speaking, to which class it belongs, and what relationship it bears to other chemical compounds.

The main classes may be enumerated as follows :

(1) Carbohydrates. These contain only carbon, hydrogen and oxygen. The simplest members are the sugars, which are aldehydes and ketones of polyhydric alcohols of the methane series of hydrocarbons. The more complex carbohydrates, such as starch, cellulose, dextrins, gums and mucilages, are condensation products of the simpler sugars. The sugars are found in solution in the cell-sap of living cells throughout the plant. Cellulose, in the form of cell-walls, constitutes an important part of the structure of the plant, and starch is one of the most widely clistributed solid "reserve materials."

(2) Fats. These also contain only carbon, hydrogen and oxygen. Chemically they are glycerides, that is glycerol esters of fatty acids. These acids are derived from two series of hydrocarbons, i.e. the methane series and the olefine series, and they usually contain a large number of carbon atoms. The fats occur as globules deposited in the cells, especially in the tissues of seeds where they form reserve materials, though they also occur in other parts of plants. The acid components of the fats are also found in the free state.

The carbohydrates and the fats both belong to the aliphatic series of organic compounds, that is to the series in which the carbon atoms are united in chains.

(3) Aromatic compounds. These are characterized by having the carbon atoms united in a ring, as in benzene. They may contain more than one carbon ring, and, moreover, aliphatic groupings may be attached 
to the carbon ring as side-chains. The number of aromatic substances is very great, and every plant contains representatives of the class. Some members are widely distributed; others, as far as we know, are restricted in their distribution, and may be peculiar to an order, a genus or even a species. This class contains the various phenols, i.e. hydroxyderivatives of benzene, such as phloroglucin; and the corresponding acids, i.e. hydroxy-derivatives of benzoic acid, such as gallic and protocatechuic acids. Just as in the case of the carbohydrates, where simpler compounds may become more complex by condensation, so the aromatic acids, aldehydes, and their derivatives may be condensed to form more complex substances, such as tannins. Other members containing more than one benzene ring are the water-soluble yellow, red, purple and blue pigments of plants, the yellow being hydroxy-flavones and flavonols, the remainder anthocyanins. The simplest aromatics occur in true solution in the cell-sap throughout the plant, and the more complex ones exist in the colloidal state.

Another section of aromatics is represented by the "essential oils." They are heterogeneous in chemical composition, though they are chiefly represented by the hydrocarbons of the terpene series. They also include various alcohols, aldehydes and ketones. They have no relationship with the true fats, but are responsible for many of the well-known scents of plants; as examples may be mentioned limonene in lemons, pinene in Conifers, borneol in Thyme and Rosemary, menthol in Peppermint and camphor in the Camphor tree (Laurus Camphora).

(4) Proteins. This large class contains substances which are in many cases built up of groupings from both the aliphatic and aromatic series. It includes not only the proteins but also their simpler derivatives, the albumoses, peptones and polypeptides. In this case, as before, the simplest derivatives, known as the amino-acids, are synthesized by condensation to form the polypeptides, peptones, albumoses and proteins, in a series of inereasing complexity. The amino-acids are compounds, either of the aliphatic or aromatic series, in which one or more hydrogen atoms are replaced by the radicle $\mathrm{NH}_{2}$. They are soluble and crystalline, but after condensing together, the final product, the protein, only exists in either the solid or the colloidal state. Proteins, in the latter condition, constitute the bulk of the complex material, protoplasm; in the solid state, in the form of grains and granules, they occur as reserve material in the cell.

The above-mentioned classes will be dealt with in greater detail in the later chapters. There are, of course, a large number of other 
substances in the plant, some of which may be includerl with the above, while others form additional small classes, as for instance, the alkaloids: others, again, bear no close relationship to any class, such as the all-important pigment, chlorophyll.

In order to appreciate the subject of plant chemistry, the plant, which is familiar as a botanical entity, must be interpreted in chemical terms. The principal classes of the more essential and widely distributed compounds found in plants have already been indicated on the broadest basis, so that they may now be referred to without additional comment.

From the botanical point of view, the plant may be regarded as a structure composed of many living protoplasmic units enclosed in cellwalls and combined together to form tissues. There are also certain tissues, known as dead tissues, which assist in giving rigidity to the plant. All these structural elements can be translated into terms of chemical compounds.

One of the chemical processes most frequently met with in the plant is that of synthesis by condensation, with elimination of water, of large complex molecules from smaller and simpler molecules. The formation of cellulose, for instance, is a case in point. Cellulose has the composition $\left(\mathrm{C}_{6} \mathrm{H}_{10} \mathrm{O}_{5}\right)_{n}$ and, on hydrolysis with dilute acids, it yields glucose as a final product. Hence it is concluded that the complex molecule of cellulose is built up from the simpler carbohydrate by condensation. The synthesis of proteins from amino-acids affords another example. These acids contain either an aliphatic or aromatic nucleus (let it be $R$ ), and one or more carboxyl and amino groups. Condensation takes place in the plant, with elimination of water, according to the following scheme:

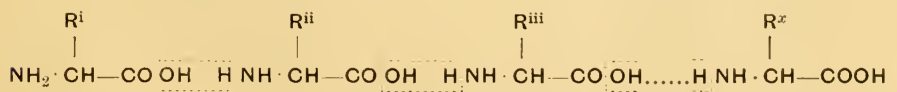

The products of such condensation, the proteins, vary among themselves according to the number and kind of amino-acids which take part in the synthesis.

Two important results arise from this process. First, the substances formed by condensation have molecules of a very large size; secondly, whereas the simple compounds, sugars and amino-acids, are soluble, crystalline and diffusible, the condensation products are either insoluble, e.g. cellulose, or exist in the colloidal state, as is the case of many proteins and other plant constituents. As these very large molecules do not dialyze, 
they remain where they are synthesized, and build up the solid structure of the plant, as for instance, the cell-walls.

Matter in the colloidal state is of very great importance in the plant and is probably responsible for many of the properties of "living" material. Thus it will not be out of place, though it will be referred to again in a later chapter, to make at this point a few remarks on the colloidal state. It has been known for some time that certain metals, e.g. gold and silver, and also certain metallic hydroxides and sulphides, e.g. ferric hydroxide and arsenious sulphide, though insoluble in water under ordinary conditions, can, by special methods, be obtained as solutions which are clear to the unaided vision. Such solutions are termed colloidal. Investigation has shown that the matter is not present in true solution, but in a very finely divided state, i.e. as particles many times larger than simple molecules, but smaller than any particles obtainable by mechanical means of division. Such solutions are known as artificial colloidal solutions, but there are a number of organic substances, with very large molecules, such as proteins, starch, gums, agar, etc., which at once dissolve in water giving colloidal solutions. The main feature of the colloidal state is that the system consists of two phases, or conditions of matter. In the case of the artificial colloidal solutions first mentioned, one state is solid, the gold particles; the other state is liquid, the water. The solid is known as the dispersed phase, and the water as the continuous phase, and such colloidal solutions are termed suspensoids. In the case of proteins, starch, etc., both phases are liquid: the dispersed phase, a concentrated solution of protein, etc.; the continuous phase, a dilute solution of protein, etc. Such colloidal solutions are known as emulsoids.

An important point in connexion with the colloidal state is that the molecules, or aggregates of molecules, forming the dispersed phase are so large that they exhibit some of the phenomena of surface energy, electrical charge, etc., associated with matter in mass. These properties come to be of considerable importance, when we consider how large a surface is presented by matter in this state in comparison with its mass.

A material in the plant upon which much interest naturally centres is the protoplasm and its nucleus. It has been shown that the protoplasm consists, chemically, largely of proteins in the colloidal state. It is itself a liquid, and embedded in it are substances of various chemical constitution, in the form of granules of solid matter and also liquid globules. Numerous chemical reactions are continually taking place in the 
protoplasm throughout the cell, and since many of these reactions can take place both simultaneously and independently, the protoplasm must have some form of organized structure. Though many phenomena of "life" may be accounted for by the physical and chemical properties of such substances as proteins, it is impossible to say, with our present knowledge, how far all "living" phenomena may yet be explained in this way.

Some of the main lines of metabolic syntheses which take place in the plant will next be considered. A fundamental fact which should be borne in mind is that the green plant synthesizes all the complex materials of which it is composed from the simple compounds, carbon dioxide, water and certain inorganic salts. The most important factor, perhaps, which figures in plant metabolism, is chlorophyll. The green pigments of chlorophyll are esters of complex organic acids containing the elements carbon, hydrogen, oxygen, nitrogen and magnesium. They have the remarkable power of absorbing the radiant energy of the sun's rays and of transforming it into chemical energy, by means of which carbon dioxide and water are combined to form some organic compound, possibly formaldehyde, from which a simple carbohydrate is readily synthesized.

If now the initial and final products of carbon assimilation be considered in detail, it will be seen that the process is one of reduction:

$$
6 \mathrm{CO}_{2}+6 \mathrm{H}_{2} \mathrm{O}=\mathrm{C}_{6} \mathrm{H}_{12} \mathrm{O}_{6}+6 \mathrm{O}_{2} .
$$

This is confirmed by the fact that oxygen is evolved in the process. Moreover, the plant accumulates a store of energy, since the final product, the carbohydrate, has a higher potential energy than the system, water and carbon dioxide. Hence carbon assimilation, in addition to providing a basis of organic material as a starting-point for all the main metabolic functions, also provides a source of chemical energy by means of which reactions in other directions are brought about.

The setting free of this accumulated energy constitutes the process of respiration, which is, in reality, an oxidation of carbohydrate taking place in tissues throughout the plant. It is the converse of carbon assimilation, in that oxygen is absorbed and carbon dioxide and water are formed. Thus these two processes, both so fundamental and essential to the metabolism of the green plant, are constantly taking place side by side in the same cell.

The first-formed carbohydrate, which is probably a hexose, is condensed in the plant, on the general lines we have previously indicated, to form more complex disaccharides and polysaccharides, such as maltose, 
cane-sugar, starch, cellulose, etc. Some of these products, such as the disaccharides, form true solutions and may be present in the cell-sap; others, such as cellulose and starch, are present in the solid state, though they contain considerable quantities of water. Others, again, such as dextrin and gum, are present in the colloidal state. Thus, given an initial carbohydrate and a source of energy, we may proceed to indicate the other main lines of syntheses in the plant.

The next most important line of syntheses is probably that which gives rise to the nitrogen-containing constituents of the plant. Nitrogen is absorbed by the green plant in the form of nitrates and ammonium salts, but the processes which lead to the synthesis of some of the simplest nitrogen-containing compounds, such as the amino-acirls, are still very obscure. Aliphatic and aromatic acids of varions kinds are abundantly present in the tissues, but the reactions by which the $\mathrm{NH}_{2}$ groups are introduced are by no means clear. There is little doubt, however, that once the amino-acids are formed, condensation takes place as already indicated, and more complex molecules, termed polypeptides, arise. Such polypeptides have now been synthesized artificially by the condensation of amino-acids. From the polypeptides, by further stages of condensation, the albumoses, peptones, and finally proteins are produced.

Another line of syntheses is that which leads to the production of the fats and allied substances. The fats are mainly glycerides of acids of the methane and olefine series, such as butyric, palmitic and oleic acids. Like ail other plant products the fats must either directly or indirectly arise from the carbohydrates. There is evidence that the origin is fairly direct, as, for instance, in fatty seeds when the fats take the place of sugars in ripening. The sugars, as we know, are aldehydes of the polyhydric alcohols of the methane series. It has been suggested, though the actual stages have not been ascertained, that by various oxidation and reduction processes, the sugars yield fatty acid residues which then condense to form the fatty acids of high molecular weights present in fats. By a converse process, the fats, especially when they are stored as reserve materials in seeds, are broken up, and sugars are again formed which pass to other parts of the germinating seedling, and are there userl in other synthetic processes.

A third main line of syntheses is that which gives rise to the aromatics of the plant. Since no ring compound is absorbed by the green plant, it follows that by some process the aliphatic structure must be transformed into the aromatic. Thus, for instance, the trihydric phenol, 
phloroglucin, might at some stage be formed from a hexose by conversion of the aliphatic chain into a closed ring:
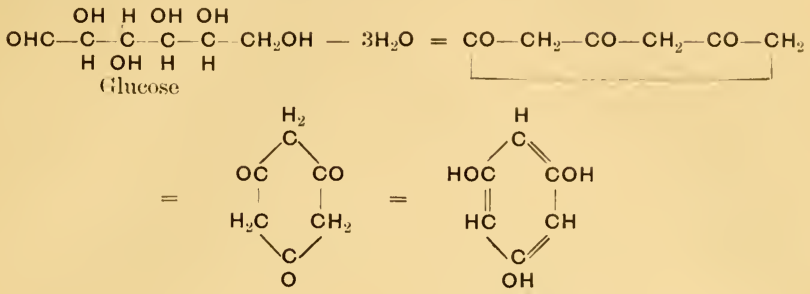

Phloroglucin

There is evidence that aromatic compounds, such as phloroglucin, tannins, flavones and anthocyanins are synthesized in the leaves, and that sugar-feeding, by floating leaves in sugar solutions, leads to the increase of aromatics in the tissues. When the ring structure has been once synthesized, further changes can take place either by the addition of side-chains to the ring or by the condensation of two or more rings. In this way the great multitude of aromatic products present in the higher plants may arise.

Thus the cell can be pictured as a colloidal solution of proteins endowed with the properties of nfatter in mass and surrounded by a permeable cell-wall of cellulose. The colloidal solution contains liquid and solid particles of very varied chemical composition. In the protoplasm are spaces, vacuoles, filled with cell-sap also containing many and various substances in solution. Throughout the protoplasm, which probably has an organized structure, many kinds of chemical reactions are continually in progress, some being the converse of others, as for instance those of oxidation and reduction which can take place side by side in the same cell.

Next will be considered the chemical reactions by which the various metabolic changes in the plant are brought about. How are these processes controlled and how do they take place?

There is a large group of organic substances, termed enzymes, many of which are present in every plant. They have a certain characteristic in common, i.e. they bring about chemical reactions in the plant without undergoing any permanent change: in other words they are organic catalysts. Many of these reactions, which take place in the cell at ordinary temperatures with considerable rapidity, need prolonged heating at high temperatures when brought about by artificial means. Enzymes 
can generally be extracted from the plant by water, especially if the tissues are thoroughly disintegrated. Their chemical constitution is at present unknown, and they are usually destroyed by temperatures greater than $60^{\circ} \mathrm{C}$. Moreover, many of the processes which they control in the plant can be brought about by them in vitro under suitable conditions, and it is by means of such experiments that information as to their rôle in plant metabolism has been ascertained. The majority of known enzymes control both hydrolysis and its converse, synthesis by condensation with elimination of water, but under artificial conditions hydrolysis most frequently occurs. The enzyme, diastase, for instance, found in all starch-containing plants hydrolyzes in vitro starch to dextrin and maltose. Similarly the enzyme, maltase, hydrolyzes maltose into glucose. Other enzymes hydrolyze proteins into amino-acids, and others, again, hydrolyze fats into fatty acids and glycerol.

Until fairly recently the fact escaped notice that such reactions are reversible, and that these enzymes in situ in the plant may, according to the conditions, control not only the hydrolytic but also the corresponding synthetic process. The latter may also be brought about, though not readily, in vitro. This, and other evidence, leads us to believe that enzymes in the plant control the reactions in both directions.

Hydrolysis, and synthesis with elimination of water are not however the only processes catalyzed by enzymes. There is another type of these catalysts, the oxidizing enzymes, which bring about oxidation of substances in the plant, notably of aromatics. In addition, there is the enzyme, zymase, which decomposes sugar with the production of alcohol and carbon dioxide.

The question which now arises is-How many reactions in the plant are catalyzed by enzymes? It is conceivable that a greater number of enzymes may exist than are at present known, but that they are unable to be extracted by our present methods of isolation. A certain number of reactions probably take place in the cell-sap between the substances in solution; others are catalyzed by enzymes which are supposed to be intimately connected with the protoplasm, but there are an enormous number to which there is at present no clue as to how they are brought about, such, for instance, as the synthesis of carbohydrates from carbon dioxide and water, and the formation of the benzene ring from the open carbon chain. Such processes are usually said to be controlled by the "living protoplasm," but what exactly is the significance of this expression is at present beyond our knowledge.

Finally, also, little is known of the question as to how the various 
lines of metabolic syntheses in different parts of plants are regulated and correlated with each other. Some of the phenomena involved are shortly outlined as follows. There is undoubtedly, under suitable conditions, a constant synthesis of sugars in the leaves. In all probability aromatic substances are also synthesized in the same organs, for there is evidence that there is an increase of these compounds in the leaf if translocation through the petiole is prevented. It is possible that amino-acids also are formed in the leaf. The above products are constantly translocated to the growing organs as material for growth. They may, nevertheless, be temporarily stored in the tissues where they have been synthesized, and of this there is evidence in at least one case, e.g. starch in the leaf. But, apart from the immediate use for growth, there is in practically every plant, some tissue where, owing to some unknown stimulus (causing probably changes in permeability of the cell-membranes), accumulation of compounds occurs. This accumulation is characteristic of organs from which growth will take place when it is impossible for the plant to obtain fresh supplies by carbon assimilation, as, for example, of bulbs, rhizomes, tubers, buds, seeds, fruits and woody tissues. In these cases, in due time, the products stored supply the growing shoots.

During storage, simple sugars, amino-acicls, etc. have been condensed to form insoluble, colloidal, or large molecules of starch, fats, aleurone, cane-sugar, etc. These will remain until they are hydrolyzed by enzymes when they can supply the growing shoots. Such stores are termed "reserve materials." The actual stimuli involved in bringing about and regulating this storage are unknown, but they are probably connected with the life cycle of the particular plant under consideration and its adaptation to external conditions.

\section{REFERENCES}

1. Abderhalden, E. Biochemisches Handlexikon. Berlin, 1911.

2. Allen's Commercial Organic Analysis. London, 1909-1917.

3. Cole, S. W. Practical Physiological Chemistry. Cambridge, 1919. 5th ed.

4. Czapek, F. Biochemie der Pflanzen. Jena, 1905.

5. Haas, P., and Hill, T. G. The Chemistry of Plant Products. London, 1917. 2nd ed.

6. Palladin, V. I. Plant Physiology. Edited by B. E. Livingston. Philadelphia, 1918.

7. Plimmer, R. H. A. Practical Organic and Biochemistry. London, 1918. 3rd ed. 


\section{CHAP'TER II}

\section{THE COLLOIDAL STATE}

Mavy of the substances of which the plant is built up exist in the living cell in the colloidal state, and it is therefore important that some account should be given of this condition of matter.

There are many organic products found in the plant (and also in the animal), such as starch, various proteins, gums, etc., that apparently dissolve in water, giving a solution which, as a rule, only differs from an ordinary solution by being opalescent. In addition, it has been known for a long time that various inorganic substances, such as sulphides of arsenic and antimony, hydroxide of iron, and also certain metals (gold, silver), can, by special methods, be obtained in "solution," though in ordinary circumstances they are quite insoluble. The above examples are representative of colloidal solutions.

A property which all the above solutions possess is that the substance dissolved will not pass through a parchment membrane, i.e. will not dialyze, whereas if a solution of sorlium chloride in water is separated from pure water by a parchment membrane, the salt will pass through the membrane until the concentration of the sodium chloride is equal on either side of it.

The conclusion drawn from investigations of various kinds is that in the colloidal solutions the substances dissolved exist in the state, either of aggregates of molecules, or of very large molecules, and hence are unable to pass through the pores of the parchment.

Moreover, certain distinctions can be drawn between colloidal solutions: soine, like those of gold, silver, metallic sulphides, hydroxides and in fact most inorganic substances, are very sensitive to the presence of small amounts of inorganic salts, i.e. electrolytes, and are precipitated by them, but will not as a rule go into solution again. Also such colloirlal solutions are very little more viscous than pure water. The organic substances, on the other hand, are only precipitated from colloidal solutions by comparatively large quantities of electrolytes. The viscosity, moreover, of these solutions is greater than that of water, and is, in fact, considerable, even if the percentage of dissolved matter is small. 
Hence two terms have been employed for the above-mentioned types of colloidal solutions: those of gold, silver, etc., are termed suspensoids (suspensoid sols): those of starch, proteins, etc., emulsoids (emulsoid sols).

The essential feature of both forms is that they are systems consisting of two phases, or conditions of matter, known respectively as the "dispersed" phase and the "continuous" phase.

A suspensoid may be defined as having a dispersed phase composed of ultramicroscopic particles or aggregates of molecules suspended in a continuous phase composed of a liquid.

An emulsoid may be defined as having a dispersed phase composed of ultramicroscopic drops of a highly concentrated solution of the substance suspended in a continuous phase composed of a dilute solution of the same substance.

As a rule, therefore, the difference between a suspensoid and an emulsoid is that, whereas in the former the liquid is restricted to the continuous phase, and the solid to the disperser phase, in an emulsoid both phases are liquid, though containing different proportions of the dissolved substance.

The terms suspensoid and emulsoid are used on account of the resemblance of these states of matter respectively to suspensions and emulsions. If microscopic particles of a solid are shaken up in water, what is known as a suspension is obtained; in time, however, the solid particles, if heavy enough, will settle and separate from the water, and the whole process can be repeated. Thus a suspension differs from a suspensoid solution in that the latter is stable, though, if precipitated, the reaction is usually not reversible.

If two liquids which are insoluble in each other, such as oil and water, are shaken up together, finely divided drops of oil in water are obtained. This is known as an emulsion. In time, however, the oil separates from the water, because the tension on the films of water separating the oil drops, when in contact, is too great, and they break, with the result that the oil drops coalesce. But if, instear of water, a solution of soap, saponins, or certain other substances is used, the surface tension of the water is so lowered that the films of soap solution separating the oil drops are permanent, and a system is obtained consisting of minute drops of oil separated by soap solution. This system resembles an organic colloidal solution, as, for instance, that of protein in which we suppose a concentrated solution of protein exists in drops separated by a dilute solution of protein. Milk and latex constitute natural emulsions: 
Expt. 1. Formation of " suspension. Precipitate a solution of barium chloride with some sulphuric acid and shake up well the fine precipitate of barium sulphate. Note the gradual settling of the precipitate.

Expt. 2. Formation of un emulsion. Take a drop of olive oil in a test-tube and half fill the tube with alcohol. Shake well and pour into a beaker of water. A fine white emulsion of oil in water will be formed from which the oil will not separate. Hy this method the oil is obtained in such small drops that stability is ensured.

Take about equal quantities of olive oil in two test-tubes and add an equal quautity of water to each. To one tube add a drop or two of $10 \%$ caustic alkali solution. Shake both test-tubes well. An emulsion is formed in both, but in the tuhe without alkali the oil will separate out on standing. In the other tube the emulsion is permanent. This is due to the fact that the olive oil (unless specially purified) contains some free fatty acid. The latter forms soap with the alkali (see P. 82) and renders the emulsion permanent.

Expt. 3. Preparation of suspensoid sols. (a) Gold. Take two I00 c.c. measuring cylinders and thoroughly clean them with nitric acid, and afterwards wash well with freshly distilled water. In one make a $0.5 \%$ solution of tannic acid (using the purest sample obtainable) in water. In the other. 2 c.c. of commercial $1 \%$ gold chloride are made up to 100 c.c. with water. Use freshly distilled water in both cases. Mix equal portions of the two solutions in a clean beaker. A purple colloidal solution of gold will be formed. If three parts of the chloride solution are mixed with one part of the tamin solution, and both solutions heated before mixing, a red colloidal solution is obtained. (b) Silver. Take 5 c.c. of a $1 \%$ solution of silver nitrate and add dilute amnonia solution until the precipitate first formed just disappears, and then dilute with 100 c.c. of water. Mix equal volumes of this solution and the tannic acid preprared for ( $\iota)$. A colloidal solution of silver will be formed which is clear brown by transmitted light, but has a green fluorescence by reflected light. (c) Ferric hydroxide. Take 5 c.c. of a filtered $33 \%$ solution of ferric chloride and pour into 500 c.c. of hoiling distilled water in a beaker. A colloidal ferric hydroxide sol is formed and the colour changes to a deep brown-red. The yellow solution of ferric chloride is decomposed by excess of water with the production of a soluble colloidal form of ferric lıydroxide, and hydrochloric acid is set free. (d) Arsenic trisulphide. Take 2 gms. of arsenious acid and boil with 150 c.c. of distilled water, filter and cool. Then pass sulphuretted hydrogen through the solution. A colloidal solution of the sulphide is formed which is orange, with a greenish surface.

The ahove sols should be kept for further experiment [see Expt. 8].

Expt. 4. Preparation of emulsoid sols. (a) Starch. Weigh out 2 gms. of dry starch, and mix well with a little cold distilled water. Boil 100 c.c. of distilled water in a Hask, and, when boiling, pour in the starch paste and boil for a few minutes longer, stirring well all the time. A eolloidal solution of starch is obtained which is faintly opalescent. It is not affected by heating and does not change its state on cooling. (b) Gum arabic. Make a $5 \%$ solution of gum arabic hy boiling 5 gus. with 100 c.c. of distilled water. Note that a sticky or viscous solution is formed which froths on shaking. (c) Protein. Weigh out 10 gms. of white flour and add 100 c.c. of distilled watcr. Let the mixture stand for 2 or 3 hours and then filter. The extract contains protein. Note that the solution froths on shaking. (d) Soap. Make a 5-10\% solution 
of soap in distilled water. It is opalescent and froths strongly. (e) Chloropleyll. [See Expt. 32.]

The above sols should be kept for further experiment [see Expt. 9].

Expt. 5. Dialysis of sturch and salt solution. Make a $2 \%$ solution of starch in water, as in Expt. 2, and mix it with an equal volume of a $2 \%$ solution of sodium chloride in water. Pour the mixture into a parchment dialyzer and dialyze in a beaker of distilled water. (The dialyzer should first be carefully tested to ascertain if there be a leak.) Test the liquid in the beaker with solutions of both iodine and silver nitrate. Some precipitate of chloride will be given, but no blue colour with iodine. After 24 hours, test the liquid again. There will be an increased amount of silver chloride formed, but a negative result with iodine. On addition of iodine to the liquid in the dialyzer, a blue colour is obtained. Hence we may assune that the colloidal starch does not pass through the membrane.

Some substances, such as gelatine (animal) and agar (vegetable), are only in the emulsoid condition at a raised temperature. When cold they set to form a "gel," in which the particles of the dispersed phase are no longer separate but united to make a solid. Silicic acid, the best known inorganic emulsoid, also sets to a gel on standing, either spontaneously or on addition of electrolytes. It is of classical interest since it was the substance largely used by Graham, the first worker on colloids.

Expt. 6. Preparation of gels. (a) Agar. Weigh out 2 gms. of agar and put it to soak in 100 c.c. of distilled water for an hour or two. Then boil : the agar gives a thick opalescent solution (sol) which sets to a gel on cooling. On warming, the gel again becomes a sol, and, on cooling, again sets to a gel. Thus the change is a reversible one. Agar is a mucilage which is obtained from certain genera of the Rhodophyceac (see p. 49). (b) Silicic acid. Weigh out 20 gms. of commercial "waterglass" syrup (a concentrated solution of sodium silicate) and dilute with 100 c.c. of freshly boiled distilled water (free from carbon dioxide). Pour 75 c.c. of this solution into a mixture of 25 c.c. of concentrated hydrochloric acid and 75 c.c. of water. Dialyze the mixture in a parchment dialyzer against ruming water for 3-4 hours. If to the dialyzed liquid a little very dilute ammonia is added, a gel will be formed in the course of a few hours. In this case, however, the process is irreversible, that is the gel cannot be reconverted again into the sol.

An interesting point in connexion with the colloidal state is that emphasized by Ostwald, i.e. that this condition is a state, not a type, of matter. Further, substances in the colloidal state do not constitute a definite class. It is reasonable to suppose that all substances which exist in the colloidal state can, under suitable conditions, also exist in the crystalline state, and vice versa. Further, the continuous phase is not always water. Sodium chloride, which is a very definite crystalloicl, can be obtained in the colloidal state in petroleum ether. Most metals, even the alkali metals, have been obtained in colloidal solution: also a great many metallic oxides, hydroxides and sulphides. 
The colloidal phases so far dealt with can be tabulated as follows':

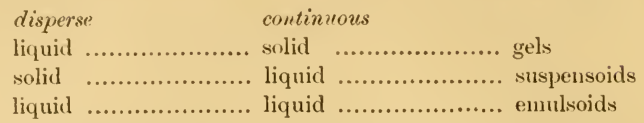

Some of the properties of colloidal solutions may now be considered. $A$ point that has already been emphasized in the previous chapter is that the surface of particles in the colloidal state is very great in propertion to their mass. Such particles, moreover, unlike ions and small molecules in true solution, possess the properties of the surfaces of matter in mass, as, for instance, those connected with surface tension, electrical charge, etc., and these are especially marked on account of the proportionately large surfaces involved. Other properties are their inability, as a rule, to exert an osmotic pressure, to raise the boiling point, and to lower the freezing point of water. Some of the metallic suspensoids are characterized by their colour, this being red, purple or blue as in the case of gold sols.

An apparatus, by means of which the colloiclal state can be demonstrated ocularly, is the ultramicroscope. This is a special form of microscope in which a powerful beam of light is directed upon a colloidal solution, which is then seen to contain a number of particles in rapid motion. When analyzed by special methods, this motion has been found to be identical with that shown by much larger, though still microscopic, particles, which has been termed Brownian movement.

Expt. 7. Demonstration of Browniun morement of microscopic particles. Mount a little gamboge in water and examine under the high power of a microscope. The particles will be seen to be in rapid motion.

It has been shown that Brownian movement is the outcomie of the movement of the molecules of the liquid in which the particles are suspended. This movement is one of the factors which keeps the sol stable and prevents the particles from "settling" as in the case of a true suspension.

Another factor tending to keep the sol stable is the electrical charge borne by the particles. It is commonly known that there is usually a difference of potential between the contact surfaces of phases. If the

1 There are also the following combinations (Bayliss, 1):

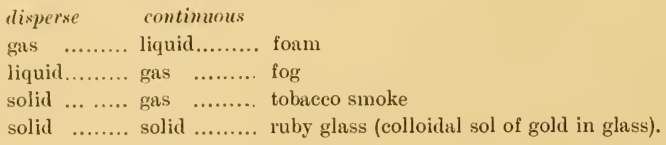


particles in a colloidal solution all have the same charge, then they will tend to repulse one another mutually. It is found that the particles are charged, but the origin of the charge is not always clear. Sometimes if the substance in colloidal state is capable of electrolytic dissociation, the charge may arise in this way. Substances, however, as already mentioned, which are not dissociated may also bear a charge, and most frequently it is a negative one. It follows, then, that when an electrolyte is adderl to a colloidal solution, the charges on the colloidal particles are neutralized by the oppositely charged ions of the electrolyte, and they coalesce together and are precipitated.

As regards their behaviour to electrolytes the two classes, suspensoids and emulsoids, are very different. The suspensoids are very sensitive to traces of electrolytes, and, as they usually have a negative charge, it is the cation of the electrolyte which is the active ion; and of such, less of a divalent ion; than of a monovalent ion, is needed for precipitation and still less of a trivalent ion.

The emulsoids are far less sensitive to electrolytes in solution than the suspensoids; in fact, electrolytes, such as neutral alkali salts, must be added in very large quantities to emulsoids before precipitation takes place. Also, as a rule, whereas the precipitation of suspensoids is irreversible, that of emulsoids is reversible, that is, they pass into solution again on addition of water. In the case of an emulsoid in neutral solution this form of precipitation, unlike that of the suspensoids, may be regarded as consisting of two processes. First, a process analogous to that of "salting out" of soaps, esters, etc., in organic chemistry, which is, in effect, a withdrawal of water from one phase into another. Secondly, the precipitation is also affected to some extent by the valency of the ions of the salt used in precipitation.

When, however, a neutral solution of such an emulsoid as protein is made either slightly acid or alkaline, its behaviour towards neutral salts becomes altered. The precipitating power of salts in acid or alkaline medium is now in accordance with that on suspensoids. In alkaline solution the coagulating power of a salt depends on the valency of the cation; in an acid solution it depends on the valency of the anion.

The behaviour of proteins in acid and alkaline media is undoubtedly due to the fact that they are built up of amino-acids containing both amino and carboxyl groups. Such molecules may behave either as an acid or a base with the formation of salts. These are subject to electrolytic dissociation and hence acquire an electric charge. Such substances have been termed "amphoteric electrolytes" (see p. 120). 
Expt. 8. Precipitution of suspensoid sols by electrolytes. The sols of gold, silver ind arsenious sulphide carry an electro-negative eharge : hence they are most readily preeipitated ly di- or tri-valent positive ions, such as $\mathrm{Ba}^{\prime \prime}$ or $\mathrm{Al}^{\prime \prime}$. Add a few drops of barinm chloride solution to the three sols (Expt. 3) respectively, and note that they are preeipitated, though some time may elapse before the precipitation is complete. The ferrie hydroxide sol, on the eontrary, earries a positive charge. Hence it is most readily precipitated by a sulphate or phosphate. If a drop of sodium sulphate solution is added while the sol is hot, it is immediately precipitated.

Expt. 9. Precipitation of emulsoid sols by electrolytes. Saturate the starch, protein and soap, solutions prepared in Expt. 4 with solid ammonium sulphate. Precipitation takes place in each ease, and it is seen how large a quantity of electrolyte is needed for the "salting out" of emulsoid sols. Filter off the protein precipitate and suspend in distilled water. It will go into solution again, showing that the reaction is reversible.

\section{REFEREN('ES}

1. Bayliss, W. M. Principles of General Physiology. London, 1918. 2nd ed.

2. Burton, E. F. The Physical Properties of Colloidal Solutions. London, 1916.

3. Hatschek, E. An Introduction to the Physies and Chemistry of Colloids. London, 1919. 3rd ed.

4. Philip, J. C. Physical Chemistry: its Bearing on Biology and Medicine. London, 1913. 2nd ed.

5. Taylor, W. W. The Chemistry of Colloids. London, 1915. 


\section{CHAPTER III}

\section{ENZY ME ACTION}

Some indication has been given in the previous chapter of the large number of complex processes which take place in the plant, and it has been mentioned that many of these are controlled by enzymes.

The most remarkable feature in connexion with the chemical processes of plant metabolism is the ease and rapidity with which, at ordinary temperatures, chemical reactions take place, when under artificial conditions they need a much longer time and higher temperatures.

It has been found that many of the chemical reactions in the plant can be brought about in vitro on addition of certain substances which can be extracted from the plant. These substances are known as enzymes. It is the property of enzymes that they are able to accelerate reactions which, in their absence, would only take place very slowly. The enzyme cannot initiate these reactions and does not form part of their final products.

Some inorganic substances have the same property of accelerating reactions, and such substances are termed catalysts. For example, when water is added to ethyl acetate, the latter begins to be decomposed slowly into ethyl alcohol and acetic acid:

$$
\text { ethyl acetate }+ \text { water } \longrightarrow \text { ethyl alcohol + acetic acid, }
$$

but if, in addition, some hydrochloric acid is added, hydrolysis takes place with much greater rapidity, and at the end of the reaction the hydrochloric acid is found mnchanged. Hence in this case hydrochloric acid is an inorganic catalyst. Many other similar instances are known as, for example, the catalyzing effect of a small quantity of manganese dioxide which brings about the liberation of oxygen from potassium chlorate at a much lower temperature than by heat alone.

By analogy, therefore, an enzyme may be defined as an organic catalyst produced by the plant.

Another point in connexion with the above-mentioned reaction of water with ethyl acetate, is the fact of its being representative of the type known as reversible. After a certain amount of acetic acid and ethyl alcohol has been formed, these recombine to form ethyl acetate until in time a certain point of equilibrium is reached. Since the same 
point of equilibrium is reached whether hydrochloric acid is used or not, it is obvious that the hydrochloric acid accelerates the reaction in both dircetions : ethyl acetate + water $\rightleftarrows$ ethyl alcohol + acetic acid.

Such a reaction is termed a reversible one. Many of the processes accelerated by enzymes in the plant are reversible, and there is reason to believe that the enzyme accelerates the reaction in both directions.

The substance upon which the enzyme acts is termed the substrate, and it is supposed that some kind of loose combination occurs between these two substances. The enzyme is unaltered when the reaction is complete, unless it is affected by the products formed.

The enzymes are very widely distributed and form constituents of all living cells, though all tissues do not necessarily contain the same enzymes.

There is no doubt that many enzymes are specific, in which case an enzyme can only accelerate one reaction, or one class of reaction. We cannot be sure that any enzyme is specific and different from all others, until it has been proved that it accelerates one process which is incapable of being accelerated by any other enzyme. It is possible that some enzymes, to which separate names have been given, are really identical.

Most of the plant enzymes are soluble in water and dilute glycerol and sometimes in dilute alcohol. Some can be extracted by simply macerating the tissues with water; others are more intimately connected with the protoplasm, and are only extracted if the protoplasm is killed by certain reagents, of which those most frequently employed are toluol and chloroform. These substances kill the protoplasm and do not, in many cases, affect the enzyme. After the death of the protoplasm, the enzymes are more readily extracted from the cell. Fron aqueous solutions enzymes can usually be precipitated by adding strong alcohol.

The majority of enzymes are destroyed by raising the temperature above $60^{\circ} \mathrm{C}$. In vitro their reactions are generally carried out most rapirlly between the temperatures of $35-4.5^{\circ} \mathrm{C}$.

In performing experinents with enzymes in vitro, it is always necessary to add an antiseptic, otherwise the reaction to be studied will be masked or entirely superseded by the action of bacteria unavoidably present. Toluol and chloroform mentioned above, as well as thymol, may be usecl. These reagents prevent any bacterial aetion from taking place. Some enzymes, however, are susceptible to chloroform, as, for instance, maltase. 
The chemical nature of enzymes is at present unknown, because it is difficult to purify them without destroying them, and hence to obtain them of sufficient purity for chemical analysis. They were originally thought to be proteins, but with the improvements in methods for purification, it has been found that the protein reactions disappear, although the enzyme activity does not decrease. In solution they exist in the colloidal condition.

The questions as to their origin and their relation to the protoplasm cannot yet be answered with any certainty. It is also impossible to say whether the majority of chemical processes in the plant are catalyzed by enzymes.

A feature of enzyme action which is of considerable interest and which has already been mentioned is the question as to whether enzymes catalyze the synthetic as well as the hydrolytic reaction. There is evidence that this is so, since, in many cases, the hydrolysis is not complete. If the enzyme were a catalyst in one direction only, the reaction would be complete. Further evidence is supplied by the fact that, under suitable conditions, i.e. strong concentration of the substances from which synthesis is to take place, certain syntheses have been carried out in vitio. As an example may be quoted the synthesis of maltose from a concentrated solution of glucose by maltase (Bayliss, 2 ).

In the living cell it is supposed that the hydrolysis and synthesis are balanced. On the "death" of the protoplasm, which may be caused by mechanical injury, vapour of chloroform or toluol, etc. (Armstrong, 7, 8), the reactions catalyzed by enzymes cease to be balanced and proceed almost always in the direction of hydrolysis and the splitting up of more complex into simpler substances. This phenomenon is obvious when any of the products can be recognized by smell or colour, as, for instance, the smell of benzaldehyde on injuring leaves of plants containing cyanogenetic glucosides (see P. 146), or the production of coloured oxidation products when some of the aromatic glucosides are decomposed (see p. 113).

If plant tissuesare disintegrated, and the mass is kept at a temperature of about $38^{\circ} \mathrm{C}$, the above-mentioned hydrolytic processes continue to be catalyzed by the enzymes present until equilibrium is reached, which will be near complete hydrolysis, especially if water has been added. Such a process is termed "autolysis."

The ehief plant enzymes may be classified under the following headings:

A. Hydrolytic enzymes. 'These constitute by far the greater number of known enzymes. In their activity they either add or eliminate water. 
According to the substances upon which they act (the substrates) they may be further sub-classified as follows:

(1) Fat-splitting enzymes, which hydrolyze fats into fatty acids and glycerol: lipase.

(2) Carbohydrate-splitting enzymes:

Diastase, which hydrolyzes starch into dextrin and maltose.

Invertase, which hydrolyzes cane-sugar into dextrose and laevulose.

Maltase, which hydrolyzes maltose into dextrose.

Inulase, which hydrolyzes inulin into laevulose.

Cytase, which hydrolyzes hemicellulose into mannose and galactose.

Pectinase, which hydrolyzes pectic compounds into arabinose.

(3) Glucoside-splitting enzymes:

Emulsin, which hydrolyzes amygdalin into benzaldehyde, prussic acid and glucose.

Myrosin, which hydrolyzes sinigrin into allyl isothiocyanate, potassium hydrogen sulphate and glucose.

(4) Protein-splitting enzymes (proteases):

Pepsin-like enzymes, which hydrolyze proteins into albumoses and peptones.

Erepsin-like enzymes, which hydrolyze peptones into polypeptides and amino-acids.

B. Oxidizing enzymes :

Peroxidases, which decompose peroxides and set free oxygen in the active state, probably as atomic oxygen.

Catalases, which decompose hydrogen peroxide and set free oxygen in the molecular condition.

C. Fermenting enzymes: Zymase of yeast and also of higher plants, which brings about the decomposition of certain hexoses, such as glucose, with the formation of alcohol and carbon dioxide. Probably a series of reactions including oxidation, reduction and hydrolysis are involved.

D. Coagulating enzymes: Pectase, which coagulates soluble pectic conipounds.

E. Reducing enzymes: Reductase. The precise function of these enzymes is unknown.

Most of these various classes of enzymes will be dealt with in detail in connexion with the chemical substances on which they react.

An excellent demonstration of the fact that a single cell may contain all the various enzymes connected with the processes of metabolism is 
afforded by the unicellular Fungus, Yeast (Saccharomyces), of which many species and varieties are known. The feature of special interest in connexion with the Yeast plant is its power of fermenting hexoses, with the formation of alcohol and carbon dioxide, the process being carried out by means of an enzyme, zymase. The reaction is generally represented as follows, though there is little doubt that several stages are involved:

$$
\mathrm{C}_{6} \mathrm{H}_{12} \mathrm{O}_{6}=2 \mathrm{CO}_{2}+2 \mathrm{C}_{2} \mathrm{H}_{5} \mathrm{OH} \text {. }
$$

In aldition to zymase, yeast contains the enzymes, invertase, protease, peroxidase, catalase, reductase, glycogenase, carboxylase, a glucosidesplitting enzyme, and some form of diastatic enzyme. The carboxylase decomposes a large number of keto-acids, of which the most important is pyruvic acid $\mathrm{CH}_{3} \cdot \mathrm{CO} \cdot \mathrm{COOH}$. The reaction involves the formation of the corresponding aldehyde with the evolution of carbon dioxide. Yeast also stores, as a reserve material, the polysaccharide, glycogen, which oceurs in animal tissues though it is rarely found in plants: this is hydrolyzed by glycogenase into a monosaccharide. Finally, yeast contains invertase, and most species, in addition, maltase, but from a few species the latter enzyme is absent. Hence yeasts are able to ferment the disaccharides, cane-sugar and maltose, since they can first hydrolyze them to monosaccharides.

As in the case of the enzymes of other tissues, those of yeast can be made to carry out their functions after the death of the living protoplasm. The method of demonstrating this is to "kill" the cells by means of drying at $25-30^{\circ} \mathrm{C}$., by treatment with a mixture of alcohol and ether, or by treatment with acetone and ether. In this way the protoplasm is destroyed, but the enzymes remain uninjured. Yeast treated thus has been termed "zymin."

From zymin some of the enzymes, e.g. invertase and the glucosidesplitting enzyme, can be extracted with water: other enzymes, e.g. zymase and maltase, are not so readily extracted. From the living cells the enzymes are only obtained with difficulty, the extraction of yeast juice, containing zymase and other enzymes, nceding, by Buchner's method, a pressure as great as 500 atmospheres.

In connexion with alcoholic fermentation by zymase, the following point is of special interest. For carrying out this process, two other substances are necessary in addition to the enzyme, i.e. a co-enzyme of unknown nature and a phosphate. The separation of zymase from the co-enzyme has been accomplished by filtering expressed (Buchner) yeast juice through a special form of gelatine filter under a pressure of 50 
atmospheres. The phosphate and co-enzyme can also be removed from zymin by washing with water. The washed residue is then found to be incapable of fermentation, as also are the washings. If, however, the boiled washings are added to the washed residue, the system is synthesized and can now carry out fermentation again. The chemical nature of the co-enzyme, which is thermostable, and the precise part played by it in the process, are as yet unknown (Harden, 4).

Expt. 10. Preparation of zymin. (a) By alcohol and ether. For the following experiments fresh yeast should be used which has been washed several times with distilled water and dried on a filter-pump. Weigh out 25 gms. of yeast and stir it up well in a mixture of 300 c.c. of absolute alcohol and 100 c.c. of ether for 4-5 minutes, and then filter on a filter-pump. Next wash the yeast with 50 e.c. of ether. Then spread it out on a piece of filter-paper and allow it to dry for one hour. (b) By acetone and ether. Take $50 \mathrm{gms}$. of yeast and stir it into $300 \mathrm{c.c}$. of acetone. Continue stirring for 10 minutes, and filter on a filter-pump. The mass is then mixed with 100 c.c. of acetone for 2 minutes and again filtered. The residue is ronghly powdered, well-kneaded with 25 c.c. of ether for 3 minutes, filtered, drained and spread on tilter-paper for an hour in the air. It can be finally dried at $45^{\circ} \mathrm{C}$. for 24 hours.

Expt. 11. Action of zymase. Fill a small test-tube with $40 \%$ glucose solution. Add 2 gms. of the zymin (from Expt. 10) for each 10 c.c. of solution and a little toluol, and shake. Then fit a slightly larger test-tube over the mouth of the first tube. Now invert. A small quantity of air will rise to the top of the first tube which, however, will remain filled with the sugar solution. Place the tubes either in an incubator or water-bath at $22-25^{\circ} \mathrm{C}$. A control set of tubes should also be arranged containing sugar solution and zymin which has been previously well boiled in a little water. Bubbles of carbon dioxide will be evolved from the unboiled zymin.

Expt. 12. Action of multase. (Harden and Zilva, 12.) Into two test-tubes, $(\alpha)$ and (b), put the following:

(a) 20 c.c. of a $2 \%$ solution of maltose $+0.5 \mathrm{gm}$. of zymin.

(b) 20 c.c. of the same solution of maltose $+0.5 \mathrm{gm}$. of zymin which has been well boiled in distilled water.

Plug both tubes with cotton-wool, after adding a few clropss of toluol, and place in an incubator at $38^{\circ} \mathrm{C}$. for $12-24 \mathrm{hrs}$. Test the liquid in looth tubes by making the usazone (see 1. 49). Glucosazone will crystallize out in tube $(a)$, maltosazone in tube $(b)$.

Expt. 13. Action of peroxidase. (Harden and Zilva, 12.) Into fonr small evaporating dishes, $(a),(b),(c)$ and $(d)$, put the following:

(a) A suspension of $0.5 \mathrm{gm}$. of fresh yeast in 10 c.c. distilled water +1 c.c. of benzidine solution ( $1 \%$ in $50 \%$ alcohol $)+2-3$ drops of hydrogen peroxide (20 vols.).

(b) A suspension of $0.5 \mathrm{gm}$. of zymin in 10 c.c. of distilled water +1 c.c. of henzidine solution $+2-3$ drops of hydrogen peroxide.

(c) $A$ suspension of $0.5 \mathrm{gm}$. of washed zymin in 10 c.c. of distilled water +1 e.c. 
of benzidine solution + 2-3 drops of liydrogen peroxide. (The zymin is washed by putting it on a double folded filter-paper in a funnel and adding distilled water from time to time. $50 \mathrm{ccc}$. of water should be used for $0.5 \mathrm{gm}$. of zymiu.)

(d) A suspension of $0.5 \mathrm{gm}$. of washed zymin in 10 e.c. of washings +1 c.c. of benzidine solution $+2-3$ drops of hydrogen peroxicle.

A blue colour will develop in $(\alpha)$ showing that fresh ycast contains a peroxidase (see p. 109). A blue colour will also develop, in (c) but not in $(b)$ and $(d)$. This is explained by assuning that the zymin contains an inhibitor, not present in fresh yeast, but which is leveloped during the preparation of the zymin, and that this inhibitor can be washed away by water. On adding the washings to the washed zynin the reaction is inhibited again.

Expt. 14. Action of catulase. (Harden and Zilva, 12.) Completely fill a test-tube with hydrogen peroxide $(20$ vols.) solution which has been diluted with an equal volume of water and add $0.5-1 \mathrm{gm}$. of zymin. Place the thumb firmly over the mouth of the tube, invert and place the mouth under water in a small basin, clamping the tube in position. A rapid evolution of oxygen takes place. When the tube is about three-fourths full of gas, close the mouth with the thumb while still under water and remove the tube. Plunge a glowing splint in to the gas and it will re-kindle to a flame.

Expt. 15. Action of protease. Weigh out $10 \mathrm{gms}$. of white flour, and allow it to extract with 100 c.c. of distilled water for one hour, shaking from time to time. Then filter on a filter-pump. The extract will contain the albumin, leucosin (see p. 124). Into small Hasks $(\alpha)$ and $(b)$ put the following:

(a) 40 c.c. of the flour extract $+1 \mathrm{gm}$. of zymin +1 e.c. of tolnol.

(b) 40 e.c. of flour extract $+1 \mathrm{gm}$. of hoiled zymin +1 e.c. of toluol.

Shake both tubes, plug with cotton-wool and place them in an incubator at $38^{\circ} \mathrm{C}$. for 48 hrs. After incubation, boil the liquid in both tubes, in order to coagulate unaltered protein, and filter. To the filtrates of the respective tubes add bromine water drop by drop (see p. 138). A pink, or purplish-pink colour, due to the presence of tryptophane, will he formed in tube $(\alpha)$. Hence hydrolysis of protein has taken place. Tube $(b)$ will show no colour or only that due to bromine. Add a little amyl alcohol to both tubes and shake. The alcohol will be coloured pink or purplish in the tube giving the tryptophane reaction.

Expt. 16. Action of reductase. (Harden and Norris, 11.) Take two small flasks, $(a)$ and $(b)$, provided with well-fitting corks and put in the following:

(a) $1 \mathrm{gm}$. of zymin +20 c.c. of distilled water +0.5 c.c. of methylene blue solution (made by diluting 5 c.c. of a saturated alcoholic solution to 200 e.e. with distilled water).

(b) $1 \mathrm{gm}$. of hoiled zymin +20 e.e. of distilled water +0.5 c.c. of methylene blue solution.

Cork both tuhes after adding a few drops of toluol and place in an incubator at $38^{\circ} \mathrm{C}$. for 3 hours. The blue colour will practically disappear from tube $(a)$ but will renain in tulse $(b)$.

The methylene blue is reduced to a colourless leucu-compound which will become blue again on re-oxidation. 
Expt. 17. Enzyme actions of an aqueous extract of zymin. Weigh out 2 gms. of zymin and place them on a double folded filter-paper in a funnel and wash with 80 c.c. of distilled water. With the filtrate make the following experiments.

(A) Action of invertase. (Harden and Zilva, 12.) Into two small flasks (a) and (b) put the following :

(a) 10 c.c. of a $2 \%$ solution of pure eane-sugar +10 c.c. of the filtrate from zymin.

(b) 10 c.c. of the same solution of cane-sugar +10 c.c. of the hoiled filtrate from z.smin.

Put both flasks in an incubator at $38^{\circ} \mathrm{C}$. After 30 minutes add equal quantities (about 1-2 c.c.) of Fehling's solution to both test-tubes and boil (see p. 52). Tube ( $\alpha$ ) will show consideralle reduction of the Fehling. Tube $(b)$ will show comparatively little reduction, that which does take place probably being due to the sugar formed by the action of glycogenase on stored glycogen.

(B) Action of the glucoside-splitting enzyme. (Caldwell and Courtauld, 9; Henry and Auld, 13.) This enzyme will act unen the glucoside, amygdalin, which is present in bitter almonds, with the production of glucose, benzaldehyde and prussic acid (sce p. 145). Into two small flasks $(a)$ and $(b)$ put the following :

(a) 20 c.c. of a $2 \%$ solution of amygdalin +20 c.c. of the filtrate from zymin.

(b) 20 c.c. of the same solution of anygdalin +20 c.c. of the boiled filtrate from zymin.

Add a few drops of toluol to both flasks and then eork, inserting, with the cork, a strip of paper which has been dipped in solutions of picric acid and sodium carbonate (see p. 146). Put both flasks in an incubator at $38^{\circ} \mathrm{C}$. for $12-24$ hours. The picrate paper in flask ( $\alpha$ ) will have reddened. Add a little Fehling's solution to the liquid in the same flask and boil. The Fehling will be reduced. The liquid in flask (b) will only reduce Fehling slightly [see Expt. A (b)] and the picrate paper will not be reddened.

\section{REFERENCES}

Books

1. Abderhalden, E. Biochenisches Handlexikon, v. Berlin, 1911.

2. Bayliss, W. M. The Nature of Enzyme Action. London, 1919. 4th ed.

3. Euler, H. General Chemistry of the Enzymes. Translated by T. H. Pope. New York and London, 1912.

4. Harden, A. Alcoholic Fermentation. London, 1914. 2nd ed.

5. Vernon, H. M. Intracellular Enzymes. London, 1908.

6. Wohlgemuth, J. Grundriss der Fermentmethoden. Berlin, 1913.

\section{PAPERS}

7. Armstrong, H. E., and Armstrong, F. F. The Origin of Osmotic Effects. III. The Function of Hormones in Stimulating Enzymic Change in Relation to Narcosis and the Phenomena of Degenerative and Regenerative Change in Living Structures. Proc. R. Soc., 1910, B Vol. 82, pp. 588-602. Ibid. IV. Note on the Differential Sejta in Plants with reference to the Trauslocation of Nutritire Materials. Proc. R. Soc., 1912, B Vol. 84, pl. 226-229. 
8. Armstrong, H. E., and Armstrong, E. F. The Function of Hormones in regulating Metabolism. Amn. Bot., 1911, Vol. 25, pp. 507-519.

9. Caldwell, R. J., and Courtauld, S. L. Studies on Enzyme Action. IX. The Enzymes of Yeast: Amygdalase. Proc. R. Soc., 1907, B Vol. 79, pl. 350-359.

10. Harden, A. The Enzymes of Washed Zymin and Dried Yeast. I. Carboxylase. Biochem. J., 1913, Vol. 7, pp. 214-217.

11. Harden, A., and Norris, R. V. The Enzymes of Washed Zymin and Dried Yeast. II. Reductase. Biochem. J., 1914, Vol. 8, pp. 100-106.

12. Harden, A., and Zilva, S. S. The Euzymes of Washed Zymin and Dried Yeast. III. Peroxydase, Catalase, Invertase and Maltase. Biochem.J., 1914, Vol. 8, PI. $217-226$.

13. Henry, T. A., and Auld, S. J. M. On the Probable Existence of Emulsin in Yeast. Proc: R. Soc., 1905, B Vol. 76, pp. 568-580. 


\section{CHAPTER IV}

\section{CARBON ASSIMLATION}

THE fact has already been emphasized that the plant synthesizes all the complex organic substances of which it is built from the simple compounds, carbon rlioxide, water and inorganic salts. The initial metabolic process and the one from which all others have their starting-point is that of a synthesis of a carbohydrate from carbon dioxide and water. This synthesis can only be carried out in the light, and only in a green plant, i.e. a plant containing chlorophyll. Chlorophyll may almost be considered the chemical substance of primary importance in the organic world, for upon it depends the life of all plants and animals. Animals depend for their existence on certain complex amino-acids, some of which they are unable to synthesize for themselves, and which they derive from plants. Plants in turn are unable to exist except by virtue of the properties of chlorophyll.

The property of chlorophyll which is so important is the power it possesses of absorbing the radiant energy of the sun's rays and converting it into chemical energy by means of which a carbohydrate is synthesized. This summarizes the whole process, which, however, can scarcely be very simple, and probably consists of several reactions at present undifferentiaterl. If the formula for carbonic acid is compared with that of a simple carbohydrate such as a tetrose, pentose or hexose, the following relationship is seen :

$$
\mathrm{H}_{2} \mathrm{CO}_{3} \rightarrow\left(\mathrm{H}_{2} \mathrm{CO}\right)_{x} \text { where } x=4,5 \text { or } 6
$$

that is, in the synthesis of a carbohydrate a reducing reaction must take place.

Many hypotheses have been formulated as to the nature of these reactions. The one which has most frequently been advanced suggests that formaldehycle is the first product of the synthesis from carbon dioxide and water which takes place in the green plant; that the reaction involves rerluction with elimination of oxygen:

$$
\mathrm{H}_{2} \mathrm{CO}_{3}=\mathrm{H}_{2} \mathrm{CO}+\mathrm{O}_{2} \text {, }
$$

and that this product is later condensed to form a hexose,

$$
6 \mathrm{H}_{2} \mathrm{CO}=\mathrm{C}_{6} \mathrm{H}_{12} \mathrm{O}_{6} \text {. }
$$


As the concentration of sugar increases in the cell, further condensation may take place to form starch :

$$
x\left(\mathrm{C}_{6} \mathrm{H}_{12} \mathrm{O}_{6}\right)=\left(\mathrm{C}_{6} \mathrm{H}_{11} \mathrm{O}_{5}\right)_{x}+x \mathrm{H}_{2} \mathrm{O} .
$$

The facts in agreement with these views are: first, in most plants a volume of oxygen is given off approximately equivalent to the volume of carbon dioxide absorbed; secondly, in some plants starch, in others sugar, is known to be produced during photosynthesis. The detection of formaldehyde, either in the plant or in certain systems containing chlorophyll, as a proof of its formation during photosynthesis, has been shown to be invalid (see p. 36) (Jörgensen and Kidd, 2).

The value and significance of this reducing reaction is seen when it is realized that, by oxidation of the carbohydrates synthesized, energy is produced to supply the needs of the whole metabolism of the plant (see p. 5).

In the chemical treatment of the subject of carbon assimilation, some of the chemical properties of chlorophyll will first be considered, and, later, its behaviour under certain conditions: the chemistry, however, of the phenomenon itself is as yet unknown.

The following account, as far as it concerns chlorophyll, and the accompanying experiments are taken from a résumé (Jörgensen and Stiles, 3) of the original work (Willstätter und Stoll, 1) upon which the entire knowledge of the subject is based.

\section{Chlorophyll.}

Our knowledge of the chemistry of chlorophyll has, within recent years, been set upon a firm experimental basis (Willstätter und Stoll, 1). The results which have been arrived at may broadly be summarized as follows :

In all plants examined the chloroplastids contain four pigments, of which two (termed respectively chlorophylls $a$ and $b$ ) are green, and two are yellow. They occur in about the following proportions in fresh leaves:

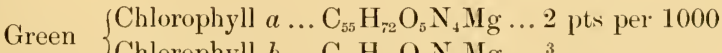

$$
\text { \{Chlorophyll } b \ldots \mathrm{C}_{55} \mathrm{H}_{70} \mathrm{O}_{6} \mathrm{~N}_{4} \mathrm{Mg} \ldots \frac{3}{4}, ",
$$

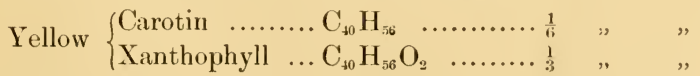

A point of great interest in connexion with chlorophyll is that it contains magnesium to the extent of $2.7 \%$ but no other metal is present. Chlorophyll a, when isolated, is a blue-black solirl giving a green-blue 
solution in the solvents in which it is soluble, i.e. ethyl alcohol, acetone, chloroform, ether, carbon bisulphide, pyridine and benzene. Chlorophyll $\mathrm{b}$, when isolated, is a green-black solid giving a pure green solntion : it has much the same solubilities as chlorophyll $a$. The two chlorophylls, however, can be separated by their different solubilities in methyl alcohol. Both can be obtained in microscopic crystals.

Carotin crystallizes in orange-red crystals, and xanthophyll in yellow crystals.

In the chloroplastids these pigments occur mixed with various colourless substances, fats, waxes, and salts of fatty acids.

When chlorophyll is spoken of, it will be understood to refer to the green pigments and not to the yellow.

The pure pigments, when isolated, are readily soluble in acetone, ether and benzene. When very thoroughly dried nettle leaves are treated with pure acetone, no green colour is extracted, but if a few drops of water are added, the extract becomes green. Also if acetone is poured on to fresh leaves, the pigment is extracted. The explanation offered for these phenomena is that chlorophyll is present in a colloidal condition in the cell. This point will be considered again later (see p. 35).

The Common Nettle (Urtica) is the plant which has been used for material for the extraction of chlorophyll on a large scale, and it also forms very useful material for extraction on a small scale. The pigment has been found to be unaltered by drying, and, since dried leaves involve far less bulk and dilution of solvents, material should be dried before using. Some leaves (Elder and Conifers) are spoilt by drying. From dried leaves pure solvents, such as petrol ether, benzene and acetone, extract very little pigment for reasons which will be mentioned later, but if the solvents contain a moderate amount of water, the pigment is readily soluble. About $80 \%$ acetone is the best solvent. The nettle leaves are removed from the stalks and laid on sheets of paper to dry. When well air-dried they are finely powdered, and the powder further dried at $30-40^{\circ} \mathrm{C}$. in an incubator. The leaf-powder can be kept for a consiclerable time in a well-stoppered bottle.

Expt. 18. Extruction of pigment. Two grams of leaf-powder are sucked to a filterpaper on a small porcelain funnel and 2-3 c.c. of $85 \%$ acetone are added. This is allowed to soak into the powder for a few minutes. The fluid is then sucked through with the pump. The operation is repeated until 20 c.c. of the solvent have been added, when the powder is sucked dry. A deep blue-green solution with a red fluorescence is sbtained which contains all the four pigments from the leaf. The acetone extract thus obtained is then poured into double the quantity of petrol ether contained in a separating fumnel. An equal quantity of distilled water is adderl, this 
being poured gently down the side of the fumel in order to avoid the formation of emulsions. In the course of a few minutes, the ether layer separates out and now contains the pigments. The lower layer, which is slightly green, is run off. 'The addition of distilled water and subsequent renoval of the lower layer is repeater about four times, in order completely to remove the acetone from the ether solution. If the ether solution should have become at all emulsified, it can be cleared wy shaking with anlydrous sodium sulphate and filtering.

The whole process should be repeated with another 2 guns. of leaf-powder and the pigment transferred to ether, since a solution in this solvent is required for later experiments.

Expt. 19. Demonstration of the presence of chlorophylls a and b. Of the petrol ether solution from the last experiment, 10 c.c. are shaken with 10 c.c. of $9.2 \%$ methyl alcohol. Two layers are formed of which the petrol ether layer contains chlorophyll $a$, and the methyl alcohol layer chlorophyll $b$. The solution of chlorophyll $a$ is blinegreen, while that of chlorophyll $b$ is a purer green, but the colour difference between them is dininished owing to the presence of the yellow pigments, of which earotin is in the petrol ether, and xanthophyll in the methyl alcohol.

As will be explained later, the green pigments of chlorophyll can be saponified by alkalis and are then insoluble in ethereal solution. This method can be adopted to separate the green from the yellow pigments, xanthophyll and carotin.

Expt. 20. Separation of green and yellow pigments. Shake 5 e.e. of an ether solution of the pigments (Expt. 18) with 2 c.c. of $30 \%$ caustic potash in methyl alcohol (obtained by dissolving 30 gnis, of potassium hydroxide in 100 c.e. of methyl alcohol ${ }^{1}$ ). After the green eolour has reappeared, slowly add 10 e.c. of water and then add a little more ether. On shaking the test-tube, two layers are produced, of which the lower watery-alkaline one contains the saponified green pigments, while the carotin and xanthophyll are eontained in the upper ethereal layer.

Expt. 21. Separation of the two yellow pigments. The ether layer obtained in the last experiment is washed with water in a separating fumnel, and evaporated down to 1 e.c. It is then diluted with 10 c.c. of petrol ether and next inixed with 10 e.c. $90 \%$ methyl alcohol. The methyl alcoholic layer is removed and the petrol ether layer is again treated with methyl alcohol and the methyl aleohol again removed. This process is repeated until the methyl aleolol is no longer coloured. The methyl alcohol contains the xanthophyll, the petrol ether the carotin.

Further accounts of the yellow pigments are given on p. 39 .

The best known reactions of chlorophyll are those which take place with acids and alkalies respectively.

Chlorophyll is a neutral substance, and, on treatment with alkalies, it forms salts of acids, the latter being known as chlorophyllins. These salts are soluble in water forming green solutions which are not however

1 The methyl alcohol must be very pure, otherwise the alcoholic potash solution will become brown and discoloured. 
Huorescent. Chlorophyll a may be represented as the methyl phytyl ester of an acid chlorophyllin (phytol is a primary alcohol, see p. 38):<smiles>CCONOCCCCC(=O)OCC</smiles>

('hlorophyll $a$

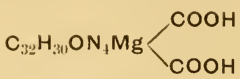

Chlorophyllin

On treatment in the cold with alkali, the ester is saponified, and the alkali salt of chlorophyllin is formed. During saponification, there is a change of colour in the pigment, the so-called brown phase, followed by il return to green.

Expt. 22. Saponification of a mirture of the green pigments. Four a little of the ether solution obtained in Expt. 18 into a test-tube, and in a pipette take a little $30 \%$ solution of potash in methyl alcohol. Place the lower end of the pipette at the bottom of the test-tube and allow the potash to run in below the chlorophyll solntion. At the interface between the solntions there appears immediately a browncoloured layer which diffuses on shaking. In about ten minutes it changes back throngh an olive-green colour to pure green.

The ehlorophyll has been saponitied to the potassium salt of the acid chlorophyllin. This salt is insoluble in ether, so if water is added to bring about a separation of the two layers, the green colour is no longer present in the ethereal layer.

The change of colour on saponification is different for the two chlorophylls, the brown phase produced in the above mixture of chlorophylls being due to a yellow phase produced by chlorophyll $a$, and a brown-red phase produced by chlorophyll $b$. To demonstrate this the phase test (Expt. 22) may also be carried out separately on the two chlorophylls.

Expt. 23. Saponification of chlorophylls a and $b$ separutely. The nethyl alcohol solution obtained in Expt. 19 is transferred to ether as in Expt. 18. Both the latter and the petrol ether solution of chlorophyll $a$ are saponified as in the previons experiment.

As already demonstrated the potassium salts of the chlorophyllins which are produced by saponification of the mixture of green pigments in the cold are not fluorescent. By saponification of chlorophyll with hot alkali, isochlorophyllins are formed (see Expt. 24 below) which are Hnorescent.

On heating chlorophyllins with concentrated alcoholic alkalies, a series of decomposition products, phyllins (also acids) are obtained by removal of carboxyl groups. The final phyllin has only one carboxyl group. When this is removed, a substance, aetiophyllin, $\mathrm{C}_{31} \mathrm{H}_{34} \mathrm{~N}_{4} \mathrm{Mg}$, is obtained which contains no oxygen (see Scheme 1, p. 34).

Another difference between the results of treating chlorophyll with hot and cold alkali is that in the former process the yellow pigments are 
destroyed. If then water is added after saponification with hot alkali, and the solution is shaken up with ether, the ether will remain colourless.

When chlorophyll is treated with acids, a different reaction takes place. The chlorophyll changes in colour to olive-green and loses most of its fluorescence. The magnesium of the molecule is removed, being replaced by hydrogen, and the resulting product is termed phaeophytin (see Scheme 1, p. 34).

From phaeophytin a series of decomposition products have been obtained, which fall into two groups, the phytochlorins and the phytorhodins. The phytochlorins are olive-green in colour, and are derived from chlorophyll $a$; the phytorhodins are red, and are derived from chlorophyll $b$. The phaeophytins from the two chlorophylls are indistinguishable until the above decomposition products are obtained. (The original discovery of two kinds of chlorophyll was brought about by the differentiation of these decomposition products.)

A number of phytochlorins and phytorhodins have been identified and are designated by letters $a, b$, etc. By employing a uniform method of treatment, however, two of these products, phytochlorin $e$ and phytorhodin $g$, can be secured.

The phytochlorins and the phytorhodins are of course magnesium-free compounds and can be obtained by the action of acid on the chlorophyllins and isochlorophyllins. Phytochlorin $e$ and phytorhodin $g$, in particular are obtained by the action of acid on isochlorophyllins, i.e. they are magnesium-free isochlorophyllins. They are formed by the addition of acid to the products of saponification with hot alkali.

The separation of the various phytochlorins and phytorhodins can be brought about by means of their different distribution between ether and hydrochloric acid: each compound can be extracted from ether according to the concentration of the acid used.

Expt. 24. The formation of phytochlorin and phytorhodin. 5 e.e. of an ether solution eontaining both chlorophylls $a$ and $b$ are evaporated to dryness in a testtube in a water-hath, and the residue treated with 3 c.c. of boiling $30 \%$ potash solution in methyl alechol, and boiled gently for half a minute. A liquid with a red fluorescence is produced which consists of a solution of the potassium salts of isoehlorophyllins. The solution is diluted with double its volune of water, and eoneentrated hydrochloric acid is added until the solution is just aeid. The liquid is then shaken with ether in a separating fumnel : the dissociation produets produced by the previons treatment pass into the ether solution whieh thms acquires an olive-brown colour.

The ether solution is shaken twice, each time with 10 c.c. of $4 \%$ hydrochloric acid (sp. gr. $1 \cdot 02$ i.e. 12.9 e.c. strong acid: $87 \cdot 1$ e.c. water), and the green-blue aeid layer is separated and neutralized with ammonia and shaken with more ether, which 
then contains in solution phytochlorin $e$, the derivative of chlorophyll $a$. The phytochlorin $e$ gives to the ether an olive-green colour.

The ether layer remaining in the fumnel, after the separation of the green-blue acid layer, is now extracted with 10 e.e. of $12 \%$ hydrochloric acid (sp. gr. 1.06 i.e. 38.1 c.c. strong acid: 61.9 c.e. water). The green acid solution so obtained is diluted with water and shaken with ether which then becomes coloured red and contains phytorhodin $g$, the derivative of chlorophyll $b$.

If the phyllins are acted upon by mineral acids, they lose their magnesium in the same way as the chlorophyllins, and the series of substances obtained in this way are termed porphyrins. Thus aetiophyllin will give aetioporphyrin $\mathrm{C}_{31} \mathrm{H}_{36} \mathrm{~N}_{4}$ (see Scheme 1, p. 34).

The derivatives of chlorophyll which are free from magnesium, such as phaeophytin, phytochlorin, phytorhodin, the various porphyrins, etc. combine readily with the acetates of some metals such as copper, zinc and iron, and they form intensely coloured, stable compounds. The change of colour is so noticeable that the smallest traces of certain metals can be detected in this way. Hence it is very difficult to prepare the magnesium-free chlorophyll unless the reagents are perfectly pure and all contact with certain metals is avoided.

Expt. 25. Substitution of copper for magnesium in chlorophyll. 2 c.c. of an ether solution of chlorophyll are shaken with a little $20 \%$ hydrochloric acid (sp. gr. 1.10 i.e. $62 \cdot 4$ c.e. strong acid: $37 \cdot 6$ e.c. water), and then washed with water in a separating fummel. In this way is produced in ether solution the magnesinm-free chlorophyll derivative, phaeophytin. The solution is evaporated down on a water-bath, and the residue dissolved in 5 e.c. of aleohol. The solution is olive-green in colour. This is heated and a grain of copper acetate or zine acetate is added. The colour changes back to a brilliant green, but without fluorescence (if all the chlorophyll has been converted into phaeophytin).

From the results of these recent investigations, it is now possible to write formulae for the two chlorophylls as follows:

$$
\begin{array}{lll}
\text { chlorophyll } a & \left(\mathrm{C}_{32} \mathrm{H}_{30} \mathrm{O} \mathrm{N} \mathrm{N}_{4} \mathrm{Mg}\right)\left(\mathrm{COOCH}_{3}\right)\left(\mathrm{COOC}_{20} \mathrm{H}_{39}\right) \\
\text { chlorophyll } b & \left(\mathrm{C}_{32} \mathrm{H}_{28} \mathrm{O}_{2} \mathrm{~N}_{4} \mathrm{Mg}\right)\left(\mathrm{COOCH}_{3}\right)\left(\mathrm{COOC}_{20} \mathrm{H}_{39}\right)
\end{array}
$$

from which it will be seen that the phytol component amounts to onethird of the weight of the chlorophyll.

From the analyses of chlorophylls from different plants, it was found that the phytol content varied, and plants which yielded little phytol most readily produced "crystalline chlorophyll," a form of the pigment which has been known for some considerable time to previous workers. The Cow Parsuip (Heracleum Sphondylium), Hedge Woundwort (Stachys sylvatica) and Hemp-nettle (Galeopsis Tetrahit) are plants which readily give crystalline chlorophyll. In this connexion it has been suggested 
that the chlorophyll in plants is accompanier by an enzyme, chlorophyllase, which, in alcoholic merlia, brings about alcoholysis of the chlorophyll, and replaces the phytyl by the ethyl radicle. The products, formerly known as crystalline chlorophyll, are now termed chlorophyllides:

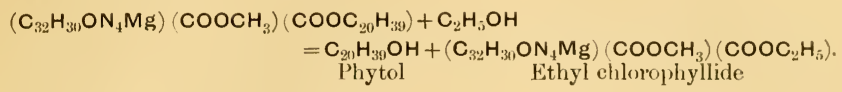

Similar chlorophyllides are produced by other alcohols. In aqueous solutions chlorophyllase brings about hydrolysis and the free acid chlorophyllide is formed (see Scheme 2, p. 34):

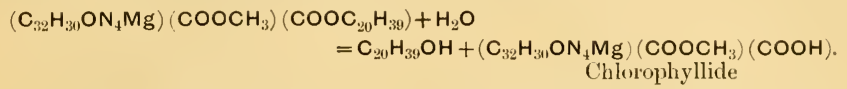

Chlorophyllase is a very stable enzyme; it is not even destroyed by boiling in alcohol for a short time, but if leaves are boiled in water, the enzyme is destroyed.

Expt. 26. Microscopic examination of ethyl chlorophyllide. Prepare sections of fresh Heracleum leaves and mount them in a drop of $90 \%$ alcohol. Leave the slide under a bell-jar containing a dish of alcohol. The section slowly dries in the course of half a day or a day. It is then examined under the microscope when there will be observed the characteristic triangular and hexagonal crystals of ethyl chlorophyllide (crystalline chlorophyll).

Expt. 27. Production of methyl chlorophyllide in the leaf. Sections may be used as in the preceding experiment, or a piece of a leaf may be employed. In the latter case a test-tube with 4 c.c. of $75 \%$ methyl alcohol is taken and $1 \mathrm{gm}$. of fresh leaf is added to it. The leaf first becomes a darker green and then during the course of a few hours becomes yellowish. On holding the leaf to the light there can be observed with the naked eye a number of black points. If sections of the leaf be eut and examined under the microscope, these spots appear as aggregates composed of rhombohedral crystals, occurring in certain cells.

Expt. 28. Extraction of ethyl chlorophyllide. Two grams of dry Hercelerm leafpowder are left for a day in a test-tube containing 6 c.c. of $90 \%$ alcohol. The extract is then filtered through a smatl porcelain funnel and the powder on the filter washed with a little acetone. The filtrate is mixed with an equal quantity of ether, and then with some water. The ether solution is transferred to a separating fumel and thoronghly washed with water, and then concentrated on a water-bath to $\frac{1}{2}$ or 1 c.c., and 3 c.c. of petrol ether are added. On standing, the ethyl chlorophyllide is preeipitated in the form of crystalline aggregates. It is freed from yellow pigments by shaking with a little ether, and can be further purified by redissolving in ether and precipitating again with petrol ether.

Expt. 29. The action of chlorophylluse. Fresh leaves of a species rich in chlorophyllise, e.g. Heracleum or Galeopsis, are finely divided and put in a $70 \%$ acetone solution, 3 c.c. of solution being used for every gram of leaf-powder. The chlorophyll,

o. 
by means of the chlorophyllase, is hydrolyzed into phytol and the acid chlorophyllide. This can be demonstrated after about a quarter of an hour if the solution is diluted with water, trausferred to ether and shaken with $0.05 \%$ sodium hydroxide. The sodium hydroxide takes up more colouring matter the further the enzyme action has prugressed.

Expt. 30. The destruction of chlorophyllase. If fresh leaves of a species rich in chlorophyllase are first steeped in boiling water for a few minutes before they are placed in the acetone solution, unaltered chlorophyll is extracted which does not react with dilute alkali.

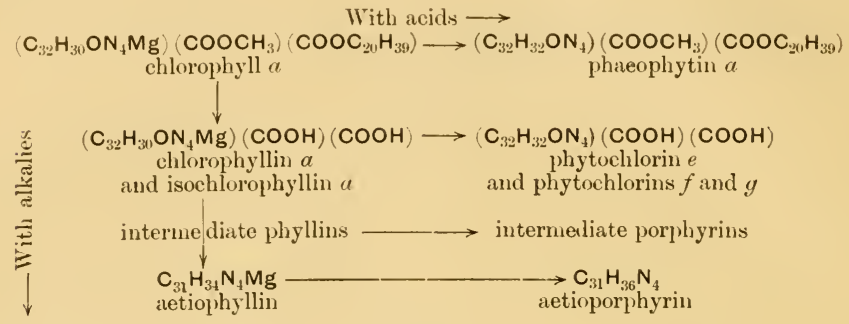

Scheme 1.

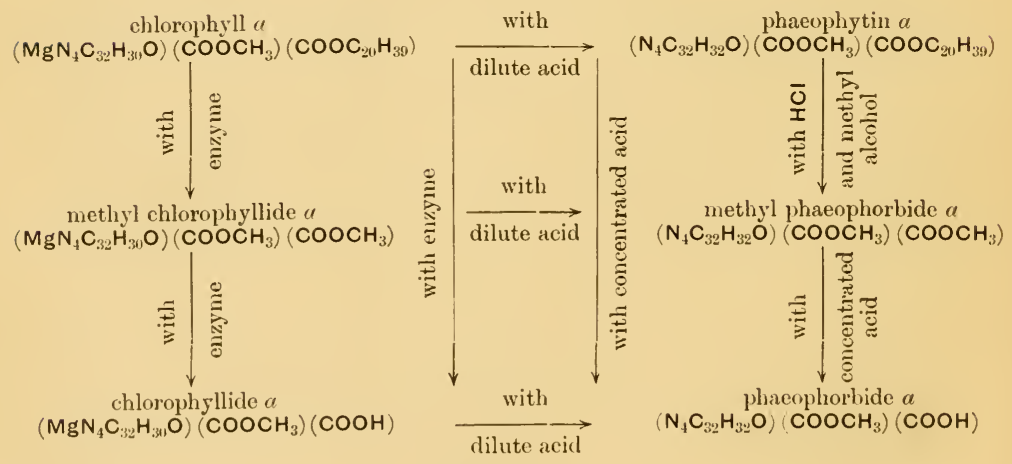

Scheme 2.

By treatment with acids, magnesium is removed from the chlorophyllides, with the production of the corresponding phaeophorbides. Thus methyl chlorophyllide $a$ gives methyl phaeophorbide $a$, etc. (see Scheme 2. above).

It has been previously mentioned that water-free solvents, such as acetone, ether and benzene, in which pure extracted chlorophyll is 
soluble, will not extract the pigment from thoroughly dried leaves, but if a little water is added, it realily goes into solution. From fresh leaves also these solvents can extract the pigments.

As an explanation of the above phenomena, it has been suggester that chlorophyll in the chloroplastirl is in the colloidal state, and that, when water is added to the dried leaf, a solution of mineral salts in the leaf is formed which alters the colloidal condition of the chlorophyll and makes it soluble. This view is supported by the fact that if a colloidal solution of chlorophyll in water, made from the pure extracted pigment, is shaken with ether, the ether remains colourless. If, however, a little salt solution is added and the mixture shaken, the ethereal layer becomes green. In preparing the colloidal solution the solvent, acetone, is replaced by the medium, water, in which chlorophyll is insoluble.

The condition of chlorophyll is altered by plunging the leaves into boiling water. The pigment is then much more readily soluble in ether, etc., even when the leaves are subsequently dried. It is supposed that the chlorophyll has diffused out from the plastids, and is in true solution in accompanying waxy substances which have become liquid owing to change of temperature.

Expt. 31. Prepuration of a colloidul solution of chlorophyll. Take 10 e.c. of an acetone extract of chlorophyll (Expt. 18) and pour this acetone solution into a large volume of distilled water (100 e.c.), the liquid being continually stirred. This operation ean be most eonveniently done by taking the acetone solution in a pipette and allowing it to run out of the pipette while the latter is used as a stirring rod in the water. Note the ehange in colour to a purer green, and the disappearance of Huorescence.

Expt. 32. To demonstrate the difference betreen a tme und a colloidal solution of chlorophyll. Evaporate 10 c.e. of an acetone extraet (Expt. 18) to complete dryuess and test its solulility in ether, petrol ether and benzene. It is soluble in all three solvents. Now add these solvents to some of the colloidal solution prepared in the last experiment, and note that the chlorophyll does not dissolve in any of these solvents. If, however, some salt solution, e.g. a little magnesiun sulphate, be added, the chlorophyll is precipitated from its colloidal state and is now soluble in ether and other solvents.

Expt. 33. To show that chlorophyll in the plant is probably in the colloidal condition. Some nettle powder is carefully dried, e.g. by keeping it at $30-40^{\circ} \mathrm{C}$. in an oven, and then further drying in a vacum desiceator over sulphurie acid. Small quantities of this dry powder are put in test-tubes, and different pure water-free substances such as acetone, ether, benzene and absolute alcohol are added. Note that these solvents are not coloured by the chlorophyll. It can be demonstrated that the extrated pigment is easily soluble in any of these substances. Repeat the experiment with nettle powder moistened with a few dropss of water, and note that the solvents are immediately coloured. 
E.xpt. 34. Pure solvents are able to extract chlorophyll from fiesh leaves. Crush 10 gms. of fresh leaves of nettle, horse-chestnut or elder in a mortar with some clean sand, and put the crushed material on a filter-paper in a porcelain funnel. Add 20 e.e. of pure acetone and suck it through by means of a water-pump. Repeat this several times. The pure solvent is here able to extract the pigment.

Expt. 35. Treatment of fresh leaves with boiling vater changes the condition of the chlorophyll. Dry a quantity of leaves which have been put in boiling water and examine their solubility as in Expt. 33. Note that the ehlorophyll in this powder is soluble in pure solvents.

There is finally another change which chlorophyll can undergo, namely that of allomerization, which takes place in alcoholic solution. The characteristic of allomerized chlorophyll is that it does not give the brown phase when treated with alkali (see Expt. 22). Allomerization is accelerated in alkaline solution but inhibited by small quantities of acid.

Expt. 36. To demonstrate that allomerized chlorophyll dies not give the brown phase test. Dissolve a little erude ehlorophyll, obtained by evaporating an ether solution, in absolute alcohol. To a sample of this add a little alkali, and perform the phase test, from time to time, till at last the brown phase no longer appears.

\section{Connexion of Chlorophyll with Formaldehyde.}

In addition to the above, another chemical property of chlorophyll of great interest, is that connected with the production of formaldehyde. Those investigators, who have sought to confirm the formaldehyde hypothesis of carbon assimilation, have based their evidence on tests for formaldehyde both in the plant and in chlorophyll-containing systems outside the plant. By exposing films, or solutions, of chlorophyll to light in presence of carbon dioxide, they have detected formaldehyde as a result (Usher and Priestley, 5).

The most recent investigations (Jörgensen and Kidd, 2) have shown that the experimental evidence is at present inadequate to support the hypothesis, since formaldehyde arises from chlorophyll itself in the absence of carbon clioxide.

In this later work (Jörgensen and Kidd, 2) on the behaviour of extracted chlorophyll in light, use has been made of a colloidal solution (see p. 35) of pure chlorophyll (chlorophylls $a$ and $b$ ) for experimental work. The solution for this purpose must be prepared from pure chlorophyll, which has been tested and shown to be free from yellow pigments, since the latter absorb oxygen and may confuse the issue of the experiment. The pure chlorophyll is prepared by extracting dried nettle leaves with $80-85 \%$ acetone in the usual way and transferring to petrol ether (p. 28). 
The petrol ether extract is then washed with $80 \%$ acetone to remove colourless impurities, and with $80 \%$ methyl alcohol to remove xanthophyll. Finally all traces of acetone and methyl alcohol are removed by washing with water. This renders the chlorophyll insoluble in petrol ether, since it is only soluble in this solvent if traces of other solvents are present. Hence the pigment is precipitated out as a fine suspension, leaving the carotin in solution. The chlorophyll is filtered off through powdered talc, taken up in ether, reprecipitated by petrol ether and finally obtained as a blue-black micro-crystalline substance. The colloidal solution or sol is made by dissolving $0.4 \mathrm{gm}$. of pure chlorophyll in 3 c.c. of absolute alcohol and pouring into 300 c.c. of distilled water.

The advantage of using such a solution is that the experimental conditions, in all probability, approach more nearly to the conditions in the plant, and reactions with other substances take place more readily than when the chlorophyll is used as a film. The use of pure, instead of crucle, chlorophyll is also important as by this means it is possible to determine the changes taking place in chlorophyll itself without complications arising from the accompanying impurities. The discordant results of various workers on this subject are doubtless due to the employment of crude chlorophyll. Ethyl alcohol is the best solvent for preparing the sol since it does not produce formaldehyde when exposed to light under ordinary circumstances in glass vessels. Methyl alcohol and acetone should be avoided as they themselves either contain or give rise to formaldehyde.

The chlorophyll sol is electro-negative. It is stabilized by weak alkalies, but precipitated by weak acids.

Working with such a colloidal solution the results may be summarized as follows.

When a chlorophyll sol is exposed to light in an atmosphere of nitrogen in a sealed tube, no apparent change takes place in the chloruphyll, and no formaldehyde is produced.

When exposed in an atmosphere of carbon dioxide in a sealed tube, the chlorophyll rapidly turns yellow- or brown-green. In the case of sols of high concentration, the colour-change is preceded by precipitation of the pigment. The same change takes place in the dark, only more slowly. No formaldehyde is produced, and no absorption of carbon dioxide conld be detected. The yellow product has been shown to be the magnesium-free derivative, phaeophytin, which is produced from the pigment by the action of acirls. The changes observed are explained by the fact that the carbon dioxide, acting as a weak acid, first precipitates 
the sol, if concentrated, and then acts, like other weak acids, on the chlorophyll, producing phaeophytin. If the solution is kept neutral by addition of sodium bicarbonate, there is no colour change. The identity of phaeophytin was shown by the spectrum and by the restoration of colour on adding a trace of copper acetate.

When exposed to light, and the atmosphere in the sealed tube is replaced by oxygen or air, the chlorophyll turns yellow- or brown-green as before and then bleaches. The change of colour from green to yellow or brown is again due to the formation of phaeophytin, this being brought about by the presence of an acid substance, which is produced during bleaching, and increases thronghout the process. Formaldehyde can be detected in a very slight amount during bleaching, but is formed in much greater quantity after bleaching is complete.

It is suggested that the formaldehyde is produced by the oxidation and breaking down of the phytol component of the chlorophyll:

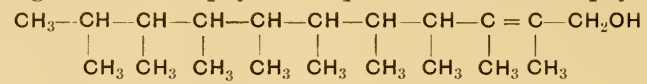

There is no reason for ascribing to any of the above reactions any part in carbon assimilation. There is at present no hypothesis, supported by satisfactory evidence, as to the process of carbon assimilation.

Expt. 37. Detection of formaldehyde as a product of oxidation of chlorophyll. Extract 2 gms. of dried nettle leaf powder with 20 e.c. of $80 \%$ acetone and transfer it to petrol ether as in Expt. 18. Then shake the petrol ether extraet four or five times with an equal volume of $80 \%$ acetone to remove colourless impurities. Next the petrol ether extraet is sinilarly shaken up with $80 \%$ methyl alcohol whieh removes the xanthophyll. This shonld be repeated until the methyl alcohol is colourless. The petrol ether is finally washed repentedly with water to remove traces of acetone and methyl alcohol. The chlorophyll is in time precipitated as a fine suspension, being insoluble in pure petrol ether. This suspension is filtered through either kieselguhr or powdered talc on a small porcelain filter. The ehlorophyll is extracted from the powder on the filter with as small a quantity as possible of absolute aleohol. This alcoholie solution is then poured, with eonstant stirring, into 100 c.e. of distilled water by whieh means a colloidal solution of chlorophyll is obtained.

The test to he employed for formaldehyde is as follows (Schryver, 4). To 10 c.e. of the liquid to be tested add 2 e.e. of a $1 \%$ solution (freshly made) of phenylhydrazine hydrochloride, 1 c.e. of a $5 \%$ solution (freshly made) of potassium ferricyanide and 5 c.c. of concentrated hydrochloric acid. If formaldehyde is present a pink to magenta colour is developed, either deep or pale, according to the quintity of formaldehyde. The reaction is due to the formation of a condensation product of formaldehyde and phenylhydrazine, and this compound, on oxidation, yields a weak base forming in coloured salt with concentrated hydroeblorie acid. The salt is readily dissociated again on dilution of the solution. 
Two modifications (Schryver, 4) can be adopted in applying this test. First, in testing for formaldehyde in pigmented solutions, the following course can be pursued. The reaction mixture, after addition of phenylhydrazine, ferricyanide and hydrochloric aeirl, is diluted with water, and ether is added in a separating fumel. The hydrochloride of the ehromatogenic base is dissociated and the base is taken up by the ether. The aqueous solution is run off', and on addition of strong hydrochlorie acid to the ether, the base passes into the acid as a coloured hydrochloride again. By using a small quantity of acid, the sensitiveness of the test is increased, since the colour is now distributed through a small quantity of liquid only.

The seeond modification consists in warming the solution to be tested for a short time with the phenylhydrazine hydrochloricle before adding the other reagents. In this way, formaldehyde ean also be detected if it should be in a polymerized form.

As a control, 10 c.c. of the colloidal solution of chlorophyll should he tested, using both the above modifications. The remainder of the solution shonld be exposed to sunligbt (or the light from either an are or mercury vapour lamp) in a loosely corker vessel, mutil it is completely bleached. The bleached solution, on testing, will be found to give a positive test for formaldehyde.

\section{The Yellow Plastid Pigments.}

These have alrearly been mentioned in connexion with the leaf pigments (pp. 28 and 29 ). In addition, however, they have a further significance in that they constitute the pigments, located in plastids, of most yellow and orange flowers and fruits. Sometimes also they occur in other organs, i.e. root of Carrot (carotin).

Carotin, $\mathrm{C}_{40} \mathrm{H}_{56}$, is an unsaturated hydrocarbon. It erystallizes in lustrous rhombohedra which are orange-red by transmitted and blue by reflected light. It is readily soluble in chloroform, benzene and carbon bisulphide, but with difficulty in petrol ether and ether.

One of its most characteristic properties is that it readily undergoes oxidation in air, and becomes bleacherl. With concentrated sulphuric acid it gives a deep blue colour.

Xanthophyll, $\mathrm{C}_{40} \mathrm{H}_{56} \mathrm{O}_{2}$, also forms yellow crystals with a blue lustre. It is soluble in chloroform and ether, but insoluble in petrol ether. It is more soluble than carotin in methyl alcohol. It gives a blue colour with sulphuric acid, and also oxidizes in air with bleaching.

The separation of the two pigments (see Expt. 21) is based on the fact that in a mixture of petrol ether and methyl alcohol containing a little water, the carotin passes entirely into the petrol ether, whereas the greater part of the xanthophyll remains in the methyl alcohol layer. 


\section{REFERENCES}

Воокs

1. Willstätter, R., und Stoll, A. Untersuchungen iiber Chlorophyll. Methoden und Ergebnisse. Berlin, 1913.

\section{PAPERS}

2. Jörgensen, I., and Kidd, F. Some Photochenical Experiments with Pure Chlorophyll and their Bearing on Theories of Carbon Assimilation. Proc. R. Soc., 1917, B Vol. 89, pp. 342-361.

3. Jörgensen, I., and Stiles, W. Carbon Assimilation. A Review of Recent Work on the Pigments of the Green Leaf and the Processes eonnected with them. New Phytologist, Reprint, No. 10. Loudon, 1917.

4. Schryver, S. B. The Photochemical Formation of Formaldehyde in (treen Plants. I'roc. R. Soc., 1910, B Tol. 82, pp. 226-232.

5. Usher, F. L., and Priestley, J. H. A Study of the Mechanism of Carbon Assimilation in Green Plants. I. Proc. R. Soc., 1906, 13 Vol. 77, pp. 369-376. II. Ibid. 1906, B Vol. 78, pp. 318-327. III. Ibid. 1912, B Vol. 84, pp. 101-112. 


\section{CHAP'TER V}

\section{CARBOHYDRATES AND THEIR HYDROLYZING ENZYNES}

THE carbohydrates which occur in plants may be classified as follows :

Monosaccharides..... $\left\{\begin{array}{c}\text { Pentoses, } \mathrm{C}_{5} \mathrm{H}_{10} \mathrm{O}_{5}-\text { Arabinose, xylose. } \\ \text { Hexoses, } \mathrm{C}_{6} \mathrm{H}_{12} \mathrm{O}_{6} \text { - Glucose, galactose, } \\ \text { mannose, laevulose. }\end{array}\right.$

Disaccharides ........ Sucrose, maltose, $\mathrm{C}_{12} \mathrm{H}_{22} \mathrm{O}_{11}$.

'irisaccharides........ \{Raffinose and others.

Pentosans, $\left(\mathrm{C}_{5} \mathrm{H}_{8} \mathrm{O}_{4}\right)_{n}-$ Araban, xylan.

Polysaccharides Starches, $\left(\mathrm{C}_{6} \mathrm{H}_{10} \mathrm{O}_{5}\right)_{n}$-Starch, dextrin, inulin. Mannans, galactans, gums, mucilages, pectic substances. Celluloses, $\left(\mathrm{C}_{6} \mathrm{H}_{10} \mathrm{O}_{5}\right)_{n}$.

The carbohydrates are widely distributed in plants and form most important parts of their structure. Those most commonly found are : cellulose, starch, pentosans, dextrin, glucose, sucrose, laevulose, and maltose. Other sugars, especially trisaccharides, are known in addition to those mentioned above, but they are somewhat restricted and specific in their distribution.

As in the case of the proteins, so with the carbohydrates, the molecules of the more simple and soluble crystalline compounds, such as the monosaccharides, are synthesized into more complex molecules which exist, either in the colloidil (dextrin), or insoluble state (starch, cellulose). The last-mentioned build up parts of the solid structure of the plant. The resolution of the solid complex substances into simple ones is known in many instances to be brought about in the plant by enzymes, and it is highly probable that the synthesis of the complex from the simple is also controlled by these enzymes.

The most commonly occurring sugars in plants are glucose, laevulose, sucrose and maltose: sucrose is hydrolyzed by the enzyme, invertase, into one molecule of glucose and one molecule of laevulose: maltose by the enzyme, maltase, into two molecules of glucose. Both invertase and maltase are widely distributed. The connexion between various sugars and photosynthesis, and their inter-relationships with each other in the leaves, are reserved for another section. 
Of the polysaccharides, cellulose is universally distributed in higher plants and constitutes the greater part of the cell-walls. The pentosans, galactans and mannans also, but to a lesser degree, are components of their structure. Starch, in addition, is very widely distributed : it is converted by the enzyme, diastase, in to dextrin and maltose, and possibly the same enzyme also controls its synthesis. In some plants no starch is formed, and its place in metabolism is taken by inulin or cane-sugar.

The various carbohydrates will first be dealt with in detail, and later their inter-relationships will be considered.

\section{MoNosaccharides.}

These are termed tetroses, pentoses or hexoses according to the number of carbon atoms in the molecule. They contain primary $\left(-\mathrm{CH}_{2} \mathrm{OH}\right)$ or secondary $(=\mathrm{CHOH})$ alcohol groups, and either an aldehyde $(-\mathrm{CHO})$ group, as in glucose, or a ketone $(=\mathrm{C}=\mathrm{O})$ gromp, as in laevulose. They are, as a class, white crystalline substances, soluble in water and aqueous alcohol, but insoluble in ether, acetone and many other organic solvents. They are capable of certain characteristic chemical reactions which form a basis for their detection and estimation. One of the most important is that connected with the aldehyde and ketone groups, owing to which they act as reducing agents, being themselves oxidized. The reducing action usually employed is that which takes place with copper salts in hot alkaline solution, whereby cuprous oxide is formed. Hence they are termed "rerlucing" sugars. Another important reaction is the formation of crystalline osazones (only in the case of sugars with aldehyde or ketone groups), which, by virtue of their melting points and characteristic crystalline forms, constitute, in several cases, valuable tests for the presence of sugars.

\section{PENTOSES.}

These sugars contain five carbon atoms, and have the general formula $\mathrm{C}_{5} \mathrm{H}_{10} \mathrm{O}_{5}$. They are said to be present in the free state to some extent in leaves (Davis and Sawyer, 10). In plants they occur chiefly, however, as condensation products formed with elimination of water. These products are termed the pentosams, and are widely distributed; on hydrolysis they yield pentoses again. The various gums found in plants consist largely of pentosans, and the pectins also contain pentose groups; both consequently yield pentoses on hydrolysis (see pp. 61 and 64). 
If we examine the structural formula of a pentose, as for example, arabinose :

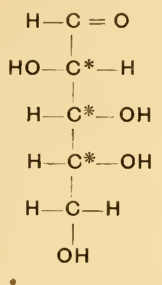

we see that each of the three carbon atoms marked * is united to four different atoms or groups of atoms. Each of these carbon atoms is therefore asymmetric, and, with regard to it, there are two possible isomers (see p. 9, Cole, 3, for stereoisomerism). It will be found on examination that there are eight possible isomers of the formulae given above:<smiles>O=CC(O)C(O)C(O)CO</smiles>

l-Ribose<smiles>O=C[C@H](O)[C@H](O)[C@H](O)CO</smiles>

l-Arabinose<smiles>O=C[C@H](O)[C@H](O)[C@H](O)CO</smiles>

d-Ribose<smiles>O=C[C@H](O)[C@H](O)[C@H](O)CO</smiles>

d-Arabinose<smiles>O=C[C@H](O)[C@H](O)[C@H](O)[14CH2]O</smiles><smiles>O=CC(O)C(O)C(O)CO</smiles>

l-Lyxose unknown<smiles>[Y19][C@H](CO)[C@@H](O)[C@H](O)[C@@H](O)C=O</smiles><smiles>O=C[C@H](O)[C@H](O)[C@H](O)CO</smiles>

Of these only seven have been isolated. The two pentoses which occur in plants are $l$-arabinose and $l$-xylose. These, however, are known almost solely as condensation products, pentosans, in gums, woody tissue, etc. The pentoses form osazones (see p. 49 for reactions and eomposition).

Arabinose. This sugar occurs as the pentosin, araban, in varions gums, such as Cherry Gum, Gum Arabic, etc. (see p. 45).

Some of the properties and reactions of the pentoses are demonstrated in the following experiments. 
Expt. 38. Tests for arabinose. For reactions a-e use a $1 \%$ solution of arabinose : for reaction $f$ a $0 \cdot 2 \%$ solution.

If pure arabinose is not available, a solution for tests $a, b$ and $c$ can be prepared from gum arabic. Boil $5 \mathrm{gms}$, of the gum in 100 c.c. of water with 10 c.c. of concentrated hydrochloric acid for 5 minutes and then neutralize to litmus with aikali. Such a solution is only suitable for, the specific tests for arabinose, since it also contaius galactose (see p. 61). For tests $a, b$ and $c$ small pieces of solid gum arabic may even be used.

(a) Heat a few c.c. of the sugar solution in a test-tube with about half its volume of concentrated hydrochloric acid. In the mouth of the test-tube place a piece of filter-paper soaked with aniline acetate (made by mixing equal quantities of aniline, water and glacial acetic acid). A pink colour will be produced in the paper. This is due to the fact that furfural is formed by the action of the acid on the pentose, and the furfural then gives a red colour with aniline acetate solution :

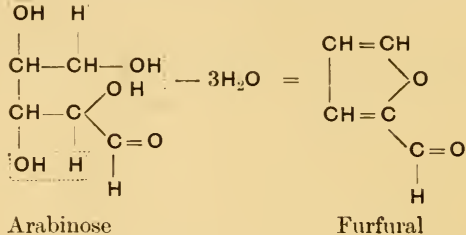

This reaction, however, is also given by the hexoses but to a much less extent.

(b) Warm a few c.c. of the sugar solution with an equal volume of concentrated hydrochloric acid in a test-tube, and add a small quantity of phloroglucin. A bright red coloration is produced.

(c) To a few c.c. of the sugar solution in a test-tube add an equal quantity of concentrated hydrochloric acid, and then a little solid orcinol. Divide the solution into two equal portions. Heat one portion. The solution will become red changing to violet and finally blue, blue-green or green. To the other portion, after heating for a time, add a few drops of $10 \%$ ferric chloride solution. A deep green colour is at once produced. In leoth cases, on the addition of a little amyl alcohol, the green colour will be extracted by the alcohol.

(d) $a$-Naphthol reaction. Add to a little of the sugar solution a few drops of a $1 \%$ solution of a-naphthol in alcohol. Mix the two solutions and then run in about 5) c.c. of concentrated sulphuric acid down the side of the test-tube. A violet coloration is produced at the junction of the two liquids. The coloration is due to a condensation product of a-naphthol with furfural, the latter being formed by the action of the acid on the carbohydrate. This reaction is likewise given by licevulose and cane-sugar (since it yields lievulose, see p. 52), and less strongly by ghcose and maltose ; also by some proteins which contain a carbohydrate group.

(e) Boil a little of the arabinose solution with a few drops of Fehling's solution. Reduction will take place.

( $f$ ) Make the osazone of arabinose following the instructions given for glucosazone (see 1. 49). 
A solution of arabinose which will give the pentose reactions can also be obtained by hydrolysis of Cherry Gum. The gum oozes from the bark of various species of Prumus, such as the Cherry (Prums Cercesus) and the Bird Cherry (P. Padus).

Expt. 39. Preparation of arabinose solution from Cherry $G u m$. The gum is heated, on a water-bath in a round-bottomed flask fitted with an in conclenser ${ }^{1}$, with dilnte sulphuric acid (1 pt. by wt. of gum : 7 pts. by wt. of $4 \%$ sulphuric ceid) for about 5 hours. The solution is then neutralized with caleium carbonate and filtered. Perform the tests $a, b$ and $c$ of Expt. 38 on the solution. A positive result is obtainer in each case. Since the solution contains other sugars as impurities, it cannot conelusively he used for tests $d, e$ and $f$. If a eousiderable quantity of gum is available, crystallization of arabinose should be attempted by eoncentrating the aqueous sugar solution, extracting this with $90 \%$ alcohol and again concentrating in a desiceator (see p. 53). If a very small quantity of gum only is available, the tests $a, b$ and $c$ should be performed directly on a small piece of the gum in a test-tube.

A purer preparation of arabinose, which may be used for all the tests of Expt. 38, can be obtained by the hydrolysis of araban (see Expt. 48).

Xylose. This sugar occurs very widely distributed in woody tissue as the pentosan, xylan (see p. 53). A solution of xylose which will give the pentose reactions can be obtained from the hydrolysis of straw.

Expt. 40. Preparation of xylose solution from straw. Take about $50 \mathrm{gms}$, of straw, which has been eut up into small pieces, and put it into a round-bottomed flask fitted with an air condenser. Add sufficient $5 \%$ sulphuric acid to enver the straw and heat on a water-bath for 2-3 hrs. Filter off the solution, neutralize with caleium earbonate and filter again. Make with the solution the tests a and $c$ of Expt. 38. The solution will also reduce Fehling's solution strongly, but this reduction may be partly due to other sugars formed in the hydrolysis.

The presence of xylan giving the pentose reactions ean also be demonstrated in straw, bran or sawdust by merely heating small quantities of these substances in a test-tube with the above reagents (see Expt. 49).

A purer solution of xylose can be obtained from the hydrolysis of xylan (see Expt. 51).

When xylose is oxidized with bromine, it yields xylonic acid which has a characteristic cadmium salt. The formation of this salt is used as a method for identifying the sugar (see Expt. 51).

\section{HEXOSES.}

Glucose. This substance, which is also known as grape-sugar, is very common and very widely distributed in plants. It occurs in the tissues of leaves, stems, roots, Howers and fruits. It is produced as a result of

1 i.e. a wide piece of glass tubing about $3 \mathrm{ft}$. long passing through the cork. 
the hydrolysis of cane-sugar and maltose, and, in all probability, is the first sugar synthesized from carbon dioxide and water. Its synthesis and its relationships to other sugars will be discussed later (see p. 69). It is a white crystalline substance, readily soluble in water and aqueous alcohol, but only slightly soluble in absolute alcohol.

If, as in the case of a pentose, we examine the structural formula for a hexose, such as glucose:<smiles>O=C[C@H](O)[C@@H](O)[C@H](O)[C@H](O)[C@H](O)CO</smiles>

we see that there are four carbon atoms marked * which are united to four different groups of atoms. It will be found in this case that there are sixteen possible isomers:<smiles>O=C[C@H](O)[C@H](O)[C@H](O)[C@H](O)CO</smiles>

l-Mannose<smiles>O=C[C@H](O)[C@H](O)[C@H](O)[C@H](O)CO</smiles>

d-Mannose<smiles>O=C[C@H](O)[C@H](O)[C@H](O)[C@H](O)CO</smiles>

l-Glucose<smiles>O=C[C@H](O)[C@H](O)[C@H](O)[C@H](O)CO</smiles>

d-Flucose<smiles>O=C[C@H](O)[C@H](O)[C@H](O)[C@H](O)CO</smiles>

$l$-Idose<smiles>O=C[C@H](O)[C@H](O)[C@H](O)[C@H](O)CO</smiles>

d-Idose<smiles>O=C[C@H](O)[C@H](O)[C@H](O)[C@H](O)CO</smiles>

l-Gulose<smiles>O=C[C@H](O)[C@H](O)[C@H](O)[C@H](O)CO</smiles>

d-Gulose 
<smiles>O=C[C@H](O)[C@H](O)[C@H](O)[C@H](O)CO</smiles>

l-Galactose<smiles>O=C[C@H](O)[C@H](O)[C@H](O)[C@H](O)CO</smiles>

d-Galactose<smiles>O=C[C@H](O)[C@H](O)[C@H](O)[C@H](O)CO</smiles>

l-Talose<smiles>O=C[C@H](O)[C@H](O)[C@H](O)[C@H](O)CO</smiles>

$d$-Talose<smiles>O=C[C@H](O)[C@H](O)[C@H](O)[C@H](O)CO</smiles><smiles>O=C[C@H](O)[C@H](O)[C@H](O)[C@H](O)CO</smiles><smiles>O=C[C@H](O)[C@H](O)[C@H](O)[C@H](O)CO</smiles>

These four unknown<smiles>O=C[C@H](O)[C@H](O)[C@H](O)[C@H](O)CO</smiles>

Though many of the above sugars have been synthesized artificially; only three are known to occur naturally, i.e $d$-glucose (dextrose or grapesugar), $d$-mannose and $d$-galactose.

Since compounds containing asymmetric carbon atoms are optically active, i.e. can rotate a plane of polarized light, it follows that the sugars under discussion are optically active.

$d$-glucose is dextro-rotatory.

When either $d$ - or $l$-glucose is first dissolved in water, it is chemically less active than would be expected of the aldehyde form depicted above. This is explained by assuming that glucose, when first dissolved in water, exists in the condition of a $\gamma$-lactone:

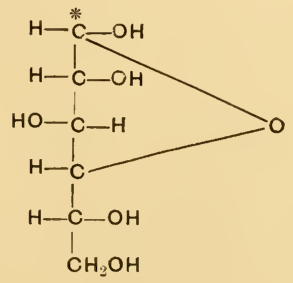


In the above state the carbon atom marked * is also asymmetric so that two forms of glucose are possible, $a$ - and $\beta$-glucose :
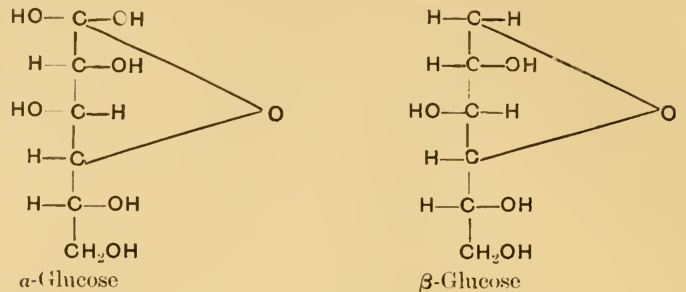

In solution, both the above forms pass by tautomerism into the aldehyde form.

In the plant there are, as will be described later (p. 142), many aromatic and other compounds containing one or more hydroxyl groups. These hydroxyl groups of the aromatic substances are frequently replaced by a glucose (or other sugar) molecule, and such compounds are termed glucosides, as, for instance, salicin, the glucoside of salicylic alcohol which occurs in Willow bark (see p. 152):

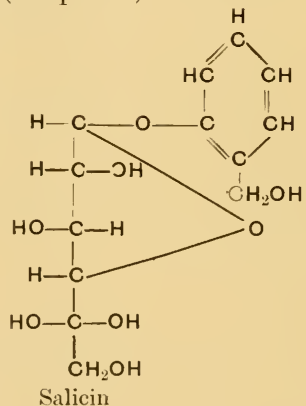

These substances, moreover, may be classified either as $a$ - or $\beta$ glucosides according to which of the above $a$ or $\beta$ forms of glucose combine with the residual part of the compound. Various glucosides will be dealt with in Chaps. viI and Ix.

Expt. 4\}. Tests for glucose. Before dealing with the sugars actually isolated from the plant, it is advisable that the following tests and reactions should be performed with pure glucose using a $0 \cdot 2 \%$ solution.

(a) Moore's test. Boil a little of the glucose solution with an equal volume of caustic soda solution. A yellow colour is developed which is due to the formation of it condensation product (caramel) of the sugar. 
(b) Trommer's test. Add a few drops of a $1 \%$ copper sulphate solution to $2-3$ c.c. of $5 \%$ caustic soda solution. A blue precipitate of cupric hydroxide is formecl. Add now 2-3 c.c. of the glucose solution, and the precipitate will dissolve. On boiling, the blue colour disappears, and a yellow or red precipitate of cuprous oxide is formed. If only a little sugar is present the blue colour will disappear, but no oxide maty be formed.

(c) Fehting's test. Boil a few c.c. of freshly made Fehling's solution in a test-tube and note that it is unaltered. Then add an equal quantity of the glucose solution and boil again. A red precipitate of cuprous oxide is formed.

(d) Osazone test. Take 10 e.c. of a $0.5 \%$ solution of glucose in a test-tube and add as much solid phenylhydrazine hydrochloride as will lie on a sixpenny piece, at least twice as much solid sodium acetate and also 1 c.c. of strong acetic acicl. Warm gently until the mixture is dissolved and filter into another test-tube. Then place the tube in a beaker of boiling water for at least $\frac{1}{2}$ hour, keeping the water boiling all the time. Let the test-tube cool slowly, and a yellow crystalline deposit of phenylglucosazone will separate out. Examine this under the microseope and it will be found to consist of fine yellow needles variously aggregated into sheares amd rosettes. Glucosazone melts at $204-205^{\circ} \mathrm{C}$.

The osazone reaction takes place as follows:

$$
\mathrm{CH}_{2} \mathrm{OH}(\mathrm{CHOH})_{4} \mathrm{CHO}+\mathrm{H}_{2} \mathrm{~N} \cdot \mathrm{NHC}_{6} \mathrm{H}_{5}=\mathrm{CH}_{2} \mathrm{OH} \underset{\text { Glucose phenylhydrazone }}{(\mathrm{CHOH})_{4}} \mathrm{CH}: \underset{\mathrm{H}_{2}}{\mathrm{~N}} \cdot \underset{\mathrm{HC}_{6} \mathrm{H}_{5}}{\mathrm{H}_{2} \mathrm{O}} .
$$

The phenylhydrazone is very soluble, but if an excess of phenylhydrazine is used, a second hydrazine complex is introduced and an insoluble osazone is formed:

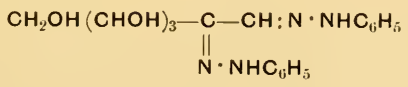

Glucose reacts in this way by virtue of its aldehyde group. Phenylhydrazine hydrochloride does not give an osazone when boiled with glucose unless excess of sodium acetate be added. This acts on the hydrochloride to form phenylhydrazine acetate and sodium chloride.

Galactose. Galactose rarely, if ever, occurs free in plants, though it is fairly widely distributed in the form of condensation products, the galactans, in combination with other hexoses and with pentoses (see p. 60). These galactans form constituents of various gums, mucilages, etc. Agar-agar, which is a mucilage obtained from certain genera of the Red Seaweeds (Rhodophyceae), yields a high percentage of galactose on hydrolysis with acids. Galactose also occurs as a constituent of some glucosides from which it may be derived on hydrolysis.

One of the most important reactions of galactose is the formation of mucic acid on oxidation with nitric acid. Mucic acid is practically insoluble in water and separates out as a crystalline precipitate on pouring the products of oxidation into excess of water. 
Expt. 42. Preparation of galuctose from agar-agar. Weigh out $50 \mathrm{gms}$. of agaragar. Put it into a round-bottomed flask fitted with an air condenser (see p. 45). Add 500 c.c. of $2 \%$ sulphuric acid and heat on a water-bath for 4 hrs. Neutralize the solution with calcium carbonate and filter. ('oncentrate on a water-bath to a syrup. On standing, crystals of galictose will separate out. Then add a little $50-75 \%$ alcohol and warm gently on a water-hath. By this means much of the dark-coloured product will go into solution and can be poured off leaving the crystalline residne. Take up this residue in a little hot water, boil well with animal charcoal to decolorize the solution and filter. Concentrate again on a water-bath. On cooling, colourless prisms of galactose will separate out.

Expt. 43. Oxidation of gulactose to mucic acid. Heat the galactose obtained in the last experiment with nitric acid ( $1 \mathrm{gm}$. galactose to 12 c.c. of nitric acid of sp. gr. $1 \cdot 15$, i.e. 5 pts. of concentrated acid and 12 pts. of water) on a water-bath, until the liquid is reduced to one-third of its bulk. Then pour the product into excess of distilled water. On standing (for a day or two), a white sandy microcrystalline precipitate of mucic acid will separate out.

Mannose. Mannose has not been detected free in many plants, but is widely distributed as condensation products, the mannans, in certain mucilages and in the cell-walls of the endosperm of various seeds (see p. 59). From the mannans the sugar can be obtained by hydrolysis. On adding phenylhydrazine hydrochloride and sodium acetate to a solution of mannose, the phenylhydrazone, which is nearly insoluble in water, is formed almost immediately and hence constitutes a ready method for the detection of the sugar.

Laevulose. This sugar, which is also termed fructose, is widely distributed in plants, in the tissues of leaves, stems, fruits, etc. It is formed, together with glucose, in the hydrolysis by acids of cane-sugar. The original cane-sugar is dextro-rotatory, whereas laevulose is more laevo-rotatory than glucose is dextro-rotatory; hence the mixture from the hydrolysis is laevo-rotatory and is known as invert sugar, the change being termed inversion. The same hydrolysis is brought about by the widlely distributed enzyme, invertase. The polysaccharide, inulin, also yields laevulose on acid hydrolysis. Laevulose is a white crystalline substance, soluble in water and alcohol. Unlike glucose, it contains a ketone instead of an aldehyde group:<smiles>O=C(O)CC(O)C(O)C(O)C(O)C(=O)CO</smiles> 
Laevulose reduces Fehling's and other copper solutions. It yields the same osazone as glucose with phenylhydrazine hydrochloride and sodium acetate. It also forms an osazone with methylphenylhydrazine (m.p. $158^{\circ}$ C.), a reaction which constitutes a distinction from glucose since the latter gives no osizone with this substance.

Expt. 44. Tests for laevulose. The following tests should be performed with a $0 \cdot 2 \%$ solution of laevulose in the same way as for glucose (see $\mathrm{P} .48$ ).

(a) Moore's test. A positive result is obtained.

(b) Trommer's test. A positive result is obtained.

(c) Fehling's test. Reduction takes place.

(d) Osazone test. Note that the crystals are identical with those formed from glucose.

(e) a-Naphthol test (see p. 44). A strong reaction is given.

(f) Seliwanoff's test. To 5 c.c. of Seliwanoff's solution (prepared by dissolving $0.05 \mathrm{gm}$. of resorcinol in 100 c.c. of 1 in 2 hydrochloric acid) add a few drops of laevulose solution and boil. A red coloration and a red precipitate are formed. Add a little alcohol and the precipitate forms a red solution.

\section{DISACCHARIDES,}

These sugars are formed from the monosaccharides by condensation with elimination of water. By boiling with dilute acids, or by the action of certain enzymes, they are hydrolyzed into monosaccharides. The two most important disaccharides found in plants are maltose and cane-sugar.

Maltose. Maltose or malt-sugar, though it probably occurs in smaller quantities than glucose and laevulose, is widely distributed in plant tissues. It is formed in the hydrolysis of starch, and its relationships in the plant to starch and to other sugars will be considered later. It is a white crystalline substance soluble in water and alcohol. In constitution it is a glucose- $\alpha$-glucoside :

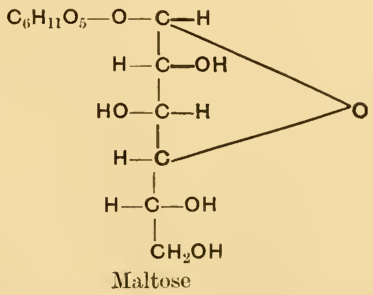

It reduces Fehling's solution; but less readily than glucose. With phenylhydrazine hydrochloride and sodium acetate it forms an osazone 
(m.p. $206^{\circ} \mathrm{C}$.), which is more soluble than glucosazone and crystallizes in broader flatter needles. Maltose is dextro-rotatory.

Expt. 45. Tests for maltose. The tests $a, b, c$ and $e$ should be performed with a $0.2 \%$ solution of maltose ; test $d$ with a $2 \%$ solution (see also glucose, p. 48).

(a) Moore's test. A positive reaction is given.

(b) Trommer's test. A positive reaction is given.

(c) Fehling's test. Reduction takes place, but less strongly than with glucose.

(d) Osazone test. Take 10 c.c. of the solution and treat as for glucosazone. The crystals of maltosazone will be found to be much broader than those of glucosazone.

(e) Hydrolysis. Take 20 c.c. of the sugar solution and add 2 c.c. of concentrated hydrochloric acid. Heat in a boiling water-bath for half an hour. Neutralize and test for the osazone. Glucosazone will be formed.

Sucrose. Sucrose or cane-sugar is very widely distributed in plants, in leaves, stems, roots, fruits, etc. It is a white substance which crystallizes well, and is soluble in water and alcohol. As previously stated it is hydrolyzed by dilute acids and by invertase into one molecule of ghcose and one molecule of laevulose. It is formed by the condensation of glucose and laevulose with the elimination of water. Its constitution is in all probability as follows:

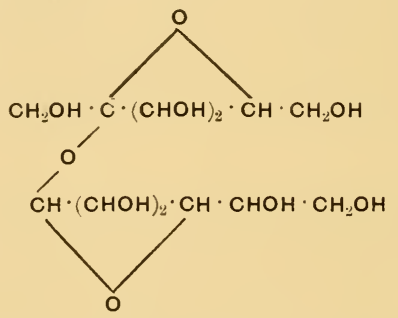

so that both the ketone and aldehyde groups are rendered inactive. It does, not reduce Fehling's solution and does not form an osazone. It is dextro-rotatory.

Expt. 46. Tests for cune-sugar. The following tests should be made with a $1 \%$ solution of pure crystalline cane-sugar (sce also glucose, p. 48).

(a) Moore's test. A negative result is obtained.

(b) Fehling's test. No reduction takes place.

(c) a-N Tuphthol test. A positive result is given since sucrose yields laevulose.

(d) Hydrolysis. To a few c.c. of the solution add a drop of strong sulphuric acid and boil for two minutes. Then neutralize with caustic soda using litmus as indicator. Boil again and adll Fehling's solution drop by drop. A reduction takes place owing to the inversion of the cane-sugar by sulphuric acid.

(e) Seliwanoff's test. A positive result is fobtained owing to the liberation of laevulose. 


\section{PolysaCCHARIDES.}

These substances are formed by condensation, with elimination of water, from more than three molecules of monosaccharides.

\section{PENTOSANS.}

It has already been mentioned that condensation products of the pentoses, the pentosans, are widely distributed. The two most frequently occurring pentosans are xylan and araban. No enzymes are known which hydrolyze the pentosans. It is characteristic of xylan and araban that they form copper compounds in Fehling's solution in presence of excess of alkali.

Araban. This pentosan may be regarded as a condensation product of arabinose as already indicated. It occurs in various gums (Gum Arabic, Cherry Gum) frequently in combination with other substances. On hydrolysis with acids, araban yields arabinose. (See also gums and arabinose.)

Expt. 47. Preparation of aruban from Gum Arabic. (Salkowski, 27.) Weigh out $20 \mathrm{gms}$. of gum arabic and dissolve in 500 c.c. of warm water in a large evaporating dish. Then add 200 c.c. of Fehling's solution and excess of caustic soda solution. The araban will be precipitated as a white gummy mass which will settle at the bottom of the dish. Filter off through muslin. Take up the precipitate in dilute hydrochloric acid ( 1 pt. of acid : 1 pt. of water), and then add alcohol. The araban separates out as a white precipitate. Wash away the copper chloride with alcohol.

E.ept. 48. Hydrolysis of araban. The araban from the last experiment is put into a round-bottomed flask with about 200 c.c. of $2 \%$ sulphuric acid and heated on a water-bath for 2 hours, the flask being fitted with an air condenser (see p. 45). Then neutralize the liquid with calcium carbonate, filter from calcium sulphate, and concentrate on a water-bath. The sugar is extracted from the syrup with $90 \%$ alcohol. Arabinose crystallizes with difficulty but the process may be facilitated by sowing the concentrated alcoholic solution with a few crystals of arabinose. Some of the solution of arabinose should be tested with all the tests given in Expt. 38 .

Xylan. This pentosan occurs in lignified cell-walls, and is the chief constituent of "wood gum." It is found in the wood of many trees (not Coniferae), in bran, in wheat and oat straw, in maize cobs, in the shells of coconuts and walnuts, in the testa of the cotton (Gossypium) and in many other tissues: also in some gums. On hydrolysis, xylan yields xylose; hence wood shavings, bran, straw, etc., will give the pentose reactions on hydrolysis. 
Expt. 49. Detection of pentose from pentosans in bran, savdust and strau. Take ' a small quantity of bran and boil it up several times with $98 \%$ alcohol, filtering off the alcohol after each treatment. This should remove any sugars or glucosides present. Allow the alcohol to evaporate off from the bran, and then make the following tests for pentoses (see Expt. 38) :

(a.) Heat, for about one minute, a small quantity of the bran in a test-tube, with sufficient concentrated hydrochloric acid to cover it. Care should be taken not to char the material. Then add as much solid orcinol as will lie on the tip of a penknife. Heat gently again for a few seconds. Then add one or two drops of strong ferric chloride solution ; a green coloration will be produced. Add amyl alcohol and the green colour will pass into the alcohol.

(b) Heat again another portion of the bran with the same quantity of concentrated hydrochloric acid in a test-tube, but this time heat more strongly. After heating a few minutes place a piece of filter-paper soaked in a solution of aniline acetate in the mouth of the test-tube. A cherry-red coloration will denote the formation of furfural.

The above method and tests with bran may be repeated in exactly the same way using sawdust or straw.

Expt. 50. Preparation of xylan from saudust. Extract one kilo of sawdust with 4 litres of $1-2 \%$ ammonia solution for $24 \mathrm{hrs}$. Then filter off the ammoniacal solution through muslin and repeat the extraction. The xylan is insoluble in ammoniacal solution, and in this way colouring matters are removed. Finally wash the sawdust well with water and press dry from the liquid. Then add to the sawdust sufficient $5 \%$ caustic soda solution to make a thick mush (about 1000-1500 c.c.) and allow it to stand for $24 \mathrm{hrs}$. in a warm place. The alkaline solution is then pressed out through calico and filtered through filter-paper. To the clear filtrate add an equal volume of $96 \%$ alcohol which will precipitate the xylan as a sodium compound. Filter off this precipitate, wash with alcohol, and decompose with alcohol to which a little strong hydrochloric acid has been added to remove the sodium. The free xylan is again washed with alcohol, and can be dried by washing with absolute alcohol and ether and finally in a desiccator. It is a dirty-white powder which is almost insoluble in water. Make the tests for peutoses (see Expt. 38) on a little of the solid xylan. The reaction will be given in each case.

Expt. 51. Hydrolysis of xylan. Put the xylan obtained in the last experiment in a round-bottomed flask fitted with an air condenser (see 1).45). Add 100 c.c. of $4 \%$ sulphuric acid and heat on a water-bath for 4 hrs. Neutralize the solution with calcium carbonate, filter from calcium sulphate and concentrate on a water-bath. Test a portion for pentoses (see Expt. 38) and a positive reaction will be obtained. To a small quantity add also a few drops of Fehling's solution and boil. Reduction will take place.

To the remainder of the xylose solution add bromine (sce p. 45) gradually until there is excess. Then remove the excess of bromine by warming on a water-bath. Neutralize the solution, which contains xylonic acid, with eadmium carbonate and evaporate on a water-bath. Extract the residue with alcohol and filter. On concentrating the alcoholic extract, white prismatic needles of cadmium xylonate separate out. 
It has been shown that pentosans, xylan and probably araban, oceur in leaves (Davis, Daish and Sawyer, 15). It is likely that the xylan is widely distributed in all tissues since it forms a constituent of lignifierl cell-walls.

Expt. 52. Detection of pentoses from pentosuns in leaves. (Davis, Daish and Sawyer, 15.) Take two large leaves of the Sunflower (Helianthus annuns). Tear into small pieces and drop into boiling $98 \%$ alcohol in a flask. Boil well and filter off the alcohol. Repeat until all the green colour is removed. Then dry off the alcohol and grind up the leaf residue. Perform the test for pentoses (Expt. $38 a$ and $c$ ) on the dry leaf tissue. It should give the above tests showing the presence of pentosans.

Leaves of the Violet (Viola odorata) and Nasturtiun (Tropaeolum majus) may also be used.

Expt. 53. Method for determination of pentosans in tissues, brun and leaves, ete. Weigh out $2 \mathrm{gms}$. of bran, put it into a round-bottomed flask, add 100 c.c. of $12 \%$ hydrochloric acid and fit the flask with a water condenser. Heat gently over wire gauze and distil into a solution of phloroglucin in $12 \%$ hydrochloric acid. A green precipitate of furfural phloroglucide is formed which eventually becomes almost black. For accurate estimations of pentosans this is filtered off and weighed on a Gooch crucible. The same method may be used with leaf residue as in Expt. 52.

\section{STARCHES.}

Starch. This is a very widely distributed substance in plants. It occurs as solid grains throughout the tissues, in leaves, stems, roots, fruits and seeds. It is absent, however, from a number of Monocotyledons, e.g. Iris, Snowdrop (Galanthus), Hyacinthus, etc. It forms one of the chief reserve materials of plants, that is, it is synthesized from sugar when carbon assimilation and carbohydrate synthesis are in progress, and is stored in the solid form in tissues as grains. In other circumstances of the plant's existence, when material for metabolism is not available from carbon assimilation, as for instance in germinating seeds or growing bulbs or rhizomes, the starch is hydrolyzed into dextrin and soluble sugar, which is translocated and used as a basis for metabolism. During the night in leaves there is also a similar hydrolysis of the starch which has been temporarily stored from the excess of sugar synthesized during the day.

Starch has a very large molecule and thus a high molecular weight. It is insoluble in cold water. When heated with a little water it gives starch paste, but on boiling with water it gives an opalescent "solution" which really contains starch in the colloidal state as an emulsoid. In this condition it does not diffuse through dialyzing membranes and does not depress the freezing point of water. The "solution" cannot, strictly 
speaking, be filtered, but generally, when hot, it passes to some extent through ordinary filter-paper. Starch is insoluble in alcohol and is precipitated by it.

The most characteristic reaction of starch is the blue colour it gives with iodine solution. This blue colour disappears on heating, but reappears again on cooling. Starch is precipitated from "solution" by half saturation with ammonium sulphate: it does not reduce Fehling's solution.

By boiling with dilute acids, starch is first converted into "soluble starch" which still gives a blue colour with iodine. On further boiling, various dextrins (see dextrins) are obtained which give either purple, red or no colonr with iodine. The final product, after prolonged boiling with acids, is glucose. Hydrolysis with diastase yields dextrin and maltose (see diastase, p. 73).

Expt. 54. Preparation of starch from Wheat. Starch may be prepared from a cereal by the following method.

Take 2.5 gms. of flour and make it up into a dongh with a little water. Allow it to stand for half an hour. Then tie a piece of muslin over the top of a beaker which is filled with water. Place the dough on the top of the muslin and rub it gently with a glass rod. The starch will be separated from the gluten, and will be washed through the muslin and on standing will sink to the bottom of the beaker. Allow this to stand till the starch has settled, then decant off the bulk of the liquid. Filter uff the starch, and wash well with water, then with alcohol and finally with ether. Dry in the steam-oven.

For the detection of starch in green leaves, see Expt. 77.

Expt. 55. Tests for starch. Take a small quantity of the starch prepared in the previons experiment and shake up with a little cold water in a test-tube. Filter, and test the filtrate with a drop of iodine (in potassium iodide) solution. No blue colour is oltained. Pour a drop of the iodine solution on the residue in the filter. It turns deep blue.

Weigh out 2 gmis. of the starch prepared in the last experiment, and mix it into a thin cream with a little water. Boil rather more than 100 c.c. of water in an evaporating dish, and then gradually add to it the starch paste, keeping the water boiling all the time. An opralescent "solution" is oltained. With a few c.c. of the solution in each case make the following tests:

(ii) Add 1-2 drops of iodine solution. A blue colour is oltained. Heat the solution : the blue colsur disappears, but reappears on cooling.

(b) Add an equal volume of alcohol : the starch is precipitated.

(c) Add an equal volume of saturated ammonium sulphate solution : the starch is precipitated, i.e. by half saturation with this salt.

(d) Add basic lead acetate solution : the starch is precipitated.

Expt. 56. Hydrolysis of starch. To 50 c.c. of the starch solution prepared in the last experiment add 1 c.c. of strong sulphuric acid. Boil for 10-20 minutes in a 
round-bottomed flask. Test a portion of the solution with iodine from time to time ; a purple, red or brown colour is formed due to the dextrin produced in hydrolysis. To the remainder of the solution after neutralization, using litmus as indicator, add some Fehling's solution and boil. Reduction takes place owing to the glucose formed in hydrolysis.

\section{DEXTRINS.}

These compounds occur in the plant as transitory substances, since they are formed as intermediate products of the hydrolysis of starch by diastase. They are also formed on heating starch or by boiling it with mineral acids (see previous experiment). The hydrolysis of starch to dextrins is fairly rapid, but the conversion of dextrins into maltose is a much slower process.

Both starch and dextrins have the same empirical formula. Various forms of the latter have been identified, such as amylodextrin which gives a blue colour with iodine, erythrodextrin which gives a brownish-red colour with iodine, and achroodextrin which gives no colour with iodine. The dextrins are readily soluble in water; they are precipitated by alcohol but not by basic lead acetate. On hydrolysis with acids, they are converted into glucose.

Expt. 57. Preparation of dextrin by hydrolysis of starch. (a) By diustase from leaves of the Pea (Pisun sativum). Weigh out $10 \mathrm{gms}$. of commercial potato starch and make it into a solution in 250 c.c. of boiling distilled water as in Expt. 55 and cool. Then weigh out 10-15 gms. of fresh leaflets of the Pea (Pisum sativum) and pound them well in a mortar. Add to the pounded mass 100 c.c. of distilled water and a few drops of chloroform (see maltase, p. 75) and filter. The filtrate will contain diastase (see also Expts. 78-80). Then add the diastase extract to the starch solution in a flask, plug with cotton-wool and put in an incubator for 48 hrs. If a little of the liquid is withdrawn from time to time and tested with iodine, it will be found that the blue colour due to starch gradually disappears and is replaced by the brownish-red colour due to dextrin. After $48 \mathrm{hrs}$. there will be no trace of hlue colour; then filter the liquid and concentrate the filtrate on a water-bath to a syrup. Treat the residue with $96-98 \%$ alcohol and filter. A sticky mass of dextrin is left which should be extracted with a little hot alcohol and then reserved for the next experiment. To show the presence of maltuse, the alcololic extract is evaporated to dryness on a water-bath, the residue taken up in a little water and the osazone test made (see $p .49$ ) with the solution. Crystals of maltosazone will separate out.

(b) By diastuse from germinating Burley (Hordeum vulgare). Grind well $2.5 \mathrm{gms}$. of barley grains in a coffec-mill. Put the flour into a flask and extract with $96-98 \%$ alcohol by heating on a water-bath. This will largely free the grain from sugars. Make a starch "solution" of the residue by boiling with 500 c.c. of water and filtering through fine muslin. 
Weigh out another $25 \mathrm{gms}$. of barley grains and allow them to gerninate by soaking and spreading on damp blotting-paper for 5-7 days. Pound the grains well in a mortar, add 100 c.c. of water, allow to stand for 2-3 hrs. and filter. Precipitate the filtrate with alcohol and allow to stand for $24 \mathrm{hrs}$. Filter off the precipitate, take up in water and add it to the barley starch "solution," together with a few drops of ehloroform. Proceed as with $(\alpha)$ only the time for hydrolysis may be much shorter, i.e. $6-12$ hrs.

Expt. 58. Tests for dextrin. Make a solution of the dextrin prepared in the last experiment and note that it is very soluble in water. With the solution make the following tests :

(a) Add a little iodine solution. A reddish-brown colour is produced. Heat the solution and the colour will disappear. Cool again and the colour will reappear.

(b) Add an equal volume of strong alcohol. The dextrin is precipitated.

(c) Add an equal volume of saturated ammonium sulphate solution, i.e. half saturation with ammonium sulphate. The dextrin is not precipitated.

(d) Add some basic lead acetate solution: the dextrin is not precipitated.

\section{INULIN.}

Inulin. This substance occurs as a soluble "reserve material" in the cell-sap of the underground stems, roots and also leaves of a number of plants, especially members of the Compositae, e.g. Dahlia (Duhliu variabilis), Jerusalem Artichoke (Helianthus tuberosus), Chicory (Cichorium Intybus) and the Dandelion (Taraxacum officinale). It is said to occur also in the Campanulaceae, Lobeliaceae, Goodeniaceae, Violaceae and many Monocotyledons (Hyacinthus, Iris, Muscari and Scilla).

Inulin is a condensation product of laevulose to which it bears much the same relation as starch to glucose. It is a white substance, soluble in water and insoluble in alcohol. It crystallizes out in the cells, in which it occurs, in characteristic sphaero-crystals on addition of alcohol to the tissues. It is hydrolyzed by mineral acids to laevulose : also by the enzyme inulase which occurs in the plant.

Expt. 59. Extraction of inulin. Cut off the tubers from two Dahlia (Dahliu variabilis) plants, wash well, and put them through a mincing machine. Carefully collect the liquid and the crushed tuber, and boil well with sufficient water to cover the crushed material. Add also some precipitated calcium carbonate to neutralize any free acids present. Then filter through fine muslin, and to the filtrate, which shonld again be made quite hot, add lead acetate solution until a precipitate (of mucilaginous substances, etc.) ceases to be formed. Care should be taken to avoid the addition of a large excess of lead acetate. Filter off the lead precipitate, and saturate the filtrate with sulphuretted hydrogen till all excess lead is removed. Filter off' the lead sulphide, neutralize the filtrate to phenolphthalein with ammonia, and evaporate to half bulk or less on a water-bath, when the inulin will probably 
begin to deposit. Then pour into an equal volume of alcohol, and allow to stand for one or two days. The erude precipitate of inulin is filtered off, dissolved in a small amount of water, and reprecipitated with alcohol. It ean he washed with alcolosl and ether and dries over sulphuric acid.

The Artichoke (Heliunthus tuberosus) may also be used, about 12 tubers being necessary.

Expt. 60. Tests for inulin. Make a solution of some of the inulin prepared in Expt. 59 in hot water. It will readily dissolve giving a elear solution. With the solution make the following tests:

( $a$ ) Make a very dilute solution of iodine and add to it a drop or two of inulin solution : the brown colour will be unaffected.

(b) Boil some inulin solution with a little Fehling : no reduction takes place.

If the inulin solution which is being used should reduce Fehling it indicates that sugar is present as impurity. If this is the case, then a little of the solid inulin should be washed free from sugar by means of alcohol before proceeding with the following tests.

(c) To a little inulin solution add some $1 \%$ alcoholic solution of a-naphthol and a few drops of concentrated sulphuric acid and warm. A deep violet colour is produced. This is due to the formation of furfural from the laevulose produced in hydrolysis (see laevulose, 1. 51).

(d) To a little imulin solution add about an equal quantity of strong hydrochloric acid and a few crystals of resorcin. A red coloration is formed. This reaction (Seliwanoff's test) is also due to the presence of laevulose (see laevulose, p. 51).

Expt. 61. Hydrolysis of inulin. Some inulin is dissolved in very dilute hydrochloric acid (about $0.5 \%$ ) and heated on a water-bath for half an hour in a round-bottomed flask provided with an air condenser (see p. 45). The solution is then neutralized with sodium carbonate and concentrated on a water-bath. With the concentrated solution make the following tests :

(a) Boil with a little Fehling : the solution is rapidly reduced.

(b) Nake the osazone test (see p. 49). Glucosazone crystals will be found to be formed on microscopic examination. (Laevulose forms the same osazone as glucose.)

(c) Make the tests $(c)$ and $(d)$ of the last experiment. A positive result will loe given in each case.

\section{MANVANS.}

The mannans which have already been mentioned (see p. 50) are condensation products of the hexose, mannose. They occur most frequently, either mixed, or in combination, with the condensation products of other hexoses and pentoses (glucose, galactose, fructose and arabinose) as galactomanuans, glucomannans, fructomannins, mannocelluloses, etc. Such mixtures or compounds of which mannans form a constituent are widely distributed in the seeds of many plants, i.e. Palms (including the Date-palm), Asparagus (Ruscus), Clover (Trifolium), Coffee Bean (Coffeu arabica), Onion (Allium Cepa) and of members of the Leguminosae, 
Rubiaceae, Coniferae and Umbelliferae. In seeds the mannans may constitute, together with cellulose, the thickened cell-walls of the endosperm and are included in the term " reserve- or hemi-cellulose" though they are not strictly celluloses. "Vegetable ivory," which is the endosperm of the Palm, Phytelephas macrocarpa, contains considerable quantities of a mannan and is used as a source of mannose. Mannans, in addition, form constituents of certain mucilages, as for instance those in Lily bulbs (Lilium candidum, L. bulbiferum, L. Martagon and others) (Parkin, 23) and tubers of various genera of the Orchidaceae: they are also found in the roots of the Dandelion (Turaxacum), Helianthus and Chicory, Asparagus and Clover, and in the wood and leaves of various trees.

Many of the mannans, unlike true celluloses, are readily hydrolyzed by dilute hydrochloric and sulphuric acids. The mannan in the Coffee Bean, however, is hydrolyzed with difficulty.

\section{GALACTANS.}

These substances bear the same relationship to the hexose, galactose, as the mannans to mannose, that is, they are condensation products of galactose (see p. 49). Similarly they frequently occur, together with the condensation products of other sugars, as galactoaraban, galactoxylan, galactomannan, etc. As such they form constituents of many gums and mucilages and of the cell-walls of the reserve tissue of seeds, i.e. the Coffee Bean (Coffea arabica), the Bean (Faba), the Lupin (Lupinus), the Paeony (Paeonia), the Kidney Bean (Phaseolus), the Date (Phoenix), the Pea (Pisum), the Nasturtium (Tropaeolum) and many others (Schulze, Steiger and Maxwell, 29).

\section{GUMS.}

These substances occur widely distributed among plants, especially trees. Some gums are wholly soluble in water giving sticky colloidal solutions: others are only partially soluble. They are all insoluble in alcohol. In the solid state they are translucent and amorphous.

Chemically the gums are varied in nature; they may in general be regarded as consisting of complex acids in combination with condensation products of various sugars, such as araban, xylan, galactan, etc. On hydrolysis they give mixtures of the corresponding sugars, arabinose, xylose, galactose, etc., in varying proportions, though in some cases one sugar preponderates. 
Some of the best-known gums are the following:

Gum Arabic (arabin). This substance is obtained from an Acacia (Acaciu Senegal), a native of the Sondan. The gum exudes from the branches. Other species of Acacia yield inferior gums. Gum arabic is a mixture of the calcium, magnesium and potassium salts of arabic acid, a weak acid of which the constitution is unknown, in combination with araban and galactan.

Gum Tragacanth. This is a product from several Tragacanth shrubs which are species of Astragalus (Leguminosae), chiefly A. gummifer. It is obtained by wounding the stem and allowing the gum to exude and harden. On hydrolysis it gives a mixture of complex acids and various sugars such as arabinose, galactose and xylose.

Cherry Gum (cerasin) occurs in the wood of the stems and branches of the Cherry (Prunus Cerasus), the Bird Cherry (P. Padus), the Plum ( $P$. domestica), the Almond ( $P$. Amygdulus) and other trees of the Rosaceae. It exudes from fissures of the bark. On hydrolysis it yields almost entirely arabinose.

Expt. 62. Reactions of Gum Arabic. Put a little gum arabic into an evaporating dish and add a little water. Heat gently and stir. The gum will slowly dissolve, giving a thick sticky solution which does not solidify or gel on cooling. Make the following tests, using a little of the gun solution in a test-tube each time.

(a) Add a little alcohol. The gum is precipitated.

(b) Add a little Fehling's solution and boil. No reduction takes place.

The three following experiments show the presence of pentosan complexes in the gum (see also Expt. 38, p. 44):

(c) Add a little phloroglucin to the gum and then strong hydrochloric acid. No colour is produced. Now heat, and a cherry-red colour appears.

(d) Heat the gum solution with a little concentrated hydrochloric acid and then add a trace of orcinol. Warm again and then add one or two drops of strong ferric chloride solution. A green coloration will be produced.

(e) Heat the gum solution strongly with hydrochloric acid, and, after heating for a few minutes, place a piece of filter-paper soaked in a solution of aniline acetate in the mouth of the test-tube. A cherry-red coloration indicative of furfural will be formed.

Expt. 63. Hydrolysis of Gum Arabic. Weigh out 10 gms. of gum arabic. Put it into a round-bottomed flask and add 100 c.c. of water and 4 c.c. of strong sulphurie acil. Warm gently until the gum goes into solntion. Then fit the flask with an air condenser (see 1. 45) and heat on a water-bath for about 4 hrs. Cool the solution, and neutralize with barium carbonate. Filter off the barium sulphate and concentrate the solution on a water-bath. Boil a drop or two of the syrup with Fehling's solution and show that reduction takes place. (The original gum either does not reduce Fehling at all, or, if so, only slightly.) Then add a little nitric acid 
(sp. gr. 1·15, see Expt. 43) to the syrup and heat on a water-bath almost to dryness. Pour the residue into about 100 c.c. of water and allow to stand. A mierocrystalline precipitate of mucic aeid is formed showing the presence of galactose (see p. 50) as a produet of hydrolysis.

\section{MICILAGES.}

The characteristic of these substances is that they swell up in water and produce colloidal solutions which are slimy.

Ifucilages are widely distributed and may occur in any organ of the plant. Sometimes they are confined to certain cells, mucilage sacs or canals. They are distinguished from the pectic substances by the fact that they do not gelatinize. Some of the best known examples of mucilage-containing tissues are those in the root and flower of the Hollyhock (Althaea rosea): in succulent plants (Aloe, Euphorbia), in bulbs (Scilla, Allium) and tubers (Orchis Morio): in seeds of Flax or Linseed (Linum) and in fruits of Mistletoe (Viscum album).

The mucilages vary in composition. They appear to be largely, if not wholly, condensation products of various sugars (galactose, mannose, glucose, xylose, arabinose), similar constituents to those of many gums and hemicelluloses. On hydrolysis various mixtures of sugars are produced. Of the mucilages, that from linseed has been thoroughly investigated. It has been found on hydrolysis to give sugars only, e.g. arabinose, xylose, glucose and galactose. In this respect mucilages differ from gums, since the latter have always some other accompanying substance in addition to sugars.

Expt. 64. Preparation and properties of mucilage from Linseed (Linum) (Neville, 21). Take about $60 \mathrm{gms}$. of linseed and let it soak for $24 \mathrm{hrs}$. in 300 c.e. of water. Then separate the slime from the seeds by squeezing through muslin, and add to the liquid about twice its volume of $96-98 \%$ alcohol. The mucilage is preeipitated as a thick slimy preeipitate. Filter off the precipitate and wash with alcohol. By washing with absolute alcohol and ether and finally drying in a desiccator, the mucilage may be obtained as a powder.

Add water to some of the mucilage. It swells up and finally gives an opalescent solution. Make with it the following tests:

(a) Add iodine. No colour is given.

(b) Add a little Fehling's solution and boil. No reduetion takes place.

Expt. 65. Hydrolysis of Linseed mucilage. Put the remainder of the mucilage in a round-bottomed flask and add 50 c.c. of $4 \%$ sulphuric acid. Fit the flask with an air condenser (see p. 45) and heat for at least four hours on a water-bath. Cool and neutralize with barium earbonate. Filter off the barium sulphate, and 
concentrate the filtrate on a water-bath. With the coneentrated solution make the following tests :

(a) Add a few drops to a little boiling Fehling solution. Reduction immediately takes place.

(b) Make the phlorogluein, orcinol and furfural tests for pentoses, using a sinall quantity only of the hydrolysis mixture for the tests. A positive result will be given in each case. The pentoses, arabinose and xylose, are responsible for these reactions.

(c) Add to some of the solution phenylhydrazine hydrochloride, sodium acetate and a little acetic acid, and leave in boiling water for half an hour for the osazone test [sec Expt. $41(d)$ ]. A mixture of osazones will separate out, among which glucosazone ean be identified.

(d) Concentrate the remainder of the solution and then add some nitric acid of sp. gr. $1 \cdot 15$ (see Expt. 43). Evaporate down on a water-bath to one-third of the bulk of the liquid and then pour into about 100 e.c. of water. A white mierocrystalline precipitate of mucic acid will separate out, either at once or in the course of a day or two. This demonstrates the presence of galactose.

\section{PECTHE NUBSTANCES.}

These substances are considered at this point since they are said to constitute, in more or less intimate connexion with cellulose, the middle lamella of cell-walls in many tissues. The pectic substances are frequently found in the juices of succulent fruits in which the tissues have disintegrated, such as red currants and gooseberries. They have been isolated chiefly from fleshy roots, stems or fruits, as, for instance, from turnips, beetroot, rhubarb stems, apples, cherries and strawberries.

Recent work (Schryver and Haynes, 28) points to the fact that in turnips, strawberries, rhubarb stems and apples, there is the same pectic material, and it is possible that all such substances may be identical. The compound isolated in the above case is of an acidic nature and has been termed pectinogen. When pectinogen is treated with dilute solutions of caustic alkali at ordinary temperatures, it is rapidly changed into a second substance termed pectin, which is readily converted into a gel under certain conditions.

In the case of juicy fruits, such as currants and gooseberries, the pectinogen can be precipitated as a gelatinous precipitate by adding alcohol to the expressed juice. In the case of fleshy fruits, stems and roots, the procedure is as follows. The tissues are thoroughly disintegrated in a mincing machine and pressed free from all juice in a powerful press. The residue is then dried, finely ground, washed with water and finally extracted with dilute ammonium oxalate solution in which pectinogen is soluble. The extract is concentrated and the 
pectinogen precipitated by alcohol. It may be purified by reprecipitation.

Pectinogen is precipitated from aqueous solution by alcohol as a very bulky gelatinous mass, but when dried it forms an almost colourless granular powder. Put into water it absorbs large quantities of liquid and dissolves slowly, giving an opalescent solution with a distinctly acid reaction.

As mentioned above pectinogen in alkaline solution is rapidly converted into pectin. A solution of pectinogen is not precipitated either by acid or dilute solutions of calcium salts but, after treatment with alkali and conversion into pectin, both the aforesaid reagents produce gelatinous precipitates. A similar precipitate is also formed when lime water is added in excess to a solution of pectinogen and it is allowed to stand. There is little doubt that the pectinogen is converted by the alkali into pectin. Pectin is also an acid substance and it is insoluble in water, giving an insoluble salt with calcium. After treatment of pectinogen with alkali the pectin can, as already stated, be precipitated by adding acid.

Analyses of pectin from various sources have led to the suggestion of $\mathrm{C}_{17} \mathrm{H}_{24} \mathrm{O}_{16}$ as its formula. There is also evidence that it contains one pentose group. This can be detected and estimated by the furfural phloroglucide method (see Expt. 53).

Expt. 66. Extraction and reactions of pectinogen. Take about half a pound of red currants and squeeze out the juice through fine muslin into a large beaker. Then add to the juice about 2-3 times its bulk of $96-98 \%$ alcohol. A bulky gelatinous precipitate of pectinogen will separate out. Allow the precipitate to stand for a time in the alcohol, and then filter off. Wash with alcohol and finally press free from liquid. Dissolve the precipitate in as little water as will enable it to go into solution. To two small portions of the solution add respectively $(a)$ a few drops of stroug hydrochloric acid, $(b)$ an excess of calcium chloride solution. Note that no precipitate is formed in either case.

Expt. 67. Conversion of pectinogen into pectin, and reactions of pectin. Take about one-third of the pectinogen solution prepared in Expt. 66, make it alkaline with caustic soda, and let it stand for about 10-15 minutes. Then divide the solution into two parts and add respectively $(a)$ sufficient hydrochloric acid to acidify, (b) excess of calcium chloride solution. In the first case a gel of pectin is formed: in the second case a gelatinous precipitate of the calcium salt of pectin.

To a further quantity of the pectinogen add excess of lime water and let it stand. The gelatinous calcium precipitate will separate out in a short time.

Expt. 68. Detection of the pentose group in pectinogen. Filter off the pectin gel obtained in the last experiment and allow it to dry. Then test for the pentose group by the orcinol, phloroglucinol and furfural tests (see Expt. 38). All results will be found to be positive. 
The extraction of pectinogen, etc. in the above experiments can equally well be carried out with other material, e.g. ripe gooseberries, raspberries and strawherries, using exactly the same methods.

Expt. 69. Prepuration of pectinogen from Turmips. Take two full-sized turnips and mince them fincly in a mincing machine. Then wrap the mass in a piece of strong unleached calico and press out the juice as completely as possible in a press. The juice contains little pectinogen and can be thrown away. The pressed mass is then thrown into $0.5 \%$ ammonim oxalate solution heated to $80-90^{\circ} \mathrm{C}$. on a waterbath and stirred to make a paste. The liquid is again rapidly pressed out in the press. To the viscid extract an equal volume of $96 \%$ alcohol is added, and the pectinogen seprarates ont as a voluminous gelatinous precipitate. This is filtered off and, when pressed free from alcohol and dried, can be used for tests as in the previous experiments.

The gelatinization of pectinogen can also be brought about by certain enzymes termed pectases which are found in the juices of various plants, i.e. root of Carrot (Daucus Curota) and leaves of Lucerne (Medicago sativa), Lilac (Syringa vulgaris) and Clover (Trifolium pratense).

Expt. 70. Action of pectuse on pectinogen. Make an extract of either Lucerne or Clover leaves by pounding them in a mortar with a little water, and then filter. Add the filtrate to some of the pectinogen solution prepared in Expt. 66 or 69 . On standing a gelatinous precipitate will be produced. Should the reaction be slow, it may be accelerated by placing the mixture in an incubator.

\section{CELLULOSES.}

Celluloses are very important polysaccharides. They form constituents of the structural part of all the higher plants. The cell-wall of the young cell consists entirely of cellulose, but in older cells the walls may be lignified, cuticularized, etc., i.e. the cellulose may be accompanied by other substances such as lignin, cutin, mucilage, etc. In the light of these facts the term cellulose is made to include:

1. Normal celluloses.

2. Compound celluloses.

(a) Ligno-celluloses.

(b) Pecto-celluloses.

(c) Adipo- or cuto-celluloses.

3. Pseudo- or Reserve celluloses.

True or normal cellulose. Of this substance, as we have said, many cell-walls are composed. The most familiar form of cellulose is cotton, which consists of hairs, each being a very long empty cell, from the testa or coat of the seed of the Cotton plant (Gossypium herbaceum). 
Crucle cotton (i.e. the hair cell-walls) is not quite pure cellulose, but contains a small amount of impurity from which it is freed by treatment first with alkali and subsequently with bromine or chlorine. All kinds of cotton material, cotton-wool, and the better forms of paper (including filter-paper) may be regarded as almost pure cellulose.

Pure cellulose is a white, somewhat hygroscopic, substance. It is insoluble in water and all the usual solvents for organic substances. It is, however, soluble in a solution of zine chloride in hydrochloric acid in the cold, and in a solution of zine chloride alone on warming. It is also soluble in anmoniacal cupric oxide (Schweizer's reagent).

In addition cellulose is soluble in concentrated sulphuric acid, which on standing converts it first into a hydrate and then finally into glucose. If, however, water is added to the sulphuric acid solution as soon as it is made, the gelatinous hydrate of cellulose is precipitated. This substance is termed "amyloid" since it gives a blue colour with iodine. Concentrated nitric acid converts cellulose into nitrates, of which one is the substance, gun-cotton. In $10 \%$ alkalis cotton fibres thicken and become more cylindrical. This procedure has been employed by Mercer to give a silky gloss to cotton, and the resultant product is ealled mercerized cotton.

Expt. 71. The colour tests and solubilities of cellulose.

(a) Dip a little cotton-wool into a solution of iodine in potassium iodide. Then put the stained wool into an evaporating dish and add a drop or two of concentrated sulphuric acid. A blue coloration is given. This is due to the formation of the hydrate "amyloid" mentioned above.

(b) Dip some cotton-wool into a calcium chloride iodine solution. (To 10 c.c. of a saturated solution of calcium chloride add $0.5 \mathrm{gm}$. of potassium iodide and $0 \cdot 1 \mathrm{gm}$. of iodine. Warm gently and filter through glass-wool.) A rose-red coloration is produced which eventually turns violet.

(c) Heat a strong solution of zinc chloride (6 pts. of zinc chloride to 10 pts. of water) in an evaporating dish and add 1 part of cotton-wool. The cellulose will in time become gelatinized, and if a little water is added from time to time, a solution will eventually be obtained on continuous heating.

(d) Make a solution of zinc chloride in twice its weight of concentrated hydrochloric acid and add some cotton-wool. The wool will rapidly go into solution in the cold.

(e) Add some cotton-wool to an ammoniacal copper oxide solution and note that it dissolves. (To a strong solution of copper sulphate add sume ammonium chloride and then excess of canstic soda. Filter off the blue precipitate of cupric hydroxide, wash well, dry thoroughly, and dissolve in strong ammonia.) Add strong hydrochloric acid and the cellulose is precipitated out again. Then add water and wash the precipitate until it is colourless. Test the roughly dried precipitate with a little iodine and strong sulphuric acid. A blue coloration is given. 
All the above tests may be repeated with threals from white cotton material, with filter-paper and good white writing paper.

Try tests $(a)$ and $(b)$ with newspaper, and note that they are not so distunet as with writing paper owing to the presence of ligno-cellulose (see Expt. 73).

Expt. 72. Hydrolysis of cellulose by acid. Dissolve as much filter-paper as possible in 5 e.e. of concentrated sulphurie acid and when all is in solution pour into 100 e.c. of distilled water. Boil the solution in a round-bottoned flask fitted with an air condenser (see p. 45) and use a sand-bath for heating. After boiling for an hour, cool and nentralize the solution with solid caleium earbonate. Add a little water if necessary and filter. Test the filtrate with the following tests:

(a) Make the osazone [see Expt. $41(d)$ ]. Note that crystals of glucosazone are formed.

(b) Add a little Fehling's solution and boil. Note that reduction takes place.

Instead of using filter-paper, the above experiment may also be carried out with cotton-wool or threads from white cotton material.

Ligno-cellulose. As the cells in plants grow older the walls usually become lignified, that is part of the cellulose becomes converted into ligno-cellulose. The extreme amount of change is found in wood. The least amount in such fibres as those from the stem of the Flax (Linum usitatissimum) which, when freed from such impurities, consist of cellulose only and constitute linen. Other fibres, containing more lignocellulose, are those of the stem of the Hemp plant (Camnabis sativa) and the Jute plant (Corchorus) from which string, rope, canvas, sacking and certain carpets are made. The percentages of pure cellulose in these various lignified tissues are as follows:

$\begin{array}{lr}\text { Cotton tibre ............. } & 88.3 \% \\ \text { Flax and Hemp fibre ... } & 72-73 \% \\ \text { Jute ..................... } & 54 \% \\ \text { Beech and Oak wood ... } & 35-38 \%\end{array}$

The ligno-celluloses are generally regarded as consisting of cellulose and two other constituents, of which one contains an aromatic nucleus and the other is of the nature of a pentosan (see xylan, p. 53). Both are sometimes classed together and termed lignin or lignon. The lignin reactions (see below) depend on the presence of an aromatic complex. It has been suggested that coniferin, vanillin and allied compounds which are present in wood are probably the substances responsible for the reaction (Czapek, 6).

Although the best paper is made from cellulose, cheaper forms of paper are manufactured from ligno-cellulose, and, as a result, they give reactions for lignin and are also turned yellow by exposure to light.

Expt. 73. Reactions of lignin.

One of the most striking reactions of lignin (due as it is supposed to a furfural 
gromping) is the magenta-red coloration given by phlorogluein in the presence of concentrated hydrochloric acid.

Soak the tissue to be experimented upon with an alcoholic solution of phloroghucin and then add a drop or two of strong hydrochloric acid. The magenta-red colour will be produced.

As material, practically any lignified tissue may be used. Shavings from twigs of any tree or shrub, e.g. pith and wood from the Elder (Sambucus nigra), will be foumd useful : also shavings from a match ; straw, bran, coarse string, cheap white paper, such as newspaper or white and pale-coloured papers nsed for wrapyings.

Make the phloroglucin test on good white writing paper. It should not give the reaction since it is made from cellulose.

Other phenols and their derivatives will also give colvur reactions with lignin in the presence of hydrochloric acid, but the colorations in most eases are not so much developed as with phlorogluein (Czapek, 6). For this reason (though it is also possible to use any of the lignified tissues suggested above) good results are obtained by nsing strips of any cheap newspaper, since the reagents seem to penetrate this material quickly.

Soak strips of newspaper (or other material) in alcoholic solution of the following substances, or such of them as are available, and then add a few drops of concentrated hydrochloric acid. It is useful to put the material on a white glazed tile or plate :

Reaction

\begin{tabular}{|c|c|c|c|}
\hline Phenol ... & & blue-green col & or \\
\hline Resorcinol & $\ldots$ & violet & , \\
\hline Oreinol ... & ... & red-violet & " \\
\hline Catechol & $\ldots$ & greenish-blue &, \\
\hline Pyrogallol & $\ldots$ & blue-green & $"$ \\
\hline Gnaiacol & $\ldots$ & yellow-green & , \\
\hline Cresol. & ... & greenish & " \\
\hline$a$-Niphthol & $\ldots$ & greenish & " \\
\hline Thymol & $\ldots$ & green & $"$ \\
\hline Indol $\quad \ldots$ & ... & cherry-red & \\
\hline Skatol ... & $\ldots$ & cherry-red & , \\
\hline
\end{tabular}

It should be noted that strong hydrochloric acid alone will sometimes give a red colour with woody tissues: this is due to the presence of phloroglucin in the wood itself (see phloroglucin, p. 88 ).

Expt. 74. Destruction of the lignin element in wood. Take some paper which gives the phloroglucin reaction for lignin strongly and cut it up into pieces about an inch square. Then boil the paper in some $1 \%$ sodium hydroxide solution for a short time. After washing well, put it into a flask or large test-tube with a few c.c. of brominewater and allow it to stand for an hour or two. Then wash again and heat in a $2 \%$ solution of sodium sulphite. Wash free from sulphite, dry and test with alcoholic phloroglucin solution and strong hydrochloric acid. No red colonr, or very little, will be produced. If a little red coloration is formed, the process should be repeated until finally all the lignin reaction disappears. 
Pecto-cellulose. The non-cellulose constituents in this case belong to the class of pectic substances which have already been considered (see p. 63). Such celluloses occur in the cell-walls of the tissues of many fleshy roots, stems and fruits.

Adipo- and cuto-celluloses. These products are found in the walls of corky and cuticularized tissues. Their chemical composition is obscure but they appear to contain substances of a fatty or wax-like nature.

Hemi-celluloses. These are not strictly celluloses since they are built up of mannans, galactans and pentosans on lines which have already been considered (see pp. 59 and 60). They frequently occur united with each other, for instance as galacto-, gluco- and fructomannan, galactoaraban, galactoxylan, etc. They are found in the cell-walls of the tissues of many seeds.

\section{The Synthesis and Inter-Relationships of Carbohydrates in the Plant.}

Now that the properties and characteristics of various carbohydrates have been dealt with, their synthesis and their relationships, one to another, may be considered.

In the previous chapter it has been shown how the plant synthesizes a sugar from carbon dioxide and water by virtue of the chemical energy obtained from transformation of radiant energy by means of chlorophyll. When this sugar reaches a certain concentration in the cell, in the majority of plants, starch is synthesized from it by condensation with elimination of water. The starch is thus the first visible product of assimilation and is temporarily "stored" in an insoluble form during the day, when photosynthesis is active. During the night photosynthesis ceases but the sugar is still translocated from the leaf, as it was in fact during the day; thus, since the supply ceases, the concentration in the cell falls, and the "stored" starch is then hydrolyzed again into sugar, and the process continues until the leaf is either starch-free, or contains considerably less starch. During the next day, the starch formation is repeated and so forth. The process of hydrolysis of starch is carried out by the enzyme, diastase, with the formation of dextrin and maltose. In all probability this same enzyme controls the synthesis of starch.

On the other hand, it has been shown that many plants do not form starch at all in their leaves but only sugar. Examples are the adult 
Mangold plant (Betu vulgaris) and many Monocotyledons (Allium, Scilla).

As to the question of which sugars are present in the leaf, there is only eridence from accurate work on a few plants. Careful investigations have been made of the sugars in leaves of the Mangold (Beta vulgaris) (Davis, Daish and Sawyer, 15), Garden Nasturtium (Tropaeolum mujus) (Brown and Morris, 5), the Snowdrop (Galanthus niralis) (Parkin, 24), the Potato (Solanum tuberosum) (Davis and Sawyer, 17) and the Vine (Vitis vinifera). The general conclusions drawn from these investigations are that suerose, glneose, and laevulose are always present in leaves: that maltose results from the hydrolysis of stareh, being absent from leaves which do not form starch. Maltose is not present in appreciable quantity even in stareh-produeing leaves because it is rapidly hydrolyzed into glucose by maltase. (In such eases where it has been detected it has been due to diastase action during the drying of leaves before extraction.) Other leaf carbohydrates are the pentoses which have been found in a good many species examined and may be widely distributed; the pentosans, their condensation products, also oecur as well as dextrin (Potato).

The next question to be considered is what sugar is first synthesized in the leaf. Is it glucose, laevulose, sucrose or maltose? It is known that the enzymes, invertase and maltase, are commonly present in leaves and that these enzymes respectively control the hydrolysis, of eanesugar into glucose and laevulose, and of maltose into glucose. It is also possible that they respectively control the synthesis of sucrose and maltose. Laevulose, likewise, as may be supposed, can be obtained from glucose. Thus all the sugars can be readily eonverted one into another, but to ascertain which is the first product of synthesis is not an easy problem.

In addition to the above-mentioned work on the nature of the sugars present in leaves, a good deal of eareful analysis has been made as to the proportions in which the sugars oceur relatively to each other during stated periods of time, with a view to answering the question as to which is the first-formed sugar. There are two possibilities: one, that it is suerose and that it is hydrolyzed into glucose and fruetose: the other, that it is glucose, from which fruetose is deriverl, and the two are then synthesized to form sucrose.

Opinion is divided on this point and there is not at present sufficient experimental evidence to deeide the matter. The majority of investigators regard sucrose as the first-formed sugar, and suggest that it is inverted into hexoses for purposes of translocation, since the smaller 
molecules would diffuse faster. There is experimental evidence that there is an increase in hexoses in the conducting tissues. Others farour the view that glucose is the first-formed sugar, and bring forward evidence to this effect. There is however no reason why hexoses should not be formed first and then converted into cane-sugar and temporarily stored as such, being again reinverted into hexoses for translocation. Nor is there any reason for supposing that the first-formed sugar is always the same in every plant.

There appears to be very little doubt that maltose is formed in the hydrolysis of starch, and also that starch is a temporary reserve material in the leaves, but whether formed direct from sucrose or from hexoses cannot be stated.

There is some evidence in favour of the view that glucose is more readily used in respiration than laevulose, for under circumstances when neither can be increased, the glucose tends to disappear.

From the leaf the various sugars are translocated to other organs of the plant, e.g. root, stem, flower, fruit and seed. In some cases starch is synthesized from the sugars and "stored" in roots, tubers, tuberous stems, fruits and seeds. In other cases the sugars themselves may be "stored," as, for instance, in the root of the Beet (Beta vulgaris), or they may have a biological significance, as in sweet fruits. It must also be borne in mind that sugars are employed throughout the plant in respiration and in the synthesis of more complex substances, i.e. cellulose, gums, pentosans, mucilage, aromatic substances, fats and to a certain extent proteins: in fact they or their precursors constitute the basis froin which all organic compounds are synthesized.

The following experiments can be performed with either the Garden Beet or the Mangold Wurzel, both of which are varieties of Beta vulgaris, the Common Beetroot. The sugars in the leaves and petioles of the Iangold have been investigated (Davis, Daish and Sawyer, 15) and sucrose, laevulose and glucose have been found. Starch is absent in the adult plant and also maltose. The opinion is held that sucrose is the first-formed sugar of photosynthesis and that this is hydrolyzed for translocation on account of the greater rate of diffusion of the smaller molecules of glucose and laevulose. These are again synthesized in the root to form sucrose where the latter is stored, and hexoses are almost absent from this organ. Though the facts concerning the distribution of the sugars stated above are reliable, it is not certain that the deductions are permissible. The leaf contains the enzymes, invertase, maltase and diastase (Robertson, Irvine and 1obson, 25). 
In connexion with the occurrence of various sugars in leaves it is of interest to note that glucose, fructose and mannose can pass over into one another in alkaline aqueous solution. This has been explained by their conversion into the enolic (unsaturated) form common to all three hexoses:

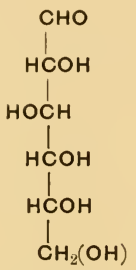

Glucose

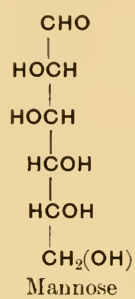

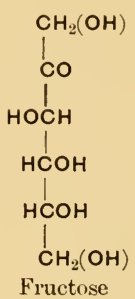

Fructose

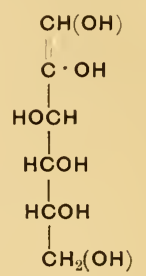

Enolic forns

Expt. 75. To show the presence of both hexoses and sucrose in the leaf (Davis, Daish and Sawyer, 15). Take about 5 gms. of fresh leaf of either the Beet or Mangold. (Leaves of the Garden Nasturtium (Tropaeolum majus) and Wild Chervil (Chaerophyllum sylvestre) may also be used.) Tear them into small pieces and drop them into boiling $90-98 \%$ alcohol in a flask on a water-bath. In this way the enzymes of the leaf are killed, and no changes will occur in the carbohydrates present. After boiling for a short time, the alcohol is filtered off and the extraction repeated. Evaporate the filtrate to dryness in an evaporating dish on a water-bath. The filtrate will contain chlorophyll and various pigments, sugars, glucosides, aromatic compounds and other substances according to the plant used. Then add about 20 c.c. of water and at intervals a few drops of basic lead acetate until it ceases to form a precipitate. By this means all hexoses combined with aromatic substances as glucosides (see p. 142) are precipitated as insoluble lead salts. The precipitate is filtered off and the lead in the fitrate removed by sodium carbonate, avoiding excess. Filter again and the filtrate will contain the sugars. Boil the latter and add Fehling's solution drop by drop till reduction eeases. Filter off the copper oxide and then boil the solution with dilute sulphuric acid for a few minutes and make neutral to phenolphthalein. Reduction will occur on adding more Fehling and boiling, owing to the inversion of the canesugar present.

Expt. 76. To show the presence of hexoses in the leuf by means of the formation of glucosazone. Leaves of Beta, Chaerophyllum sylvestre, or Tropacolum may be used. Extract as in the previons experiment and precipitate the glucosides with the ininimal amount of basic lead acetate. Test for osazone in the filtrate as in Expt. $41(d)$.

Expt. 77. To obtain sturch from green leaves. Weigh out $25 \mathrm{gms}$. of leaflets of the Pea (Pisum sativum). The leaves should have been picked in the evening after a sumny day, and it does not matter if the cut leaves are left overnight. Dip the leaflets for a moment into hoiling water, remove excess of water and drop them into 200 c.c. of $96-98 \%$ alcohol and boil till the chlorophyll is extracted: then filter. 
Take the residue of leaves and pound (but not finely) in a mortar and then wash thoroughly with distilled water. Filter through muslin and press free from water (this process extracts most of the protein). Boil the residue with 100 c.c. of water and filter. To the filtrate add iodine. At first the colour may disappear owing to the presence of protein in solution in addition to the starch. When more iodine is added a deep blue coloration is formed.

\section{Plant Enzymes which hydrolyze Carbohydrates.}

Diastase. In the plant starch may be regarded as a reserve product. It is synthesized from sugar, and may be again hydrolyzed into sugar. It can be shown experimentally that starch is converted into glucose by boiling with acids, but in the plant the hydrolysis of starch is catalyzed by the enzyme, diastase. Although the reaction is doubtless of considerable complexity, it may, broadly speaking, be represented as follows:

$$
\left(\mathrm{C}_{6} \mathrm{H}_{10} \mathrm{O}_{5}\right)_{n}+\mathrm{H}_{2} \mathrm{O} \longrightarrow \underset{\text { Dextrin }}{\left(\mathrm{C}_{6} \mathrm{H}_{10} \mathrm{O}_{5}\right)_{x}}+\underset{\text { Maltose }}{\mathrm{C}_{12} \mathrm{H}_{22} \mathrm{O}_{11}}
$$

Thus the final products under these conditions are dextrin and the disaccharide, maltose; and not glucose.

It is reasonable to assume that cells which contain starch also either contain, or are capable of producing, diastase. But the amount of diastase present, or at any rate capable of being extracted, varies in different tissues. Diastase, like most enzymes, is soluble in water. In many cases, however, a water-extract from fresh crushed tissues in which diastase occurs, will not contain any appreciable amount of enzyme. This is sometimes due to the fact that the protoplasin does not readily yield up the enzyme until it has been killed. If the tissues are dried at a morlerate tenperature $\left(30-40^{\circ} \mathrm{C}\right.$.) both the powdered leaves themselves and a water extract are fairly rich in diastase; or, if the living tissues are macerated and extracted with water to which chloroform has been added, the cells die more rapidly and yield up the enzyme to the solvent. From such a water extract, a crude precipitate containing the enzyme may be obtained by addition of alcohol. For obtaining the maximum results with diastatic activity in leaves, a water extract should be made after they have been killed, either by drying, or by the action of toluol or chloroform.

It has been shown (Brown and Morris, 5) that in leaves which contain tannin, the presence of the latter largely inhibits the action of the enzyme and may be the cause, in such cases, of an entire lack of activity in the extract. 
The diastatic activity of leaves appears to vary largely in different genera and species. The subject has been investigated (Brown and Morris, 5) and a list of their relative activities bas been drawn up as follows.

[The numbers represent the amount of maltose, expressed in grams, which 10 gms. of air-dried leaf will produce from soluble-starch (starch treated with dilute hydrochlorie acid) by hydrolysis in $48 \mathrm{hrs}$. at $30^{\circ} \mathrm{C}$.]

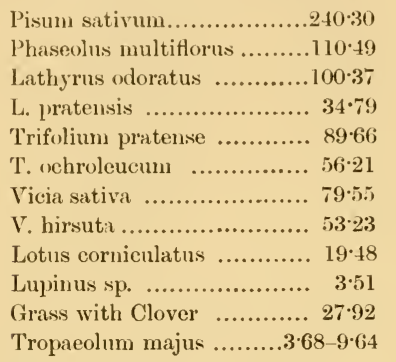

Helianthus ammuı............... $3 \cdot 94$

H. tuberosus .................... $3 \cdot 78$

Funkia sinensis .................5.91

Allium Cepa .................... $3 \cdot 76$

Hemerocallis fulva.............. $2 \cdot 07$

Populus sp). ...................... $3 \cdot 79$

Syringa vulgaris ................. 2\%3

Cotyledon Umbilicus............ 4 461

Humulus Lupulus ........2.01-y 60

Hymenophyllum demissum ... 4.20

Hydrocharis Morsus-ranae $\ldots . .6 \cdot 267$

From the above table it is seen that the leaves of genera of the Leguminosae are apparently very rich in diastase. Whether this is so, or whether in other plants the diastatic activity is inhibited by other substances, has not yet been ascertained. As mentioned above, tannins inhibit the action of diastase, and hence leaves rich in tannin, e.g. Hop (Humulus), cannot be expected to yield good results.

The tissues of germinating barley (Hordeum vulgare) also contain large quantities of diastase, and this material can be used to demonstrate the solubility, isolation and activity of the enzyme.

The action on starch of diastase from the leaf of the Common Pea (Pisum sativum) and from germinating barley grains has already been demonstrated [see Expt. $57(a)$ and $(b)$ ] in connexion with dextrin. The following experiments have special reference to the enzyme.

Expt. 78. To demonstrate the activity of diastase from germinating burley. Grind 2-3 gms. of barley grains in a coffee-mill. Boil the product with 100 c.e. of water and filter, first through fine muslin if necessary, then through filter-paper. A starch "solution" will be obtained.

Pound up 2-3 gms. of germinated barley grains in a mortar and extract the mass with 50 c.e. of water. Filter, and take two equal portions in two test-tubes. Boil one tube. To both tubes add an equal quantity of the starch solution prepared above. Place the tubes in a beaker of water at $38-40^{\circ} \mathrm{C}$. From time to time withdraw a drop from each tube with a pipette and test with iodine solution on a white tile. The starch in the unboiled tube will gradually give the dextrin reactions (see 1. 57); that in the boiled tube will remain unchanged. 
This simple method may also be alopted for showing the diastatic activity of leaves. Instead of germinating lorley, a few leatlets of the Pea (Pisum sutioum) or Clover (Trifolium pratense) should be pounderl щ) in a mortar and extracted with 50 c.c. of water and filtered.

Expt. 79. To show thut leaf-diastase is still utive ufter diying the leares at temperatures not higher than $38^{\circ} \mathrm{C}$. Take $10 \mathrm{gms}$. of fresh Pea leaves and dry by spreading them in the sun. Then powder and finally dry in an incubator at 38 C. Make up 500 c.c. of a $1 \%$ solution of starch (see Expt. 55). To this add the dry leaf powder together with a few drops of toluol and keep in an incubator at $38^{\circ} \mathrm{C}$. Test the solution with iodine from time to time and note the hydrolysis of the starch.

Erpt. 80. To show that the action of diastuse is impaired by contact of the enzyme with alcohol. Pound up $10 \mathrm{gms}$. of fresh Pea leaves, add 100 c.e. of water, a few drops of toluol and allow the mixture to stand for 12 hrs. Filter off the extract, and add at least an equal bulk of $96-98 \%$ alcohol. A white precipitate is produced which, among other substances, contains crude diastase. Filter, and wash the precipitate with a little water into 500 c.c. of a $1 \%$ stareh solution. Add a few drops of toluol, plug with cotton-wool and put in an incubator. Test with iodine from time to time. It will be found that the hydrolysis takes place much more slowly than in the previous experiments.

Expt. 81. To show that the action of diastase is inhibited by tunnic acid. Take about 0.5-1 gm. of dried powdered Pea leaf. Let it stand for abont 12 hrs. in 50 e.c. of water containing a few drops of tolnol. Filter off, and to equal amounts of the filtrate in two small flasks add about 10 e.c. of a $1 \%$ starch solution. Add also 10 c.c. of a $0.5 \%$ tannic acid solution to one test-tube. Put both tubes into an incubator. Test with iodine solution after a few hours. It will be found that the tannic acil has inhibited the action of the diastase.

Maltase. This enzyme hydrolyzes maltose into two molecules of glucose:

$$
\mathrm{C}_{12} \mathrm{H}_{22} \mathrm{O}_{11}+\mathrm{H}_{2} \mathrm{O}=2 \mathrm{C}_{6} \mathrm{H}_{12} \mathrm{O}_{6} \text {. }
$$

Investigations upon maltase have, until recently, produced rather contradictory results, but later work (Davis, 12: Daish, 13, 14) has led to more satisfactory conclusions. The latter show that maltase is most probably present in all plants in which hydrolysis of starch occurs. It has been detecter in leaves of the Nasturtium (Tropaeolum), the Potato (Solanum), the Dahlia, the Turnip (Brassica), the Sunflower (Helianthus) and the Mangold (Beta), and it is most probably widely distributed in foliage leaves. Its detection is not easy for various reasons which are as follows. It is not readily extracted from the tissues by water: it is unstable, being easily destroyed by alcohol and chloroform. Its activity is also limited or even destroyed at temperatures above $50^{\circ} \mathrm{C}$. Hence the extraction of maltase, by merely pounding up tissues with water, does not yield good results: moreover, as an antiseptic, tolnol must be 
used and not chloroform. Finally, if the enzyme is to be extracted from dried material, this must not be heated at too high a temperature previous to the extraction.

Maltase occurs in quantity in both germinated and ungerminated seeds of cereals. If, in kilning, malt has not been heated at too high a temperature, the maltase may not be destroyed, and, in such cases, malt extract will contain both diastase and maltase. This would explain the fact that glucose, instead of maltose, has sometimes been obtained by the action of malt diastase on starch. In other cases, when a higher temperature has been employed, the maltase will be destroyed. Maltase itself, of course, does not act directly upon starch but only on maltose. The use of chloroform, as an antiseptic, by some observers explains how they came to overlook the presence of maltase, thus obtaining maltose, and not glucose, as an end product in hydrolysis by malt extracts. The optimum temperature for the maltase reaction is $39^{\circ} \mathrm{C}$.

The presence of maltase in leaves is not readily shown for the following reasons. Since maltase is destroyed by alcohol, the preparation of a crude precipitate of the enzyme by precipitating a water extract of the leaves is not satisfactory. If the water extract is added directly to maltose, and incubated, hydrolysis may be demonstrated by determining the reducing power of the sugars formed. A control experiment must, however, be made by incubating the water extract alone, and subsequently determining the reducing power of any sugars present.

Invertase. This enzyme hydrolyzes cane-sugar into one molecule of glucose and one molecule of laevulose:

$$
\mathrm{C}_{12} \mathrm{H}_{22} \mathrm{O}_{11}+\mathrm{H}_{2} \mathrm{O}=\mathrm{C}_{6} \mathrm{H}_{12} \mathrm{O}_{6}+\mathrm{C}_{6} \mathrm{H}_{12} \mathrm{O}_{6} \text {. }
$$

Invertase is probably very widely distributed in plants. Its presence has been demonstrated in the leaves and stem, though not in the root, of the Beet (Beta vulgaris) (Robertson, Irvine and Dobson, 25). Also in the leaves of a number of other plants (Kastle and Clark, 20). Its detection, by its action on sucrose, is not easy on account of the presence of other enzymes and reducing sugars in leaf extracts.

The absence of invertase from the root of the Beet raises a difficulty as to how the cane-sugar is synthesized from the hexoses supplied from the leaves (see p. 71). Some observers (Robertson, Irvine and Iobson, $25)$ incline to the view that cane-sugar is synthesized in the stems and travels as such to the roots. Others (Davis, Daish and Sawyer, 15) maintain that the cane-sugar is synthesized in the root, even though invertase is absent. 


\section{REFERENC'ES'}

Books

1. Abderhalden, E. Biochemisches Handlexikon, II. Berlin, 1911.

2. Armstrong, E. F. The Simple Carbohydrates and the Glueosides. London, 1919. 3rid ed.

3. Atkins, W. R. G. Some Recent Researches in Plant Physiology. London, 1916 .

4. Mackenzie, J. E. The Sugars and their simple Derivatives. London, 1913.

\section{PAPERS}

5. Brown, H. T., and Morris, G. H. A Contribution to the Chemistry and Pliysiology of Foliage Leaves. J. Chem. Soc., 1893, Vol. 63, pp. 604-677.

6. Czapek, F. Ueber die sogenannten Ligninreaetionen des Holzes. Zs. physiol. Chem., 1899, Vol. 27, pp. 141-166.

7. Davis, W. A., and Daish, A. J. A Study of the Methods of Estimation of Carbohydrates, espeeially in Plant-extracts. A new Method for the Estination of Maltose in Presence of other Sugars. J. Agric. Sci., 1913, Vol. 5, 1p. 437-468.

8. Davis, W. A., and Daish, A. J. Methods of estimating Carbohydrates. II. The Estimation of Starch in Plant Material. The Use of Taka-Diastase. J. Agric. Sci., 1914, Vol. 6, pp. 152-168.

9. Daish, A. J. Methods of Estimation of Carbohydrates. III. The Cuprie Redueing Power of the Pentoses-Xylose and Arabinose. I. Agric. Sci., 1914, Vol. 6, p]. $255-262$.

10. Davis, W. A., and Sawyer, G. C. The Estimation of Carbohydrates. IV. The Presence of Free Pentoses in Plant Extrats and the Influence of other Sugars on their Estimation. J. Agive. Sci., 1914, Vol. 6, pp. 406-412.

11. Davis, W. A. The Hydrolysis of Maltose by Hydrochlorie Aeid under the Herzfeld Conditions of Inversion. A Reply to A. J. Kluyver. J. Agric. Sci., 1914, Vol. 6, jp. 413-416.

12. Davis, W. A. The Distribution of Maltase in Plants. I. The Function of Maltase in Stareh Degradation and its Influenee on the Amyloclastic Aetivity of Plant Materials. Biochem. J., 1916, Vol. 10, pp. 31-48.

13. Daish, A. J. The Distribution of Maltase in Plants. II. The Presence of Maltase in Foliage Leaves. Biochem. J., 1916, Vol. 10, pp. 49-55.

14. Daish, A. J. The Distribution of Maltase in Plants. III. The Presence of Maltase in Germinated Barley. Biochem. J., 1916, Vol. 10, p1. 56-76.

15. Davis, W. A., Daish, A. J., and Sawyer, G. C. Studies of the Fornittion and Transloeation of Carbohydrates in Plants. I. The Carbolnydrates of the Mangold Leaf. \%. Agric. Sci., 1916, Vol. 7, pp. 255-326.

16. Davis, W. A. Studies of the Formation, etc. II. The Dextrose-Laevulose Ratio in the Mangold. J. Agric. Sci., 1916, Vol. 7, 1)1. 327-351.

17. Davis, W. A., and Sawyer, G. C. Studies of the Formation, ete. 111. The Carbolydrates of the Leaf and Leaf Stalks of the Potato. The Meehanism of the Degradation of Starch in the Leaf. J. Agric. Sci., 1916, Vol. 7, 1'1. 352-384. 
18. Davis, W. A. The Estimation of Carbohydrates. V. The supposed Precipitation of Reducing Sugars by Basic Lead Acetate. J. Agric. Śri., 1916, Vol. 8, pp. $7-15$.

19. Haynes, D. The Gelatinisation of Pectin in Solutions of the Alkalies and the Alkaline Earths. Biochem. J., 1914, Vol. 8, 1'p. 553-583.

20. Kastle, J. H., and Clark, M. E. On the Occurrence of Invertase in Platuts. Amer. Chem. J., 1903, Vol. 30, pl. 421-427.

21. Neville, A. Linseed Mueilage. J. Agric. Sci., 1913, Vol. 5, pl. 113-128.

2.2. Parkin, J. Contributions to our Knowledge of the Formation, Storage and Depletion of Carbohydrates in Nonocotyledons. Phil. Truns. R. Soc., B Vol. 191, 18!99, pp. 35-79.

23. Parkin, J. On a Reserve Carbohydrate which produces Mannose, from the Bulb of Lilian. Proc. Camb. Phil. Soc., 1900-1902, Vol. 11, pp. 139-142.

24. Parkin, J. The Carbohydrates of the Foliage Leaf of the Snowdrop' (Gulunthus nivalis), and their Bearing on the First Sugar of Photosynthesis. Biochem. J., 1911, Vol. 6, pp. 1-47.

2.5. Robertson, R. A., Irvine, J. C., and Dobson, M. E. A Polarimetric Study of the Sucroclastic Enzymes in Beta vulgaris. Biockem. J., 1909, Vol. 4, pp. $258-273$.

26. Salkowski, E. Ueber die Darstellung des Xylans. Zs. physiol. Chem., 1901-2, Vol. 34, pp. 162-180.

27. Salkowski, E. Ueber das Verhalten des Arabans zu Fehling'scher Lösung. Zs. physiol. Chem., 1902, Vol. 35, pp. 240-245.

28. Schryver, S. B., and Haynes, D. The Pectic Substances of Plants. Biochem. J., 1916, Vol. 10, pp. 539-547.

29. Schulze, E., Steiger, E., und Maxwell, W. Zur Chemie der Pflanzen\%ellmembranen. I. Abhandlung. Zs. physiol. Chem., 1890, Vol. 14, 1). 227-273. 


\section{CHAPTER VI}

THE FATS AND LIPASES

A FAT may be defined as an ester or glyceride of a fatty acid. Just as an inorganic salt, such as sorlium chloride, is formed by the reaction of hydrochloric acid with sodium hydroxide, so a fat is formed by the reaction of the trihydric alcohol, glycerol, and a fatty acid.

The word fat is not a familiar one in botanical literature, the term oil being more commonly used. It is generally met with in connexion with the reserve products of seeds. The oils of seeds are, however, true fats. The term oil may be misleading to some extent, because a fat which is liquid at ordinary temperatures is usually spoken of as an oil, and yet there are also many other substances, of widely differing chemical composition, which have the physical properties of oils, and which are known as such.

Most of the vegetable fats are liquid at ordinary temperatures but some are solids.

The best-known series of acids from which fats are formed is the series $\mathrm{C}_{n} \mathrm{H}_{2 n} \mathrm{O}_{2}$ of which formic acid is the first member. The other members of the series which occur in fats are:
Acetic acid $\mathrm{CH}_{3} \mathrm{COOH}$ or $\mathrm{C}_{2} \mathrm{H}_{4} \mathrm{O}_{2}$
Butyric acid $\mathrm{C}_{3} \mathrm{H}_{7} \mathrm{COOH}$ or $\mathrm{C}_{4} \mathrm{H}_{5} \mathrm{O}_{2}$
Caproic acid $\mathrm{C}_{5} \mathrm{H}_{11} \mathrm{COOH}$ or $\mathrm{C}_{6} \mathrm{H}_{12} \mathrm{O}_{2}$
Caprylic acid $\mathrm{C}_{7} \mathrm{H}_{15} \mathrm{COOH}$ or $\mathrm{C}_{8} \mathrm{H}_{16} \mathrm{O}_{2}$
Capric acid $\mathrm{C}_{9} \mathrm{H}_{19} \mathrm{COOH}$ or $\mathrm{C}_{10} \mathrm{H}_{20} \mathrm{O}_{2}$
Lauric acid $\mathrm{C}_{11} \mathrm{H}_{23} \mathrm{COOH}$ or $\mathrm{C}_{13} \mathrm{H}_{24} \mathrm{O}_{2}$
Myristic acid $\mathrm{C}_{13} \mathrm{H}_{27} \mathrm{COOH}$ or $\mathrm{C}_{14} \mathrm{H}_{28} \mathrm{O}_{2}$
Palmitic acid $\mathrm{C}_{15} \mathrm{H}_{31} \mathrm{COOH}$ or $\mathrm{C}_{16} \mathrm{H}_{32} \mathrm{O}_{2}$
Stearic acid $\mathrm{C}_{17} \mathrm{H}_{35} \mathrm{COOH}$ or $\mathrm{C}_{18} \mathrm{H}_{36} \mathrm{O}_{2}$
Arachidic acid $\mathrm{C}_{19} \mathrm{H}_{39} \mathrm{COOH}$ or $\mathrm{C}_{20} \mathrm{H}_{40} \mathrm{O}_{2}$
Behenic acid $\mathrm{C}_{21} \mathrm{H}_{43} \mathrm{COOH}$ or $\mathrm{C}_{22} \mathrm{H}_{44} \mathrm{O}_{2}$

Another series is the oleic or acrylic series $\mathrm{C}_{n} \mathrm{H}_{3 n-2} \mathrm{O}_{2}$ of which the members are:

$\begin{array}{ll}\text { Tiglic acid } & \mathrm{C}_{5} \mathrm{H}_{8} \mathrm{O}_{22} \\ \text { Oleic acid } & \mathrm{C}_{18} \mathrm{H}_{34} \mathrm{O}_{2} \\ \text { Elaïdic acid } & \mathrm{C}_{18} \mathrm{H}_{34} \mathrm{O}_{2} \\ \text { Iso-oleic acid } & \mathrm{C}_{18} \mathrm{H}_{34} \mathrm{O}_{2} \\ \text { Erucic acid } & \mathrm{C}_{22} \mathrm{H}_{42} \mathrm{O}_{2} \\ \text { Brassidic acid } & \mathrm{C}_{22} \mathrm{H}_{42} \mathrm{O}_{2}\end{array}$


Of these, oleic acid (as glyceride) is the most widely distributed. Yet other series are :

The linolic $\quad \mathrm{C}_{n} \mathrm{H}_{2 n-4} \mathrm{O}_{2}$
The linolenic $\quad \mathrm{C}_{n} \mathrm{H}_{2 n-6} \mathrm{O}_{2}$
The clupanodonic $\mathrm{C}_{n} \mathrm{H}_{2 n-8} \mathrm{O}_{2}$
The ricinoleic $\quad \mathrm{C}_{n} \mathrm{H}_{2 n-2} \mathrm{O}_{3}$

The fat which occurs in an oil-containing seed is not composed of the glyceride of one acid, but is a mixture of the glycerides of several, or even a large number of different acids, often nembers from more than one of the above series. Thus the fat of the fruit of the Coconut (Cocos nucifera) consists of a mixture of the glycerides of caproic, caprylic, capric, lauric, myristic, palmitic and oleic acids. Linseed oil from the seeds of Linum usitutissimum again is a mixture of the glycerides of palmitic, myristic, oleic, linolic, linolenic and isolinolenic acids. Similar mixtures are found in other fruits and seeds.

Since glycerol is a trihydric alcohol, it would be possible for one or more of the three hydroxyls to react with the acid to form mono-, di- or tri-glycerides. All these cases occur and, sometimes, one hydroxyl is replaced by one acid, and another hydroxyl by a different acid.

When the distribution of fats among the flowering plants is considered, they are found to be more widely distributed than the botanist is generally led to suppose.

The following is a list of some of the plants especially rich in fats as reserve material in the fruits or seeds. It represents only a selection of the better known genera, since many other plants have fatty seeds. An approximate percentage of oil present in the fruit or seed is given.

Graminaceae: Maize (Zeu Mays) $4 \%$.

Palmaceae: Oil Palm (Elaeis guinensis) $62 \%$ : Coconut Palm (Cucos nuciferu) $65 \%$.

Juglandacene: Walnut (Jugluns regia) $52 \%$.

Betulaceae: Hazel (Corylus Avellanu) $55 \%$.

Moraceae: Hemp (Cannabis sutiva) $33 \%$.

Papaveraceae: Opium Poppy (Papaver sommiferum) $47 \%$.

Cruciferae: Garden Cress (Lepidium sativum) 25\%: Black Mustard (Sinapis nigra) 20\%: White Mustard (Sinapis alba) 25\%: Colza (Brassica rupa var. oleifera) 33\% $\%$ : Rape (Brassica napus) $42 \%$.

Rosaceae: Almond (Prumus Amygdalus) 42\%: Peach (P. Persicu) $35 \%$ : Cherry (P. Cerasus) $35 \%$ : Plum (P. domestica) $27 \%$.

Linaceae: Flax (Linum usitatissimum) 20-40\%.

Euphorbiaceae: Castor-oil (Ricinus communis) $51 \%$. 
Malvaceat: Cotton (Gossypium herbaceum) 24\%.

Sterculiaceae : Cocoa (Theobroma Cacao) $54 \%$.

Lecythidaceae: Brazil Nut (Bertholletia excelsa) $68 \%$.

Oleaceae: Olive (Olea europaea) 20-70\%: Ash (Fraxinus excelsior) $27 \%$.

Rubiaceae: Coffee (Coffec arabica) $12 \%$.

Cucurbitaceae: Pumpkin (Cucurbita Pepo) $41 \%$.

Compositae: Sunflower (Helianthus annuus) $38 \%$.

The conclusion must not be drawn from the above list that the seeds of the plants mentioned have exclusively fats as reserve materials. In many cases fat may be the chief reserve product, but in others it may be accompanied by either starch or protein or both.

Some of the best-known examples of fat-containing seeds which yield " oils" of great importance in commerce, medicine, etc., are Ricinus (castor oil), Brassica (colza oil), Gossypium (cotton-seed oil), Cocos (coconut oil), Elaeis (palm oil), Olea (olive oil).

In the plant the fats are present as globules in the cells of the fatcontaining tissues.

Plant fats may vary from liquids, through soft solids, to wax-like solids which generally have low melting-points. They float upon water in which they are insoluble. They are soluble in ether, petrol ether, benzene, chloroform, carbon tetrachloride, carbon bisulphide, etc. : some are soluble in alcohol. With osmic acid fats give a black colour, and they turn red with Alkanet pigment which they take into solution.

Expt. 8.2. Tests for fats. Weigh out $50 \mathrm{gms}$. of Linseed (Limum usitatissimum) and grind in a coffee-mill. Put the linsced meal into a flask, cover with ether, cork and allow the mixture to stand for 2-12 hrs. Filter off the ether into a flask, fit with a condenser and distil off the ether over an electric heater. (If a heater is not available, distil from a water-bath of boiling water after the flame has been turned out.) When the bulk of the ether is distilled off, pour the residue into an evaporating dish on a water-bath and drive off the rest of the ether. With the residue make the following tests in test-tubes:

(a) Try the solubilities of the oil in water, petrol ether, alcohol and chloroform. It is insolnble in water aud alcohol, but soluble in petrol ether and chloroform.

(b) Add a little 1\% solution of osmic acid. A black colour is formed. (This reaction is employed for the detection of fat in histological sections.)

(c) Add to the oil a small piece of Alkanet (Anchuse officinulis) root, and warm gently on a water-bath. The oil will he coloured red. Divide the oil into two portions in test-tubes. To one add a little water, to the other alcohol. The colonred oil will rise to the surface of the water in one case, and sink leelow the alcohol in the other. The Alkanet pigment being insoluble in both water and alcohol, these liryids remain uncoloured.

Keep some of the linseed oil for Expt. 83.

o. 
It is well known that the hydrocarbons of the unsaturated ethylene series $\mathrm{C}_{n} \mathrm{H}_{2 n}$ will combine directly with the halogens, chlorine, bromine and iodine to give additive compounds, thus:

$$
\mathrm{C}_{2} \mathrm{H}_{4}+\mathrm{Br}_{2}=\underset{\text { ethylene bromide }}{\mathrm{C}_{2} \mathrm{H}_{4} \mathrm{Br}_{2}}
$$

The acids of this series also behave in the same way, and since many plant fats contain members of the series, the fats will also combine with the halogens.

Expt. 83. To show the presence of unsaturated groups in a fat. To a little of the linseel extract add bromine water. Note the disuppearance of the bromine and the formation of a solid product.

One of the most important chemical reactions of fats is that known as saponification. When a fat is heated with an alkaline hydroxide the following reaction takes place:

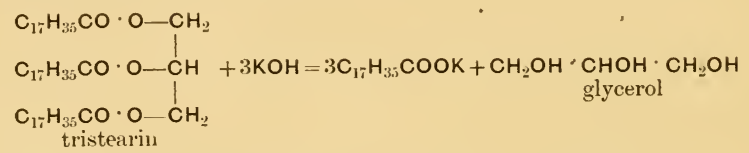

The potassium salt, potassium stearate, of the fatty acid, stearic acid, is termed a soap. The ordinary soaps used for washing are mixtures of such alkali salts of the various fatty aeids occurring in vegetable and animal fats, and are manufactured on a large scale by saponifying fats with alkali. The soaps are soluble in water, so that when a fat is heated with a solution of caustic alkali, the final product is a solution of soap, glycerol and excess of alkali. The soap is insoluble in saturated salt (sodium chloride) solution, and when such a solution is added to the saponified mixture, the soap separates out and rises to the surface of the liquid. This process is known as "salting out." If the saponified mixture is allowed to cool without salting out, it sets to a jelly-like substance. When caustic potash is used for saponification and the product is allowed to set, a "soft" soap is formed. Hard soaps are prepared by using caustic soda and salting out.

The properties of soaps in solution are important. When a soap goves into solution, hydrolysis takes place to a certain extent with the formation of free fatty acid and free alkali. The free fatty acid then forms an acid salt with the unhydrolyzed soap. This acid salt gives rise to an opalescent solution and lowers the surface tension of the water with the result that a lather is readily formed.

The property of soaps of lowering surface tension is the reason for 
their producing very stable emulsions when added to oil and water (see chapter on colloids, p. 11).

Expt. 84. Hydrolysis of fat with alkali. Take 12 Brazil nuts, the seeds' of Bertholletia (Lecythidaceae). Crack the seed coats and pound the kernels in a mortar. Put the pounded nut in a flask, cover it with ether, and allow the mixture to stand for 2-12 hrs. Filter into a weighed or counterpoised flask and distil off the ether as in Expt. 82. Weigh the oil roughly and add 4-5 times its weight of alcoholic caustic soda (prepared by dissolving caustic soda in about twice its weight of water and mixing the solution with twice its volume of alcohol). Heat on a water-bath until no oil can be detected when a drop of the mixture is let fall into a beaker of water. Then add saturated sodium chloride solution. The soaps will rise to the surface. Allow the soaps to separate out for a time and then filter. Press the soap dry with filter-paper, and test a portion to see that it will make a lather. Neutralize the filtrate from the soap with hydrochloric acid and evaporate as nearly as possible to dryness on a water-bath. Extract the residue with alcohol and filter. Test the filtrate for glycerol by means of the following tests:

(a) To a little of the solution add a few drops of copper sulphate solution and then some sodium hydroxide. A blue solution is obtained owing to the fact that glycerol prevents the precipitation of eupric hydroxide.

(b) Treat about 5 c.c. of a $0.5 \%$ solution of borax with sufficient of a $1 \%$ solution of phenolphthalein to produce a well-marked red colour. Add some of the glycerol solution (which has first been made neutral by adding acid) drop by drop until the red colour just disappears. Boil the solution: the colour returns. The reaction is probably explained thus. Sodium borate is slightly hydrolyzed in solution and boric acid, being a weak acid, is only feebly ionized, and therefore the solution is alkaline. On adding glycerol, glyceroboric acid (which is a strong acid) is formed and so the reaction changes to acicl. On heating, the glyceroboric acid is hydrolyzed to glycerol and boric acid, and the solution again becones alkaline.

(c) Heat a drop or two with solid potassium hydrogen sulphate in a dry test-tube; the pungent odour of acrolëin (acrylic aldehyle) should be noted :

$$
\mathrm{C}_{3} \mathrm{H}_{8} \mathrm{O}_{3}=\mathrm{C}_{2} \mathrm{H}_{3} \cdot \mathrm{CHO}+2 \mathrm{H}_{2} \mathrm{O} \text {. }
$$

In addition to Brazil nuts, the following material can also be used: endosperm of Coconut, ground linseed, almond kernels and shelled seeds of the Castor-oil plant (Ricinus): about 50 gms. should be taken in each case.

Expt. 85. Reactions of soaps. (a) Take some of the soap which has been filtered off and shake up with water in a test-tube. A lather should be formed. $(b)$ Make a solution of a little of the soap in a test-tube and divide it into three parts. To each add respectively a little barium chloride, calcium chloride and lead acetate solutions. The insoluble barium, calcium and lead salts will be precipitated. (The curd which is formed in the case of soap and hard water is the insoluble calcium salt.) Thirdly, take the remainder of the soap and acidify it with dilute acid in an evaporating dish, and warm a little on a water-bath. The soap is decomposed and the fatty acids are set free and rise to the surface. 
Expt. 86. Reactions of fatty acids. (u) Try the solubilities in ether and alcohol of the acids from the previous experiment. They are soluble. (b) Shake an alcoholic solution of the fatty acids with dilute bromine water. The colour of the bromine is discharged owing to the bromine forming additive compounds with the unsaturated acids.

The question of the metabolism of fats in the plant is a very complicated one and has not yet been satisfactorily investigated. All plants may have the power of synthesizing fats, and a great number, as we have seen, contain large stores of these compounds in the tissues of the embryo, or endosperm, or both. The point of interest is that of tracing the processes by which these fats are synthesized, and are again hydrolyzed and decomposed. The products of decomposition may serve for the synthesis of other more vital compounds as the embryo develops, and before it is able to synthesize the initial carbohydrates, and to absorb the salts requisite for general plant metabolism.

One fact seems fairly clear, namely that when fat-containing seeds germinate, an enzyme is present in the tissues which has the power of hydrolyzing fats with the formation of fatty acids and glycerol. Such enzymes are termed lipases.

The lipase which has been most investigated is that which occurs in the seeds of the (astor-oil plant (Ricinus communis). It has been shown that if the germinating seeds are crushed and allowed to autolyze (p. 19) in the presence of an antiseptic, the amount of fatty acid increases, whereas in a control experiment in which the enzyme has been destroyed by heat, no such increase takes place (Reynolds Green, 9, 10).

Investigation has shown the enzyme to be present also in the resting seed, but in an inactive condition as a so-called zymogen (Armstrong, $4,5,6,7)$. The zymogen is considered to be a salt and, after acidification with weak acids, the salt is decomposed, and the enzyme becomes active. After the preliminary treatment with acid, however, the enzyme is most active in neutral solution. The effect of acid on the zymogen may be demonstrated by autolyzing the crushed seed with a little dilute acetic acid; the increase of acidity will be found to be much greater than in the case of a control experiment in which acid has not been added.

It has not been found possible to extract the enzyme from the resting seed. An active material can be obtained by digesting the residue, after extraction of the fat, with dilute acetic acid and finally washing with water. This material can then be used for testing the hydrolytic power of the enzyme on various fats. 
There is little doubt that lipase catalyzes the synthesis of fats as well as the hydrolysis; the reaction, in fact, has been carried out to a certain extent in vitro.

Expt. 87. Demonstration of the existence of lipase in ungerminated Ricinus seeds.

A. Remove the testas from about two dozen Ricinus seeds and pound the kernels up in a mortar. Into three small flasks $(a),(b)$ and $(c)$, put the following :

(a) 2 gms. of pounded seed +10 c.c. of water.

(b) 2 gms. of pounded seed +10 c.c. of water +2 c.c. of N/10 acetic acid.

(c) 2 gms. of pounded seed +10 c.c. of water +2 c.c. of $\mathrm{N} / 10$ acetic acid, and boil well.

Add a few drops of chloroform to all three flasks, plug them with cotton-wool, and allow them to incubate for 12 hours at $37^{\circ} \mathrm{C}$. Then add 2 c.c. of $\mathrm{N} / 10$ acetic acid to flask $(a)$, and 25 c.c. of alcohol to all three flasks. Titrate the fatty acids present with $\mathrm{N} / 10$ alkali, using phenolphthalein as an indicator. A greater amount of fat should be hydrolyzed in $(b)$ than in $(a)$, and also slightly more in $(a)$ than in $(c)$. The addition of alcohol checks the hydrolytic dissociation of the soap formed on titration.

B. Pound up about 15 gms. of Ricinus seeds which have been freed from their testas, and let the pounded mass stand with ether for $12 \mathrm{hrs}$. Then filter, wash with ether and dry the residue. Weigh out three lots, of $2 \mathrm{gms}$. each, of the fat-free meal and treat as follows :

(a) Grind up the 2 gms. of meal in a mortar with 16 c.c. of $\mathrm{N} / 10$ acetic acid (i.e. 8 c.c. of acid to $1 \mathrm{gm}$. of meal), and let it stand for about 15 minutes. Then wash well with water to free from acid, and transfer the residue to a small flask. Add 5 c.c. of castor oil, 2 c.c. of water and a few drops of chloroform.

(b) Treat the $2 \mathrm{gms}$. of meal as in (a), but, after washing, and before transferring to the flask, boil well with a little distilled water. Add 5 c.c. of oil, 2 c.c. of water and a few drops of chloroform.

(c) Put the 2 gms. of meal into the flask without treatment and then add 5 c.c. of oil, 2 c.c. of water and a few drops of chloroform.

Incubate all three flasks for 12 hours, and then titrate with $\mathrm{N} / 10$ caustic sodin, after addition of alcohol as in $A$. A certain amount of acetic acid is always retained by the seed residue, and this is ascertained from the value for flask (b). Flask (c) will act as the control.

Another question to be considered is the mode of synthesis in the plant of the complex fatty acids which form the components of the fats. No conclusive work has been done in this direction, but many investigators have held the view that the fats arise from carbohydrates, notably the sugars. In fact, it has been shown that in Paeonia and Ricinus, as the seeds mature, carbohydrates disappear and fats are formed.

The sequence of events, however, in the synthesis of fatty acids from sugars is very obscure. If we examine the formulae, respectively, of a hexose : 
and a fatty acid, e.g. myristic acid:

$\mathrm{H}_{3} \mathrm{C}-\mathrm{CH}_{2} \cdot \mathrm{CH}_{2} \cdot \mathrm{CH}_{2} \cdot \mathrm{CH}_{2} \cdot \mathrm{CH}_{2} \cdot \mathrm{CH}_{2} \cdot \mathrm{CH}_{2} \cdot \mathrm{CH}_{2} \cdot \mathrm{CH}_{2} \cdot \mathrm{CH}_{2} \cdot \mathrm{CH}_{2} \cdot \mathrm{CH}_{2} \cdot \mathrm{COOH}$

it is seen that three main changes are concerner in the synthesis of such a fatty acid from sugar, i.e. reduction of the hydroxyl groups of the sugar, conversion of the aldehyde group into an acid group, and finally the condensation or linking together of chains of carbon atoms. 'An interesting fact in connexion with this point is that all naturally occurring fatty acids have a straight, and not a branched, carbon chain. It has been suggested (Smedley, etc., 11-13) that acetaldehyde and a ketonic acid, pyruvic acid, may be formed from sugar. By condensation of aldehyde and acid, another aldehyde is formed with two more carbon atoms. By repetition of the process, with final reduction, fatty acids with straight chains are produced.

\section{REFERENCES}

Books

1. Abderhalden, E. Biochemisches Handlexikon, I11. Berlin, 1911.

2. Leathes, J. B. The Fats. London, 1910.

3. Allen's Commercial Organic Analysis. Vol. 2. London, 1910.

\section{PAPERS}

4. Armstrong, H. E. Studies on Enzyme Action. Lipase. Proc. R. Soc., 1905, B Vol. 76, pp. 606-608.

5. Armstrong, H. E., and Ormerod, E. Studies on Enzyme Action. Lipase. II. Proc. R. Soc., 1906, B Vol. 78, pp. 376-385.

6. Armstrong, H. E., and Gosney, H. W. Studies on Enzyme Action. Lipase. III. Iroc. R. Soc., 1913, B Vol. 86, pp. 586-600.

7. Armstrong, H. E., and Gosney, H. W. Studies on Enzyme Action. Lipase. IV. The Correlation of Synthetic and Hydrolytic Activity. Proc. R. Soc., 1915, B Vol. 88, pp. 176-189.

8. Miller, E. C. A Physiological Study of the Germination of Helianthus annuus. Ann. Bot., 1910, Vol. 24, pp. 693-726. Ibid. 1912, Vol. 26, pp. 889-901.

9. Reynolds Green, J. On the Germination of the Seed of the Castor-oil Plant (Ricinus communis). Proc. R. Soc., 1890, Vol. 48, Pl). 370-392.

10. Reynolds Green, J., and Jackson, J. Further Observations on the Germination of the Sceds of the Castor-oil Plant (Ricinus communis). Proc. R. Soc., 1906, B Vol. 77, 1p. 69-85.

11. Smedley, I. The Biochemical Synthesis of Fatty Acids from ('arbohydrate. J. Physiol., 1912, Vol. 45, pl. xxv-xxvii.

12. Smedley, I., and Lubrzynska, E. The Biochemical Synthesis of the Fatty Acids. Biochem. .J., 1913, Vol. 7, pp, 364-37t.

13. Lubrzynska, E., and Smedley, I. The Condensation of Aromatic Aldehydes with Pyruvic Acid. Biochem. J., 1913, Vol. 7, pl). 375-379. 


\section{CHAPTER VII}

\section{AROMATIC COMPOUNDS AND OXIDIZING ENZYMES}

THE aromatic compounds may be clefined as substances containing the benzene earbon ring or a similar ring. A very great number occur among the higher plants but of these many are restricted in distribution, and may only be found in a few genera or even in one genus: others, on the other hand, are widely distributed. At present our knowledge of the part they play in general plant metabolism is obscure.

The more widely distributed aromatic plant products may be grouped as :

1. The phenols, and their derivatives.

2. The aromatie alcohols, aldehydes and acids (including the tannins), and their derivatives.

3. The tlavone, flavonol and xanthone pigments, known as the soluble yellow colouring matters.

4. The anthocyan pigments, known as the soluble red, purple and blue coloming matters.

In connexion with the aromatic compounds it should be noted that many of them contain hydroxyl groups, and one or more of these groups may be replaced by the glucose residue, $\mathrm{C}_{6} \mathrm{H}_{11} \mathrm{O}_{5}$-, with elimination of water and the formation of a glucoside, in the way already described (see p. 48). The majority of such compounds are sometimes classed together as a group-the glueosides-regardless of the special nature of the substance to which the glucose is attached (this course has been followed to some extent in Chapter Ix with compounds, the chief interest of which lies in their glucosidal nature). In treating of the aromatic substances in the following pages, mention will be made when they oecur as glucosides, this combination being in these cases only a subsidiary point in their strueture.

The various groups of aromatic substances will now be considered in detail.

\section{PHENOLS.}

There are three dihy!lic phenols, resorcinol, catechol and hydroquinone, but of these only the last is known to exist in the free state in plants. The two former frequently occur as constituents of complex plant products, and may be obtained on decomposition of such complexes by fusion with strong alkali, ete. 


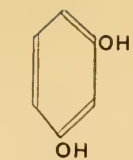

Resorcinol

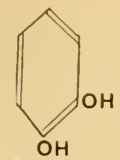

Catechol

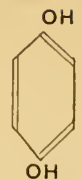

Hydroquinone

Hydroquinone has been found in the free state in the leaves and Howers of the Cranberry (Vaccinium Vitis-Idaea). As a glucoside, known as arbutin, it occurs in many of the Ericaceae (see also p. 151).

Phloroglucin is the only member of the trihydroxy phenols found uncombined in plants. It is very widely distributed in the combined state in various complex substances (Waage, 27).

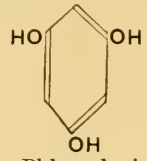

Phloroglucin

\section{Aromatic Alcohols and Aldehydes.}

The following are some of the better known compounds of this group:

Saligenin, or salicylic alcohol, in the form of the glucoside, salicin, occurs in the bark of certain species of Willow (Salix), and in the Hower-buds of the Meadow-sweet (Spiraea Ulmaria). Salicin is hydrolyzed by an enzyme contained in the plant in which it occurs, into saligenin and glucose (see also p. 152).<smiles>O=[N+]([O-])c1ccc(O)cc1</smiles>

Salicylic aldehyde occurs in species of Spircee and other plants.

Coniferyl alcohol, as a glucoside, coniferin, is found in various conifers and also in Asparagus (Asparagus officinalis). Coniferin is hydrolyzed by dilute acids or by enzymes (emulsin) into coniferyl alcohol and glucose (see also p. 151).

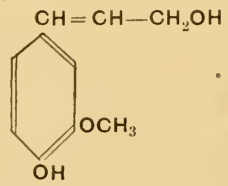

Coniferyl alcohol 
Coniferyl alcohol when oxidized yields the aldehyde, vanillin (so much used for flavouring), which occurs in the fruits of the Orchid (Vanilla planifolia).

\section{Aromatic Acids.}

Of this group the following are some of the best known representatives :

Salicylic acid is a monohydroxybenzoic acid. It occurs both in the form of esters and in the free state in various plants.

Protocatechuic acid is a dihydroxybenzoic acid. It has been found in the free state in a few plants, but is more widely distributed as a constituent of many plant products. As will be shown later it forms the basis of one of the series of tannins.

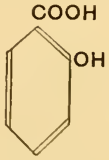

Salicylic acid

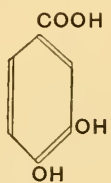

Protocatechuic acid

Gallic acid is a trihydroxybenzoic acid:<smiles>O=C(O)c1ccc(O)cc1O</smiles>

It occurs free in gall-nuts, in tea, wine, the bark of some trees and in various other plants. It forms a constituent of many tannins. It is a crystalline substance not very readily soluble in cold but more soluble in hot water. In alkaline solution it rapidly absorbs oxygen from the air and becomes brown in colour.

Expto 88. The extraction und reactions of gallic acid. Take $100 \mathrm{gms}$. of tea, dry in a steam oven and grind in a mortar. Put the powder into a flask and cover well with ether. The preliminary drying and grinding can be omitted, but if carried ont will make the extraction more complete. After at least 24 hrs. filter off the extract, and either distil or evaporate off the ether. The ether will be coloured deep green by the chlorophyll present in the dried leaves, and a green residue will be left. Add about 20 c.c. of distilled water to the residue, heat to boiling and filter. Heatiug is necessary because the gallic acid is only sparingly soluble in cold water. Keep the residue for Expt. 91. With the filtrate make the following tests; for $(\alpha),(b)$ and $(c)$ dilute a few drops of the filtrate in a porcelain dish :

(a) Add a drop of ferric chloride solution. A bluc-black coloration is given. 
(b) Add a drop or two of iodine solution. A transient red colour appears.

(c) Add a drop or two of lime water. A reddish or blue coloration will be given.

(d) To a few c.c. of the filtrate in a porcelain dish add a little lead acetate solution. A precipitate is formed which turns red on addition of caustic potash solution, and dissolves to a red solution with excess of potash.

(e) To a few c.c. of the filtrate in a test-tube add a little potassium cyanide solution. A pink colour appears, but disappears on standing. On shaking with air it reappears.

$(f)$ To a few c.c. of the filtrate in a test-tuhe add a few drops of $10 \%$ gelatine solution. No precipitate is formed.

(g) To a few c.c. of the filtrate in a test-tube add a little lead nitrate solution. No precipitate is formed.

\section{Tanness.}

This is a large group of substances, many of which are of complex composition. They arise in the plant from simpler compounds, such as protocatechuic, gallic and ellagic acids. Their formation takes place in various ways, either by condensation, accompanied by elimination of water, or by oxidation, or both; there may also be condensation with other aromatic complexes.

The tannins are widely distributed in the higher plants and, although no very systematic investigation has been made, it is obvious that some plants are rich in these substances, others poor, and others, again, apparently entirely without them. The tannins generally occur in solution in the cells of tissues of the root, stem, leaf, fruit, seerl and flowers: sometimes they are confined to special cells, tannin-sacs, but after the death of the cell, the cell-walls of the dead tissue become impregnated with the tannin. In tannin-producing plants, the tannin is generally found throughout the plant, and it probably tends to accumulate in permanent or dear tissues, such as the bark (dead cortex and cork), woody tissue, underground stems, etc.

Tannins appear to be more frequent in woody than in herbaceous plants, though in the latter they naturally only accumulate in the persistent underground stems and root-stocks. In annuals, also, tannins seem to be more rare: this may be due to the fact that in a short-lived plant, comparatively little tannin is formed and is not so readily detected as in the tissues of a perennial.

In certain plants which are highly tannin-producing and are also woody perennials, the bark becomes very rich in tannins. These barks are consequently of considerable eommercial importance for tanning of 
leather. As examples may be taken species of Caesalpinia, Spanish Chestnut (Castanea), Eucalyptus, Oak (Quercus), Mangrove (Rhizophora), Sumac (Rhus). Tamnins also occur in quantity in galls, especially on species of Quercus.

As a class, the tamins are non-crystalline and exist in the colloidal state in solution. They have a bitter astringent taste. They have certain properties and reactions in common, i.e. they precipitate gelatine from solution, are themselves precipitated from solution by potassium bichromate, and give either blue or green colorations with solutions of iron salts. Many tannins occur as glucosides but this is by no means always the case.

It is possible to classify the tannins into two groups according as to whether they are complexes derived from protocatechuic acid or gallic acid:

1. The pyrogallol tannins. These give a dark blue colour with ferric chloride solution, and no precipitate with bromine water.

2. The catechol tannins. These give a greenish-black colour with iron salts, and a precipitate with bromine water.

Expt. 89. Reactions of tannins. Take three oak galls (the brown galls formed by species of Cynips on the Common Oak) and ponnd them finely in a mortar. Boil up the powder well with a small amount of water in an evaporating basin and let stand for a short time. Then filter. The filtrate will contain tannin together with impurities. Make the following tests with the extract:

(a) Put 2 c.c. of the tannin extract into a small evaporating dish, dilute with water, and add a drop or two of ferric chloride solution. A deep blue-black colour is produced.

(b) Put 2 or 3 drops of the tannin extract into a small evaporating dish, and dilute with water: add a little dilute ammonia and then a few drops of a dilnte solution of potassium ferricyanide solution. A red coloration will appear.

(c) To 5 c.c. of the tannin solution in a test-tube add some strong potassium dichromate solution. The tannin will be precipitated.

(d) To about 5 c.c. of the tamin extract in a test-tube add a little lead acetate solution. The tarmin will be precipitated.

(e) Melt a little of a $10 \%$ solution of gelatine by warming gently and then pour drop by drop into a test-tube half full of tannin extract. The gelatine will be precipitated.

For the above tests, in addition to galls, the bark stripped from two to three year old twigs of Quercus may also be used, and will give the same reactions. The bark should be cut into small pieces for extraction.

It should be noted that although many tannins give the above reactions, it does not necessarily follow that all tannins will give all the reactions. 
Expt. 90. T'o demonstrate the existence of pyrogallol and catechol tannins. The existence of a pyrogallol tanniu which gives a blue reaction with iron salts has been illustrated in the last experiment on the Oak galls and the bark from Oak twigs. The bark of the Sumac (Rhus Coriaria) and the fruit pericarp, leaves and bark of the Sweet Chestnnt (Castunea vulgaris) may be used as additional material for pyrogallol tannins.

For an iron-greening tannin strip off the outer bark from two to three year old twigs of the Horse Chestnut (Aesculus Hippocastamum). Cut or tear the bark into small pieces and boil well with a little water in an evaporating dish. Filter and test the filtrate with ferric ehloride solution as in Expt. 89. A green coloration will be given. Iron-greening tamnins may also be extracted from the bark of twigs of the Walnnt (Jugluns regia) and of the Lareh (Larix europaea).

In the case of both classes of tannins, in addition to the ferric chloride reaction, the tests of Expt. $89(c)$ and $(e)$ should also be made on the extracts, in order to confirm the presence of tannin, since other substances, such as flavones, may give a green colour with iron salts (see p. 94).

Some of the individual tannins will now be considered.

Gallotannic (or tannic) acid is one of the most important of the pyrogallol tannins. It occurs in Oak galls and Oak wood, in tea, in the Sumac (Rhus Coriaria), etc. According to recent investigations (Fischer and Freudenberg, 8) tannic acid may be regarded as a compound of one molecule of glucose with five inolecules of digallic acid in which five hydroxyls of the sugar are esterified by five molecules of acid:

$$
\mathrm{CH}_{2}(\mathrm{OX}) \cdot \mathrm{CH}(\mathrm{OX}) \cdot \mathrm{CH} \cdot \mathrm{CH}(\mathrm{OX}) \cdot \mathrm{CH}(\mathrm{OX}) \cdot \mathrm{CH}(\mathrm{OX})
$$

where

$$
\mathrm{X}=-\mathrm{CO} \cdot \mathrm{C}_{6} \mathrm{H}_{2}(\mathrm{OH})_{2} \cdot \mathrm{O} \cdot \mathrm{CO} \cdot \mathrm{C}_{6} \mathrm{H}_{2}(\mathrm{OH})_{3}
$$

Tannic acid is an almost colourless amorphous substance. It has an astringent taste, is soluble in water and alcohol, only slightly soluble in ether, and insoluble in chloroform. It is decomposed, by boiling with $2 \%$ hydrochloric acid, into gallic acid.

Expt. 91. Extraction and reactions of tannic (or gallotannic) acid. By a crude method a solution of gallotannic acid can be obtained from tea. About 5 gms, of the residue, after the extraction with ether in Expt. 88, is again extracted with ether once or twice which will remove all but traces of gallic acid. Boil up the residue from ether with a little water and filter. With the filtrate make the following tests which differentiate between gallic and gallotannic acid :

(a) To about 10 c.e. add a little $10 \%$ gelatine. The gelatine is precipitated.

(b) To a little of the filtrate add a few drops of lead nitrate solution. The tannic acid is preeipitated.

The remaining tests are given in common with gallic aeid. If the extract is too coloured, dilute with water.

(c) Dilute a few drops of the filtrate with water in a porcelain dish and add a drop of ferric chloride solution. A blue-llack colour is given. 
(d) Dilute a few drops of the filtrate with water in a porcelain dish and add a drop or two of iodine solution. A transient red colour is formed.

(e) To a little of the filtrate in a test-tube add a few drops of potassium cyanide solution. A reddish-brown colour is formed which changes to brown but becomes red again on shaking with air.

In addition to tannic acid, a great many other tannins are known, but their constitution is obscure.

Expt. 92. To demonstrate that in tannin-containing plants the tunin may be also present in the leaves. Take about two dozen leaves of the Common Oak ((uercus Robur) and pound them in a mortar. Then boil the crushed mass in an evaporating dish with a little water. Filter, and with the filtrate make the tests for tannin. Leaves of other trees also may be used, e.g. the Wig Tree (Rhus Cotinus), Sweet Chestnut (Castanea vulgaris).

Expt. 93. To demonstrute that tannins may be present in herbaceous as well as woody plants. Extract some leaves, as in the last experiment, of Scarlet Geranium (Pelargonium zonale) and test for tanuin.

Expt. 94. To demonstrate that tannins may be present in petals and fruits, in addition to other parts of the plant. Extract and test for tannins as in the last experiment, using petals of Pelargonizm zonale, Common Paeony (Paconia officinalis) or Rose (any garden variety), inflorescence of Flowering Currant (Ribes sunguineum), flowers of Horse Chestnut (Aesculus Hippocastanum) or pericarp of Sweet Chestnut (Castanea).

\section{The Flavone and Flayonol Pigments.}

These yellow colouring matters are very widely distributed in the higher plants (Shibata, Nagai and Kishida, 26). They are derived from the mother substances, flavone and flavonol, the latter only differing from the former in having the hydrogen in the central $\gamma$-pyrone ring substituted by hydroxyl:

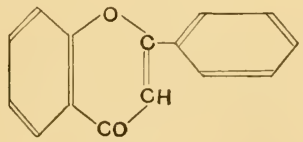

Flavone

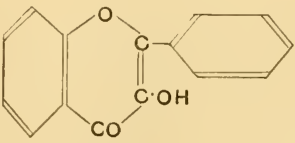

Flavonol

The naturally occurring pigments, however, have additional hydrogen atoms replaced by hydroxyl groups, that is they are hydroxyHavones and flavonols, and the various members differ among each other in the number and position of these hydroxyl groups. Some of the members are widely distributed, others less so. Quite often more than one representative is present in a plant. 
The flavone and flavonol pigments are yellow crystalline substances, and as members of a class they have similar properties. They occur in the plant most frequently as glucosides, one or more of the hydroxyl groups being replaced by glucose, or, sometimes, by some other hexose, or pentose. In the condition of glucosides, they are much less coloured than in the free state, and, being present in the cell-sap in very dilute solution, they do not produce any colour effect, especially in tissues containing chlorophyll. Occasionally they give a yellow colour to tissues, as in the rather rare case of some yellow flowers (Antirrlinum) where colour is due to soluble yellow pigment.

In the glucosidal state, the flavone and flavonol pigments are, as a rule, readily soluble in water and alcohol, but not in ether. In the nonglucosidal state they are, as a rule, readily soluble in alcohol, somewhat soluble in ether, but soluble with difficulty in water.

The flavone and Havonol pigments can be easily detected in any tissue by the fact that they give an intense yellow colour with alkalies (Wheldale, 29). If plant tissues be held over ammonia vapour, they turn bright yellow, showing the presence of flavone or flavonol pigments: the colour disappears again on neutralization with acids. (The reaction is especially well seen in tissues free from chlorophyll, such as white flowers.) This reaction will be found to be almost universal, showing how wide is their distribution. With iron salts, solutions of the pigments give green or brown colorations. With lead, insoluble salts are formed. Several of the members are powerful yellow dyes, and hence some plants in which they occur, such as Ling (Evica cinerea), Dyer's Weld or Rocket (Reseda luteola), have been used for dyeing purposes. The value of these colouring matters as dyes has led to their chemical investigation, and as a result the constitution, etc., of the hydroxy-flavones and flavonols is well established.

Expt. 95. Demonstration of the presence of flavone or flavonol pigments in tissues without chlorophyll. Take flowers of any of the undermentioned species and put them in a flask with a few drops of ammonia. They will rapidly turn yellow owing to the formation of the intensely yellow salt of the flavone or flavonol pigments present in the cell-sap. If the flowers are next treated with aeid the yellow colour will disappear.

Also make an extruct of some of the flowers with a little boiling water. Filter, cool and add the following reagents :

(a) A little alkali. A yellow colour is produced.

(b) A little ferric chloride solution. Either a green or brown coloration is produced.

(c) A little basic lead acetate solution. A yellow precipitate of the lead salt of the flavone or flavonol pigment is formed. 
The flowers of the following species can be used: Snowdrop (Galunthus nivalis), Narcissus (Narcissus poeticus), white variety of Lilac (Syringa vulgaris), Hawthorn (Crataegus O.xyacantha), White Lily (Litium candidum), white var. of Phlox, double white Pink, white Stock (Matthiola) ete., ete., in fact almost any species with white flowers or a white variety.

E.xpt. 96. Demonstration of the presence of Huvone or flavonol pigments in tissues contcining chlorophyll. Make a hot water extract of the leaves of any of the undermentioned species. Make with it the same tests as in the previous experiment.

The following plants may be used : Snowdrop (Galanthus nivalis), Dock (Rumex abtusifolius), Goutweed (Aegopodium Podagraria), Dandelion (Taraxacum officinale), Violet (Viola odorata), Ribwort Plantain (Plantago lanceolata), Elder (Sambucus $n i g i \cdot \alpha)$.

The most important flavone pigments are apigenin, chrysin and luteolin.

Apigenin has not yet been found to be widely distributed. Its formula is :

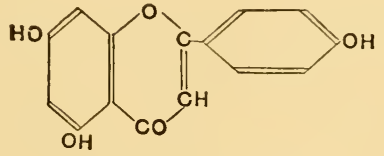

It occurs in the Parsley (Carum Petroselinum) (Perkin, 18) and in the flowers of the ivory-white variety of Snapdragon (Antirrhinum majus) (Wheldale and Bassett, 30).

Expt. 97. Extraction of apiin, the glucoside of apigenin, from the Parsley (Carum Petroselinum). Take some Parsley leaves and boil in as little water as possible. Filter off the extract and make the following tests for apigenin :

(a) Add alkali. A lemon yellow coloration is given.

(b) Add basic lead acetate solution. A lemon yellow precipitate is formed.

(c) Add ferric chloride solution. A brown colour is produced.

(d) Add ferrous sulphate solution. A reddish-brown colour is produced.

Apiin frequently separates out in a gelatinous condition from aqueous and dilute alcoholic solutions.

Chrysin is a flavone occurring in the buds of various species of Poplar (Populus). It has the formula:

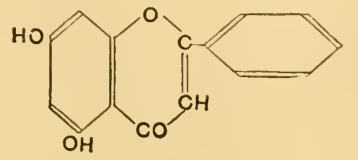


Luteolin does not appear to be widely distributed, though possibly it occurs in many plants in which it has not yet been demonstrated. Its formula is represented as:

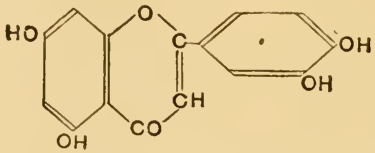

It occurs in the Dyer's Weld or Wild Mignonette (Reseda luteola) (Perkin, 17), Dyer's Greenweed or Broom (Genistu tinctoria) (Perkin, 23) and in the yellow variety of flowers of the Snapdragon (Antirrhinum majus) (Wheldale and Bassett, 32). It has been much used as a yellow dye: hence the names of the first two plants (Perkin and Horsfall, 20).

The inost important flavonol pigments are quercetin, kaempferol, myricetin and fisetin.

Quercetin is apparently one of the most widely distributed of the whole group of yellow pigments, and has the formula:

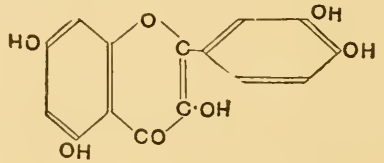

It occurs, either free, or eombined with various sugars (glucose, rhamnose) as glucosides, in many plants, as for instance the following: in the bark of species of Oak (Quercus), in berries of species of Buckthorn (Rhamnus), in flowers of Wallflower (Cheiranthus Cheiri), Hawthorn (Cratuegus Oxyacantha) (Perkin and Hummel, 22), Pansy (Viola tricolor) (Perkin, 19) and species of Narcissus: in leaves of Ling (Calluna erica) (Perkin, 23), and the outer scale leaves of Onion bulbs (Perkin and Hummel, 21).

Expt. 98. Preparation of a glucoside of quercetin from Narcissus flowers. The species of Nareissus which can be used are $V$. Tazetta, N. incomparabilis, and any of the common yellow trumpet varieties. Pound about 50 flowers in a mortar and then extract in a flask with boiling alcohol. Filter off the alcoholic extract and evaporate to dryuess; then arld a little water and ether and transfer the whole to a separating funnel. The ether takes up the plastid pigments, but at the plane of separation of the liquids, the glueoside separates out as a erystalline deposit. This can be filtered off'; with a dilute solution in aleohol make the following tests :

(a) Add a little alkali. The yellow colour is intensified, but the intensifieation disappear's on adding acid. 
(b) Add a little lead acetate solution. An orange precipitate of the lead salt is formed.

(c) Add a little ferric chloride solution. A green coloration is produced.

(d) Heat some of the aleoholie solution on a water-bath, acidify with strong hydrochloric acid and add zinc dust. A magenta colour is produced (see 1) 106).

E.pt. 99. Prepreration of erude quercetin from Onion skins (Perkin, 21). Take about 50 gms. of the brown outer skins of onions and boil with 900 c.c. of water for an hour. Then filter and allow the filtrate to stand for 24 hrs. A brownish-yellow deposit is formed which is crude querectin. Filter this off and dissolve in $75 \%$ alcohol and allow to evaporate slowly. Quercetin will be deposited. With a solution in dilute alcohol make the same tests as in the last experiment.

Expt. 109. Preparution of a quercetin glucoside from Wallflower (Cheiranthus Cheiri),flowers (Perkin and Hummel, 22). Take 20 guss. of petals of flowers of either the brown or yellow variety and drop them into boiling aleohol in a flask. Filter and evaporate the extract to dryness on a water-bath. Dissolve the residue in water and add ether. In the ease of the yellow variety the yellow plastid pigments are taken $u p$ by the ether, and the quercetin glucoside partly erystallizes out from the water as in Expt. 98. In the ease of the brown variety both quercetin glucoside and anthocyan pigment are present as well as plastid pigments. The two former go into solution in the water and the glucoside in tine crystallizes out. In either case the glucoside ean be filtered off and tested as in the previous experiment. A positive result will be given in each case.

Kaempferol occurs in the flowers of a species of Larkspur (Delphinium consolida) (Perkin and Wilkinson, 25) and Prunus (Perkin and Phipps, 24) and in the leaves or flowers of several other plants. It has the formula:

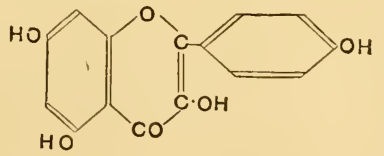

Myricetin and fisetin are two other flavones which have been found in species of Sumac (Rhus) and other plants. They have respectively the formulae:

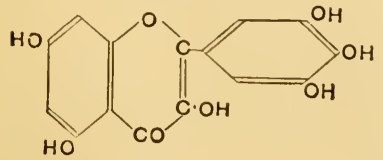

Myricetin<smiles>O=C(O)c1ccc(O)cc1Oc1ccccc1O</smiles>

Fisetin 


\section{The Anthocyan Pigments.}

These pigments are the substances to which practically all the blue, purple and red colours of flowers, fruits, leaves and stems are due (Wheldale, 3). They occur in solution in the cell-sap and are very widely distributed, it being the exception to find a plant in which they are not produced. As members of a group, they have sinilar properties, but differ somewhat among themselves, the relationships between them being much the same as those between the various flavone and flavonol pigments. They occur in solution in the cell-sap but occasionally they crystallize out in the cell. They are present in the plant in the form of glucosides, and in this condition they are known as anthocyanins; as glucosides they are readily soluble in water and as a rule in alcohol [except blue Columbine (Aquilegia), Cornflower (Centaurea Cyanus) and some others] but are insoluble in ether and chloroform. The glucosides are hydrolyzed by boiling with dilute acids, and the resulting products, which are non-glucosidal, are termed anthocyınidins (Willstätter and Everest, :35). The latter, in the form of chlorides, are insoluble in ether, but are generally soluble in water and alcohol. The anthocyanins can be distinguished from the anthocyanidins in solution by the addition of anyl alcohol after acidification with sulphuric acid. The anthocyanidins pass over into the amyl alcohol, the anthocyanins do not. The anthocyanins and anthocyanidins themselves (with one exception) have not yet been crystallized, but of both classes crystalline derivatives with acids have been obtained (Willstätter and Everest, 35).

In considering the reactions of anthocyan pigments the difference between those given by crude extracts and those of the isolated and purified substances must be borne in mind. With acids the anthocyan pigments give a red colour: with alkalies they give, as a rule, a blue or violet colour when pure, but if flavone or flavonol pigments are present (as may be the case in a crude extract) they give a green colour, due to mixture of blue and yellow. In solution in neutral alcohol and water many anthocyan pigments lose colour, and this is said to be due to the conversion of the pigment into a colourless isomer which also gives a yellow colour with alkalies (Willstätter and Everest, 35); hence even a solution of a pure anthocyan pigment may give a green coloration with alkali due to mixture of blue and yellow. The isomerization can be prevented or lessened by addition of acids or of neutral salts which form protective addition compounds with the piginent. With lead acetate 
anthocyan pigments give insoluble lead salts, blue if the pigment is pure, or green, as in the case of alkalies, if it is mixed with flavone or Havonol pigments, or the colourless isomer.

When anthocyan pigments are treated with nascent hydrogen, the colour disappears but returns again on exposure to air. It is not known what reaction takes place.

Expt. 101. The reactions of anthocyanins and anthocyanidins. Extract petals of the plants mentioned below with boiling aleohol in a flask. Note that the anthocyan colour may disappear in the alcoholie extraet. Filter off some of the alcoholie extract and make the following tests $(a)$ and $(b)$ with it :

(a) Add a little acid and note the bright red colour.

(b) Add a little alkali and note the green eolour.

The decolorized petals, after filtering off the extract, should be warmed with a little water in an evaporating dish. The colour is brought back if pigment is still retained by them.

Evaporate the remainder of the alcoholie extract to dryness and note that the anthocyan colour returns. Dissolve the residue in water and continue the following tests, taking a little of the solution in each case :

(c) Add ether and shake. The anthoeyan pigment is not soluble in ether.

(d) Add acid. A bright red colour is produeed.

(e) Add alkali. A bluish-green or green colour is produced which may pass to yellow.

$(f)$ Add basic or nornal lead acetate solution. A bluish-green or green preeipitate is produced.

(g) Add a little sulphuric aeid and then amyl alcohol and shake: the latter does not take up any of the red colour, indieating that the pigment is in the anthocyanin (glueosidal) state.

(h) Heat a little of the solution on a water-bath with dilute sulphurie acid and then cool and add amyl alcohol. T he eolour will pass into the amyl alcohol, indicating that the pigment is now in the anthoeyanidin (non-glucosidal) state.

(i) Aeidify a little of the solution with hydrochloric aeid and add small quantities of zine dust. The eolour disappears. Filter off the solution and note that the colour rapidly returns again.

For the above reactions it is suggested that the following flowers be used as material: magenta Snapdragon (Antirrhinum majus), brown Wallfower (Cheiranthus Cheiri), crimson Paeony (Paeonia officinalis), magenta "Cabbage" Rose, Violet (Viola odorata), but the majority of coloured flowers will serve equally well.

Though the above represent the reactions and solubilities given by the greater number of anthocyan pigments, it will be found that all are not alike in these respects.

Expt. 102. Demonstration that anthocyanins may be insoluble in alcohol but soluble in water. Extract petals of any of the species mentioned below with boiling alcohol and note that they do not lose their eolour. It will be found that the pigments are either completely or largely insoluble in alcohol, but are soluble in water. Test the 
water extract as in Expt. $101(c)-(i)$. Also take equal quantities of the water extract in two evaporating dishes. To one add sodium chloride. Note (as mentioued above, see 1.98 ) that the colour fades less rapidly from the extract containing the salt. The flowers of the following species can be used : blue Larkspur (Delphinium), Cornflower (Centanrea Cyanus), blue Columbine (Aquilegiu).

There is a small group of plants belonging to some allied natural orders, of which the anthocyan pigments give chemical reactions still more different from the general type already described, though they nevertheless resemble each other. Such, for instance, are the pigments of various genera of the Chenopodiaceae [Beet (Beta), Orache (Atriplex)], Amarantaceae (Amaranthus and other genera), Phytolaccaceae (Phytolacca) and Portulacaceae (Portulaca). These anthocyan pigments are insoluble in alcohol but soluble in water: they give a violet colour with acids, red to yellow with alkalies, and a red precipitate with basic lead acetate.

Expt. 103. Reuctions of the Beet-root (Beta vulgaris) pigment. Take some Beetroot leaves, tear them into small pieces and put them into alcohol. Allow the leaves to stand for some time and note that the chlorophyll is extracted but the red pigment is insoluble. Then pour off the alcohol and add water : the red pigment goes into solution. Filter off the solution and make the following tests :

(a) Add acid. The pigment turns violet.

(b) Add alkali. The pigment becomes redder and finally turns yellow.

(c) Add basic lead acetate. A red precipitate is formed.

(d) Acidify with hydrochloric acid and add zine dust. The colour disappears, but on filtering off from the zine it does not return again.

Anthocyan pigments may also occur in leaves, and this is very obvious in red-leaved varieties of various species such as the Copper Beech, the Red-leaved Hazel, etc.

Expt. 104. Extraction of anthocyun pigment from the Red-leaved Hazel. Extract some leaves of the Blood Hazel (Corylus A vellana var. rubra) with alcohol. Filter off and evaporate the solution to dryness. Add water. Pour a little of the crude mixture in the dish into a test-tube and add ether. There will be a separation into a green ethereal layer containing ehlorophyll, and a lower water layer containing anthocyan pigment. Filter the extract remaining in the dish and with the filtrate make the tests already given in Expt. $101(c)-(i)$.

The leaves of the Copper Beech (Fugus sylvaticu var. purpurea) can also be used.

In many flowers, the cells of the corolla may contain yellow plastid (see p. 39) in addition to anthocyan pigments. The colour of the petals is in these cases the result of the combination of the two, and is usually some shade of brown, crimson or orange-red, as in the brown-flowered variety of Wallflower (Cheiranthus Cheiri). 
Expt. 105. Demonstration of the presence of anthocyan and plastid pigments together in petals (see also Expt. 100). Extract petals of the brown-flowered variety of Wallflower with alcohol. Filter, and evaporate the extract to dryness. Take up with water and add ether. Pour the mixture into a scparating funnel. The plastid pigment will pass into solution in the ether, and the anthocyan pigment will remain in the water. Test the aqueous solution as in Expt. $101(c)-(i)$.

The following may be used as material: ray florets of bronze or crimson Chrysanthemum, ray florets of Gaillardia, and orange-red flowers of Nasturtium (Tropaeolum majus).

Anthocyanins and anthocyanidins have been isolated from various species. The pigments themselves with one exception have not been obtained in the crystalline state, but crystalline compounds with acids have been prepared both of the glucosidal and non-glucosidal forms.

All the pigments so far described appear to be derived from three fundamental compounds, pelargonidin, cyanidin and delphinidin, of which the chlorides are represented thus:<smiles>Oc1ccc(O)c(O)c1</smiles>

Pelargonidin chloride<smiles>O=C(O)c1ccc(O)c(O)c1</smiles>

Cyanidin chloride<smiles></smiles>

Delphinidin chloride

It has been suggested, at least in the case of cyanidin, the pigment of the Cornflower (Centaurea Cyanus), that the pigment itself is a neutral substance, purple in colour and of the following structure (Willstätter, $33,36)$ :

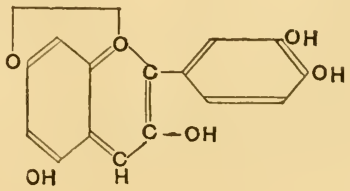


Further, that the blue pigment of the flower is the potassium salt of the purple, and the red acid salt, cyanidin chloride, depicted above, is a so-called oxonium compound of the purple.

Pelargonidin, moreover, has been prepared synthetically (Willstätter and Zechmeister, 45).

The above three pigments, either as glucosides or in the form of methylated derivatives, are found in a number of plants which are listed below (Willstätter, etc., 33-46). The sugar residues or methyl groups may, of course, occupy different positions, thus giving rise to isomers :

Pelargonidin.

Callistephin Pelargonin
Monoglucoside of pelargonidin Diglucoside of pelargonidin
Flowers of Aster (Callistephus chinensis)

Flowers of Scarlet Geranium (I'largonium zonale), pink var. of Cornflower (Centuurea Cyanus) and certain vars. of Dahlia (D. variabilis)

Cyanidin.

\begin{tabular}{l|l|}
$\begin{array}{l}\text { Asterin } \\
\text { Chrysanthemin }\end{array}$ & $\begin{array}{l}\text { Monoglucoside of cyanidin } \\
\text { Monoglucoside of cyanidin } \\
\text { Monogalactoside of cyanidin } \\
\text { Diglucoside of cyanidin }\end{array}$ \\
$\begin{array}{l}\text { Mekocyanin } \\
\text { Keracyanin }\end{array}$ & $\begin{array}{l}\text { Diglucoside of cyanidin } \\
\text { Rhamnoglueoside of cyanidin } \\
\text { Diglucoside of peonidin (cyanidin } \\
\text { monoethyl ether) }\end{array}$
\end{tabular}

\section{Delphinidin.}

Violanin

Delphinin

Ampelopsin

Myrtillin

Althaein

Petınin

Malvin

Oenin monoethyl ether)
Flowers of Aster (Callistephus chinensis)

Flowers of Chrysanthemum (C. indicum) Fruit of Cranberry (I'accinium Vitis-Idaea) Flowers of Cornflower (Centaurea Cyanus), Rosa gallica and certain vars. of Dahlia (D. variabilis)

Flowers of Poppy (Papaver Rhoeas)

Fruit of Cherry (Prunus Cerasus)

Flowers of Paeony (Paeonia officinalis) \begin{tabular}{l|l} 
Rhamnoglncoside of delphinidin & Flowers of Pansy (Viola tricolor)
\end{tabular}

Diglucoside of delphinidin + $p$-hydroxybenzoic acid

Monoglucoside of ampelopsidin (delphinidin monomethyl ether)

Monogalactoside of myrtillidin (delphinidin monomethyl ether)

Monoglucoside of myrtillidin

Diglucoside of petunidin (delphinidin monomethyl ether).

Diglucoside of malvidin (delphi- Flowers of Mallow (Malva sylvestris) nidin dimetliyl ether)

Monoglucoside of oenidin (delphi- Fruit of Grape (Vitis vinifera) nidin dimethyl ether) 
Of the methylated compounds, myrtillidin and oenidin may be represented thus:
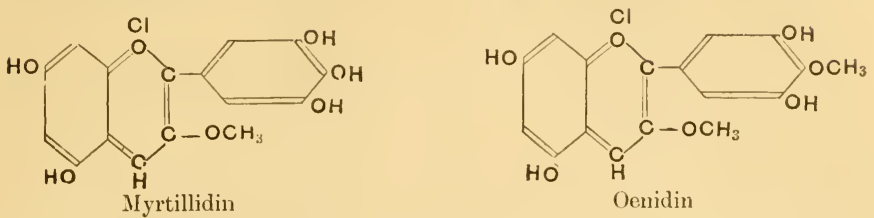

Expt. 106. Preparation and reactions of pelargonin chloride. Extract the flowers from two or three large bosses of the Scarlet Geranium (Pelargonium zonale) in a flask with hot alcohol. Filter off' and concentrate on a water-bath. 'Then pour the hot concentrated solution into about half its volume of strong hydrochloric acid. On cooling, a crystalline precipitate of pelargonin chloride separates out. Examine under the microscope and note that it consists of sheaves and rosettes of needles. Filter off the crystals, take $u \mathrm{p}$ in water and make the following experiments with the solution :

(a) Add alkali. A deep blue-violet colour is produced.

(b) Take two equal quantities of solution in two evapolating dishes. To one add as quickly as possible some solid sodium chloride. The colour in the solution without salt will rapidly fade owing to the formation of the colourless isomer in neutral solution: this change is prevented to a considerable extent in the solution containing salt owing to the formation of an addition compound of the pelargonin with the sodium chloride which prevents isomerization (see p. 98). To portions of the water solution (without sodium chloride) which has lost its colour add respectively acid and alkali. The red colour returns with acid owing to the formation of the red acid oxonium salt: with alkali a greenish-yellow colour will be produced due to the formation of the salt of the colourless isomer. If alkali is added to the portion of the pigment solution containing the sodium chloride, it will be found that it still gives a violet colour.

(c) Add sulphuric acid and amyl alcohol. The alcohol does not take up the colour. Add amyl alcohol after acidifying another portion of the solution with sulphuric acid and heating on a water-bath. The alcohol now abstracts some of the colour. This shows that the glncoside pelargonin exists in the first ease, but is decomposed into the non-glucosidal pelargonidin after heating with acid.

(d) Acidify with hydrochloric acid and add zinc dust: the colour disappears and returns again after filtering.

Expt. 107. Preparation of the ucetic ucid sult of pelargonin. Make an alcoholic extract of petals as in Expt. 106. Evaporate down and pour into glacial acetic aeid instead of hydrochloric acid. The crystals of the salt formed are smaller and more purple in colour than those of the chloride.

Expt. 108. Preparation and reretions of crude peonin chloride. Extract the petals of one or two flowers of the Crimson Paeony (Paeonia officinalis) with $95-98^{\circ} \%$ alcohol. Filter and evaporate nearly to dryness. Then add some methyl alcohol and 
pour into a little strong hydrochloric acid. Then add ether to the mixture in a separating funnel. A crude precipitate of peonin chloride will separate out after a time, which may be more or less crystalline. Filter off this precipitate, take up in water and make the following experiments:

(a) Take two equal quantities of the solution in two evaporating dishes. To one add solid sodium chloride as in Expt. $106(b)$. Then neutralize both portions carefully with very dilute sodium carbonate solution until the colour changes slightly to purple. The colour will fade more rapidly in the solution without sodium chloride on account of the formation of a colourless isomer, as in the case of pelargonin chloride. The water solution after standing will give a green colour with alkali owing to admixture with the yellow sait of the isomer.

(b) Add alkali. A deep blue colour is produced. A crude extract of the fresh petals made as in Expt. 101 will give a green or bluish-green colour with alkali owing to the presence of the accompanying flavone.

(c) Add amyl alcohol and sulphuric acid. No colour is taken up by alcohol. The pigment is present as the glucoside peonin. Boil another portion with sulphuric acid and add amyl alcohol. The pigment is partly hydrolyzed and the peonidin goes into solution in the alcohol.

(d) Reduce another portion with zinc dust and hydrochloric acid. The colour returns after filtering.

In considering the anthocyan pigments, the question now arises- . What is the chemical significance of the various shades in the living plant? Apparently the same pigment may be present in two flowers of totally different colours, as in the blue Cornflower and the magenta Rosa gallica. It has been suggested that in such cases the pigment is modified by other substances present in the cell-sap: thus it may be present in one flower as a potassium salt, in another as an oxonium salt of an organic acid, and in a third in the unaltered condition. But exactly how these conditions are brought about is not elear. In one or two cases, moreover, where there is a red or pink variety of a blue or purple flower, the variety, when examined, has been found to contain a different pigment and one less highly oxidized than that in the species itself. The above phenomena are exemplified in the Cornflower (Centaurea Cyanus). The flowers of the blue type contain the potassium salt of cyanin, the purple variety, cyanin itself, while those of the pink variety contain pelargonin.

The mode of origin of anthocyan pigments in the plant is as yet obscure. It has been suggested (Wheldale, 29) that they have an intimate connexion with the flavone and flavonol pigments, which can be seen at once by comparing the structural formula of quercetin with that suggested for cyanidin: 


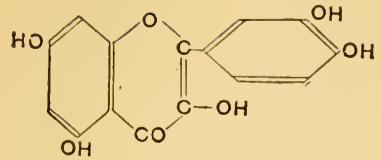

Quercetin

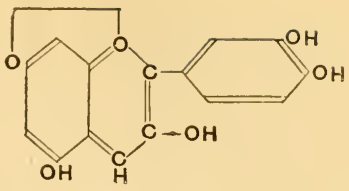

Cyanidin

All the anthocyan pigments so far isolated, however, have been found to contain the flavonol, and not the flavone, nucleus.

Just as in the case of the flavone and flavonol pigments, some of the anthocyan pigments are specific, while others, on the contrary, are common to various genera and species. Also more than one anthocyan pigment may be present in the same plant.

It will be pointed out later that small amounts of a substance identical with cyanidin are said to be formed by reduction of quercetin with nascent hydrogen, but this does not necessarily prove that the formation of anthocyan pigments in the plant takes place on the same lines. If we compare the formulae for a number of anthocyan with flavone and flavonol pigments, it is seen that they may be respectively arranged in a series, each member of which differs from the next by the addition of an atom of oxygen:

Luteolin, kaempferol and fisetin $\mathrm{C}_{15} \mathrm{H}_{10} \mathrm{O}_{6}$

Quercetin $\mathrm{C}_{15} \mathrm{H}_{10} \mathrm{O}_{7}$

Myricetin $\mathrm{C}_{15} \mathrm{H}_{10} \mathrm{O}_{8}$
Pelargonidin $\mathrm{C}_{15} \mathrm{H}_{10} \mathrm{O}_{5}$ Cyanidin $\quad \mathrm{C}_{15} \mathrm{H}_{10} \mathrm{O}_{6}$ Delphinidin $\mathrm{C}_{15} \mathrm{H}_{10} \mathrm{O}_{7}$

The relationship between these two classes of substances in the plant can only be ascertained by discovering which flavone, flavonol and anthocyan pigments are present together, and then to determine whether the relationship is one of oxidation or reduction, a problem which has not yet received adequate attention (Everest, 6).

A reaction which is of interest in connexion with the relationship between the above two classes of pigments is that which takes place when solutions of some flavone or flavonol pigments are treated with nascent hydrogen. If an acid alcoholic solution of quercetin is treated with zinc dust, magnesium ribbon or sodium amalgam, a brilliant magenta or crimson solution is produced, and this solution gives a green colour with alkalies (Combes, 5). The red substance thus produced has been termed "artificial anthocyanin" or allocyaniclin. The product is not a 
true anthocyan piginent but has, it is suggested, an open formation (Willstätter, 36):

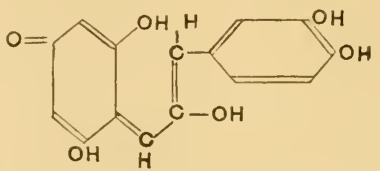

It is said, however, to contain small quantities of a substance identical with natural cyanidin from the Cornflower (Willstätter, 36). The fact that small quantities of a natural anthocyan pigment can be obtainerl artificially from a hydroxyflavonol by reduction does not necessarily imply that one class is derived from the other in the living plant.

From the above reaction of quercetin the result follows that when many plant extracts [most plants (see p. 94) contain flavone or flavonol pigments] are treated with nascent hydrogen, artificial anthocyan pigment is produced. Noreover, it seems probable that if the yellow pigments acted upon are in the glucosidal state, and if the reduction takes place in the cold, allocyanin (the glucoside of allocyanidin) is formed and the product is not extracted from solution by anyl alcohol. But if the flavone is non-glucosidal, or if the solution is boiled before or after reduction, then allocyanidin (non-glucosidal) is formed and is extracted by amyl alcohol.

Expt. 109. Formation of allocyanidin from quercetin. Make an alcoholic solution of a little of the glucoside of quereetin prepared from either Narcissus or Cheiranthus: (see Expts. 98 and 100). Acidify with a little strong hydrochloric acid and heat on at water-bath. Add a little zine dust from time to time. A brilliant magenta colour due to allocyanidin is produeed. To a little of this solution add some alkali : a green colour is produeed. If the alcohol and hydrochloric acid are evaporated off, and a little water and sulphurie acid added, on shaking up with amyl alcohol, all the allocyanidin passes into the anyl alcohol. (The distribution of the allocyanidin in the amyl alcohol is greater with aqueous sulphuric acid than with aqueous hydrochloric acid.)

Expt. 110. Formation of allocyanin from quercetin. Make a suspension of the glucoside of quercetin from Cheirunthus or Y'arcissus (see Expts. 98 and 100) in about $2 \mathrm{~N}$ sulphuric aeid, and then add zine dust (or a drop) of mercury about the size of a pear and a little magnesium powder) in the cold. The red or nagenta colour is gradually developed. Divide the colonred solution into two parts in two test-tubes. Boil one for 5-10 minutes. Then add amyl alcohol to each. In the unboiled test-tube the amyl alcohol extracts no colour, since allocyanin is present. In the boiled test-tuke allocyanidin is taken up by the anyl aleohol as in Expt. 109. 
Expt. 111. Formetion of allocyanin and allocyunidin from plant extracts. For this purpose the yellow varieties "Primrose" or "Cloth of Gold" of the Wallflower (Cheirunthus Cheiri) can be used. The flowers are pounded in a mortar, extracted with cold water, the water extract acidified with sulphuric acid, and zinc dust (or mercury and magnesium powder as above) added. A red coloration is slowly developed. To some of the red solution add amyl alcohol. The colonr is not abstracted (allocyanin). Boil another portion. The allocyanin is thus converted into allocyanidin which is then taken up on addition of amyl alcohol.

\section{The Oxidizing Enzymes.}

There is a certain group of enzymes of which we have most information in their connexion with aromatic substances. These are the oxidizing enzymes.

The presence of such enzymes in plants was long ago associated with the following phenomena. If the expressed juices, or water extracts of the tissues, of some plants are added to a solution of guaiacum gum, in the presence of air, a deep blue colour is obtained in a short time. On the other hand, expressed juices, or water extracts, of other plants added to guaiacum solution produce no blue colour. On addition, however, of a few drops of hydrogen peroxide, in the latter case, the blue colour rapidly develops. Plants are sail to contain an oxidase when the extracts give the blue colour with guaiacum tincture alone. Those, of which the extracts only bring about blueing on addition of hydrogen peroxide, are said to contain a peroxidase (Chodat, 1 ).

Expt. 112. Demonstration of the presence of an oxidase. Take a portion of a fresh Potato tuber and pound well in a mortar with a little water. Filter, and to the extract, in a white evaporating dish, add a few drops of $1 \%$ guaiacum solution in alcohol. The guaiacum tincture will be found to give a blue colonr at once with the potato extract.

A control tube should be prepared by well boiling some of the water extract of the tuber, cooling and then adding gnaiacum. No colour is produced, owing to the fact that the enzyme has been destroyed by boiling. Other tissues which may be used to demonstrate the above reactions are : root of beet and fruits of apple, pear and plum.

Guaiacum gum is obtained from two West Indian species of Guaiacum trees, G. officinale and $G$. sanctum, partly as a natural exudation and partly by means of incisions. It gives a yellow solution with alcohol which contains guaiaconic acid, and the latter, on oxidation, yields guiacum blue. As far as possible, inner portions of the resin lumps should be used, as the resin oxidizes in air, and then nary give unreliable results. It is best to make the tincture freshly before use, and, as a precaution, to boil it on a water-bath with a little animal charcoal and filter. Guaiacum gum tends to form peroxides on exposure to air, and these are renoved hy the alove treatment. 
Expt. 113. Demonstration of the presence of a peroxidase. Repeat the above experiment, using seales from an Onion bulb. Add a few drops of hydrogen peroxide solution. Green pea tissue may also be used. No blue colour is produced until after the addition of hydrogen peroxide.

If a systematic examination is made of genera from various natural orders with the guaiacum test, it will be found that the oxidase reaction is shown by all, or nearly all, genera of some orders, for instance most Umbelliferae, Labiatae, Boraginaceae and many Compositae. In other orders, i.e. Cruciferae and Crassulaceae, the peroxidase reaction is predominant.

Moreover, the oxidase-containing genera show another phenomenon, as follows. If the tissue extracts are left in air, they become darkcoloured, generally brown or reddish-brown. If the plants themselves are bruised or injured, they turn brown. The same effect nay be produced very rapidly by the action of chloroform vapour. These phenomena, the darkening of extracts and the discoloration, both on injury and in chloroform, will be found to be absent from plants giving the peroxidase reaction only.

Expt. 114. To show the distribution of oxidases and peroxidases in various plants, and the correlation between the presence of oxidase and browning on injury or in chloroform vapour. Take a selection of the plants given below, and in each case grind up a portion of the plant in a mortar with a little water and filter. Divide the filtrate into two parts in small porcelain dishes. Allow one part to stand in air, and note the darkening in colour in cases where an oxidase is present. To the other add a few drops of guaiacum. To extracts containing a peroxidase only, after 5-10 minutes, add in addition a few drops of hydrogen peroxide. Further, small pieces of the plants to be tested should be placed in a corked flask containing a few drops of chloroform, and the development of browning noted in the case of plants containing an oxidase. For demonstration of oxidases the following plants may be used : (Christmas Rose (Helleborus niger), Dandelion (Taraxacum officinale), Forget-me-not (Myosotis), Hawthorn (Crataegus) and White Dead Nettle (Lamium album). For peroxidases: Arabis, Aubrietic, Buttercup (Ranunculus acris), Pea (Pisum sativum), Stock (Matthiola), Wallflower (Cheiranthus Cheiri) and Violet (Viola).

Various hypotheses have been suggested in explanation of the reactions of oxidizing enzymes. The one most generally accepted (Chodat, 1) is that the oxidase consists of two components, a peroxide and a peroxidase. The peroxide may be either hydrogen peroxide or some organic peroxide. The peroxidase acts upon the peroxide, depriving it of an atom of oxygen which is transferred, in an "active" condition, to some substance (acceptor) which becomes oxidized. Guaiacum is the acceptor in the above experiments. The reaction may be approximately expressed thus :

$$
\begin{aligned}
& 2 \mathrm{AO}+\mathrm{O}_{2}=2 \mathrm{AO}_{2} \text { (peroxide) } . \\
& \mathrm{AO}_{2}+\text { peroxidase }=\mathrm{AO}+\mathrm{O} .
\end{aligned}
$$


The above conception would represent a system which is capable of absorbing molecular oxygen and of transforming it into active oxygen. In this way substances can be oxidized which would not be affected by molecular oxygen to any extent.

Accordingly, on the basis of the above hypothesis, it is assumed that an organic compound which can act as a peroxide is present in the expressed plant juices or extracts which give the oxidase reaction. When this organic peroxide is absent, hydrogen peroxide must be added to complete the oxidase system.

The above definition of oxidases and peroxidases is based upon their behaviour towards guaiacum. There are, however, a number of other oxidizable substances, such as $\alpha$-naphthol, benzidine, $p$-phenylenediamine, pyrogallol, etc. :

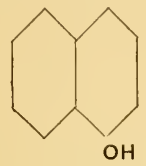

$a$-Naphthol

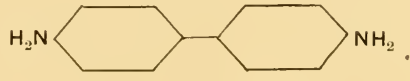

Benzidine

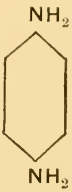

$p$-Phenylenediamine

which are only oxidized by oxidases with the assistance of hydrogen peroxide, the oxidase system being insufficient; they are also of course oxidized by the hydrogen-peroxide-peroxidase system. Such substances (in the presence of hydrogen peroxide) are used as tests for oxidizing enzymes.

Expt. 115. Additional tests for oxidizing enzymes. To a few e.e. of an extract of Potato tuber (Expt. 112) in a small evaporating dish, add a few drops of the following reagents, and subsequently a few drops of hydrogen peroxide :

(a) A $1 \%$ solution of a-naphthol in $50 \%$ alcohol. A lilac colour is developed.

(b) A $1 \%$ solution of benzidine in $50 \%$ aleohol. A blue colour is developed.

(c) A $1 \%$ solution of $p$-phenylenediamine hydrochloride in water. A greenish colour is developed.

The peroxidases, like other enzymes, can be extracted either with water or dilute alcohol and precipitated from solution by strong alcohol.

Expt. 116. Preparation of peroxidase from Horse-radish (Cochlearia) roots. Hince up the Horse-radish roots in a mincing machine. The product is allowed to stand for 24 hrs. to enable the glucoside, potassium myronate, to be hydrolyzed by the enzyme, myrosin. Then extract with $80 \%$ alcohol. The alcohol is decanted off, and the residue pressed free from aleohol in a press. The residue is next extracted with $40 \%$ alcohol for 48 hrs., filtered and precipitated with $90 \%$ alcohol. The precipitate, which contains the peroxidase, is filtered off. Dissolve up in water and make the test for peroxidases (Expt. 113). 
The oxidation of pyrogallol, in the presence of a peroxidase and hydrogen peroxide, has been userl as a method for estimating the activity of these enzymes. Solutions of known strength of pyrogallol and hydrogen peroxide are used, and to the mixture a solution of a known weight of prepared peroxidase is added. An oxidation product, termed purpurogallin, is formed. After a definite time, the reaction is stopped by adding acid, and the purpurogallin extracted by ether. The ether extract is colorimetrically compared with an extract containing a known amount of purpurogallin (Willstätter and Stoll, 47).

Expt. 117. Outline of method for estimating peroxidase by formation of purpurogallin. Make a solution of $0.5 \mathrm{gm}$. of pyrogallol in 200 c.c. of distilled water, and add to it 1 c.c. of $5 \%$ hydrogen peroxide. Then add about 5 c.c. of a solution of Horse-radish peroxidase from Expt. 116. After 5 minutes add to half the mixture 2.) c.c. of dilute sulphuric acid and extract the purpurogallin with ether in a separating funnel. The purpurogallin will be extracted by the ether, giving a yellow solution. Allow the other half of the mixture to stand. The colour will deepen, and a reddish deposit of purpurogallin will be precipitated. Examine a little of the deposit under the microscope. It will be found to consist of sheaves of crystals.

A solution of peroxidase from Alyssum leaves [Expt. $119(b)$ ] can also be used.

It has recently been shown (Wheldale Onslow, 11) that the peroxidase element (Expt. 118) of certain oxidases (fruit of Pear, tuber of Potato) can directly oxidize the phenol catechol (see p. 88), as well as other substances containing the catechol grouping, that is two hydroxyl groups in the ortho position, e.g. protocatechuic acid and caffeic acid :

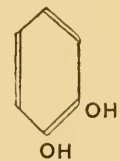

Catechol

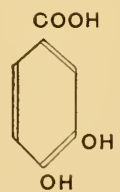

Protocatechuic acid

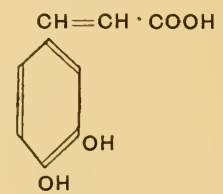

Caffeic acid

A brown colour is produced, giving rise to some oxidation product which will then act as a peroxide, the peroxidase being present, to form the system (oxidase) which will blue guaiacum.

It appears probable that the above phenomenon, as illustrated in the Pear and Potato, affords an explanation of the reaction of the oxidizing enzymes of all plants which give the oxidase reaction and turn brown on injury. For such plants usually contain an aromatic substance with the catechol grouping. On the death of the cell (which may be brought about, either by injury, or treatment with chloroform vapour, i.e. on autolysis, see p. 19) this aromatic substance is oxidized by the 
peroxidase with the formation of a brown colour (browning on injury) and an oxidation product which then acts as an organic peroxide (as postulated above) in the oxidase system.

Further, the peroxidases, of plants which give the oxidase reaction and brown on injury, appear to be specific in their action on the catechol grouping and will not oxidize other phenolic groupings, i.e. those of resorcinol, hydroquinone, pyrogallol, etc.

In plants (e.g. Alyssum) which only give the peroxidase reaction and do not brown on injury, the ąbove-mentioned aromatic compounds are not present, nor do the peroxidases of such plants act on catechol.

It should, however, be borne in mind that in some plants the components of the oxidase system may be present, but the reaction is masked by the presence of an excess of tannin, sugars, etc.

Hence it appears that the oxidase reaction of plants (as detected by guaiacum) is the outcome of post-mortem changes after the death of the cell. It is possible, however, that the processes giving rise to it may take place to some extent, though under control, in the living cell.

It has also been shown that in the Pear fiuit and Potato tuber (Wheldale Onslow, 11) it is possible by chemical methods to separate the elements which go to make up the oxidase system, i.e. the peroxidase and the aromatic substance. If the tissues are ground up rapidly with alcohol, and filtered before oxidation can take place, and the process repeated, the aromatic substance, which is soluble in alcohol, is washed away, and a water extract of the residue gives only a peroxidase reaction. From the alcoholic extract the aromatic substance can be precipitated as a lead salt, the lead then removed as insoluble lead sulphate, and the aromatic set free again in solution. If the peroxidase is then added to the solution of the aromatic, the brown colour appears together with the formation of the oxidation product (peroxide), and the mixture will give the blue reaction of an oxidase with guaiacum.

Expt. 118. Resolution of the components of the oxidase in the Potato tuber. (A) Separation of peroxidase. Cut a few thin slices from a peeled potato and put them in a mortar which contains sufficient $96 \%$ alcohol to prevent, as far as possible, exposure to the air, and pound them thoroughly. Filter quickly on a filter-pump, and repeat the process several times until a colourless powder, consisting of cellresidues, starch, etc. is obtained. The enzymes (including the peroxidase) of the cells are precipitated by the alcohol and remain in the cell-residue. Make a water extract of the white powder and filter. To a portion of the filtrate add a few drops of guaiacum tincture: no blue colour is given. Add further a few drops of dilute hydrogen peroxide : a blue colour appears. (B) Separation of the aromatic substance. Take about $500 \mathrm{gms}$. of freshly peeled potato tuber, ent it into thin slices and drop 
them as rapidly as possible into a flask containing 250 c.c. of boiling $96 \%$ alcohol on a water-bath. Continue boiling for 15 mins., and then filter. Evaporate off the alcohol from the filtrate, take $u$, the residue in a little water, warm and filter. To the filtrate add concentrated lead acetate solution until a precipitate ceases to be formed. Filter off' the precipitate, which is pale yellow in colour, stir up in a little water and add $10 \%$ sulphuric acid drop by drop until the yellow colour is destroyed, and the lead is converted into lead sulphate. Filter off the lead sulphate: the filtrate contains the aromatic substance in solution. Neutralize the solution carefully with $1 \%$ caustic soda and make the following tests with separate portions in small evaporating dishes :

(a) Add a drop of ferric chloride solution : a deep green colour appears. Add further a few drops of $1 \%$ sodium carbonate solution. The green colour changes to a bluish-and finally, a reddish-purple. This reaction is characteristic of aromatic compounds containing the catechol grouping, i.e. two hydroxyl groups in the ortho position (see p. 110).

(b) Add a little of the peroxidase solution prepared in (A). The mixture will gradually turn brown owing to the oxidation of the aromatic by the peroxidase.

(c) To $(b)$ add a few drops of guaiacum tincture. A blue colour is given owing to the presence of the peroxide formed in $(b)$, the oxidase system being now complete.

Expt. 119. Action of peroxidases on catechol. (a) The peroxiduse of the Potato tuber (or Pear fruit). Nake a $1 \%$ solution of catechol in distilled water. To some of this solution, in a small evaporating dish, add a little of the peroxidase solution from Expt. 118 (A). Note that the catechol solution gradually turns brown. Add further a few drops of guaiacum tincture. A blue colour appears. (b) Peroxidase of Alyssum leaves. Pound up 2-3 Alyssum leaves in a mortar with some $96 \%$ alcohol, and filter on a filter-pump. Repeat the process mntil the residue is practically colourless. Extract the residue with a little distilled water and filter. Proceed as in (a). No browning of catechol takes place and no blue colour is formed on the subsequent addition of guaiacum.

For section $(a)$ the following material may also be used : fruits of Apple and Greengage, flowers of Horse Chestnut (Aesculus) and leaves of Pear, the method of preparation in $(b)$ being employed. For section $(b)$ flowers of white Arabis may also be used.

If in the preparation of the peroxidase from the Potato tuber, the tissue is allowed to brown before extracting with alcohol, the cell-residue is tinged with brown and, on extraction with water, the filtrate will give an oxidase reaction with guaiacum. This is to be explained by the fact that the peroxide has been adsorbed by the tissue residue. This phenomenon is probably the explanation of the preparation of some oxidases called "laccases." Such enzymes have been obtained by the precipitation with strong alcohol of the expressed juices (containing peroxide since they were obtained by crushing the tissues) of plants which brown on injury. The enzyme and other organic matter is precipitated and carries with it the peroxide. 
The browning of plants on injury, as already mentioned, is very wide-spread: more rarely, the same type of reaction may lead to the formation of variously coloured products, other aromatic substances in addition to the peroxide being in all probability involved. The following examples may be quoted. In some of the Higher Fungi, Boletus luridus and B. cyunescens, when the pileus is broken across or injured, the tissue rapidly turns a deep Prussian blue on exposure to the air. Also in the Fungus, Russula nigricans, the colour changes from pink or reddish to black. The latex of the tree, Rhus vernicifera, when exposed to air, turns black and constitutes the product, Japanese lacquer.

Analogous pigments formed after death have been observed in Schenchia blumenaviana (Rubiaceae) where the whole plant turns bright red in chloroform vapour, as well as in species of Jacobinic and Aloe. Blue pigments are also formed after death in the Teasel (Dipsacus), in the flowers of an Orchid (Phajus), in the Dog's Mercury (Mercurialis perennis), annual Mercury (M. апnua) and in the well-known indigoproducing plants, the Woad (Isatis tinctoria) and the Indigo (Indigofera) (Walther, 28) (see p. 152). It has not been shown, however, that oxidizing enzymes are present in all the above cases.

There is a well-known oxidizing enzyme, tyrosinase, which is somewhat specific in its action in that it will only oxidize tyrosine and a few other substances, such as $p$-cresol. It occurs in the tubers of the Dahlia (Dahlia variabilis) and Potato (Solanum tuberosum), in grains of barley (Hordeum) and wheat (Triticum) and in Papaver orientale. In the lower plants it is found among the Basidiomycetes.

When tyrosinase acts upon tyrosine, a yellowish-pink colour is first produced which rapidly darkens to red, brown and finally black. A solution of $p$-cresol

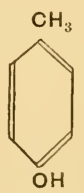

can be used as a delicate test for the enzyme. If the enzyme is present, a yellowish- or orange-red colour is formed.

Tyrosinase of the Potato tuber can be precipitated from a water extract with absolute alcohol: or if the potato tissue is extracted with cold $96 \%$ alcohol, the enzyme is precipitated and remains in the 
tissue residue, as does the peroxidase [Expt. $118(\mathrm{~A})$ ], but the tyrosine is almost entirely washed away.

Expt. 120. Demonstration of the presence of tyrosinase in the Potato. Take about half a potato and proceed as in the preparation of peroxidase [see Expt. $118(\mathrm{~A})$ ]. Roughly dry the powder left on the filter and then add about 100 c.c. of water and allow to stand for 15 mins. Filter, and divide the filtrate into six portions $a, b, c, d$, $e$ and $f$. Make a suspension of a little tyrosine in water (tyrosine is only slightly soluble in cold water).

To $a$ add 5 c.c. of tyrosine suspension.

To $b$ add 5 c.c. of tyrosine suspension and a few drops of hydrogen peroxide.

To $c$ add 5 c.c. of tyrosine suspension and boil.

To $d$ add a few drops of hydrogen peroxide only.

To $e$ add some $p$-cresol.

To $f$ nothing is added.

Plug all the tubes with cotton-wool, put in an incubator at $38^{\circ} \mathrm{C}$. for $2-3 \mathrm{hrs}$. Note that tubes $a$ and $b$ fairly rapidly turn red, then brown and finally black. Tubes $d$ and $f$ may darken a little owing to the action of tyrosinase and peroxidase on the traces of plant aromatics left in the tissue. Tube $c$ remains unaltered. Tube $e$ gives an orange-red colour.

Another point which may be touched upon is the significance of the oxidizing enzymes in plant metabolism. The facts as they present themselves may be stated thus. On death or injury we discover a system (oxidase) in some plants which can oxidize certain acceptors, either artificially introduced, such as guaiacum, or other aromatic substances present in the plant itself.

The question is whether the oxidase system as described above functions in metabolism for the purpose of oxidation and respiration in the living plant. If it does, there are various suggestions as to how it may act. For instance, it is possible that aromatic substances are oxidized to pigments by the oxidase system, and the pigment is then deoxidized by products of anaerobic respiration, hence constituting a mechanism for this function. Such pigments have been termed "respiration pigments" (Palladin, 12-16). It is suggested that they are not present in any quantity in the living plant and their production is controlled by oxidizing and reducing systems :

antoxidizable substance + molecular oxygen $=$ peroxide peroxide + peroxidlase $=$ active oxygen

aromatic substance (acceptor or chromogen) + active oxygen $=$ pigment

pigment + reducing substance $=$ chromogen .

The above hypothesis is only applicable to plants containing oxi- 
dases, so that some inodification would be necessary to fit the case of plants containing peroxidases only.

It should be mentioned that the aromatic substances which become oxidized are frequently present in the plant as glucosides, that is, some of the hydroxyl groups are replaced by sugar. Indoxyl, the precursor of indigo, forms a good example, as it is present in the plant as a colourless glucoside, indican (see p. 152). It is probably only after the hydrolysis of the glucosides that the aromatic substances can become oxidized.

\section{REFERENCES}

Books

1. Chodat, R. Darstellung von Oxydasen und Katalasen tierischer und pflanzlicher Herkunft. Methoden ihrer Anwendung. Handbuch der biochemischen Arbeitsmethoden. E. Abderhalden, Berlin, 1910, Vol. 3 (1), pp. 42-74.

2. Perkin, A. G., and Everest, A. E. The Natural Organic Colouring Matters. Loudon, 1918.

3. Wheldale, M. The Anthocyanin Pigments of Plants. Cambridge, 1916.

\section{PAPERS}

4. Clark, Đ. D. The Nature and Function of the Plant Oxidases. Torreyc, 1911, Vol. 11, pp. 23-31, 55-61, 84-92, 101-110.

5. Combes, R. Sur la présence, dans des feuilles et dans des fleurs ne formant pas d'anthocyane, de pigments jaunes pouvant être transformés en anthocyane. C. R. Acad. sci., 1914, Vol. 158, pp. 272-274.

6. Everest, A. E. The Production of Anthocyanins and Anthocyanidins. Part IlI. Proc. R. Soc., 1918, B Vol. 90, pp. 251-265.

7. Ewart, A. J. A Comparative Study of Oxidation by Catalysts of Organic and Inorganic Origin. Proc. R. Soc., 1915, B Vol. 88, pp. 284-320.

8. Fischer, E., und Freudenberg, $\mathbf{K}$. Ueber das Tannin und die Synthese ähnlicher Stoffe. Ber. D. chem. Ges., 1912, Vol. 45, pp. 915-935.

9. Keeble, F., and Armstrong, E. F. The Rôle of Oxydases in the Formation of the Anthoeyan Pigments of Plants. J. Genetics, 1913, Vol. 2, pp. 277-311.

10. Moore, B., and Whitley, E. The Properties and Classification of the Oxidising Enzymes, and Analogies between Enzymic Activity and the Effects of immune Bodies and Complements. Biochem. J., 1909, Vol. 4, pp. 136-167.

11. Onslow, M. Wheldale. Oxidising Enzymes. I. The Nature of the "Peroxide" naturally associated with certain direct Oxidising Systems in Plants. Biochem. J., 1919, Vol. 13, pp. 1-9.

12. Palladin, W. Das Blut der Pflanzen. Ber. D. bot. Ges., 1908, Vol. $26 \alpha$, Pp. 125-132.

13. Palladin, W. Die Verbreitung der Atmungschromogene bei den Pflanzen. Ber. D. bot. Ges., 1908, Vol. 26 a, pp. 378-389.

14. Palladin, W. Ueber die Bildung der Atmungschromogene in den Pflanzen Ber. D. bot. Ges., 1908, Vol. 26 a, pp. 389-394. 
15. Palladin, W. Ueber Prochromogene der pflanzlichen Atmungschromo. gene. Ber. D. bot. Ges., 1909, Vol. 27, pp. 101-106.

16. Palladin, W. Ueber das Wesen dor Pflanzenatmung. Biochem. Zs, 1909, Tol. 18, pp. 151-206.

17. Perkin, A. G. Luteolin. Part I. J. Chem. Soc., 1896, Vol. 69, pp. 206212. Part 1I. Ibid., 1896, Vol. 69, pp. 799-803.

18. Perkin, A. G. Apiin and Apigenin. J. Chem. Soc., 1897, Vol. 71, pp. 8(15818. Ibid., 1900, Vol. 7\%, pp. 416-423.

19. Perkin, A. G. Robinin, Violaquercetin, Myrticolorin and Osyritrin. J. Chem. Soc., 1902, Vol. 81, pp. 473-480.

20. Perkin, A. G., and Horsfall, L. H. Luteolin. Part III. J. Chem. Soc., 1900, Vol. 77, pl). 1314-1324.

21. Perkin, A. G., and Hummel, J. J. Occurrence of Quercetin in the Outer Skins of the Bulb of the Onion. J. Chem. Soc, 1896, Vol. 69, pp. 1295-1298.

22. Perkin, A. G., and Hummel, J. J. The Colouring Matters occurring in various British Plants. Part I. J. Chem. Soc., 1896, Vol. 69, pp. 1566-1572.

23. Perkin, A. G., and Newbury, F. G. The Colouring Matters contained in Dyer's Broom (Genista tinctoria) and Heather (Calluna vulgaris). J. Chem. Soc., 1899, Vol. 75, pp. \$30-839.

24. Perkin, A. G., and Phipps, S. Notes on some Natural Colouring Matters. J. Chem. Soc., 1904, Vol. 85, pp. 56-64.

25. Perkin, A. G., and Wilkinson, E. J. Colouring Matter from the Flowers of Delphinium Consolida. J. Chem. Soc., 1902, Vol. 81, pp. 585-591.

26. Shibata, K., Nagai, I., and Kishida, M. The Occurrence and Physiological Significance of Flavone Derivatives in Plants. J. Biol. Chem., 1916, Vol. 28, pp. 93 108.

27. Waage, T. Ueber das Vorkommen und die Rolle des Phloroglucins in der Pflanze. Ber. D. bot. Ges., 1890, Vol. 8, pp. 250-292.

28. Walther, O. Zur Frage der Indigobildung. Ber. D. bot. Ges., 1909, Vol. 27, pp. 106-110.

29. Wheldale, M. On the Nature of Anthocyanin. Proc. Camb. Phil. Soc., 1909, Vol. 15, pp. 137-168.

30. Wheldale, M., and Bassett, H. Ll. The Flower Pigments of Antirrlinum majus. II. The Pale Yellow or Ivory Pigment. Biochem. J., 1913, Vol. 7, pp. 441-444.

31. Wheldale, M., and Bassett, H. Ll. The Flower Pigments of Antirrhinum majus. III. The Red and Magenta Pigments. Biochem. J., 1914, Vol. 8, pp. 204-208.

32. Wheldale, M., and Bassett, H. Ll. The Chemical Interpretation of some Mendelian Factors for Flower-Colour. Proc. R. Soc., 1914, B Vol. 87, pp. $300-311$.

33. Willstätter, R. Ueber die Farbstoffe der Blïten und Frïchte. SitzBer. Ak. Wiss., 1914, pp. 402-411.

34. Willstätter, R., und Bolton, E. K. Ueber den Farbstoff der Scharlachpelargonie. Liebigs A hn. Chem., 1915, Vol. 408, pp. 42-61.

35. Willstätter, R., und Everest, A. E. Ueber den Farbstoff' der Kornblume. Liebigs Ann. Chem., 1913, Vol. 401, pp. 189-232. 
36. Willstätter, R., und Mallison, H. Ueber die Verwandtschaft der Anthocyane und Flavone. SitzBer. Ak. Wiss., 1914, pp. 769-777.

37. Willstätter, R., und Mallison, H. Ueber den Farbstoff' der Preiselbeere. Liebigs Ann. Chem., 1915, Vol. 408, pl. 15-41.

38. Willstätter, R., und Mallison, H. Ueber Variationen der Blittenfarben. Liebigs Ann. Chem., 1915, Vol. 408, pp. 147-162.

39. Willstätter, R., und Martin, K. Ueber den Farbstoff der Althaea rosea. Liebigs Ann. Chem., 1915, Vol. 408, pp. 110-121.

40. Willstätter, R., und Mieg, W. Ueber ein Anthoeyan des Rittersporns. Liebigs Ann. Chem., 1915, Vol. 408, pp. 61-82.

41. Willstätter, R., und Mieg, W. Ueber den Farbstoff der wilden Malve. Liebigs Ann. Chem., 1915, Vol. 408, pp. 122-135.

42. Willstätter, R., und Nolan, T. J. Ueber den Farbstoff der Rose. Liebigs Ann. Chem., 1915, Vol. 408, pp. 1-14.

43. Willstätter, R., und Nolan, T. J. Ueber den Farbstoff der Päonie. Liebigs Ann. Chem., 1915, Vol. 408, pp. 136-146.

44. Willstätter, R., und Weil, F. J. Untersuchungen über Anthocyane. Liebigs Ann. Chem., 1916, Vol. 412, pp. 113-251.

45. Willstätter, R., und Zechmeister, L. Synthese des Pelargonidins. SitzBer. Ak. Wiss., 1914, pp. 886-993.

46. Willstätter, R., und Zollinger, E. H. Ueber die Farbstoffe der Weintraube und der Heidelbeere. Liebigs Ann. Chem., 1915, Vol. 408, pp. 83-109.

47. Willstätter, R., und Stoll, A. Ueber Peroxydase. Liebigs Ann. Chem., 1918, Vol. 416, pp. 21-64. 


\section{CHAPTER VIII}

\section{THE PROTEINS AND PROTEASES}

No class of compounds is of more fundamental significance than the proteins. The matrix of protoplasm largely consists of proteins in the colloidal state, and, without doubt, they occur to some extent in the same condition in the cell-sap. They are also found in the cell in the solid state, in the form of either amorphous granules, termed aleurone, or crystalline or semi-crystalline bodies, termed crystalloids. Both solid forms constitute "reserve material" and are often found in seeds, tubers, bulbs, buds and roots.

Plant proteins may be classified on the following plan:

1. The simple proteins.
(a) Albumins.
(b) Globulins.
(c) Prolamins (Gliadins).
(d) Glutelins.

2. Conjugated proteins.

(a) Nucleoproteins.

3. Derived proteins.

(a) Metaproteins.

(b) Proteoses (Albumoses).

(c) Peptones.

(d) Polypeptides.

Although they are present in every cell in all parts of plants, little, however, is known of plant proteins, except of those in seeds, because of the difficulties of obtaining them in sufficiently large quantities, and of separating them from each other.

Proteins are in the colloidal state when in so-called solution, and are unable to diffuse through parchment membranes. The proteoses and peptones, however, which have simpler molecules, can diffuse through such membranes.

The vegetable proteins are soluble in various solvents according to the nature of the protein; some are soluble in water, others in dilute salt solutions, others, again, in dilute alkalies, and a few in dilute alcohol. Vegetable albumins are coagulated from solution on boiling, 
but most of the globulins, unlike the corresponding animal products, are only imperfectly coagulated on heating and some not at all. The precipitate formed when coagulation is complete will not go into solution again either in water, acid, alkali or salts. Alcohol precipitates the proteins; in the case of animal proteins, the precipitate becomes coagulated and insoluble if allowed to remain in contact with the alcohol, but this does not appear to be so with plant proteins.

In addition, certain neutral salts, the chlorides and sulphates of sodium, magnesium and ammonium, have the property of precipitating proteins (except peptones) from solution when added in sufficient quantity. The protein is quite unchanged in precipitation and can be made to go into solution again. The various proteins are precipitated by different concentrations of these salt solutions (see p. 124).

The salts of calcium and barium and the heavy metals produce insoluble precipitates with the proteins, and in this case the reaction is irreversible.

In regard to chemical composition, the proteins contain the elements carbon, hydrogen, nitrogen, oxygen and sulphur. There is every reason to believe that the protein molecule is constituted of amino-acids condensed, with elimination of water, on the plan which may be depicterl as follows :
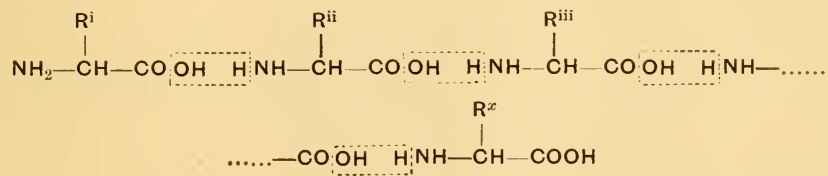

Conversely, when the proteins are acted upon by hydrolyzing enzymes, a series of hydrolytic products are formed which have smaller molecules than the original proteins. They may be enumerated as:
1. Albumoses.
2. Peptones.
3. Amino-acids.

In the same way when proteins are boiled with acids, a number of the amino-acids are obtained as an end-product.

The above amino-acids may be either aliphatic or aromatic, and they are characterized by having one or more hydrogen atoms, other than those in the carboxyl groups, replaced by the group $-\mathrm{NH}_{2}$. Thus they are acids by virtue of the carboxyl groups, and bases by virtue of the $-\mathrm{NH}_{2}$ groups: towards strong acids they act as bases, and towards 
strong bases as acids. The amino-acid, alanine, for instance, forms salts, sodium amino-propionate with a base, and alanine hydrochloride with an acid :<smiles>CC(N)C(=O)ON</smiles><smiles>CC(N)C(=O)O</smiles>

Substances behaving in this way have been termed "amphoteric" electrolytes (see also p. 15).

In the proteins, which are formed by condensation, as explained above, there are always some $\mathrm{NH}_{2}$ and $\mathrm{COOH}$ groups left uncombined. Hence a protein must, in the same way, have the properties of both an acid and a base.

The amino-acids which are obtained by the hydrolysis of plant proteins may be classified as follows:

\section{Aliphutic compounds.}

Mono-carboxylic mono-amino acids :

Glycine or $a$-amino-acetic acid

$$
\mathrm{CH}_{2}\left(\mathrm{NH}_{2}\right) \cdot \mathrm{COOH}
$$

Alanine or a-amino-propionic acid

$$
\mathrm{CH}_{3} \cdot \mathrm{CH}\left(\mathrm{NH}_{2}\right) \cdot \mathrm{COOH}
$$

Valine or $\boldsymbol{a}$-amino-iso-valeric acid<smiles>CC(C)C=NC(=O)O</smiles>

Leucine or $a$-amino-iso-caproic acid<smiles>CC(C)CC(N)C(=O)O</smiles>

Iso-leucine or $a$-amino- $\beta$-methyl- $\beta$-ethyl-propionic acid

$$
\mathrm{C}_{2} \mathrm{H}_{5}>\mathrm{CH} \cdot \mathrm{CH}\left(\mathrm{NH}_{2}\right) \cdot \mathrm{COOH}
$$

Serine or a-amino- $\beta$-hydroxy-propionic acid

$$
\mathrm{CH}_{2} \mathrm{OH} \cdot \mathrm{CH}\left(\mathrm{NH}_{2}\right) \cdot \mathrm{COOH}
$$

Dicarboxylic mono-amino acids :

Aspartic acid or a-amino-succinic acid

$$
\mathrm{COOH} \cdot \mathrm{CH}_{2} \cdot \mathrm{CH}\left(\mathrm{NH}_{2}\right) \cdot \mathrm{COOH}
$$

Glutaminic acid or a-amino-glutaric acid

$$
\mathrm{COOH} \cdot \mathrm{CH}_{2} \cdot \mathrm{CH}_{2} \cdot \mathrm{CH}\left(\mathrm{NH}_{2}\right) \cdot \mathrm{COOH}
$$


Mono-carboxylic di-amino acids:

Arginine or $\delta$-guanidine-a-amino-valeric acid<smiles>N=C(N)NCCCCNCC(=O)O</smiles>

Lysine or a- $\epsilon$-di-amino-caproic acid

$$
\mathrm{CH}_{2}\left(\mathrm{NH}_{2}\right) \cdot \mathrm{CH}_{2} \cdot \mathrm{CH}_{2} \cdot \mathrm{CH}_{2} \cdot \mathrm{CH}\left(\mathrm{NH}_{2}\right) \cdot \mathrm{COOH}
$$

Dicarboxylic di-amino acid :

Cystine (dicystëine) or di- $\beta$-thio- $\alpha$-amino-propionic acid

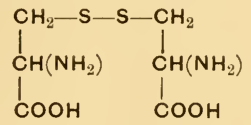

Aromatic compounds.

Mono-carboxylic mono-amino acids :

Phenyl-alanine or $\beta$-phenyl- $a$-amino-propionic acid

$$
\mathrm{C}_{6} \mathrm{H}_{5} \cdot \mathrm{CH}_{2} \cdot \mathrm{CH}\left(\mathrm{NH}_{2}\right) \cdot \mathrm{COOH}
$$

Tyrosine or $p$-hydroxy-phenyl-alanine

$$
\mathrm{OH} \cdot \mathrm{C}_{6} \mathrm{H}_{4} \cdot \mathrm{CH}_{2} \cdot \mathrm{CH}\left(\mathrm{NH}_{2}\right) \cdot \mathrm{COOH}
$$

\section{Heterocyclic compounds.}

Proline or a-pyrrolidine-carboxylic acid<smiles>O=C(O)C1CCCN1</smiles>

Histidine or $\beta$-iminazole-alanine

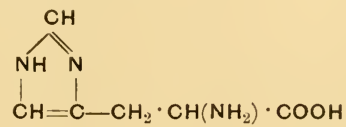

Tryptophane or $\beta$-indole-alanine $\mathrm{C}_{8} \mathrm{H}_{6} \mathrm{~N} \cdot \mathrm{CH}_{2} \cdot \mathrm{CH}\left(\mathrm{NH}_{2}\right) \cdot \mathrm{COOH}$<smiles>NC(Cc1c[nH]c2ccccc12)C(=O)O</smiles>

Different proteins are formed by various combinations of the above acids and hence give different amounts on hydrolysis.

There are certain properties and chemical reactions by means of 
which proteins can be detected. These are illustrated in the following experiment.

Expt. 121. Tests for proteins. Weigh out about $10 \mathrm{gms}$. of dried peas (Pisum), grind them in a coffee-mill and then add 100 c.c. of water to the ground mass. Allow the mixture to stand for an hour. Filter, and make the following tests with the filtrate (see p. 133).

(a) The xanthoproteic reaction. To a few c.c. of the protein solution in a test-tube add about one-third of its volume of strong nitric acid. A white precipitate is formed (except in the case of proteoses, peptones, etc.). On boiling, the precipitate turns yellow, and may partly dissolve to give a yellow solution. Cool under the tap, and add strong ammonia till the reaction is alkaline. The yellow colour becomes orange. The precipitate is due to the fact that metaprotein (see p. 127) is formed by the action of acid on albumins or globulins, and this metaprotein is insoluble in strong acids. The yellow colour is the result of the formation of a nitro-compound of some aromatic component of the protein, such as tyrosine, tryptophane and phenylalanine.

(b) Millon's reaction. To a few c.c. of the protein solution adid about half its volume of Millon's reagent'. A white precipitate is formed. On warming, the precipitate turns brick-red, or disappears and gives a red solution. The white precipitate is due to the action of the mercuric nitrate on the proteins. The reaction is characteristic of all aromatic substances which contain a hydroxyl group attached to the benzene ring. The aromatic complex in the protein to which the reaction is due is tyrosine.

(c) The glyoxylic renction (Hopkins and Cole). To about 2 c.c. of protein solution add an equal amount of "reduced oxalic acid"?. Mix the solutions, and then add an equal volume of concentrated sulphuric acid, pouring it down the side of the tube. A purple ring forms at the junction of the two liquids. If the liquids are mixed by shaking the tube gently, the purple colour will spread throughout the solution. The substance in the protein molecule to which the reaction is due is tryptophane. If carbohydrates are present in the liquid to be tested, the colour is not good, owing to blackening produced by the charring with the strong sulphuric acid.

(d) The biuret reaction. To a few c.c. of the protein solution add an excess of sodium hydrate and a drop of a $1 \%$ solution of copper sulphate. A violet or pink colour is produced. The reaction is given by nearly all substances containing two CONH groups attached to one another, to the sime nitrogen atom, or to the same carbon atom. The cause of the reaction with proteins is the presence of one or more

1 This reagent is made by dissolving 30 c.c. of mercury in 570 c.c. of concentrated nitric acid and then adding twice its bulk of water. It contains mercurous and mercuric nitrates, together with excess of nitric acid and a little nitrous acid.

${ }^{2}$ Reduced oxalic acid is prepared as follows : (a) Treat 500 c.c. of a saturated solution of oxalic acid with $40 \mathrm{gms}$. of $2 \%$ sodium amalgam. When hydrogen ceases to be evolved, the solution is filtered and diluted with twice its volume of distilled water. The solution contains oxalic acid, sodium binoxalate and glyoxylic acid ( $\mathrm{COOH} \cdot \mathrm{CHO})$. (b) Put $10 \mathrm{gms}$. of powdered magnesium into a flask and just cover with distilled water. Add slowly 250 c.c. of saturated oxalic acid, cooling under the tap. Filter off the insoluble magnesium oxalate, acidify with acetic acid and dilute to a litre with distilled water. 
groupings formed by the condensation of the carboxylic group of an amino-acid with the amino group of another amino-acid (see p. 119).

(e) The sulphur reaction. Boil a few c.c. of the protein solution with some $40 \%$ sodium hydrate for two minutes, and then add a drop or two of lead acetate. The solution turns black. This reaction is due to the formation of sodium sulphide by the action of the strong alkali on the sulphur of the protein. On addition of the lead salt, a black precipitate of lead sulphide is formed. The sulphur in the protein molecule is mainly present as cystine.

For the following reactions, a protein solution free from other impurities is required. For this purpose take 40 gms. of ground peas, add to the meal about 200 c.c. $10 \%$ sodium chloride solution, and allow the mixture to stand, with occasional stirring, for 3-12 hrs. (see p. 134). Then filter off the extract, first through muslin, and, subsequently, through filter-paper. Put the extract to dialyze for 24 hrs. in a collodion dialyzer ${ }^{1}$ until the protein is well precipitated. (Toluol should be added to the liquid in the dialyzer.) Then filter off the protein. Reserve half, and dissolve the other half in about 50 c.c. of $5 \%$ sodium nitrate solution. With this solution (after reserving a portion for Expt. 123) make the following tests:

( $f$ ) Precipitation by alcohol. To a few c.c. in a test-tube, add excess of absolute alcohol. The protein is precipitated.

(g) Precipitation by the heavy metals. Measure ont a few c.c. of the protein solution into three test-tuhes, and add respectively a little (1) copper sulphate solution, (2) lead acetate solution, (3) mercuric chloride solution: the protein is precipitated in each case.

The following test cannot be demonstrated on the Pea protein, since carbohydrates are absent in this case. It can, however, be demonstrated in later experiments (see p. 130).

(h) Molisch's reaction. To a few c.c. of the protein solution add a few drops of a $1 \%$ solution of a-naphthol in alcohol. Mix, and then run in an equal volume of strong sulphuric acid down the side of the tube. A violet ring is formed at the junction of the two liquids. The reaction signifies the existence in the protein of a carbohydrate group which gives rise, on treatment with acid, to furfural. The latter then condenses with $a$-naphthol to give a purple colour (see also Expts. 38, 44, 46).

(i) Precipitation by salts of alkaline earth metals. To a few c.c. of the protein solution add a little barium chloride solution. A precipitate is formed on standing.

(j) Precipitation by neutral salts. Saturate a few c.c. of the protein solution with finely powdered ammonium sulphate. The protein is precipitated or "salted out."

Since from a neutral salt solution the pea globulin is precipitated by acid (see p. 125), the tests $(k)-(m)$ should be carried out with a solution of the protein in dilute acid. Dissolve, therefore, the remander of the solid pea globulin in about 40 c.c. of $10 \%$ acetic acid, filter, and make the following tests:

(k) Precipitation by tannic acid. Add a little tannic acid solution : the protein is precipitated.

1 The collodion solution is made by adding $75 \mathrm{c}$.c. of ether to $3 \mathrm{gms}$. of well-dried pyroxylin, allowing it to stand for 10-15 minutes and then adding 25 c.c. of absolute alcohol. The dialyzers are prepared by coating the inside of a large test-tube with the solution and then filling with water, after the film is sufficiently dried so as not to be wrinkled by touching with the finger. The sac can then be withdrawn from the tube. 
(l) Precipitation by Esbach's solution ${ }^{1}$. Add a little Esbach's solution: the protein is precipitated.

(m) Precipitation by phosphotungstic acid. Add a little $2 \%$ solution of phosphotungstic acid in $5 \%$ sulphuric acid: the protein is precipitated.

The substances used in the tests $(k)-(m)$ are termed "alkaloidal reagents" because they also cause precipitation of alkaloids (see Chap. $\mathrm{x}$ ).

We are now in a position to deal with the different groups of proteins in detail:

Albumins. Very few vegetable albumins have been investigated. They can be best defined as proteins which are soluble in water and are coagulated by heat. Animal albumins are distinguished by the fact that they are not precipitated by saturating their neutral solutions with sodium chloride or magnesium sulphate; nor are they precipitated by half-saturation with ammonium sulphate. This distinction cannot be applied to vegetable proteins, since some are precipitated by the above treatment. It is often not easy to determine whether a plant protein is an albumin, on account of the difficulty of removing traces of salts, acids or bases which cause solubility, and also of separating the albumins from the globulins with which they occur. Albumins are however probably widely distributed in plant tissues.

The best-known albumins are:

Leucosin, which occurs in the seeds of Wheat (Triticum vulgare), Rye (Secale cereale) and Barley (Hordeum vulgare).

Legumelin, which occurs in seeds of the Pea (Pisum sativum), Broad Bean (Vicia Faba), Vetch (Vicia sativa), Lentil (Ervum Lens) and some other Leguminous seeds.

Phaselin, which occurs in the Kidney-bean (Phaseolus vulgaris).

Ricin, which occurs in the Castor-oil Bean (Ricinus communis).

Expt. 122. Demonstration of the presence of an albumin (leucosin) in wheat or barley flour (see also Expts. 128 and 130). Weigh out $10 \mathrm{gms}$. of wheat or barley flour, add 100 c.c. of distilled water and allow to stand, with occasional stirring, for 2-6 hrs. Then filter off the solution. Slowly heat the solution to boiling, and note that a precipitate of coagulated protein is formed.

Globulins. These may be defined as the proteins which are insoluble in water but soluble in dilute salt solutions, the concentration. of the salt solution necessary for complete solution (see p. 125) varying with the salt or protein under consideration. It should be noted that, in making water-extracts of plant tissues, it may happen that globulins

1 Esbach's solution is prepared by dissolving $10 \mathrm{gms}$. of picric acid and $10 \mathrm{gms}$. of citric acid in water and making the solution up to a litre. 
pass into solution to some extent owing to the presence of inorganic salts in the tissues themselves. This has also already been illustrated in Expt. 121 in which an extract of the globulin of the Pea was obtained by treating ground Pea seeds with distilled water only.

It is characteristic of animal globulins that they are precipitated by saturation of their solutions with magnesium sulphate. Many of the vegetable globulins cannot be precipitated by the above means, though they are all, as far as tested, precipitated by sodium sulphate at $33^{\circ} \mathrm{C}$. Many also (like animal globulins) are precipitated by half-saturation with ammonium sulphate, though others are not precipitated until their solutions are nearly saturated with this salt [see Expt. $121(j)$ ].

Unlike animal globulins, vegetable globulins are, as a rule, only imperfectly coagulated by heat, even on boiling.

Expt. 123. Demonstration of the coagulation of globulin. Heat a few c.c. of the solution of dialyzed Pea globulin (from Expt. 121) in a test-tube. Note that the protein is largely precipitated, but the solution does not become quite clear.

One very important characteristic of the vegetable globulins is the ease with which a number of them can be obtained in crystalline form. This result may be achieved by dialyzing a salt solution of the globulin. The salt passes out through the membrane, and the protein is deposited in the form of crystals. An alternative method is to dilute the saline solution of globulin with water at $50-80^{\circ} \mathrm{C}$. until a slight turbidity appears. Then warm further until this goes into solution, and cool gradually, when the protein will separate in crystals. The globulin, edestin, from seeds of the Hemp (Cannabis sativa) crystallizes very readily (see Expt. 133) and crystals can also be obtained of the globulins from the seeds of the Brazil nut (Bertholletia excelsa) (see Expt. 136), the Flax or Linseed (Linum usitatissimum) (see Expt. 135), the Oat (Avena sativa) and the Castor-oil plant (Ricinus communis) (see Expt. 134); other globulins separate out on dialysis as spheroirls, sometimes mixed with crystals.

The solubilities of plant globulins are further complicated by the fact that some of these substances form acid salts which have different solubilities from the proteins themselves. Thus edestin is insoluble in water, but soluble in either dilute salt solution or acid. In the presence of acid it forms salts which are insoluble in dilute salt solutions. Thus edestin in dilute acid solution is precipitated by a trace of salt, or in dilute salt solution by a trace of acid (see Expt. 124). Legumin, on the other hand, from the Pea and other Leguninosae is soluble in water in 
the free state: combined with a small amount of acid as a salt, it is insoluble in water but soluble in neutral salt solution, that is, it has the solubilities of a globulin (see p. 134).

Expt. 124. The formation of salts by edestin. Grind up 5 gms. of sceds of the Hemp (Cannabis sativa) in a coffee-mill. Extract with 50 c.c. of warm (not above $60^{\circ}$ C.) $10 \%$ sodium chloride solution and filter. Add a drop of strong hydrochloric acid to the filtrate. Edestin chloride, which is insoluble in salt solutions, is precipitated. Filter and drain off all the liquid, and then suspend the precipitate in distilled water. Add 1 or 2 drops of hydrochloric acid carefully and stir till most or all of the precipitate goes into solution. Filter, and to the filtrate add a few drops of saturated sodium chloride solution. The edestin acid salt is again precipitated.

The following is a list of the principal known globulins (Osborne, 2):

Legumin, in seeds of .............. (Pea (Pisum sativum). Broad Bean (Vicia Faba). Vetch (Vicia sutiva). (Lentil (Ervum Lens).

Vignin, in seeds of ................ Glycinin, in seeds of .............

Phaseolin (crystalline), in seeds of

Conglutin, in seeds of Cow Pea (Vigna sinensis). Soy Bean (Glycine hispida). Kidney Bean (Phaseolus vulgaris). $\{$ Adzuki Bean (P. radiatus). Lima Bean (P. lunutus).

Lupin (Lupinus).

Vicilin, in seeds of Pea (Pisum sativum). Broad Bean (Vicia Faba). Lentil (Ervum Lens).

Corylin, in seeds of Hazel Nut (Corylus Avellana).

Amandin, in seeds of ............. (Almond (Prunus Amygdalus). Peach (P. Persica). Plum ( $P$. domestica). Apricot (P. Armeniaca).

Juglansin, in seeds of............. (European Walnut (Juglans regia). American Black Walnut (J. nigra). American Butter-nut (J. cinerea).

Excelsin (crystalline), in seeds of Edestin, in seeds of .............. Avenalin, in seeds of ............... Castanin, in seeds of ..............

Maysin, in seeds of ................. Tuberin, in tubers of .............. Brazil Nut (Bertholletia excelsa). Hemp (Cannabis sativa). Oat (Avena sativa). Sweet Chestnut (Castanea vulgaris).

Maize (Zea Mays). Potato (Solanum tuberosum). 
Crystalline globulins have also been isolated from the following seeds but have as yet no distinctive names: Flax (Linum usitatissimum), Squash (Cucurbita maxima), Castor-oil Bean (Ricinus communis), Coconut (Cocos nucifera), Cotton-seed (Gossypium herbaceum), Sunflower (Helianthus annuus), Radish (Raphanus sativus), Peanut (Arachis hypogaea), Rape (Brassica campestris) and Mustard (Brassica alba).

It will be seen that the majority of reserve proteins of seeds are globulins. It is probable that native and artificial crystalline proteins are identical in many cases.

Prolamins. These proteins are characterized by the fact that they are insoluble in water and dilute saline solutions, but are soluble in $70-90 \%$ alcohol. Such proteins are peculiar to plants, and are formed to a considerable extent in the seeds of cereals. The principal ones which have been isolated are:

Gliadin found in the seeds of Wheat (Triticum vulgare).

$\begin{array}{llll} & & & \text { Rye (Secale cereale). } \\ \text { Hordein } & " & " & \text { Barley (Hordeum vulgare). } \\ \text { Zein } & " & , & \text { Maize (Zea Mays). }\end{array}$

The properties of the gliadins are demonstrated in Expts. 128, 129, 130 and 131.

Glutelins. The proteins of this group are insoluble in water, dilute saline solutions and in alcohol, but they are soluble in dilute alkalies. Glutenin of wheat is the only well-characterized member of this class which has so far been isolated, though other cereals most probably contain similar proteins. A protein of this nature has also been obtained from seeds of Rice (Oryza sativa). The properties of the glutelins are demonstrated in Expts. 128, 129 and 131.

Nucleoproteins. Though these proteins probably form constituents of all cells, the only members of the class investigated are those of the wheat embryo. This has been possible since nuclei form a large proportion of the tissue of the embryo. They may be regarded as protein salts of nucleic acid, i.e. protein nucleates. On hydrolysis with acids or enzymes they split up into various proteins and nucleic acid. The nucleoproteins are also connected with the purins (see p. 164).

Metaproteins. These are hydrolytic products of albumins and globulins formed by the action of water or dilute acid or alkali. They are insoluble in water, strong mineral acids and all solutions of neutral salts, but are soluble in dilute acids and alkalies in the absence of any large amount of neutral salt. 
Expt.125. Reactions of metaprotein. Dissolve about $1 \mathrm{gm}$. of edestin (see Expt. 133) in 50 c.c. of a $2 \%$ hydrochloric acid and keep on a boiling water-bath for 2 hrs. Neutralize with dilute sodium carbonate solution. A copious precipitate of metaprotein separates out which is insoluble in water. Filter off the precipitate and wash. Make with it the following tests :

(a) Dissolve up some of the precipitate again in $0.4 \%$ hydrochloric acid. To portions of the solution add: (i) Dilute sodium carbonate : the metaprotein is precipitated again and redissolves in excess. (ii) Concentrated hydrochloric acid: the motaprotein is precipitated. (iii) Boil some of the acid solution. No coagulum is formed: the metaprotein is not precipitated by boiling when in solution, and can still be precipitated by neutralizing with sodium carbonate.

(b) Suspend some of the precipitate in water and boil. Cool and add $0.4 \%$ hydrochloric acid : the precipitate is now insoluble, since the metaprotcin is coagulated when boiled in suspension.

(c) To some of the precipitate suspended in water, add gradually saturated ammonium sulphate solution : the metaprotein is insoluble in all concentrations of the salt.

Proteoses (albumoses) and peptones. These substances are formed as products of hydrolysis by enzymes. When present in extracts from seeds, however, it is sometimes uncertain whether they formed original constituents of the seeds or resulted from hydrolysis.

As a result of the enzyme hydrolysis of proteins a mixture of various proteoses is usually produced (Chittenden and Mendel, 4) which can be separated by various methods, such as different solubilities in ammonium sulphate, alcohol, etc. The albumoses are soluble in water, salt solutions, dilute acids and alkalies. They are all precipitated by complete saturation with ammonium sulphate, and some by half-saturation with the same salt. On the whole, they give the general colour reactions of the proteins, and are precipitated by the protein precipitants, though some groups of proteoses show certain exceptions. Their solutions are not coagulated on boiling.

The peptones are the only proteins not precipitated by complete saturation with ammonium sulphate. They give the protein colour reactions and are precipitated by tannic acid and lead acetate.

Expt. 126. Separation and reactions of proteoses. Take $2 \mathrm{gms}$. of the globulin edestin (prepared as in Expt. 133) and put in a flask with 100 c.c. of $0.2 \%$ hydrochloric acid and warm until as much as possible of the edestin goes into solution. Then cool and add $0.5 \mathrm{gm}$. of commercial pepsin: add also a little toluol, shake and plug with cotton-wool. Leave in an incubator at $38^{\circ} \mathrm{C}$. for 4 days. (A control experiment should also be made with 100 c.c. of $0.2 \%$ hydrochloric acid and $0.5 \mathrm{gm}$. of pepsin. Since pepsin itself gives a biuret reaction, a control is necessary for comparison in the next experiment.) The preliminary changes in edestin hydrolysis are rapid, for it will be found that if the edestin solution is tested with sodium 
chloride solution even after 24 hours in the incubator, no precipitate will be given with sodium chloride, in contrast with the copious precipitate given on the addition of salt solution to the maltered acid solution of edestin (see also Expt. 124). After four days, the incubated mixture is neutralized with dilute sodium carbonate solution, filtered and saturated while boiling with solid ammonium sulphate. A precipitate of proteoses is formed, which can be gradually collected together as a sticky mass and removed with a glass rod. Dissolve the precipitate in some hot water, filter and make the following tests:

(a) Xunthoproteic reaction. Add a few drops of nitrie acid. It is characteristic of most proteoses that a precipitate is formed which disappears on heating and reappears on cooling. In the case of the proteoses from edestin, only a slight preeipitate may be given, but it is increased by adding a little sodiun chloride solution. The colour is intensified in the usual way by addition of ammonia.

(b) Millon's reaction. A positive result is given.

(c) Glyoxylic reaction. A positive result is given.

(d) Biuret reaction. A pink or pinkish-violet colour is given.

(e) Sulphur reaction. A positive result is given.

(f) Add a little tannic acid solution. A precipitate is formed.

(g) Add a drop of copper sulphate solution. A preeipitate is formed.

(h). Add a drop of strong acetic acid and then a comple of drops of potassium ferrocyanide. A precipitate is formed which disappears on heating and reappears on cooling.

(i) Boil some of the solution. No coagulum is formed.

Expt. 127. Detection of peptone. The saturated solution, from which the proteoses have been precipitated, is then filtered and to a measured quantity (about 5 c.c.) twice the volume of $40 \%$ sodium hydroxide is added and a drop of $1 \%$ eopper sulphate solution. A pink colour appears, due to the presence of peptone. A test should be made with the control solution eontaining hydrochloric acid and pepsin only. An adequate amount should be saturated with ammonium sulphate, filtered and 5 c.e. tested for peptone. The reaction is less marked than in the actual hydrolytic product. Concentrate the remainder of the peptone solution on a water-bath and pour off from the excess of ammonium sulphate crystals. Filter and make the following tests: (i) Xanthoproteic, (ii) Millon's, (iii) Glyoxylic, (iv) Tannic acid. A positive result is obtained in each case.

\section{The Seed Proteins of certain Plants.}

The proteins present in the seeds of certain genera and species, upon which special investigations have been made, may now be considered.

It should be borne in mind that there are always several proteins present in the seed. Some are reserve proteins of the cells of the endosperm or of the storage tissue of the cotyledons: others are proteins of the protoplasm and nuclei of the tissues of the embryo and of the endosperm. 


\section{ProteINS OF CEREALS (GRAMINACEAE).}

As far as investigations have gone it may be said that the starchy seeds of cereals are poor in albumins and globulins. The chief reserve proteins belong to the peculiar group of prolamins, and a considerable portion also consists of glutelins.

The grain of Wheat (Triticum vulgare) contains some proteose and a small percentage of an albumin, leucosin. A globulin occurs only in very small amount. The bulk of the protein consists of gliadin (a prolamin) and of glutenin (a glutelin). Nucleoproteins are present in the embryo, but there is no gliadin or glutenin (Osborne and Voorhees, 14).

Expt. 128. Extraction of the proteins of the Wheat grain. (a) Extraction of albumin (leucosin) and proteose. Take $100 \mathrm{gms}$. of white flour (the same quantity of wheat grains which have been ground in a coffee-mill may be used, but the extraction in this case is slower), put the ground mass in a large flask or beaker and add 250 c.c. of distilled water. Let the mixture stand for 1-4 hrs., shaking occasionally. Filter off some of the liquid, first through muslin and then on a filter-pump. Reserve the residue on the filter and test the filtrate for proteins [Expt. 121, $(\alpha)-(d)]$.

Boil a second portion of the filtrate (after adding a drop or two of acetic acid). A precipitate of the albumin, leucosin, is formed. Filter off this precipitate, cool the filtrate and make the protein tests again. All the above tests are given by the proteose in solution: in the case of the xanthoproteic, the precipitate disappears on heating and reappears on cooling (Expt. 126). Also make the following special test for proteoses (Expt. 126): Add a little potassium ferrocyanide solution and acetic acid. A white precipitate is formed which disappears on heating and reappears on cooling.

(b) Extraction of the globulin. Take the residue of ground wheat and drain on a filter-pump. Then extract with 250 c.c. of $10 \%$ sodium chloride solution for 12-24 hrs. Filter off, first through muslin, and then through paper on a filterpump. Put the extract to dialyze in a collodion dialyzer for 24 hrs. (toluol should be added to the liquid in the dialyzer). Filter off the precipitate, which will he very slight, and dissolve it in a little $10 \%$ sodium chloride. (Though so little globulin is present, the experiment is instructive for comparison with the large amount of globulin obtained from many other seeds.) Make the tests for protein [Expt. 121, $(\alpha)-(d)]$ with the solution (Millon's cannot be used on account of the presence of chlorides). Also try the effect of (i) boiling the sodium chloride solution : coagulation is not complete, (ii) adding a little acid: a precipitate is formed as in the case of edestin.

(c) Extraction of gliadin. Take the wheat residue, which has been filtered from the sodium chloride solution, and add 250 c.c. of $95 \%$ alcohol. Warm on a waterbath and filter. Evaporate the tiltrate, which contains gliadin, on a water bath (or better distil off the alcohol in vacuo). When reduced to about half its bulk, take a little of the filtrate and filter. Divide this filtrate into two parts in test-tubes. To one add water: to the other absolute alcohol. A white precipitate of gliadin is formed in each case, since it is insoluble in both water and strong alcohol, though soluble in dilute alcohol. The remainder of the gliadin extract is evaporated almost 
to dryness, and then poured into a large volume of distilled water. A milky precipitate of gliadin is formed which may be made to settle by adding a little solid sodium chloride and stirriug. Filter off the gliadin and dissolve in $10 \%$ acetic acid. With the solution make the tests for protein [Expt. 121, $(a)-(d)$ ].

(d) Extraction of glutenin. Take half the wheat residue from the alcoholie extraction, pound well in a mortar and extract again with warm alcohol and subsequently with water. The residue must be free from water- and alcohol-soluble proteins as they are also soluble in alkalies. Then extract the residue with $0.1 \%$ caustic potash solution. Filter off the extract which contains the glutenin. To a portion of the filtrate add $\frac{\mathrm{N}}{10}$ sulphuric acid drop by drop. A precipitate of glutenin is formed. Test the remainder of the filtrate for proteins [Expt. 121, $(\alpha)-(d)]$.

The gliadin of wheat has the peculiar property of combining with water to form a sticky mass which binds together the particles of glutenin, the whole forming what is termed gluten. It is this phenomenon which gives the sticky consistency and elastic properties to dough.

Expt. 129. To demonstrate the fact that gluten formation depends on the presence of gliudin. Take two small evaporating dishes. Fill one with ordinary flour. Fill the other with flour that has been extracted with $70 \%$ alcohol for two or three days. (The alcohol is allowed to stand on the wheat in the cold. It is then poured off, and more added, and the process repeated. The flour is now dried again, first in air, then in the steam-oven and finally is ground in a mortar.) A little water is added to each of the dishes and the flour worked up into a dough. This is then allowed to stand for half an hour. The dough consists of gluten (gliadin and glutenin) to which the starch adheres. Next take two beakers, fill with water, and over the top of each tie a muslin cover. Place the two samples of dough on the muslin on the two beakers, and rub gently with a glass rod. The starch will be washed away into the beakers. In the case of the normal flour a sticky mass of gluten will remain. In the other case there will be no gluten on account of the absence of gliadin. To the suspension of starch in the beaker add some iodine solution, and it will turn a deep blue-black colour.

In the Barley (Hordeum vulgare) grain, small percentages of an albumin, apparently identical with leucosin, and of a globulin, barley edestin, are present, together with some proteose. The main protein is a prolamin, hordein, very similar to, but not identical with, gliadin. There is no well-defined glutelin (Osborne, 9).

Expt. 130. Extraction of the proteins of the Barley grain. (a) Extraction of the albumin and proteose. Grind up 100 gms. of barley grains in a coffee-mill, or use preferably barley flour. Add 250 c.c. of distilled water to the ground meal, and allow the mixture to stand for 1-4 hrs. Filter off the extract, first through muslin and then through filter-paper. The extract will contain a small quantity of the albumin, leucosin, and proteose. With the filtrate make the tests for proteins [Expt. 121, (a)-(d)].

Boil a second portion of the filtrate. A white precipitate of the coagulated protein is formed. Filter off the precipitate, cool the filtrate containing the proteose 
and test for proteins. All the tests will be positive: in the case of the xanthoproteic, the precipitate disappears on heating and reappears on cooling, a characteristic of proteoses (Expt. 126). Make also the special test for proteoses: Add a little potassium ferrocyanide and acetic acid. A white precipitate is formed which disappears on heating and reappears on cooling.

(b) Extraction of the globulin. To the barley residue, after extraction with water, add 250 c.c. of $10 \%$ sodium chloride and allow the mixture to stand for 12-24 hrs. Filter first through muslin and then filter-paper, and put the extract to dialyze for $24 \mathrm{hrs}$. Filter off the precipitate of globulin which will have formed, and take it up into solution again in as small a quantity as possible of $10 \%$ sodium chloride. Make with the solution the following tests: (i) The usual (except Millon's) tests for proteins [Expt. 121, $(a)-(d)]$ : these will give positive results. (ii) Boil a little of the solution : imperfect coagulation will take place. (iii) Add a little acid: a precipitate is formed, as is usual with plant globulins.

(c) Extraction of the prolamin, hordein. The residue, after the sodium chloride extraction, is then extracted with 250 e.c. of warm $95 \%$ alcohol. Filter, and concentrate the filtrate on a water-bath (or better, distil in vacuo). After concentration, test a little filtered extract as follows: pour a few drops into (1) absolute alcohol, (2) distilled water. A white precipitate of hordein is produced in each case, since, like gliadin, it is insoluble in both strong aleohol and water, but soluble in dilute alcohol. Then pour the whole extract into a large volume of water. The protein is precipitated as a fine white suspension, but will settle out more readily if a little solid sodium chloride is added. Filter off the hordein, and dissolve in $1 \%$ acetic acid. Make the usual protein tests [Expt. 121, $(a)-(d)$ ] ; there will be a positive result in each case.

In the Rye (Secale cereale) grain there are small percentages of proteose, and of leucosin and edestin. The greater part of the protein is gliadin, said to be identical with that in wheat.

In the Maize (Zea Mays) grain there is apparently no true albumin, though there is some proteose. There are small quantities of globulin, but the greater part of the protein is a prolamin, termed zein, and a glutenin (Osborne, 10).

Expt. 131. Extraction of proteins of the Maize grain. (a) Extraction of proteins soluble in water. Grind up 100 gms. of maize grains in a coffee-mill, or preferably use maize meal. Add 250 c.c. of water and allow the mixture to stand 1-4 hrs. Filter off, first through muslin, and then filter-paper. The filtrate contains proteose and probably a little globulin which has gone into solution owing to the presence of salts in the seed. Make the usual tests for protein [Expt. 121, $(\alpha)-(d)]$.

Boil another portion of the filtrate. Some coagulation of protein will take place. Filter, cool the filtrate and test for protein [Expt. 121, $(a)-(d)]$. Positive results will be given by the proteose present. Make also the special test for proteoses: Add a little potassium ferrocyanide and acetic acid. A white precipitate is formed, which disappears on heating and reappears on cooling.

(b) Extraction of globulin. The residue, after water extraction, is next treated with about 250 e.c. of $10 \%$ sodium chloride solution for 12-24 hrs. Filter, first. 
through muslin, and then through filter-paper. Dialyze the extract for $24 \mathrm{hrs}$. Then filter off the precipitate of globulin which will have separated out, and dissolve in $10 \%$ sodium chloride. Make with the solution the following tests: (i) The usual (except Millon's) tests for proteins [Expt. 121, $(a)-(d)]$ : these will give positive results. (ii) Boil a little of the solution: imperfect coagulation takes place. (iii) Add a little acid: the protein is precipitated.

(c) Extraction of the prolamin, zein. The residuc after salt extraction is then extracted with 250 c.c. of hot $95 \%$ alcohol. Filter, and concentrate the filtrate, which contains the zein, on a water-bath (or, better, distil in vacuo). Pour a few drops of the concentrated extract into (1) absolute alcohol, (2) distilled water. As in the case of gliadin and hordein, a precipitate of zein will be formed. Then pour the whole extract, after evaporating to a small bulk, into excess of distilled water, and add a little solid sodium chloride. The precipitate of zein will slowly settle, and can be filtered off. Zein is not readily soluble in acids and alkalies. Hence Millon's and the xanthoproteic tests should be made on the solid material. Zein does not contain the tryptophane nucleus. To demonstrate this, the glyoxylic reaction should be made by shaking up some solid zein in reduced oxalic acid and adding sulphuric acid and mixing. No purple colour is formed.

(d) Extraction of glutenin. 'Take about half of the residue after the alcoholic extraction, pound in a mortar, and extract again with alcohol. Then extract the residue with $0 \cdot 1 \%$ caustic potash solution. Filter off the extract which contains the glutenin. To a portion of the filtrate add $\frac{\mathrm{N}}{10}$ sulphuric acid drop by drop. A precipitate of glutenin is formed. Test the remainder of the filtrate for proteins [Expt. 121, $(a)-(d)$ ].

\section{Proteins of Leguminous SEeds (LEGUMinosaE).}

In the Leguminosae, which are starchy seeds, the chief reserve proteins, as contrasted with those of cereals, are globulins. The various proteins occurring may be enumerated as:

Legumin. A globulin which forms the chief protein in the seeds of the Broad Bean (Vicia Faba), the Pea (Pisum sativum), the Lentil (Ervum Lens) and the Vetch (Vicia sativa). Legumin itself is soluble in water, but occurs as salts which are insoluble in water and soluble in saline solutions. Some portion can be extracted from the seed by water only.

Vicilin. A globulin occurring in smaller quantities than legumin and found only in the Pea, Bean and Lentil seeds.

Phaseolin. A globulin forming the bulk of the protein of the Kidney Bean (Plaseolus vulgaris).

Conglutin. A globulin forming the bulk of the protein in Lupin (Lupinus luteus) seeds. 
Legumelin. An albumin found in small quantities in the Pea, Broad Bean, Vetch and Lentil.

Phaselin. An albumin found in small quantity in the seeds of the Kidney Bean (Phaseolus vulgaris).

Small quantities of proteoses are found in most of the above seeds.

Expt. 132. Extraction of the proteins of the Pea (Pisum sativum) (Osborne and Campbell, 11, 12; Osborne and Harris, 13). As we have seen (Expt. 121), a certain amount of protein, including globulin, goes into solution when ground peas are extracted with water. A more complete method of extraction is as follows. Grind in a coffee-mill 20-30 gms. of peas, add to the ground mass 50-60 c.c. of $10 \%$ sodium chloride solution and allow the mixture to stand for 1-2 his. Then filter off' and saturate the filtrate with solid ammonium sulphate. The globulins, legumin and vicilin, are precipitated out. Filter off the precipitate, and then take up in dilute anmonium sulphate $\left(\frac{1}{100}\right.$ saturated) and add saturated ammonium sulphate in the proportion of 150 c.c. to every 100 c.c. of the solution ( $\frac{6}{10}$ saturation). The legumin is precipitated and can be filtered off. Saturate the filtrate with ammonium sulphate: the vicilin is precipitated and can be filtered off. Dissolve up a little of each precipitate in 10\% sodium chloride, and boil. The vicilin is coagulated, but the legumin is not. Then dissolve up the remainder of the precipitates in dilute ammonium sulphate, and test both the solutions for protein by the usual reactions [Expt. 121, $(a)-(d)$ ].

The albumin, legumelin, which occurs only in small quantities in the seeds, can be obtained by dialyzing a water extract of the ground peas until all the globulin is precipitated. On filtering and heating the filtrate, a coagulum of legumelin is formed.

\section{Proteins of Fat-CONTAINING SEEDS.}

Of the seeds which contain fat as a reserve material, those investigated have been found, in contrast to the cereals, to contain largely globulin as reserve protein. In many cases these globulins have been obtained in crystalline form after extraction from the plant.

The Hemp-seed (Cannabis sativa) contains one of the best-known crystalline globulins, namely edestin. Pure neutral edestin is insoluble in water but soluble in salt solutions. In the presence of acid, however, edestin forms salts which are insoluble in salt solutions. Hence a solution of edestin in sodium chloride is precipitated by even small quantities of acids, and, conversely, a solution of edestin in acid is precipitated by small quantities of salt (Osborne, 8 ).

Expt. 133. Extraction and crystullization of edestin from Hemp-seed. Take $50 \mathrm{gms}$. of hemp-seed and grind in a coffee-mill. Put the ground seed in a large evaporating dish and add 200 c.c. of $5 \%$ sodium chloride solution. Heat with a small flame and stir constantly. A thermometer should be kept in the dish, and the liquid must not rise above $60^{\circ} \mathrm{C}$. Filter off, in small quantities at a time, keeping the solution in the dish warm. On cooling, the edestin separates out from the filtrate more or less in 
crystals. To obtain better crystals, filter off the edestin that has been deposited, and pour the filtrate into a dialyzer; add a little toluol, and suspend the dialyzer in rumning water. As soon as it is cloudy, examine the dialyzed solution for crystals under the microscope. Add a little $5 \%$ sodium chloride solution to the original precipitate of edestin in the filter. Make with the filtrate the following tests: (i) The tests for proteins [Expt. 121, $(a)-(d)$, except Millon's]. (ii) Boil a little of the solution: it is imperfectly coagulated. (iii) Add a little acid: edestin chloride is precipitated.

In the Castor-oil seed (Ricinus communis) there is also present a globulin which can be obtained in a crystalline form by the method of Expt. 134. In addition, there is present an albumin, ricin, which has peculiar toxic properties (Osborne, 8 ).

A well-crystallized globulin can be obtained from the Linseed (Linum usitutissimum), and a globulin, excelsin, from the Brazil nut (Bertholletic excelsa) also in crystalline or semi-crystalline form. Similar globulins can be extracted from a number of other seeds, i.e. Coconut (Cocos nucifera), Sunflower (Helianthus annuus), Cotton-seed (Gossypium herbaceum), Mustard-seed (Brassica alba) and many others. The fat is first removed from the ground seed by ether or benzene; the residue is then extracted with dilute sodium chloride and the extract dialyzed.

Expt. 134. Extraction of the globulin from Ricinus. Weigh out about 50 gms. of Ricinus seeds, take off the testas and pound in a mortar. Extract the oil by the method given in Expt. 82. After extracting the oil, grind up the residue again in a mortar, and then treat it with about twice its bulk of $10 \%$ sodium chloride solution for 6-12 hrs. Filter successively through muslin and filter-paper and dialyze the filtrate. The globulin will be precipitated in semi-crystalline spheroids. When the bulk of the globulin has separated out, filter off the precipitate, and dissolve it in as dilute a sodium chloride solution as possible. Make the following tests with the solution: (i) The tests for proteins [Expt. 121, $(a)-(d)$, except Millon's]. (ii) Boil a little of the solution: the coagulation is not complete. (iii) Add a little hydrochloric acid: a precipitate is formed.

Expt. 135. Extraction of the globulin from Linseed (Osborne, 7, 8). Weigh out about $50 \mathrm{gms}$. of Linseed and grind it in a coffee-mill. Extract the oil as in Expt. 82. Treat the residue with about twice its bulk of $10 \%$ sodium chloride solution for 6-12 his. Then filter through muslin and filter-paper, and dialyze the filtrate. The globulin separates out in octahedra. Filter off the protein, and take up in dilute sodium chloride. Test the solution as in the ease of Ricinus globulin in the previous experiment.

Expt. 136. Extraction of the globulin (excelsin) from the Brazil nut (Osborne, 8). Weigh out about $100 \mathrm{gms}$. of the nut, free from the testas, and, after pounding in a mortar, extract the oil by the usual method. Then proceed as in the two previous experiments. The protein separates out in semi-crystalline spheroids. Filter off the precipitated excelsin, and dissolve in dilute sodium chloride solution. Make with it the tosts as for the globulins in the last two experiments. 


\section{The Anino-Acids.}

There is every reason to believe, since they always arise in hydrolysis of proteins, that amino-acids are universally distributed in the plant. It is, however, difficult to isolate and detect them, except in certain special cases, as, for instance, in germinating seeds when a large store of protein is being rapidly hydrolyzed and translocated. The following is a short account of the occurrence of some of the amino-acids in the free state (see also p. 120).

Valine has been isolated from seedlings of the Vetch (Vicia), Lupin (Lupinus) and Kidney Bean (Phaseolus). It is present in larger amounts in etiolated seedlings of Lupin than in the green plants.

Leucine is widely distributed. It has been isolated from seedlings of Vicia, Vegetable Marrow (Cucurbita), Lupinus, Pea (Pisum) and Goosefoot (Chenopodium). It has also been found in Phaseolus, Water Ranunculus (Ranunculus aquatilis), buds of Horse Chestnut (Aesculus Hippocastanum) and in small quantities in Potato tubers and other plants.

Isoleucine has been extracted from seedlings of Vicia sativa.

Aspartic acid. The amide of this acid, i.e. asparagin,

\section{$\mathrm{CONH}_{2} \cdot \mathrm{CH}_{2} \cdot \mathrm{CHNH}_{2} \cdot \mathrm{COOH}$}

is widely distributed in plants. It is present in shoots of Asparagus from which it derives its name. It has also been extracted in very considerable quantities from etiolated seedlings of Vicia, Lupin, and from various plants such as Potato, Dahlia, Garden Nasturtium (Tropaeolum), Cucurbita and Sunflower (Helianthus).

Glutaminic acid. The amide, again, of this acid, i.e. glutamine,

$$
\mathrm{CONH}_{2} \cdot \mathrm{CH}_{2} \cdot \mathrm{CH}_{2} \cdot \mathrm{CHNH}_{2} \cdot \mathrm{COOH}
$$

is widely distributed. It has been isolated from seedlings of Cucurbita, Lupinus, Helianthus, Castor-oil plant (Ricinus), Spruce Fir (Picea excelsa) and a number of Cruciferae.

Arginine has been isolated from seedlings of Lupinus, Cucurbitu, Vicia, and Pisum. It is especially abundant in the seellings of some Coniferae, i.e. Picea excelsa, Silver Fir (Abies pectinatu) and Scotch Fir (Pinus sylvestris). It also occurs in roots and tubers, as for instance in those of the Turnip (Brassicu campestris), Artichoke (Helianthus tuberosus), Chicory (Cichorium Intybus), Beet (Betu vulgaris), Potato and Dahlia, and in the inner leaves of the Cabbage (Brassica oleracea). 
Lysine has been isolated from seedlings of Lupinus, Vicia and Pisum. Also from the inner leaves of the Cabbage and tubers of the Potato.

Phenylalanine has been isolated from seedlings of Lupinus luteus, Vicia sativa and Phaseolus vulgaris.

Tyrosine is very widely distributed. It is present in seedlings of Vicia sativa, Cucurbita, Lupinus, Tropaeolum and tubers of Potato, Turnip, Dahlia, Beet and Celery. Also in berries of Elder (Sambucus), in Clover (Trifolium), Bamboo (Bambusa) shoots and other plants.

Proline has been isolated in very small quantities from etiolated seedlings of Lupinus albus.

Histidine has been isolated from seedlings of Lupinus and tubers of Potato.

Tryptophane has been isolated from seedlings of Lupinus albus and Vicia sativa.

\section{The Proteases.}

We have seen in the previous pages that proteins can be hydrolyzed artificially with the intermediate production of proteoses and peptones, and the final production of a number of amino-acids. There is no doubt that this process of hydrolysis takes place in the living plant, and it is believed that the converse process, the synthesis of these proteins from amino-acids, also takes place in the cell.

There is evidence that this hydrolysis of proteins is catalyzed by certain enzymes which have been termed proteases. On analogy with other enzymes, we may suppose that these enzymes also catalyze the synthesis of the proteins.

It seems highly probable that the proteases are of two types:

1. Pepsin-like enzymes, which catalyze the hydrolysis of proteins to peptones, and, in all probability, the reverse process.

2. Erepsin-like enzymes, which catalyze the hydrolysis of albumoses and peptones to amino-acids, and, in all probability, the reverse process.

We now turn to the evidence for the existence of proteases. In autolysis (see p. 19) the hydrolytic activity of many enzymes is uncontrolled, and in the case of the proteins, the amino-acids are formed as end-products. Amino-acids are rarely present in plants in sufficient quantity to be detected readily, at any rate in small quantities of material, but if the tissues are put to autolyze at temperatures of $38-40^{\circ} \mathrm{C}$., 
the amino-acids then accumulate and can be detected. Of all the aminoacids the one which is most readilyidentified is tryptophane. If the autolyzed product is boiled, acidified and filtered to remove the remaining proteins, and, to the filtrate, bromine is added, drop by drop, the formation of a pink or purple colour will indicate the presence of free tryptophane, and hence it may be assumed that protein-hydrolysis has taken place. Probably the formation of amino-acids in autolysis is a universal property of plant tissues, for tryptophane has been detected on antolysis of many different parts of plants. Examples are the germinating seeds of the Bean (Vicia Faba), Scarlet Runner (Phaseolus multiflorus), Pea (Pisum sativum), Lupin (Lupinus hirsutus) and the Maize (Zea Mays): and in ungerminated seeds of the above, though less readily. It is also said to be formed on autolysis of leaves of Spinach (Spinacia), Cabbage(Brassica), Nasturtium (Tropaeolum majus), Scarlet Geranium (Pelargonium zonale), Dahlia (Dahlia variabilis) and others: also of fruits of Melon (Cucumis Melo), Cucumber (Cucumis sativus), Banana (Musa sapientum), Tomato (Lycopersicum esculentum) and others: of bulbs of the Tulip (Tulipa), Hyacinth (Hyacinthus orientalis) and underground roots of Turnip (Brassica), Carrot (Daucus Carota) and Beet (Beta vulgaris) (Vines, 16-24; Blood, 3; Dean, 5, 6).

Expt. 137. The formation of tryptophane on autolysis of resting seeds. Grind up in a coffee-mill 15 gms. of Mustard (Brassica alba) seed. Transfer to a flask, and add 100 c.c. of distilled water and about 2 c.c. of toluol. Plug the mouth of the flask with cotton-wool and put in an incubator for 3 days. Then filter off the liquid, boil the filtrate and add a fow drops of acetic acid. Filter off any precipitate formed, cool the filtrate and add bromine water slowly and carefully drop by drop, shaking well after each drop. A pink or purple colour denotes the presence of tryptophanc. Excess of bromine will destroy the colour. Then shake up with a little amyl alcohol. The purple colour will be extracted by the anyl alcohol which will rise to the top of the water solution. A control experiment should be made using $10 \mathrm{gms}$. of seed which has been well boiled with water in an evaporating dish.

It has been assumed that the formation of amino-acids from proteins on autolysis is the outcome of two processes, the hydrolysis of proteins to peptones by pepsins, and the hydrolysis of peptones to amino-acids by erepsins.

The next point to be considered is the possibility of detecting these two classes of enzymes separately. If either the pulp, or water extract, of various plant tissues be added to peptone solution and allowed to incubate at $38^{\circ} \mathrm{C}$., tryptophane can be readily detected after a day or two. This has been found to be true for the tissues of many seeds, seedlings, roots, stems, leaves and fruits (such as those already mentioned 
above and others); the result indicates the wide distribution of an erepsin type of enzyme. The detection of this enzyme is facilitated by the addition of the artificial supply of peptone.

Expt. 138. The detection of erepsins in plants.

(a) In resting seeds. Grind up $10 \mathrm{gms}$. of seeds in a coffee-mill, and add 100 c.e. of water, $0.2 \mathrm{gm}$. of Witte's peptone and a little toluol. Incubate for 2-3 days. The following seeds may be used: Hemp (Cannabis sativa), Castor-oil (Ricinus communis), Pea (Pisum sativum), Scarlet Runner (Phaseolus multiflorus), Broad Bean (Vicia $F a b a)$ and fruit of Wheat (Triticum vulgare). Test for tryptophane. Controls should be made in these and the following cases.

(b) In germinating seeds. Take 10 germinating peas, pound in a mortar, add 100 c.c. of distilled water, $0.2 \mathrm{gm}$. of Witte's pejtone, and a little toluol. Inculate for 3 days. 'Test for tryptophane.

(c) In leaves. Pound up a small cabbage leaf, add 100 c.c. of water, $0 \cdot 2 \mathrm{gm}$. of Witte's peptone and a little toluol. Incubate for 3 days. Test for tryptophane.

(d) In roots. Pound up about $20 \mathrm{gms}$. of fresh earrot root. Add about 100 c.c. of water, $0.2 \mathrm{gm}$. of Witte's peptone and a little toluol. Incubate for 3 days. Test for tryptophane.

The pepsin type of enzyme is less readily detected. It has long been known that the pitchers of the Pitcher-plant (Nepenthes) secrete an enzyme which digests fibrin. A few other cases of protein-digesting enzymes are well known, such as the so-called "bromelin " from the fruit of the Pine-apple (Ananas sativus), "cradein " from the latex and fruit of the Fig (Ficus) and "papain" from the fruit and leaves of the Papaw Tree (Carica Papaya). Such enzymes were formerly termed "vegetable trypsins" as they were thought to be of the type of animal trypsin which, alone, hydrolyzes proteins to amino-acids. On analogy with the results of research with other enzymes, it seems likely that "papain," "cradein" and "bromelin" are all mixtures of pepsin and erepsin. In addition to these better known cases, it has also been stated that fibrin is digested by extracts or pounded pulp of the fruits of the Cucumber and the Melon, the "germ " (embryo) of Wheat, the bulbs of Tulip and Hyacinth, the seedlings of the Bean, Pea, Scarlet Runner, Lupin and Maize, and the ungerminated seeds of the Pea, Lupin and Maize. These have also been shown to contain erepsin.

A separation of pepsin from erepsin has been achieved in the case of the seeds of the Hemp (Cannabis sativa) by means of the different solubilities of the two enzymes in water and salt solutions.

Expt. 139. The extraction and the separation of the two enzymes, erepsin and pepsin, from Hemp-seed (Cannabis sativa) (Vines, 22). Weigh out $50 \mathrm{gms}$. of hemp-seed, grind it in a coffec-mill and extract with 250 c.c. of $10 \%$ sodium chloride solution. 
Allow the mixture to stand all night and then filter. Both operations should be carried out at as low a temperature as possible. Measure the filtrate, and add acetie acid to the extent of $0.2 \%$. A dense preeipitate is formed. Filter again, keeping as cool as possible.

The acid filtrate contains the erepsin, but not the pepsin. Measure out 40 c.c. into each of three small flasks, and add the following: (i) $0.2 \mathrm{gm}$. of Witte's peptone, (ii) the same, only boil the whole solution, (iii) $0 \cdot 2 \mathrm{gm}$. of carmine fibrin ${ }^{1}$. Add a little toluol to all three flasks, plug with cotton-wool, and incubate for three to four days. Test for tryptophane in flasks (i) and (ii); the first gives a marked reaction, the second little or no reaction. The fibrin in (iii) will remain unaltered.

The precipitate produced by the acetic acid is then washed on the filter twice with 100 c.c. of $10 \%$ sodium ehloride solution, containing $0.2 \%$ acetie acid, to remove traces of erepsin. The precipitate is then treated with about 70 c.e. of water, allowed to stand for a time, and then filtered. The filtrate is divided into three equal portions. Add the following respectively: (i) $0 \cdot 1 \mathrm{gm}$. of carmine fibrin, (ii) the same, but the solution is boiled, (iii) $0.2 \mathrm{gm}$. of Witte's peptone. Add a little toluol to all three flasks, plug with cotton-wool and incubate for 3-4 days. The fibrin will be seen to digest slowly in flask (i): (ii) will show no digestion, and (iii) will give no tryptophane reaction.

\section{REFERENCES}

Books

1. Abderhalden, E. Biochemisches Handlexikon, IV. Berlin, 1911.

2. Osborne, T. B. The Vegetable Proteins. London, 1909.

\section{PAPERS}

3. Blood, A. F. The Erepsin of the Cabbage (Brassica oleracea). J. Biolog. Chem., 1910-1911, Vol. 8, pp. 215-225.

4. Chittenden, R. H., and Mendel, L. B. On the Proteolysis of Crystallized Globulin. .J. Physiol., 1894, Vol. 17, pp. 48-80.

5. Dean, A. L. On Proteolytic Enzymes. I. Bot. Gaz., 1905, Tol. 39, pp. 321-339.

6. Dean, A. L. On Proteolytic Enzymes. II. Bot. Gaz., 1905, Vol. 40, pp. 121-134.

7. Osborne, T. B. Proteids of the Flax-seed. Amer. Chem. J., 1892, Vol. 14, pp. 629-661.

8. Osborne, T. B. C'rystallised Vegetable Proteids. Amer. Chem. J., 1892, Vol. 14, pp. 662-689.

9. Osborne, T. B. The Proteids of Barley. J. Amer. Chem. Soc., 1895, Vol. 17, Pl. 539-567.

1 Freshly washed and finely chopped fibrin is placed in carmine solution (1 gm. carmine, 1 c.c. of ammonia, 400 c.c. of water) for 24 hrs. Then strain off and wash in running water till washings are colourless. 
10. Osborne, T. B. The Amount and Properties of the Proteids of the Maize Kernel. J. Amer. Chem. Soc., 1897, Vol. 19, pp. 525-532.

11. Osborne, T. B., and Campbell, G. F. Proteids of the Pea. J. Amer. Chem. Soc., 1898, Vol. 20, pp. 348-362.

12. Osborne, T. B., and Campbell, G. F. The Proteids of the Pea, Lentil, Horse Bean and Vetch. J. Amer. Chem. Soc., 1898, Vol. 20, pp. 410-419.

13. Osborne, T. B., and Harris, I. F. The Proteins of the Pea (Pisum sativum). J. Biol. Chem., 1907, Vol. 3, pp. 213-217.

14. Osborne, T. B., and Voorhees, C. G. The Proteids of the WheatKernel. Amer. Chem. J., 1893, Vol. 15, p1. 392-471.

15. Reeves, G. A new Method for the Preparation of the Plant Globulins. Biochem. J., 1915, Vol. 9, pp. 508-510.

16. Vines, S. H. Tryptophane in Proteolysis. Ann. Bot., 1902, Vol. 16, pp. 1-22.

17. Vines, S. H. Proteolytic Enzymes in Plants. I. Ann. Bot., 1903, Vol. 17, pp. 237-264. II. Ibid. pp. 597-616.

18. Vines, S. H. The Proteases of Plants. I. Ann. Bot., 1904, Vol. 18, pp. 289-317.

19. Vines, S. H. The Proteases of Plants. II. Ann. Bot., 1905, Vol. 19, pp. 149-162.

20. Vines, S. H. The Proteases of Plants. III. Ann. Bot., 1905, Vol. 19, pp. 171-187.

21. Vines, S. H. The Proteases of Plants. IV. Amn. Bot., 1906, Vol. 20, pp. 113-122.

22. Vines, S. H. The Proteases of Plants. V. Ann. Bot., 1908, Vol. 22, pp. 103-113.

23. Vines, S. H. The Proteases of Plants. VI. Ann. Bot., 1909, Vol. 23, pp. 1-18.

24. Vines, S. H. The Proteases of Plants. VII. Ann. Bot., 1910, Vol. 24, pp. 213-222. 


\section{CHAP'TER IX}

\section{GLUCOSIDES AND GLUCOSIDE-SPLITTING ENZYMES}

Attention has been drawn to the fact (Chapters $\mathrm{v}$ and vir) that in the plant, compounds containing hydroxyl groups often have one or more of these groups replaced by the $\mathrm{C}_{6} \mathrm{H}_{11} \mathrm{O}_{5}$ - residue of glucose. Such compounds are termed glucosides. The substances in which this substitution most frequently occurs are of the aromatic class, and the glucosides may be regarded, on the whole, as ester-like compounds of carbohydrates with aromatic substances. The non-sugar portion of the glucoside may vary widely in nature, and may be, for instance, an alcohol, aldehyde, acid, phenol, flavone, etc. The sugar constituent is most frequently glucose, but pentosides, galactosides, mannosides and fructosides are also known. Sometimes more than one monosaccharide takes part in the composition of the glucoside. (These various relationships are shown in the accompanying table.) The inclusion of all glucosides in a class is in a sense artificial: the character held in common (with very few exceptions) is that, on boiling with dilute acids, or, by the action of enzymes, hydrolysis takes place, and the glucoside is split up into glucose (or other sugar) and another organic constituent. A number of compounds occurring as glucosides have already been dealt with, for example, the tannins and flavone, flavonol and anthocyan piginents, but, in these cases, the significance of the compounds lies rather in the nature of their non-sugar constituents than in the fact of their being glucosides.

There are, however, a number of glucosides which have been grouped together and are more readily classified in this way than in any other. Some of them, doubtless, have come into prominence as glucosides on account of their association with well-known and specific enzymes, as, for instance, the glucoside amygdalin associated with the enzyme emulsin, and the glucoside sinigrin with the enzyme myrosin.

The hydrolyzing enzymes are by no means always specific, for in vitro one particular enzyme may be able to hydrolyze several glucosides. Many glucoside-splitting enzymes have been described, though there is no reason to suppose that each glucoside is only acted upon by an enzyme specific to that glucoside. It is likely moreover that some of the different enzymes described will probably prove to be identical.

In some cases where more than one monosaccharide is attached to 
the glucoside, the different sugar groups are removed separately by different enzymes (see later, emulsin, p. 145).

The glucosides as a whole (except flavone, flavonol and anthocyan pigments) are colourless crystalline substances. When extracting them from the plant, it is usually necessary to destroy the accompanying enzyme by dropping the material into boiling alcohol or some other reagent (see autolysis, p. 19).

In Chapter $\mathrm{v}$ it has already been mentioned that $d$-glucose exists in two stereoisomeric forms, the $\alpha$ and the $\beta$ form.

It was also pointed out that the glucosides can be classed either as $\alpha$ - or $\beta$-glucosides, according to whether the $\alpha$ or the $\beta$ form of glucose combines with the non-glucose residue.

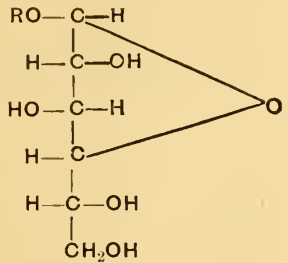

$a$-glucoside

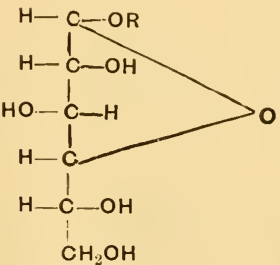

$\beta$-glucoside

Maltose, for instance, is regarded as an $\alpha$-glucoside of $d$-glucose. It has been further shown that the enzyme maltase can only hydrolyze $\alpha$-glucosides, whereas other enzymes, e.g. the prunase component of emulsin, only act on $\beta$-glucosides.

The various glucosides considered in detail in this chapter together with some others are grouped under the following headings (Armstrong, ;3):

Glucoside

Coniferin

Populin

Salicin

Syringin

Amygdalin

Dhurrin

Linamarin
Plant in which commonly found

(Coniferae, Beta, Asparagus, Scorzonera)

(Populus)

(Salix, Populus)

(Ligustrum, Syringa, Jasminum)

,
Products of hydrolysis

\section{Alcohols}

Glucose + coniferyl alcohol

Glucose + saligenin + benzoic acid

Glucose + saligenin

Glucose + syringenin

Aldehydes

Glucose + benzaldehyde + prussic acid

Glucose + parahydroxybenzaldehyde + prussic acid

Glucose + acetone + prussic acid 


\begin{tabular}{|c|c|}
\hline Glucoside & $\begin{array}{l}\text { Plant in which commonly } \\
\text { found }\end{array}$ \\
\hline Prulaurasin & (Prunus) \\
\hline Prunasin & (Cerasus, Prunus) \\
\hline Sambunigrin & (Sambucus) \\
\hline Vicianin & (Ticia) \\
\hline $\begin{array}{l}\text { Gaultherin } \\
\text { Strophanthin }\end{array}$ & $\begin{array}{l}\text { (Gaultheria, Spiraea) } \\
\text { (Strophanthus) }\end{array}$ \\
\hline $\begin{array}{l}\text { Arbutin } \\
\text { Hesperidin } \\
\text { Naringin } \\
\text { Phloridzin }\end{array}$ & $\begin{array}{l}\text { (Ericaceae) } \\
\text { (Citrus) } \\
\text { (Citrus) } \\
\text { (Rosaceae) }\end{array}$ \\
\hline $\begin{array}{l}\text { Aesculin } \\
\text { Fraxin }\end{array}$ & $\begin{array}{l}\text { (Aesculus) } \\
\text { (Fraxinus) }\end{array}$ \\
\hline Glucotropaeolin & (Tropaeolum, Lepidium) \\
\hline Sinalbin & (Brassica alba) \\
\hline Sinigrin & (Brassica nigra) \\
\hline $\begin{array}{l}\text { Apiin } \\
\text { Isoquercitrin } \\
\text { Lotusin } \\
\text { Myricitrin } \\
\text { Quercitrin } \\
\text { Robinin } \\
\text { Rutin }\end{array}$ & $\begin{array}{l}\text { (Carum) } \\
\text { (Gossypium) } \\
\text { (Lotus) } \\
\text { (Myrica) } \\
\text { (Quereus, Fraxinus, Thea) } \\
\text { (Kobinia) } \\
\text { (Ruta, Capparis, Polygonum) }\end{array}$ \\
\hline $\begin{array}{l}\text { Cyanin } \\
\text { Delphinin }\end{array}$ & $\begin{array}{l}\text { (Centaurea, Rosa) } \\
\text { (Delphinium) }\end{array}$ \\
\hline $\begin{array}{l}\text { Malvin } \\
\text { Oenin } \\
\text { Peonin } \\
\text { Pelargonin }\end{array}$ & $\begin{array}{l}\text { (Malva) } \\
\text { ('itis) } \\
\text { (Pueonia) } \\
\text { (Pelargonium, Centaurea) }\end{array}$ \\
\hline $\begin{array}{l}\text { Aucubin } \\
\text { Digitalin } \\
\text { Indican }\end{array}$ & $\begin{array}{l}\text { (Aucuba, Plantago) } \\
\text { (Digitalis) } \\
\text { (Indigofer } a)\end{array}$ \\
\hline
\end{tabular}

Products of hydrolysis

Aldehydes (cont.)

Glucose + benzaldebyde + prussic acid

Glucose + benzaldehyde + prussic acid

Glucose + benzaldehyde + prussic acid

Vicianose + benzaldehyde + prussic acid

\section{A cids}

Gilucose + methyl salicylate

Mannose + rhamnose + strophanthidin

\section{Phenols}

Glucose + hydroquinone

Glucose + rhamnose + hesperetin

Glucose + rhamnose + narigenin

Glucose + phloretin

\section{Coumarin derivatives}

Glucose + aesculetin

Glucose + fraxetin

\section{Mustard-oils}

Glucose + benzyl isothiocyanate + potassium hydrogen sulphate

G]ucose + sinapin acid sulphate+ acringlisothiocyanate

Glucose + allyl isothiocyanate + potassium hydrogen sulphate

\section{Flavone and fluronol pigments}

Apiose + apigenin

Glucose + quercetin

Glucose + prussic acid + lotoflavin

Rharnnose + myricetin

Rhamnose + quercetin

Rhamnose + galactose + kaempferol

Glucose + rhamnose + quercetin

\section{Anthocyan pigments}

Glucose + cyanidin

Glucose + oxybenzoic acid +delphinidin

Glucose + malvidin

Glucose + oenidin

Sugar + peonidin

Glucose + pelargonidiu

\section{Various constituents}

Glucose + aucubigenin

Glucose + digitalose + digitaligenin Glucose + indoxyl 


\section{Cyanophoric Glucosides.}

The characteristic of these substances is that they yicld prussic acid as one of the products of hydrolysis. They are fairly widely distributer: the following list (Greshoff, 15) includes most of the natural orders in which such glucosides occur: Araceae, Asclepiadaceae, Berberidaceae, Bignoniaceae, Caprifoliaceae, Celastraceae, Compositae, Convolvulaceae, Cruciferae, Euphorbiaceae, Graminaceae, Leguminosae, Linaceae, Myrtaceae, Oleaceae, Passifloraceae, Ranunculaceae, Rhamnaceae, Rosaceae, Rubiaceae, Rutaceae, Saxifragaceae, Tiliaceae and Urticaceae.

Amygdalin. This is one of the most important of the cyanophoric glucosides. It occurs in the seeds of the bitter Almond (Prumus Amygdalus) but it appears to be almost entirely absent from the sweet or cultivated Almond. It also occurs in the seeds of the other species of Prunus - the Plum (P. domestica), the Peach (P. Persica), etc.-of the Apple (Pyrus Malus) and the Mountain Ash (P. Aucuparia). It occurs sometimes in leaves, flowers and bark.

By the action of an enzyme, originally termed emulsin, which occurs in both the bitter and the sweet varieties of Almond, the glucoside is broken up as follows in two stages:

$$
\begin{aligned}
& \mathrm{C}_{20} \mathrm{H}_{27} \mathrm{NO}_{11}+\mathrm{H}_{2} \mathrm{O}=\mathrm{C}_{6} \mathrm{H}_{12} \mathrm{O}_{6}+{ }^{\mathrm{C}_{14} \mathrm{H}_{17} \mathrm{NO}_{6}} \text { mandelonitrile glucoside (prunasin) } \\
& \mathrm{C}_{14} \mathrm{H}_{17} \mathrm{NO}_{6}+\mathrm{H}_{22} \mathrm{O}=\mathrm{C}_{6} \mathrm{H}_{12} \mathrm{O}_{6}+\mathrm{HCN}+\underset{\text { benzaldehyde }}{\mathrm{C}_{6} \mathrm{H}_{5} \mathrm{CHO}}
\end{aligned}
$$

It should be noted that the sweet Almond contains emulsin although it is almost entirely free from amygdalin.

Recently (Armstrong, Armstrong and Horton, 8) emulsin has been shown to consist of two enzymes, amygdalase and prunase: amygdalase hydrolyzes amygdalin with formation of mandelonitrile glucoside and glucose, whereas prunase hydrolyzes mandelonitrile glucoside (prunasin) with formation of benzaldehyde, prussic acid and glucose. On the basis of these reactions amygdalin is represented as:

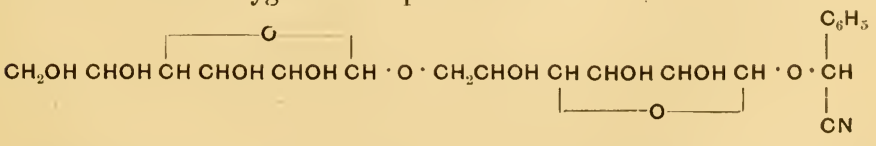

Prunasin occurs naturally in the Bird Cherry (Cerasus Padus), and it is found that prunase may exist in a plant, e.g. Cherry Laurel (P. Laurocerasus), which does not contain amygdalase. 
Prulaurasin (laurocerasin) is a glucoside occurring in the leaves of the Cherry Laurel (Prunus Laurocerasus). It has been represented as racemic mandelonitrile glucoside, prunasin being the dextro form.

Sambunigrin is a glucoside occurring in the leaves of the Elder (Sambucus nigra). It has been represented as laevo mandelonitrile glucoside.

When tissues containing cyanophoric glucosides and their corresponding enzymes are submitted to autolysis, injury, or the action of chloroform, hydrolysis takes place (see autolysis, p. 19). A rapid method (Mirande, 17; Armstrong, 5) for detecting the prussic acid is to insert paper dipped in a solution of sodium picrate into a tube containing the plant material together with a few drops of chloroform. In the presence of prussic acid the paper becomes first orange and finally brick-red owing to the formation of picramic acid.

In addition to those previously mentioned there are other British plants, the leaves of which give off prussic acid on autolysis (presumably from cyanophoric glucosides), as for example the Columbine (Aquilegia v'ulgaris), Arum (Arum maculatum), Hawthorn (Crataegus Oxyacantha), Reed Poa (Glyceria aquatica), Bird's-foot Trefoil (Lotus corniculatus), Alder Buckthorn (Rhamnus Frangula), Black and Red Currant and Gooseberry (Ribes nigrum, R. rubrum, R. Grossularia), Meadow Rue (Thalictrum aquilegifolium) and the Common and Hairy Vetches (Vicia sativa and $V$. hirsuta).

It has been shown (Armstrong, 7 ) that of the species $L$. corniculatus there is a variety (L. uliginosus) (taller and growing in moister situations) which does not produce cyanophoric substances and hence does not give off prussic acid on autolysis.

Expt. 140. Method of detection of cyunophoric glucosides in the plant. Take three flasks: in one put a whole leaf of the Cherry Laurel (Prunus Laurocerasus): in the second a leaf which has been torn in pieces and then either pricked with a needle or pounded in a mortar: in the third a leaf with a few drops of chloroform. Cork all three flasks, inserting with the corks a strip of sodium picrate paper. (The paper is prepared in the following way: strips of filter-paper are dipped in a $1 \%$ solution of picric acid, are then suspended on a glass rod and allowed to dry in air. Before using, the paper is moistened with $10 \%$ sodium carbonate solution and is suspended in the moist condition just above the matcrial to be examined. In the presence of prussic acid, the paper first becomes orange-yellow, then orange and finally brick-red.) In a short time the paper in the flask containing the leaf and chloroform will turn red : in the flask with the injured leaf, the reddening will take place rather more slowly, whereas in the case of the entire leaf, the paper will remain yellow.

The above experiment may also be carried out, usually with success, on leaves of 
the Columbine (Aquilegia vulgaris), the Arum (Arum maculatum) and plants of the Bird's-foot Trefoil (Lotus corniculatus): also with bitter almonds and apple pips, and young shoots of Flax (Linum perenne). In the case of the seeds, these may be used erushed, both with and without chloroform, the uninjured seed being used as a control.

Expt. 141. Preparation of amygdalin. Weigh ont $100 \mathrm{gms}$. of bitter alınonds. Remove the testas by immersing them for a short time in boiling water. Then pound up the almonds well in a mortar and transfer to a flask. Add abont 200-300 c.c. of ether and allow the mixture to stand for 2-12 hours. Filter off the ether and extract again with fresh ether. The greater part of the fat will be removed in this way. Then dry the residue from ether and, as rapidly as possible, extract twice or three times with boiling 90-98\% alcohol which removes the amygdalin. The residue, after ether extraction, contains both amygdalin and emulsin, and, if allowed to stand, the emulsin will hydrolyze the amygdalin: hence the necessity for rapid extraction with alcohol. Evaporate the filtered alcoholic extract on a waterbath or, better, distil in vacuo to a small bulk. Then add an equal volume of ether and allow the mixture to stand for a time. The amygdalin separates out on standing. Filter off the precipitate, dissolve in a little hot water and allow to crystallize in a desiccator.

Expt. 142. Preparation of emulsin (Bourquelot, 10). Weigh out $25 \mathrm{gms}$. of sweet almonds. (Bitter almonds can also be used. The sweet variety is preferable; since from them the emulsin can be more readily prepared free from amygdalin.) Plunge them for a moment into boiling water and remove the testas. Pound thoroughly in a mortar, and extract the bulk of the oil with ether as in the last experiment. Then grind up the residue with 50 c.c. of a mixture of equal parts of distilled water and water saturated with chloroform and allow the whole to stand for 24 hours. Filter by means of a filter-pump, and to the filtrate add glacial acetic acid ( 1 drop to 15 c.c. of the filtrate) whereby the protein is precipitated. Again filter, and to the filtrate add 3-4 times its volume of $96-98 \%$ alcohol. The emulsin is deposited as a white precipitate. Filter off the precipitate and dissolve it in about 100 c.c. of cold distilled water.

Expt. 143. (a) To demonstrate the hydrolysis of amygdalin by emulsin. Into each of two flasks put 50 c.c. of a 1-3\% solution of amygdalin. To one flask add 25 c.c. of the emulsin solution prepared in the last experiment. To the other flask add 25 c.c. of enzyme solution after it has been well boiled, and again boil the mixture after adding the enzyme. Fit each flask with a cork and sodium picrate paper. The paper in the flask containing the unboiled enzyme will rapidly turn red, the control remaining yellow. Unless both the enzyme and the amygdalin solution are well boiled in the case of the control, the paper may show reddening in time on account of traces of prussic acid present in both solutions.

(b) Simplified method for extraction of amygdalin and emulsin, and demonstration of hydrolysis of amygdalin by emulsin. Take 12 bitter almonds. Remove the testas by immersing them for a short time in boiling water. Then pound up the almonds well in a mortar and transfer to a flask. Add about 50 c.c. of alcohol and heat to boiling on a water-bath. Filter off the extract, and evaporate it to dryness on a water-bath. The residue will contain anygdalin. 
Take six sweet almonds and remove the testas as before. Pound in a mortar and transfer to a flask. Add a little ether and allow to stand for a short time. Pour off the ether, and add a little more which should again be poured off. This removes some of the fat and makes extraction of the emulsin easier. Then extract the residue with about 40 c.c. of distilled water and filter. The filtrate contains the enzyme emulsin.

Take 10 c.c. of the emulsin solution, and divide it into two portions in two testtubes. Boil one well (see Expt. $143 \alpha$ ), and to both add equal quantities of a water extract of the amygdalin prepared above. Cork the tubes and insert picric paper with the cork in each case.

It has been found, as previously mentioned, that emulsin can hydrolyze other glucosides, as for instance, salicin (see pp. 48, 15\%). On hydrolysis, salicin splits up into salicylic alcohol (saligenin) and glucose. Salicin, itself, gives no colour with ferric chloride but saligenin gives a violet colour, and by means of this reaction the course of the hydrolysis can be followed.

Expt. 144. To demonstrate the hydrolysis of salicin by emulsin. To 10 c.c. of a $1 \%$ solution of salicin in a test-tube add 10 c.c. of the emulsin solution prepared in Expt. 142 or 143. As a control boil in a second test-tube another 10 c.c. of the emulsin solution and add 10 c.c. of salicin solution. After about an hour, add to both test-tubes a few c.c. of strong ferric chloride solution. A purple colour will be given in the first test-tube but no colour in the control. The process of hydrolysis will be accelerated by placing the tubes in an incubator.

A modification can be made as follows. A second pair of test-tubes should be prepared as before and to both sufficient ferric chloride should be added to give a faint yellow tinge. The unboiled mixture will gradually acquire a purple colour at ordinary temperature.

Other cyanophoric glucosides are dhurrin, phaseolunatin (linamarin), lotusin and vicianin.

Dhurrin occurs in seedlings of the Great Millet (Sorghum vulgare). On hydrolysis it yields glucose, prussic acid and parahydroxybenzaldehyde $\left(\mathrm{C}_{6} \mathrm{H}_{4} \cdot \mathrm{OH} \cdot \mathrm{CHO}\right)$. It is hydrolyzed by emulsin.

Phaseolunatin occurs in seeds of the wild plants of Phaseolus lunatus and in seedlings of Flax (Linum). It is associated with an enzyme which hydrolyzes it into acetone, glucose and prussic acid.

Lotusin occurs in Lotus arabicus. On hydrolysis by an accompanying enzyme (lotase) it gives glucose, prussic acid and a yellow pigment, lotollavin.

Vicianin occurs in the seeds of a Vetch (Vicia angustifolia). It is hydrolyzed by an accompanying enzyme into prussic acid, benzaldehyde and a disaccharide, vicianose. 


\section{Mustard-oil Glucosides.}

These are glucosides containing sulphur and they have been found chiefly among the Cruciferae. Sinigrin and sinalbin, the glucosides of mustard, have been most investigated.

Sinigrin. This glncoside occurs in the seed of Black Mustard (Brassica nigra) and other species of Brassica. Also in the root of the Horse-radish (Cochlearia Armoracia). Sinigrin is hydrolyzed by the enzyme, myrosin (Guignard, 16; Spatzier, 18) (which occurs in the plant together with the glucoside), into allyl isothiocyanate, potassium hydrogen sulphate and glucose:

$$
\mathrm{C}_{10} \mathrm{H}_{16} \mathrm{O}_{9} \mathrm{NS}_{2} \mathrm{~K}+\mathrm{H}_{2} \mathrm{O}=\mathrm{C}_{3} \mathrm{H}_{5} \mathrm{NCS}+\mathrm{C}_{6} \mathrm{H}_{12} \mathrm{O}_{6}+\mathrm{KHSO}_{4}
$$

Expt. 145. Extrastion of sinigrin from Black Mustard. Weigh out $100 \mathrm{gms}$. of Black Mustard seed. Grind the seed in a coffee-mill and afterwards pound in a mortar. Heat 175 c.c. of $85 \%$ alcohol to boiling in a flask on a water-bath and add the pounded mustard, and after boiling about $\frac{1}{2}$ hour, filter and press out the alcohol. Then put the dried cake of residue into 300 c.e. of water and allow the mixture to stand for 12 hours. Press out the liquid and after filtering and neutralizing with barium carbonate, concentrate in vacuo to a syrup. Then extract with $90 \%$ alcohol and filter. On concentrating and exprosing in a crystallizing dish, the sinigrin separates out in white needles.

Sinalbin occurs in the seeds of White Mustard (Sinapis alba). By myrosin it is hydrolyzed to $p$-hydroxybenzylisothiocyanate, acid sinapin sulphate and glucose:

$$
\mathrm{C}_{30} \mathrm{H}_{42} \mathrm{O}_{15} \mathrm{~N}_{2} \mathrm{~S}_{2}+\mathrm{H}_{2} \mathrm{O}=\mathrm{C}_{6} \mathrm{H}_{12} \mathrm{O}_{6}+\mathrm{C}_{7} \mathrm{H}_{7} \mathrm{ONCS}+\mathrm{C}_{16} \mathrm{H}_{27} \mathrm{O}_{5} \mathrm{NHSO}_{4}
$$

Expt. 146. Extraction of sinalbin from White Mustard. Weigh out 100 gnns. of White Mustard seed. Grind and pound well and extract the fat with ether. Then extract with twice its weight of $85-90 \%$ alcohol several times and well press out the alcohol. The extract is evaporated to half its bulk and filtered. On cooling the sinalbin separates out in crystals.

Expt. 147. Preparation of myrosin. Weigh out $50 \mathrm{gms}$. of White Mustard seed and grind in a coffee-mill. Add 100 c.c. of water and allow the mixture to stand for 12 hours. Then filter and allow the filtrate to run into 200 c.c. of $95-98 \%$ alcohol. A white precipitate is formed which eontains the myrosin. Filter off the precipitate and wash on the filter with a little ether.

Expt. 148. Action of myrosin on sinigrin. Put into two test-tubes equal quantities of a solution of the sinigrin prepared in Expt. 145. Dissolve some of the myrosin prepared in the last experiment in water and divide the solution into two parts. Heat one part to boiling and then add the two portions respectively to the two testtukes of sinigrin. Plug both test-tubes with cotton-wool. After about $\frac{1}{2}$ hour a strong pungent smell of mustard oil, allyl isothiocyanate, will be detected in the unboiled tube.

A more simple method of demonstrating the action of myrosin is as follows. 
Pound about $5 \mathrm{gms}$. of Black Mustard seed in'a mortar and then boil with water. Some mustard oil will be formed before the myrosin is destroyed, so that boiling should be continued until no pungent odour can be detected. Then filter and cool the solution and divide into two parts. To one add some myrosin solution. To the other an equal quantity of boiled enzyme solution. After $\frac{1}{2}$ hour the smell of allyl isothiocyanate should be detected in the unboiled tube.

\section{SAPONINS.}

These substances are very widely distributed, being found in the orders: Araliaceae, Caprifoliaceae, Combretaceae, Compositae, Cucurbitaceae, Graminaceae, Guttiferae, Lecythidaceae, Leguminosae, Liliaceae, Loganiaceae, Magnoliaceae, Myrtaceae, Oleaceae, Piperaceae, Pittosporaceae, Polemoniaceae, Polygalaceae, Primulaceae, Proteaceae, Ranunculaceae, Rhamnaceae, Rosaceae, Rutaceae, Saxifragaceae, Thymelaeaceae and the majority of the orders of the cohort Centrospermae. On hydrolysis with dilute mineral acids the saponins yield various sugars-glucose, galactose, arabinose, rhamnose-together with other substances termed sapogenins.

The saponins are mostly amorphous substances readily soluble in water (except in a few cases) giving colloidal solutions. These solutions froth on shaking, and with oils and fats they produce very stable emulsions. By virtue of this property they have been used as substitutes for soap. The Soapwort (Saponaria) owes its name to the fact that the root contains a saponin.

\section{Coumarin Glucosides.}

These substances are hydroxy derivatives of coumarin, which itself , may be represented as:

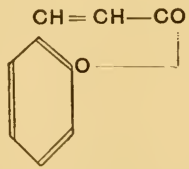

Aesculin is one of the best known of these glucosides. It occurs in the bark of the Horse Chestnut (Aesculus Hippocastanum). On hydrolysis with dilute acids it yields glucose and aesculetin, the latter being represented as:

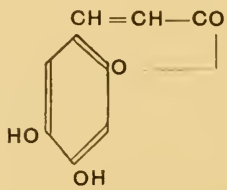


Aesculin is characterized by giving in water solution a blue fluorescence which can be detected even in great dilution. The fluorescence is increased in alkaline, and decreased in acid, solution.

Expt. 149. Demonstration of the presence of aesculin in Aesculus burk. Strip off the bark from some young twigs of Aesculus and boil in a little water in an evaporating dish. Filter and pour the filtrate into. excess of water in a large vessel. A blue flnorescent solution will le formed.

\section{Glucosides of Flavone, Flavonol and Anthocyan Pigments.}

These substances have already been considered in Chapter viI.

\section{Glucosides of various Composition.}

Coniferin. This glucoside occurs in various members of the Coniferae and also in Aspuragus. On hydrolysis with mineral acids or emulsin, it breaks up as:

$$
\underset{\text { Coniferin }}{\mathrm{C}_{16} \mathrm{H}_{22} \mathrm{O}_{8}}+\mathrm{H}_{2} \mathrm{O}=\mathrm{C}_{6} \mathrm{H}_{12} \mathrm{O}_{6}+\mathrm{OHCH}_{\text {OH }}^{\mathrm{O}} \mathrm{OCH}_{3}
$$

Arbutin. This glucoside is found in the leaves of the Bearberry (Arctostaphylos Uva-ursi), Pyrola, Vaccinium, and other Ericaceae and also of the Pear (Pyrus communis).

On hydrolysis with acids arbutin yields hydroquinone and glucose:

$$
\mathrm{C}_{12} \mathrm{H}_{16} \mathrm{O}_{7}+\mathrm{H}_{22} \mathrm{O}=\mathrm{C}_{6} \mathrm{H}_{6} \mathrm{O}_{2}+\mathrm{C}_{6} \mathrm{H}_{12} \mathrm{O}_{6}
$$

the same hydrolysis is brought about by the enzyme emulsin.

It has been suggested that the darkening of leaves of the Pear (Bourquelot and Fichtenholz, 11, 12,13) either on autolysis or injury, or at the fall of the leaf, is due to the hydrolysis of the arbutin by a glucoside-splitting enzyme in the leaf, and subsequent oxidation of the hydroquinone so formed by an oxidase.

Expt. 150. Extraction of arbutin from leaves of the Pear (Pyrus communis). Weigh out 100 gms. of fresh leaves (without petioles). Tear the leaves into small pieces and drop them as quickly as possible into about 500 c.c. of boiling $96-98 \%$ alcohol in a flask. Boil for about 20 mins., adding more alcohol if neeessary. Then filter off the alcohol and pound up the leaf residue in a mortar and extract again with 
boiling alcohol. Filter and distil off the alcohol from the extract in vacuo. Extract the residue with 100-200 c.c. of hot water and filter. Warm the filtrate and precipitate with lead acetate solution until no more precipitate is formed. This removes flavones, tannins, etc. but the arbutin is not precipitated. Filter and pass sulphuretted hydrogen into the filtrate to remove any excess of lead acetate. Filter and coneentrate the filtrate in vacuo to a syrup. Then extract twice with small quantities of ethyl acetate. Concentrate the ethyl acetate on a water-bath and cool. A mass of crystals of arbutin will separate out. This should be filtered off on a small filter, aud reerystallized from ethyl acetate. Take up a little of the purified glucoside in water and add a drop or two of ferric chloride solution. A blue coloration will be given.

Salicin. This substance occurs in the bark of various species of Willow (Salix) and Poplar (Populus): also in the flower-buds of the Meadow-Sweet (Spiraea Ulmaria). On hydrolysis with acids, or on treatment with emulsin, salicin is decomposed into saligenin or salicylic alcohol and glucose:

$$
\mathrm{C}_{13} \mathrm{H}_{18} \mathrm{O}_{7}+\mathrm{H}_{2} \mathrm{O}=\mathrm{C}_{6} \mathrm{H}_{4} \mathrm{OH} \cdot \mathrm{CH}_{2} \mathrm{OH}+\mathrm{C}_{6} \mathrm{H}_{12} \mathrm{O}_{6}
$$

Saligenin gives a violet colour with ferric chloride solution and in this way the progress of the reaction can be demonstrated (see also p. 148).

Indican (see also p. 115). This glucoside occurs in shoots of the so-called "Indigo Plants," Indigoferc Anil, I. erecta, I. tinctoria, I. sumatrana: also in the Woad (Isatis tinctoria), in Polygonum tinctorium and species of the Orchids, Phajus and Calanthe. When boiled with acid or hydrolyzed by an enzyme contained in the plant, it gives glucose and indoxyl:

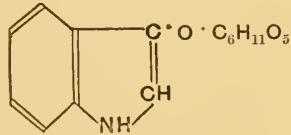

Indican

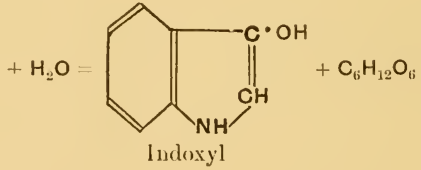

The colourless indoxyl can be oxidized either artificially or by an oxidase contained in the plant to a blue product, indigotin or indigo.

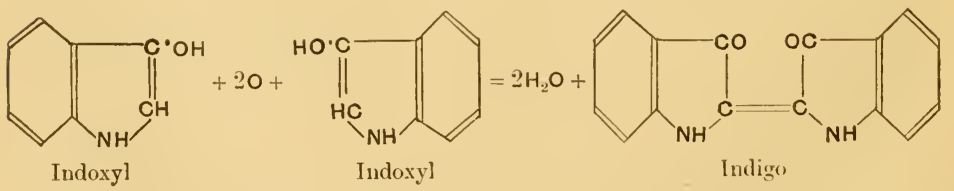




\section{REFERENCES}

Books

1. Abderhalden, E. Biochemisehes Handlexikon, II. Berlin, 1911.

2. Allen's Commercial Organic Analysis. Glueosides (E. F. Armstrong), Vol. 7, 1913, pp. 95-135.

3. Armstrong, F. F. The Simple Carbohydrates and the Glucosides. London, 1919. 3rd ed.

4. Van Rijn, J. J. I. Die Glykoside. Berlin, 1900.

PAPERS

5. Armstrong, E. F. The Rapid Detection of Emulsin. J. Physiol., 1910, Vol. 40, p. xxxii.

6. Armstrong, H. E., Armstrong, E. F., and Horton, E. Studies on Enzyme Action. XII. The Enzymes of Emulsin. Proc. R. Soc., 1908, B Vol. 80, pp. 321-331.

7. Armstrong, H. E., Armstrong, E. F., and Horton, E. Herbage Studies. I. Lotus corniculatus, a Cyanophorie Plant. Proc. R. Śoc., 1912, B Vol. 84, pp. 471-484. I1. Variation in Lotus corniculatus and Trifolium repens (Cyanophorie Plants). Proc. R. Soc., 1913, B Vol. 86, pp. 262-269.

8. Armstrong, H. E., Armstrong, E. F., and Horton, E. Studies on Enzyme Action. XVI. The Enzymes of Emulsin. Proc. R. Soc., 1912, B Vol. 85. (i) Prunase, the Correlate of Prunasin. pp. 359-362. (ii) Distribution of $\beta$-Enzymes in Plants. pp. 363-369. (iii) Linase and other Enzymes in Linaceae. 11). 370-378.

9. Armstrong, H. E., and Horton, E. Studies on Enzyme Action. XIII. Enzymes of the Emulsin Type. Proc. R. Soc., 1910, Vol. 82, pp. 349-367.

10. Bourquelot, E. Sur l'emploi des enzymes comme réaetifs dans les recherehes de laboratoire. J. pharm. chim., 1906, Vol. 24, 1p. 165-174; 1907, Tol. 25, pp. 16-26, 378-392.

11. Bourquelot, F., et Fichtenholz, A. Sur la présenee d'un glucoside dans les feuilles de poirier et sur son extraction. . J pharm. clim., 1910, Vol. 2, pp. 97-104.

12. Bourquelot, F., et Fichtenholz, A. Nouvelles recherches sur le glueoside des feuilles de poirier; son rôle dans la production des teintes automnales de ees organes. J. pharm. chim., 1911, Vol. 3, pp. 5-13.

13. Bourquelot, E., et Fichtenholz, A. Sur le glueoside des feuilles de poirier. C. R. Icad. sci., 1911, Vol. 153, pp. 468-471.

14. Dunstan, W., and Henry, T. A. The Chemical Aspeets of Cyanogenesis in Plants. Rep. Brit. Ass., 1906, pp. 145-157.

15. Greshoff, M. The Distribution of Prussie Acid in the Vegetable Kingdon. liep. Brit. Ass., 1906, 11. 138-144.

16. Guignard, L. Sur quelques propriétés chimiques de la myrosine. Bul. soc. bot., 1894, Vol. 41, pp. 418-428.

17. Mirande, M. Influence exereée par certaines vapeurs sur la cyanogenèse végétale. Procédé rapide pour la recherche des plantes à aeide eyauhydrique. C. R. Acad. sci., 1909, Vol. 149, pp. 140-142.

18. Spatzier, W. Ueber das Auftreten und die physiologisehe Bedentung des Myrosins in der PHanze. Juhrb. wiss. Bot., 1893, Vol. 25, pp. 39-77.

19. Winterstein, E., und Blau, H. Beiträge zur Kenntuis der Saponine. Zs. physiol. Chem., 1911, Vol. 75, 11. 410-442. 


\section{CHAPTER X}

\section{THE PLANT BASES}

THERE are present in plants a number of substances which form a group, and which may be termed nitrogen bases, or natural bases. These substances are of various constitution but they have the property in common of forming salts with acids by virtue of the presence of primary, secondary, or tertiary amine groupings. Such groupings confer a basic property upon a compound and, as a result, salts are former with acids on analogy with the formation of ammonium salts:

$$
\begin{aligned}
\mathrm{NH}_{3}+\mathrm{HCl} & =\mathrm{NH}_{4} \mathrm{Cl}\left(\mathrm{NH}_{3} \cdot \mathrm{HCl}\right) \\
\mathrm{CH}_{3} \mathrm{NH}_{2}+\mathrm{HCl} & =\mathrm{CH}_{3} \mathrm{NH}_{2} \cdot \mathrm{HCl} \\
\text { methylamine } & \\
\left(\mathrm{CH}_{3}\right)_{2} \mathrm{NH}+\mathrm{HCl} & =\left(\mathrm{CH}_{3}\right)_{2} \mathrm{NH} \cdot \mathrm{HCl} \\
\text { dimethylamine } & \\
\left(\mathrm{CH}_{3}\right)_{3} \mathrm{~N}+\mathrm{HCl} & =\left(\mathrm{CH}_{3}\right)_{3} \mathrm{~N} \cdot \mathrm{HCl} \\
\text { trimethylamine } &
\end{aligned}
$$

The hydrogen atoms of ammonia can also be replaced by groups of greater complexity, as will be seen below.

Complex ring compounds in which nitrogen forms part of the ring are termed heterocyclic, such as the alkaloids, purines and some amines, for instance pyrrolidine (see below).

The plant bases can be conveniently classified into four groups and this is also to a large extent a natural grouping. They are:
1. Amines
2. Betaines $\}$
Simpler natural bases.
3. Alkaloids.
4. Purine bases.

The first two groups have been termed the simpler natural bases. They are much more widely distributed in the vegetable kingdom than the alkaloids and purins, since they have probably much more significance in general metabolism. The isolation of the simpler bases is a matter of much greater difficulty than that of the alkaloids: the former are soluble in water but insoluble in ether and chloroform, and so are not readily separated from other substances. The alkaloids, however, occur in the plant as salts of acids and if the plant material is made alkaline the free bases can be extracted with ether or chloroform. 
The betaines are amino-acids in which the nitrogen atom is completely methylated, and, with one or two exceptions, this grouping does not occur in the true alkaloids. The betaines have only feebly basic properties.

The alkaloids, in contrast to the simpler natural bases, are rather restricted in their distribution, many being limited to a few closely related species or even to one species.

The purine bases are a small group of substances intimately related to each other and to uric acid.

\section{AMines.}

Methylamine, $\mathrm{CH}_{3} . \mathrm{NH}_{2}$, occurs in the Annual and Perennial Dog's Mercury (Mercurialis anmua and M. perennis) and in the root of the Sweet Flag (Acorus Calamus).

Trimethylamine, $\left(\mathrm{CH}_{3}\right)_{3} . \mathrm{N}$, occurs in leaves of the Stinking Goosefoot (Chenopodium Vulvaria), in flowers of the Hawthorn (Crataegus Oxyacantha) and Mountain Ash (Pyrus Aucuparia), and in seeds of Mercurialis annua.

Putrescine, $\mathrm{NH}_{2}\left(\mathrm{CH}_{2}\right)_{4} \cdot \mathrm{NH}_{2}$, occurs in the Thorn Apple (Datura) and tetramethylputrescine in a species of Henbane (Hyoscyamus muticus).

Hordenine occurs in germinating Barley grains. It is represented as:

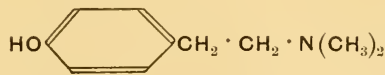

Pyrrolidine is said to occur in small quantities in leaves of the Carrot (Daucus Carota) and Tobacco (Nicotiana) leaves. It is represented as :<smiles>C1CCNC1</smiles>

Other amines occur among the lower plants (Fungi).

Choline is sometimes classified with the betaines. It is however intimately connected with the phosphatides (compounds of the fatty acids with phosphoric acid and nitrogen) which is not the case with the betaines. It may be represented as:

$$
\left(\mathrm{CH}_{3}\right)_{3} \vdots \mathrm{N}<_{\mathrm{CH}_{2} \cdot \mathrm{CH}_{2} \mathrm{OH}}^{\mathrm{OH}}
$$


Choline is very widely distributed in plants. It is a constituent of the phosphatide, lecithin, and is probably thereby a constituent of all living cells. It has been found in seeds of the Bean (Vicia Faba), Pea (Pisum sativum), Strophanthus, Oat (Avena sativa), Cotton (Gossypium herbaceum), Beech (Fagus sylvatica), Fenugreek (Trigonella Foenumgraecum) and Hemp (Camabis sativa): in seedlings of Lupins, Soy beans, Barley and Wheat: in Potatoes and Dahlia tubers and in the subterranean parts of Cabbage (Brassica napus), Artichoke (Helicenthus tuberosus), Scorzonera hispanica, Chicory (Cichorium Intybus), Celery (Apium graveolens) and Carrot (Daucus Carota): aerial parts of Meadow Sage (Sulvia prutensis) and Betony (Betonica officinalis), and many other tissues. It can only be isolated in very small quantity.

\section{Betaines.}

The betaines, as previously stated, are amino-acids in which the nitrogen atom is completely methylated. Most betaines crystallize with one molecule of water; thus betaine itself in this condition probably has the following constitution, from which its relationship to glycine or aminoacetic acid is indicated:

$$
\left(\mathrm{CH}_{3}\right)_{3}: \mathrm{N} \mathrm{CH}_{\mathrm{CH}_{2} \cdot \mathrm{COOH}}^{\mathrm{OH}}
$$

Betaine or hydroxytrimethylaminoacetic acid

\section{$\mathrm{H}_{2} \mathrm{~N} \cdot \mathrm{CH}_{2} \cdot \mathrm{COOH}$}

Aminoacetic acid

When dried above $100^{\circ} \mathrm{C}$., the betaines lose water and are represented as cyclic anhydrides; thus betaine becomes:<smiles>C[14C]1C[14C](=O)O1</smiles>

The individual betaines, probably on account of their close connexion with proteins, are more widely distributed than the individual alkaloids. Further investigation may show an even more general distribution of betaines.

Betaine or trimethylglycine occurs in all species of Chenopodiacene so far examined including the sugar Beet (Beta vulgaris) from which it derives its name; in some genera only of the Amarantaceae; in the "Tea Plant" (Lycium barbarum): in seeds of Cotton (Gossypium herbaceum), Sunflower (Helianthus annuus) and Oat (Avena sativa): in tubers of Artichoke (Helianthus tuberosus), shoots of Bamboo (Bumbusa), leaves of 'Tobacco (Nicotiana T'abacum) and in malt and wheat germs. 
Stachydrine, though a betaine, is included by most writers among the alkaloids, and this classification has been followed here (see p. 161); it is probably a derivative of proline (see p. 121).

Betonicine, $\mathrm{C}_{7} \mathrm{H}_{13} \mathrm{O}_{3} \mathrm{~N}$, is also, like stachydrine, found in the Betony (Betonica officinalis). It is a derivative of oxyproline.

Hypaphorine or trimethyltryptophane, $\mathrm{C}_{14} \mathrm{H}_{18} \mathrm{O}_{2} \mathrm{~N}_{2}$, occurs in the seeds of a tree, Erythrina Hypaphorus, which is grown for shade in Coffee plantations.

Trigonelline, like stachydrine, is usually classed with the alkaloids (see p. 160) but it should probably be included among the betaines on account both of its structure and of its wide distribution.

Other betaines, trimethylhistidine, ergothioneine, occur in the Fungi.

\section{Alkaloins.}

The plant alkaloids, so-called because of their basic properties, have attracted considerable attention on account both of their medicinal properties and, in many cases, their intensely poisonous character. They were also the plant bases to be first investigated. As previously mentioned they are not widely distributed, some being, as far as is known, restricted to one genus, or even species. Moreover, several closely related alkaloids are frequently found in the same plant. The orders in which they largely occur are the Apocynaceae, Leguminosae, Papaveraceae, Ranunculaceae, Rubiaceae and Solanaceae.

The alkaloids may be present in solution in the cell-sap in the young tissues, but in older and dead tissues they may occur in the solid state; they may be found throughout the plant or more abundantly in the seed, fruit, root or bark (quinine).

The alkaloids are, as a rule, insoluble in water, but soluble in such reagents as alcohol, ether, chloroform, etc. The majority are crystalline solids which are not volatile without decomposition, but a few, for example coniine, nicotine, which contain no oxygen, are volatile liquids.

The alkaloids occur in the plant as a rule as salts of various organic acids, such as malic, citric, succinic and oxalic, and sometimes with an acid peculiar to the alkaloid with which it is united (e.g. quinic acid in quinine and meconic acid in opium). Artificial salts, i.e. sulphates, chlorides and nitrates, are easily prepared and are readily soluble in water, and from these solutions the free base is precipitated again on addition of alkali. 
The alkaloids themselves belong to various classes of compounds, though the basic character always preponderates. Thus, for example, piperine is an amide and can be hydrolyzed into the base piperidine and piperic acid : atropine is an ester made up of the base tropine and tropic acid.

Various methods are employed for the extraction of alkaloids but the exact course of events depends on the alkaloid in question. On the whole the method is either to treat the plant material with alkali and then extract the free alkaloid with ether or chloroform and finally purify by making a salt again; or to extract the alkaloid from the plant with dilute acid, set free the insoluble, or difficultly soluble, base with alkali, and then prepare a salt of the base.

Though individual alkaloids have distinctive reactions, the group as a whole has certain reactions in common, namely the precipitation by the so-called "alkaloidal reagents." These reagents are tannic, phosphotungstic, phosphomolybdic and picric acids, also potassium-mercurioiodide solution and iodine in potassium iodide solution.

Expt. 151. General reactions of alkaloids. Make a $0.5 \%$ solution of quinine sulphate in warm water and add a few drops of each of the following reagents:

(a) Tannic acid solution. A white precipitate is formed.

(b) Mercuric iodide in potassinm iodide solution [Brïcke's reagent: $50 \mathrm{gms}$. of potassium iodide in 500 c.c. water are saturated with mercuric iodide (120 gms.) and made up, to 1 litre]. A white precipitate is formed.

(c) Phosphotungstic acid (50 gms. of phosphotungstic acid and 30 c.c. of conc. sulphuric acid are dissolved in water and made up to a litre). A white precipitate is formed.

(d) Iodine in potassium iodide solution. A brown precipitate is formed.

(e) Picric acid solution. A yellow precipitate is formed.

Expt. 152. Extraction of the free base from quinine sulphate. Add strong sodium carbonate solution drop by drop to some of the quinine sulphate solution until a white precipitate of quinine is formed. Then add ether and shake up in a separating funnel. The precipitate will disappear as the quinine passes into solntion in the ether. Separate off the ethereal solution and let it evaporate in a shallow dish. The quinine is deposited. Take up the quinine again in dilute sulphuric acid and test the solution with the alkaloidal reagents.

The alkaloids are classified into five groups according to the nucleus which constitutes the main structure of the molecule. These five groups are :

1. The pyridine group.

2. The pyrrolidine group.

3. The tropane group.

4. The quinoline group.

5. The isoquinoline group. 


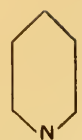

Pyridine

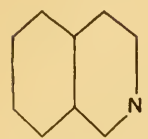

Isoquinoline

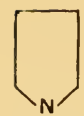

Pyrrole

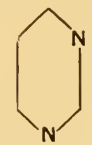

Pyrimidine

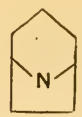

Tropane<smiles>C1CNCN1</smiles>

Iminazole

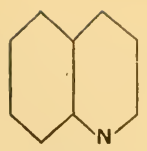

Quinoline

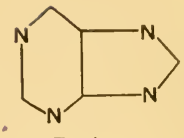

Purine

1. The pyridine alkuloids.

These are, as the name implies, derivatives of pyridine. (Pyridine is a colourless liquid which boils at $115^{\circ} \mathrm{C}$. It is a strong base and forms salts with acids.)

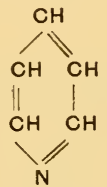

Pyridine

The more important members of this group are: arecoline, coniine, nicotine, piperine and trigonelline.

Arecoline occurs in the "Betel Nut" which is the fruit of the Areca Palm (Areca Catechu).

Coniine occurs in all parts of the Hemlock (Conium maculatum), but more especially in the seed.

Nicotine occurs in the leaves of the Tobacco plant (Nicotiana T'abacum). It is a colourless oily liquid which is intensely poisonous. Its constitution may be represented as :

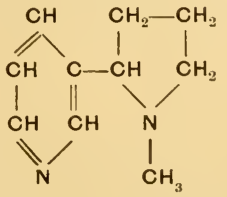

It is readily soluble in water and organic solvents. 
Expt. 153. Extraction and reactions of nicotine. Weigh out $100 \mathrm{gms}$. of plug tobacco and buil up the compressed leaves with water in an evaporating dish or in a saucepan. Filter off the extract and concentrate on a water-bath. The concentrated solution is made alkaline with lime and distilled from a round-bottomed flask fitted with a condenser, the flask being heated on a sand-bath. The distillate has an unpleasant smell and contains nicotine in solution. Test the solution with the alkaloidal reagents employed in Expt. 151. A precipitate will be obtained in each case.

The nicotine can be obtained from solution in the following way. Acidify the aqueous distillate with oxalic acid and concentrate on a water-bath. Make the concentrated solution alkaline with caustic soda, pour into a separating funnel and shake up with ether. Separate the ethereal extract and distil off the ether. The nicotine is left behind as an oily liquid which oxidizes in air and turns brown. The alkaloidal tests should be made again with the extracted nicotine.

Piperine occurs in various species of Pepper (Piper nigrum). The fruit, which is gathered before it is ripe and dried, yields a black pepper, but if the cuticle is first removed by maceration, a white pepper. Piperine is a white solid which is almost insoluble in water but soluble in ether and alcohol.

Expt. 154. Extraction and reactions of piperine. Weigh out 100 gms. of black pepper. Put it into an evaporating dish, cover well with lime-water and heat with constant stirring for 15-20 minutes. Then evaporate the mixture completely to dryness on a water-bath. Grind up the residue in a mortar, put it into a thimble and extract with ether in a Soxhlet. Distil off the ether and take up the residue in hot alcohol from which the piperine will crystallize out. With an alcoholic solution make the following tests:

(a) Add the alkaloidal reagents mentioned in Expt. 151 and note that a precipitate is formed in each case.

(b) Pour a little of the solution into water and note that the piperine is precipitated as a white precipitate.

(c) To a little solid piperine in a white dish add some concentrated sulphuric acid. It dissolves to form a deep red solution.

Trigonelline occurs in the seeds of the Fenugreek (Trigonella F'oenum-graecum), Pea (Pisum sativum), Bean (Phaseolus vulgaris), Strophanthus hispidus, Hemp (Cannabis sativa) and Oat (Avena sativa). It is also found in the Coffee Bean (Coffea arabica); in tubers of Stachys tuberifera, Potato and Dahlia and in roots of Scorzonera hispanica. It is really a betaine (see p. 157).

\section{The pyrrolidine alkaloids.}

These are derivatives of pyrrolidine, of which the mother substance is pyrrole. (Pyrrolidine is a liquid boiling at $91^{\circ} \mathrm{C}$. It is a strong base and forms stable salts with acids.) 


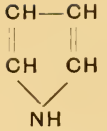

Pyrrole<smiles>C1CCNC1</smiles>

Pyrrolidine

These alkaloids form a small group containing:

Hygrine and cuskhygrine which occur in Coca leaves (Erythroxylon Coca).

Stachydrine which occurs in tubers of Stachys tuberifera and leaves of the Orange Tree (Citrus Aurantium) and in various other plants (Betonica). The formula is:

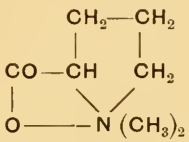

from which it is seen that it is really a betaine (see p. 157).

3. The tropane alkaloids.

These are derivatives of tropane, which may be regarded as formed from condensed piperidine and pyrrolidine groupings. (Tropane is a liquid boiling at $167^{\circ} \mathrm{C}$.)

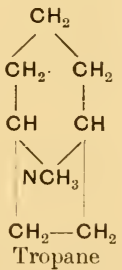

The alkaloids in this group are limited to four natural orders and are as follows:

Solanaceae: Atropine occurs in the root and other parts of the Deadly Nightshade (Atropa Belladonna), the Thorn Apple (Daturu Stramonium) and Scopolia japonica. Atropine may be represented as:

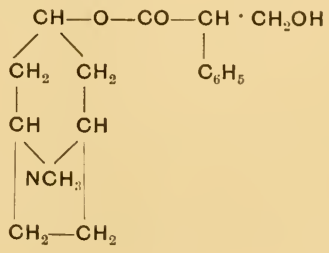

0. 
Hyoscyamine occurs in the Henbane (Hyoscyamus niger), $H$. muticus and also in the Mandrake (Mandragora).

Erythroxylaceae: Cocaine and tropacocaine occur in Coca leaves (Erythroxylon Coca) together with smaller quantities of allied alkaloids. Cocaine has the formula:

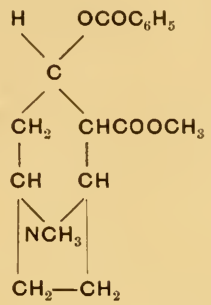

Punicaceae: Pelletierine and other allied alkaloids occur in the root and stem of the Pomegranate Tree (Punica Granatum).

Leguminosae: Sparteïne occurs in the Broom (Spartium scoparium): lupinine in the yellow and black Lupins (Lupinus luteus and L. niger) and cytisine in the Laburnum (Cytisus Laburnum).

4. The quinoline alkaloids.

These are derivatives of quinoline. (Quinoline is a colourless liquid which boils at $239^{\circ} \mathrm{C}$.) Its constitution is :<smiles>c1ccc2ncccc2c1</smiles>

These alkaloids form two natural groups, $(a)$ the cinchona alkaloids, i.e. quinine, cinchonine and allied forms, and $(b)$ the strychnine alkaloids, i.e. strychnine and brucine.

Quinine occurs in the bark of various species of the genus Cinchona (Rubiaceae) which are trees, originally natives of S. America, but now cultivated on a large scale in Ceylon, Java and India. The species employed are C. Calisaya, Ledgeriana, officinalis, succirubra. The yellow bark of Calisaya has the highest percentage, i.e. $12 \%$, of alkaloid.

Quinine is a white solid which crystallizes in long needles containing water of crystallization. It is very slightly soluble in cold water, more so in hot but readily soluble in alcohol, ether and chloroform. With 
acids it forms salts, which are soluble in water, the sulphate being commonly employed in medicine. Quinine is said to have the following constitution :

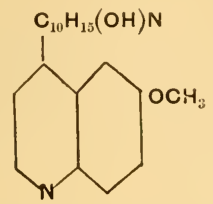

Expt. 155. Extraction and reactions of quinine. Mix 20 gms. of quicklime with 200 c.c. of water in a basin and then add 100 gms. of powdered Cinchona bark. Stir together well and then dry the mixture thoroughly on a water-bath, taking care to powder the lumps. The dried mixture is then extracted in a Soxhlet apparatus with chloroform. The chloroform extract is then shaken up in a separating funnel with 25 c.c. of dilute sulphuric acid. The chloroform layer is run off and again extracted with water. The sulphuric acid and water extracts are mixed together and neutralized with anmonia. The liquid is evaporated on a water-bath until crystals of quinine sulphate begin to separate out. With the quinine sulphate the following tests should - be made. (It is better to use a solution of the hydrochloride prepared by adding a few drops of hydrochloric acid to the sulphate solution):

(a) Test with the alkaloidal reagents of Expt. 151.

(b) Add to a little of the solution some bromine water and then some ammonia. A green precipitate is formed which gives a green solution with excess of ammonia.

(c) Dissolve a little of the solid quinine sulphate in acetic acid and pour into a large volume of water. A blue opalescence is produced which is characteristic of quinine.

Cinchonine occurs together with quinine in Cinchona bark. It is very sinilar in constitution to quinine, the latter being methoxycinchonine.

Strychnine and brucine occur in the seeds of Nux Vomica (Strychnos Nux-vomica) and St Ignatius' Bean (S. Ignatii).

Expt. 156. Tests for strychnine. Add a little concentrated sulphuric acid to a small quantity of strychnine in an evaporating dish and then add a small amount of powdered potassium bichromate. A violet coloration is produced which changes to red and finally yellow.

Curarine, the South American Indian Arrow poison, occurs in several species of Strychnos (S. toxifera and others).

5. The isoquinoline alkaloids.

These can be divided into two groups: $(a)$ the opium alkaloids and (b) the berberine alkaloids.

The opium alkaloids again fall into two classes: (1) the papaverine 
group which includes papaverine, laudanosine, narceine, narcotine and others, and (2) the morphine group including morphine, apomorphine, codeine, thebaine and others.

Opium is the dried latex obtained by making incisions in the capsules of the Opium Poppy (Papaver somiferum).

Allied to the papaverine group is hydrastine which occurs in the root of Hydrastis canadensis (Ranunculaceae).

The constitution of all these alkaloids is very complex.

Expt. 157. Tests for morphine.

(a) Add a little ferric chloride solution to a solution of a morphine salt. A deep blue coloration is formed.

(b) Dissolve some morphine in concentrated sulphuric acid and then after standing about 15 hrs. add concentrated nitric acid. A deep blue-violet colour is produced which afterwards changes to red.

Berberine occurs in the root of the Barberry (Berberis vulgaris) and is also found in isolated genera in Anonaceae, Menispermaceae, Papaveraceae, Ranunculaceae and Rutaceae.

Corydaline occurs in Corydalis cava (Fumariaceae).

Many other alkaloid substances have been isolated from a large number of different plants, but since the constitution of most of them is unknown, they have not been classified.

\section{Purine Bases.}

These substances, as indicated, have a heterocyclic ring structure and are derivatives of purine: the atoms of the ring are numbered in the order indicated below:

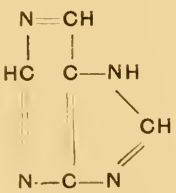

Purine

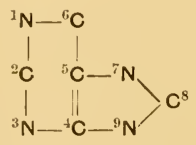

Purine itself is a crystalline basic compound (m. p. $211-212^{\circ} \mathrm{C}$.) which forms salts with acids. It is composed of two rings, the pyrimidine and the iminazole: the latter grouping also occurs in histidine (see p. 121). 
The chief purine bases which occur in plants are xanthine, caffeine, theobromine, guanine, hypoxanthine and adenine.

Xanthine may be regarded as 2, 6-dioxypurine:<smiles>O=c1[nH]c(=O)c2[nH]cnc2[nH]1</smiles>

It is widely distributed in plants and has been found in leaves of the Tea plant (Thea sinensis), in the sap of the Beetroot (Beta) and in various seedlings.

Caffeine or theine is 1,3, 7-trimethylxanthine:

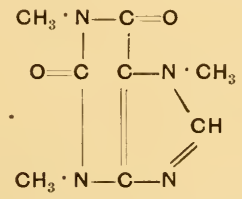

It occurs in the leaves and beans of the Coffee plant (Coffea arabica), in leaves of the Tea plant (Thea sinensis), in leaves of Ilex paraguensis ("Paraguay Tea"), in the fruit of Paullinia Cupana and in Kola nuts (Cola acuminuta).

Expt. 158. Preparation of caffeine from tea ${ }^{1}$. Digest $100 \mathrm{gms}$. of tea with 500 c.c. of boiling water for a quarter of an hour. Then filter through thin cloth or fine muslin using a hot-water filter in order to keep the liquid hot. Wash the residue with a further 250 c.c. of boiling water. Add to the filtrate a solution of basic lead acetate until no more precipitate is formed. This removes proteins and tannins. Filter hot and to the boiling filtrate add dilute sulphuric acid until the lead is precipitated as sulphate. Filter from the lead sulphate, and concentrate the solution, with the addition of animal charcoal, to $250-300$ c.c. Filter and extract the filtrate three times with small quantities (50 c.c.) of chloroform. Distil off the chloroform on a water-bath, and dissolve the residue in a small quantity of hot water. On allowing the solution to evaporate very slowly, long silky needles of caffeine separate, which may have a slightly yellow tint, in which case they should be drained, redissolved in water, and boiled with the addition of animal charcoal. The yield should be about $1.5 \mathrm{gm}$.

Evaporate a little of the caffeine on a water-bath with bromine water. A reddishbrown residue is left which becomes purple when treated with ammonia.

1 From Conen, Practical Organic Chemistry. 
Theobromine is 3, 7-dimethylxanthine:<smiles></smiles>

It occurs in the fruit of the Cocoa plant (Theobroma Cacao), in leaves of the Tea plant (Thea sinensis) and in the Kola nut (Cola acuminata).

Guanine and hypoxanthine can be represented respectively as 2-amino, 6-oxypurine and 6-monoxypurine:<smiles>Nc1nc2nc[nH]c2[nH]c1=O</smiles>

Guanine<smiles>O=C1NC2NC3=NCN1C32</smiles>

Hypoxanthine

They usually occur together and have been found in the germinating seeds of the Sycamore (Acer pseudoplatanus), Pumpkin (Cucurbita Pepo), Common Vetch (Vicia sativa), Meadow Clover (Trifolium pratense), yellow Lupin (Lupinus luteus) and Barley (Hordeum vulgare): also in the juice of the Beet (Beta).

Adenine is 6-aminopurine. It is represented as:

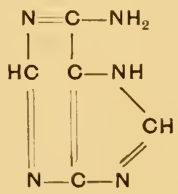

It has been found in Beet (Beta), Tea leaves (Theu sinensis) and in leaves of the Dutch Clover (Trifolium repens).

Guanine, hypoxanthine and adenine are all obtained by the hydrolysis of plant nucleoproteins. 


\section{REFERENCES}

\section{Books}

1. Abderhalden, E. Biochemisches Handlexikon, v. Berlin, 1911.

2. Allen's Commercial Organic Analysis. Vegetable Alkaloids (G. Barger), Vol. 7, 1913, pp. 1-94.

3. Barger, G. The simpler Natural Bases. London, 1914.

4. Henry, T. A. The Plant Alkaloids. London, 1913.

5. Winterstein, E., und Trier, G. Die Alkaloide. Berlin, 1910. 


\section{INDEX}

Figures in heavy type denote main references.

Abderhalden, 9, 24, 77, 86, 140, 153, 167

Abies pectinata, 136

Acacia, 61

Acacia Senegal, 61

Acer pseudoplatanus, 166

Acetic acid, 79

Acetone, 143,148

Achroodextrin, 57

Acorus Calamus, 155

Acrolëin, 83

Acrylic aldehyde (see Acrolëin)

- series, 79

Adenine, 166

Adipo-celluloses, 65, 69

Adzuki-bean, 126

Aegopodium Podagraria, 95

Aesculetin, 144, 150

Aesculin, 144, 150

Aesculus, 112, 144, 151

Aetiophyllin, 30

Hippocastanum, 92, 93, 136, 150

Aetioporphyrin, 32

Agar, 13, 49, 50

Alanine, 120

Albumins, 118, 124

Albumoses, 118, 119, 128

Alcoholic fermentation, 21

Alder Buckthorn, 146

Aleurone, 118

Alkaloidal reagents, 124,158

Alkaloids, 154, 157

Alkanet, 81

Allen, 9, 86, 153, 167

Allium, 62,70

- Cepa, 59, 74

Allocyanidin, 105, 106

Allocyanin, 106, 107

Almond, 61, 80, 126, 145, 147

Aloe, 62,113

Althaea rosea, 62, 102

Althaein, 102

Alyssum, 110, 111, 112

Amandin, 126

Amarantaceae, 100, 156

Amaranthus, 100

Amines, 154, 155

Amino-acids, 119, 136, 156

Ampelopsidin, 102

Ampelopsin, 102

Ampelopsis quinquefolia, 102

Amphoteric electrolytes, 15, 120

Amygdalase, 145

Amygdalin, 24, 142, 143, 145, 147

Amylodextrin, 57

Amyloid, 66

Ananas sativus, 139
Anchusa officinalis, 81

Aniline acetate (test for pentoses), 44

Anonaceae, 164

Anthocyan pigments, 87, 98

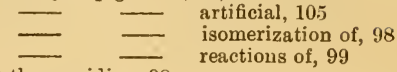

Anthocyanidins, 98

Anthocyanins, 98

Antirrhinum, 94

Antiseptics, 18 majus, 95, 96, 99

Apigenin, 95, 144

Apiin, 95, 144

Apiose, 144

Apium graveolens, 156

A pocynaceae, 157

A pomorphine, 164

Apple, 63, 107, 112, 145

Apricot, 126

Aquilegia, 98, 100

$$
\text { vulgaris, 146, } 147
$$

Araban, 43, 45, 53, 60, 61

Arabic acid, 61

Arabin (see Gum Arabic)

Arabinose, 41, 43, 44, 53, 60, 61, 62, 63

Arabis, 108, 112

Araceae, 145

Arachidic acid, 79

Arachis hypogaea, 127

Araliaceae, 150

Arbutin, 88, 144, 151

Arctostaphylos Uva-ursi, 151

Areca Catechu, 1099

Areca Palm, 159

Arecoline, 159

Arginine, 121, 136

Armstrong, 19, 24, 77, 84, 86, 115, 145, 146, 153

Aromatic acids, 87,89

- alcohols, 87,88

- aldehydes, 87,88

compounds, 1,87

Arsenic trisulphide sol, 12,16

Artichoke, 59, 136, 1506

Arum maculatum, 146, 147

Asclepiadaceae, 145

Ash, 81

Asparagin, 136

Asparagus, 59, 60, 88, 143, 1 ๖ 1

officinalis, 88

Aspartic acid, 120, 136

Aster, 102

Asterin, 102

Astragalus, 61 
Atkins, 77

Atriplex, 100

Atropa Belladoma, 161

Atropine, 161

Aubrietia, 108

Aucuba, 144

Aueubigenin, 144

Aucubin, 144

Auld, 24, 25

Autolysis, 19, 138, 146

Avena sativa, $125,126,156,160$

Avenalin, 126

Bamboo, 137, 156

Bambusa, 137, 156

Banana, 138

Barberry, 164

Barger, 167

Barley, 57, 113, 124, 127, 131, 155, 156, 166

Basidionycetes, 113

Bassett, 95, 96, 116

Bayliss, 14, 16, 19, 24

Bearberry, 151

Beech, 156

C Copper, 100

- -wood, 67

Beet, $63,71,72,76,100,107,136,137$, $138,156,165,166$

Behenic acid, 79

Benzaldehyde, 24, 143, 144, 14j

Benzidine (test for peroxidase), 109

Benzoic acid, 143

Berberidaceae, 145

Berberine, 164

Berberis vulgaris, 164

Bertholletia excelsa, 81, 83, 125, 126, 135

Beta, 72, 75, 143, 165, 166 156

Betaines, 154, 156

Betonica, 161 officinalis, 156, 157

Betonicine, 157

Betony, 156, 157

Betulaceae, 80

Bignoniaceae, 145

Bilberry, 10:

Bird Cherry, 45, ti1, 145

Bird's-foot Trefoil, 146, 147

Biuret reaction, 122

Blau, 153

Blood, 138, 140

Boletus cyanescens, 113

Luridus, 113

Bolton, 116

Boraginaceae, 108

Borneol, 2

Bourquelot, 147, 151, 153

Bran, 45, 53, 54, 55, 68

Brassica, 75, 81, 138, 149

$-\quad$ alba, $127,135,138,144$
campestris, 127,136

Napus, 80, 156
Brassica nigra, 144, 149

oleracea, 136

rapa var. oleifera, 80

Brassidic acid, 79

Brazil nut, 81, 83, 125, 126, 135

Broad Bean, 60, 124, 126, 133, 134, 138, 139,156

Bromelin, 139

Broom, 162

Brown, 70, 73, 74, 77

Brownian movement, 14

Brucine, 163

Brïcke's reagent, 158

Buchner, 21

Buckthorn, 96

Burton, 16

Buttercup, 108

Butter-nut, 126

Butyric acid, 79

Cabbage, 136, 137, 138, 139, 156;

Caesalpinia, 91

Caffeic acid, 110

Caffeine, 165

Calanthe, 152

Caldwell, 24, 25

Callistephin, 102

Callistephus chimensis, $10^{2}$

Calluna erica, 96

Campanulaceae, 58

Campbell, 134, 141

Camphor, 2

$$
\text { tree, } 2
$$

Cane-sugar (see Sucrose)

Cannabis sativa, 67, 80, 125, 126, 134, 139, 156,160

Capparis, 144

Capric acid, 79, 80

Caprifoliaceae, 145, 150

Caproic acid, 79, 80

Caprylic acid, 79,80

Carbohydrates, 1, 41 in leaves, 69

Carbon assimilation, 5, 26

Carboxylase, 21

Caricu Papaya, 13!)

Carotin, 27, 2^, 29, 39

Carrot, 39, 65, 13\%, 139, 155, 156

Carum, 144

- Petroselinum, 95

Castumea, 91, 93

Castanin, $126^{\circ}$ vulgaris, 92,126

Castor oil, 81

-plant, 80, 83, 84, 125, 136

-seed, 124, 127, 135, 139

Catalase, 20, 21, 23.

Catalysts, 17

Catechol, 68, 87, 110, 11

Celastraceae, 145

Celery, 137, 156;

Celluloses, 41, 65

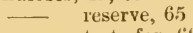

tests for, 66 
Centamrea, 144

Cyаnus, 98, 100, 101, 102, 104

Centrospermae, 150

Cerasin (see Cherry gum)

Cerasus, 144

$$
\text { Padus, } 145
$$

Chaerophyllum sylvestre, 72

('heiranthus, 106 108

$$
\text { Cheiri, 96, 47, 99, 100, 107, }
$$

Chenopodiaceae, 100,156

Chenopodium, 136

$$
\text { Vulvaria, } 155
$$

Cherry, 45, 61, 63, 80, 102

$$
\text { gum, } 43,45,53
$$

Chervil, 72

$$
\text { Laurel, 145, } 146
$$

Chicory, 58, 60, 136, 156

Chittenden, 128, 140

Chlorophyll, 13, 27

$$
\begin{array}{ll}
- & \mathrm{a}, 27,29,32 \\
- & \mathrm{b}, 28,29,32 \\
- & \text { allomerized, } 36 \\
- & \begin{array}{l}
\text { colloidal, } 35,37 \\
- \\
-
\end{array} \quad \text { erystalline, } 32
\end{array}
$$

Chlorophyllase, 33

Chlorophyllides, $3:$

Chlorophyllins, 29

Chodat, 107, 108, 115

Choline, 155

Christmas Rose, 108

Chrysanthemin, 102

Chrysanthemum, 101, 102

Chrysin, 95 inslieum, 102

Cichorium Intybus, 58, 136, 156

Cinchona, 162, 163

Calisaya, 162
$-\quad$ Ledgeriana, 162
$-\quad$ officinalis, 162
$-\quad$ succirubra, 162

Cinchonine, 163

Citrus, 144

- Aurantium, 161

Clark, 76, 78, 115

Clover, $59,60,65,74,75,137$

- Dutch, 166

- Meadow, 166

Clupanodonic acid, 80

Coca, 161, 162

Cocaine, $16: 2$

Cochlearia, 109

Cocoa, 81

$$
\text { Armoracia, } 149
$$

plant, 166

Coconut, 53, 80, 83, 127, 135

Cocos, 81

$$
\text { oil, } 81
$$

Codeine, 164

Co-enzyme, 21

Coffen arabica, 59, $60,81,160,16 i)$

Coffee bean, $59,60,81,160,16 i$

Colı acuminata, 165, 166
Cole, 9, 43, 122

Collodion dialyser, $1: 3$

Colloidal state, 4, 10 precipitation of , 15,16

Columbine, 98, 100, 146, 147

Colza, 80 oil, 81

Combes, 105, 115

Combretaceae, 150

Compositae, 58, 81, 108, 145, 150

Conglutin, 126, 133

Coniferae, 53, 60, 136, 143, 151

Coniferin, 67, 88, 143, 151

Conifers, 2, 28

Coniferyl alcohol, 88, 143, 151

Coniine, 159

Conium maculatum, 159

Continuous phase, 11,14

Convolvulaceae, 145

Corchorus, 67

Cork, 69

Cornflower, 98, 100, 101, 102, 10.1, 106

Corydaline, 164

Corydalis cava, 164

Corylin, 126

Corylus Avellana, 80, 126

Cotton plant, 53, 65, 81 var. rubra, 100

- seed, $127,135,156$

- oil, 81

Cotyledon Unbilicus, 74

Coumarin, 150

Courtauld, 24, 25

Cow Parsnip, 32

Cow Pea, 126

Cradein, 139

Cranberry, 88, 102

Crassulaceae, 108

Crataegus, 108 Oxyacantha, 95, 96, 146, 15.5

Cresol, 68, 113

Cruciferae, 80, 108, 136, 145, 14!)

Cucumber, 138, 139

Cucumis Melo, 138

- sutivus, 138

C'ucurbita, 136, 137

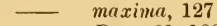

Pepo, 81, 166

Cucurbitaceae, 81,150

Curarine, 163

Currants, 63

Black, 146

Red, 146

Cuskhygrine, 161

Cutin, 65

Cuto-celluloses, 65, 69

Cyanidin, 101, 102, 105, 14

Cyanin, 102, 144

Cynips, 91

Cystine, 121, 123

Cytase, 20

Cytisine, 16:

Cytisus Labnrnum, 162

Crapek, 9, 67, 68, 77 
Dahlia, 58, 75, 102, 113, 136, 137, 138, 156, 160

Dahlia variabilis, $58,102,113,138$

Daisl, $55,70,71,72,75,76,77$

Dandelion, 58, 60, 95, 108

Date-palm, 59, 60

Datura, 155

- Stramonium, 161

Daucus Curota, 65, 138, 155, 156

Davis, $42,55,70,71,72,75,76,77,78$

Dead Nettle, 108

Deadly Nightshade, 161

Dean, 138, 140

Delphinidin, 101, 102, 105, 144

Delphinin, 102, 144

Delphinium, 100, 144 consoliula, 97,102

Dextrin, 41, 56, 57, 69, 70, 73 tests for, 58

Dhurrin, 143, 148

Dialysis, 10,13

Diastase, $20,56,57,69,73$

Digallic acid, 92

Digitaligenin, 144

Digitalin, 144

Digitalis, 144

Digitalose, 144

Dipsacus, 113

Disaccharides, 41,51

Dispersed phase, 11, 14

Dobson, $71,76,78$

Dock, 95

Dog's Mercury, 113

- — annual, 155

Dunstan, 153 perennial, 155

Dyer's Greenweed (Broom), 96 Weld (Rocket), 94, 96

Edestin, 125, 126, 128, 134

- of Barley, 131

Elaeis guinensis, 80,81

Elaïdic acid, 79

Elder, 28, 68, 95, 137, 146

Ellagic acid, 90

Emulsin, 20, 88, 142, 145, 147, 151, 1.52

Emulsions, 11, 12

Emulsoids, 11

Enolic form, 72

Enzymes, 7, 17 classification of, 19,20

Erepsin, 20, 137 hydrolysis by, 8,17 synthesis by, 8,19

Ergothioneine, 157

Erica cinerea, 94

Ericaceae, 88, 144, 151

Erucic acid, 79

Ervum Lens, 124, 126, 133

Erythrina Hypaphorus, 157

Erythrodextrin, 57

Erythroxylaceae, 16:

Erythroxylon Cocu, 161, 162

Esbach's solution, 121

Essential oils, 2
Ethylene series, 82

Eucalyptus, 91

Euler, 24

Euphorbia, 62

Euphorbiaceae, 80, 145)

Everest, 98, 105, 115, 116

Ewart, 115

Excelsin, 126, 135

Fagus sylvatica, 156

Fats, 1, 79

tests for, 81

Fatty acids, 79

- synthesis of, 85

Fehling's test, 49

Fenugreek, 156, 160

Ferric hydroxide sol, 12

Fibrin, 139

- carmine, 140

Fichtenholz, 151, 153

Ficus, 139

Fig, 139

Fischer, 92, 115

Fisetin, 97, 105

Flavone pigments, 87, 93, 104

Flavonol pigments, 87, 93, 104

Flax, 62, 67, 80, 125, 127, 147, 148

Flowering Currant, 93

Forget-me-not, 108

Formaldehyde, 26, 27, 36, 38

Fraxetin, 144

Fraxin, 144

Fraxinus, 144 excelsior, 81

Freudenberg, 92, 115

Fructomannans, 59, 69

Fructose (see Laevulose)

Fumariaceae, 164

Fungi, 20, 113, 155, 157

Funkia sinensis, 74

Furfural, 44, 67 phloroglucide, 55, 64

Gaillardia, 101

Galaetans, 41, 49, 60, 61, 69

Galactoaraban, 60, 69

Galactomannan, $59,60,69$

Galactose, $41,47,49,50,60,61,62,63,144$

Galactoxylan, 60, 69

Galunthus, 55

Galeopsis, 33

$$
\text { nivalis, 70, 9.5 }
$$

Tetrahit, 32

Gallic acid, 89, 90

Gall-nuts, 89

Gallotannic acid, 9*2

Galls, 91 Oak, 92

Garden Cress, 80

Gaultheria, 144

Gaultherin, 144

Gelatine, 13

Gels, 13, 63 
Genista tinctoria, 96

Glialin, 118, 127, 130

Globulins, 118, 124

Glucomawnans, 59,69

Glucose, $41,45,46,56,62,70,73,142$ $a$ and $\beta, 48$ tests for, 48

(ilucosides, 48, 72, 87, 91, 142

$$
\begin{aligned}
& a \text { and } \beta, 48,143 \\
& -\quad \text { coumarin, } 150 \\
& -\quad \text { eyanophoric, } 145
\end{aligned}
$$

Glucotropaeolin, 144

Glutamine, 136

Glutaminic acid, 120, 136

Glutelins, 118, 127. 130

Gluten, 131

Glutenin, 130

Glyceria aquatica, 146;

Glycerol, 79, 82, 83

Glycine, 120,156

Glycine lispida, 126

Glycinin, 126

Glycogen, 21

Glycogenase, 21, 24

Glyoxylic reaction, $12 \%$

Gold sol, 12, 16

Goodeniaceae, 58

Gooseberry, 63, (i5, 141 i

Goosefoot, 136

Gosney, 86

$$
\text { Stinking, } 155
$$

Gossypium, 53, 81, 144

(routweed, 95

herbaceum, $65,81,127,135,156$

Grahau, 13

Graminaceae, $80,130,145,150$

Grape, 102

- sugar (see Glucose)

Great Millet, 148

Greengage, 112

Greshofi, 145, 153

Guaiacol, 68

('naiaconic acid, 107

Guaiacum grun, 107

Guaiacum officinale, 107

Guanine, 166 sanctum, 107

Guignard, 149, 153

Gulose, 46

Gum Arabic, 12, 43, 53, 61

Gum Tragacantlı, 61

Gums, 41, 49, 60

Gun-cotton, 66

Guttiferae, 150

\section{Haas, 9}

Harden, 22, 23, 24, 25

Harris, 134, 141

Hatschek, 16

Hawthorn, 95, 96, 108, 146, 155

Haynes, 63, 78

Hazel, 80
Hazel, red-leaved, 100

Hedge Woundwort, 32

Helianthus, 60, 75, 136

annuus, $55,74,81,127,135$,
156
tuberosus, $58,59,74,136,156$

Helleborus niger, 108

Hemerocallis fulva, 74

Hemi-cellulose, 60, 69

Hemlock, 159

Hemp, 67, 80, 125, 126, 156, 160

- seed, 134, 139

Hemp-nettle, 32

Henbane, 155, 162

Henry, 24, 25, 153, 167

Heracleum, 33

Sphondylium, 32

Hesueridin, 144

Hesperitin, 144

Hexoses, 41, 45

Hill, 9

Histidine, 121, 137 trimethyl, 157

Hollyhock, 62, 102

Hop, 74

Hopkins, 122

Hordein, 127, 131

Hordenine, 155

IIordeum vulgare, 57, 74, 113, 124, 127. 131 . 166

Horse Chestnut, 92, 93, 112, 136, 150

Horse-radish, 109, 110, 149

Horsfall, 96, 116

Horton, 145, 153

Hummel, 96, 97, 116

Humulus Lupulus, 74

Hyacinth, 138, 139

Hyacinthus, 55, 58

Hydrastine, 164 orientalis, 138

Hydrastis canadensis, 164

Hydrocharis Morsus-ranae, 74

Hydroquinone, 87, 88, 144, 151

Hygrine, 161

Hymenophyllum demissum, 74

Hyoseyamiue, 162

Ilyoscyamus muticus, 155, 16:2

Hypaphorine, 157

Hypoxanthine, 166

Idaein, 102

Idose, 46

Ilex paragueusis, 165

Iminazole, 159, 164

Indican, 115, 144, 152

Indigo, 113, 115, 152 plants, 15:

Indigofera, 113, 144

$-\quad$ Anil, 152

sumatrana, 152

Indol, 68 tinctoria, $15^{\circ}$ 
Indoxyl, 115, 144, 152

Inulase, 20, 58

Inulin, 41, 50, 58

- tests for, 59

Invertase, 20, 21, 24, 50, 76

Invert sugar, 50

Iris, 55, 58

Irvine, $71,76,78$

Isatis tinctoria, 113,152

Isochlorophyllins, 30

Isoleucine, 120,136

Isolinolenic acid, 80

Iso-oleic acid, 79

Isoquercitrin, 144

Isouuinoline, 159

Isothiocyanate, acrinyl, 144

$$
\begin{array}{ll}
\square & \text { allyl, } 144,149 \\
- & \text { benzyl, } 144 \\
\square \text {-hydroxybenzyl, } 149
\end{array}
$$

Jacobinia, 113

Japanese lacquer, 113

Jusminum, 143

Jerusalem Artichoke, 58

Jörgensen, 27, 36, 40

Juglandaceae, 80

Juglans cinerea, 126

- nigra, 126

$$
\text { regia, } 80,92,126
$$

Juglansin, 126

Jute, 67

Kaempferol, 97, 105, 144

Kastle, 76, 78

Keeble, 115

Keracyanin, 102

Kidd, 27, 36, 40

Kidney Bean, 60, 124, 126, 133, 134, 136 , 160

Kishida, 93, 116

Kola nut, 165,166

Labiatae, 108

Laburnum, 162

Laccases, 112

$\gamma$-Lactone, 47

Laevulose, 41, 50, 58, 70

tests for, 51

Lamium album, 108

Larch, 92

Larix europaea, 92

Larkspur, 97, 100, 102

Latex, 11

Lathyrus odoraius, 74

- pratensis, 74

Laudanosine, 164

Lauric acid, 79,80

Laurocerasin (see Prulaurasin)

Leathes, 86

Lecythidaceae, $81,83,150$

Legumelin, 124, 134

Legumin, 125, 126, 133

Leguminosae, $59,74,125,133,145,150$, 157,162
Lemon, 2

Lentil, 124, 126, 133, 134

Lepidium, 144

$$
\text { sativum, } 80
$$

Leucine, 120, 136

Leucosin, 23, 124, 130

Lignin, 65, 67, 68

Ligno-celluloses, 65, 67

Lignon (see Lignin)

Ligustrum, 143

Lilac, 65, 95

Liliaceae, 150

Lilium bulbiferum, 60

— candidum, 60, 95

Lily, 60 Martagon, 60

White, 95

Lima-bean, 126

Limonene, 2

Linaceae, 80, 145

Linamarin, 143, 148

Ling, 94, 96

Linolenic acid, 80

Linolic acid, 80

Linseed, 62, 81, 125, 135

Linum, 62, 143, 148

__ perenne, 147

135 usitatissimum, 67, 80, 81, 125, 127,

Lipase, 20, 84

Lobeliaceae, 58

Loganiaceae, 150

Lotase, 148

Lotoflavin, 144, 148

Lotus, 144

- arabicus, 148

— corniculatus, 74, 146, 147 uliginosus, 146

Lotusin, 144, 148

Lubrzynska, 86

Lucerne, 65

Lupin, 60, 126, 133, 136, 138, 139, 156, 162, 166

Lupinine, 162

Lupinus, 60, 74, 126, 136, 137

albus, 137

- hirsutus, 138

- luteus, 133, 137, 162, 166 niger, 162

Luteolin, 96, 105

Lycium barbarum, 156

Lycopersicum esculentum, 138

Lysine, 121, 137

Lyxose, 43

Mackenzie, 77

Magnoliaceae, 150

Maize, 80, 126, 127, 132, 138, 139

- cobs, 53

Mallison, 116, 117

Mallow, 102

Malt, 76

Maltase, $19,20,21,22,41,75$

Maltose, $19,51,56,57,69,70,73,75$ 
Maltose, tests for, 52

Malva, 144

- sylvestris, 102

Malvaceae, 81

Malvidin, 102,144

Malvin, 102, 144

Mandelonitrile glucoside (see Prunasin)

Mandragora, 162

Mandrake, 162

Mangold, $70,71,72,75$

Mangrove, 91

Mannans, $41,50,59,69$

Mannocelluloses, 59

Mannose, 41, 46, 50, 59, 62, 144

Martin, 117

Matthiola, 95, 108

Maxwell, 60,78

Maysin, 126

Meadow-Rue, 146

- -Sage, 156

-Sweet, 88, 152

Medicago sativa, 65

Mekocyanin, 102

Melon, 138, 139

Mendel, 128, 140

Menispermaceae, 164

Menthol, 2

Mercerised cotton, 66

Mercurialis annua, 113, 155

Metaproteins, 118, 127 perennis, 113,155

Methylamine, $\mathbf{1 5 5}$

Methylene blue, 23

Methyl salicylate, 144

Mieg, 117

Mignonette, 96

Milk, 11

Miller, 86

Millon's reaction, 122

Mirande, 146, 153

Mistletoe, 62

Molisch's reaction, 123

Monocotyledons, $55,58,70$

Monosaccharides, 41, 42

Moore, 115

Moore's test, 48

Moraceae, 80

Morphine, 164

Morris, $70,73,74,77$

Mountain Ash, 145, 155

Mucic acid, 49, 50, 62, 63

Mucilages, $41,49,50,60,62,65$

Musa sapientum, 138

Muscari, 58

Mustard, Black, 80, 149

White, 80, 127, 149

Myosotis, 108 seed, 135,138

Myrica, 144

Myricetin, 97, 105, 144

Myricitrin, 144

Myristic acid, 79,80

Myrosin, 20, 142, 149
Myrtaceae, 145, 150

Myrtillidin, 102, 103

Myrtillin, 102

Nagai, 93, 116

$a-$ Naphthol tests, 44, 68, 109

Narceine, 164

Narcissus, 95, 96, 106

—_ incomparabilis, 96

poeticus, 95

Narcotine, 164

Tazetta, 96

Narigenin, 144

Naringin, 144

Nasturtium, 55, 60, 75, 101, 138

Nepenthes, 139

Garden, 70, 72, 136

Nettle, 28

Neville, 62, 78

Newbury, 116

Nicotiana, 155

Nicotine, 159, 160

Nolan, 117

Norris, 23, 25

Nucleic acid, 127

Nucleoproteins, 118, 127, 166

Nux Vomica, 163

Oak, 91, 93, 96 wood, 67,92

Oat, $125,126,156,160$

Oenidin, 102, 103, 144

Denin, 102, 144

Oil Palm, 80

Olea europaea, 81

Oleaceae, 81, 145, 150

Oleic acid, 79, 80

Olive, 81 oil, 81

Onion, 59, 96, 97, 108

Onslow, 110, 111, 115

Opium, 164 Poppy, 80, 164

Orache, 100

Orange Tree, 161

Orchid, 89, 113, 152

Orchidaceae, 60

Orchis Morio, 62

Orcinol, 68

- test for pentoses, 44

Ormerod, 86

Oryza sativa, 127

Osazones, 49

Osborne, 130, 131, 132, 134, 135, 140

Osmic acid, 81

Ostwald, 13

Oxidases, 107, 108, 151, 152

Oxidizing enzymes, 8, 107

Oxybenzoic acid, 144

Oxyproline, 157

Paeonia, 60, 85, 144

- officinalis, 93, 99, 102, 103 
Paeony, 60, 93, 99, 102, 103

Palladin, 9, 114, 115

Palm, 59, 60

- oil, 81

Palmaceae, 80

Palmitic acid, 79, 80

Pansy, 96, 102

Papain, 139

Papaver orientale, 113

- Rhoeas, 102

- somniferum, 80,164

Papaveraceae, $80,157,164$

Papaverine, 164

Papaw Tree, 139

Parkin, 60, 70, 78

Parsley, 95

Passifloraceae, 145

Paullinia Cupana, 165

Pea, 57, 60, 72, 74, 75, 108, 122, 124, $125,126,133,134,136,138,139,156$, 160

Peach, 80, 126, 145

Pea-nut, 127

Pear, 107, 110, 111, 112, 151

Pectase, 20, 65

Pectic substances, 41, 63, 69

Pectin, 63, 64

Pectinase, 20

Pectinogen, 63, 64

Pectocelluloses, 65, 69

Pelargonidin, 101, 102, 105, 144

Pelargonin, 102, 103, 144

Pelargonium, 144

Pelletierine, 162

$$
\text { zonale, } 93,102,103,138
$$

Pentosans, 42, 53, 54, 55, 61, 67, 69, 70

Pentoses, 41, 42, 54, 55, 63, 64, 70

Peonidin, 102, 144

Peonin, 102, 144

Pepper, 160

Peppermint, 2

Pepsin, 20, 128, 137

Peptones, 118, 119, 128, 129, 137

Perkin, 95, 96, 97, 115, 116

Peroxidase, 20, 21, 22, 107, 108, 109

Peroxides, 108 inhibitor, 23

Petunia violacea, 102

Petunidin, 102

Petunin, 102

Phaeophorbides, 34

Phaeophytin, 31, 37, 38

Phajus, 113, 152

Phaselin, 124, 134

Phaseolin, 126, 133

Phaseolunatin, 148

Phaseolus, 60, 136, 143

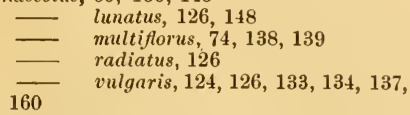

Phenol, 68

Phenols, 87
Phenylalanine, 121, 122, 137

$p$-l'henylenediamine (test for peroxidase), 109

Philip, 16

Phipps, 97, 116

Phloretin, 144

Phloridzin, 144

Phloroglucin, 7, 68, 88

Phlox, 95

(test for pentoses), 44

Phoenix, 60

Phosphatides, 155

Phosphotungstic acid, 124, 158

Phyllins, 30

Phytelephas macrocarpa, 60

Phytochlorins, 31

Phytol, 30, 33, 38

Plytolacca, 100

Phytolaccaceae, 100

Phytorhodins, 31

Picea excelsa, 136

Picramic acid, 146

Pine-apple, 139

Pinene, 2

Pink, 95

Pinus sylvestris, 136

Piper nigrum, 160

Piperaceae, 150

Piperidine, 161

Piperine, 160

Pisum, 60, 122, 136, 137

- sativum, $57,72,74,75,108,124$,

$126,133,134,138,139,156,160$

Pitcher-plant, 139

Pittosporaceae, 150

Plantago, 144

lanceolata, 95

Plastid pigments, 39, 101

Plimmer, y

Plum, 61, 80, 107, 126, 145

Polarization, 47

Polemoniaceae, $\mathbf{1 5 0}$

Polygalaceae, 150

Polygonum, 144 tinctorium, 152

Polypeptides, 118

Polysaccharides, 41, 53

Pomegranate Tree, 162

Poplar, 95, 152

Poppy, 102

Populin, 143

Populus, 74, 95, 143, 152

Porphyrins, 32

Portulaca, 100

Portulacaceae, 100

Potassium hydrngen sulphate, 144

Potato, 70, 75, 110, 111, 112, 113, 114, 126, $136,137,156,160$

Priestley, 36, 40

Primulaceae, 150

Prolamins, 118, 127, 130

Proline, 121, 137, 157

Proteaceae, 150

Proteases, 23, 137 
Proteins, 2, 12, 16, 118

- crystalline, $125,127,134$ of cereals, 130 of fat-containing seeds, 134 of Leguminosae, 133 tests for, 122

Proteoses, 118, 128

Protocatechuic acid, 89, 90, 110

Protoplasm, 4, 8

Prulaurasin, 144, 146

Prunase, 145

Prunasin, 144, 145

Prunиs, 97, 143, 144, 145

- Amygdalus, 61, 80, 126, 145

Armeniaca, 126

Cerasus, 45, 61, 80, 102 domestica, 61, 80, 126, 145

Laurocerasus, 145,146

Padus, 45, 61

Persica, 80, 126, 145

Prussic acid, 24, 143, 144, 145

Punica Grunatum, 162

Punicaceae, 162

Pumpkin, 81, 166

Purine, 159, 164

bases, 127, 154, 164

Purpurogallin, 110

Putrescine, 155

Pyridine, 159

Pyrimidine, 159, 164

Pyrogallol, 68, 109, 110

Pyrola, 151

Pyrrole, 159, 161

Pyrrolidine, 155, 161

Pyrus, 143

- Aucuparia, 145, 155

communis, 151

Malus, 145

Pyruvic acid, 86

Quercetin, 96, 105, 106, 144

Quercitrin, 144

Quercus, 91, 96, 144

- Robur, 93

Quinine, 158, 162

Quinoline, 159, 162

Radish, 127

Raffinose, 41

Ranunculaceae, 145, 150, 157, 164

Ranunculus acris, 108

Rape, 80,127

$$
\text { aquatilis, } 136
$$

Raphanus sativus, 127

Raspberry, 65

Red Seaweeds, 49

Reductase, 20, 21, 23

Reed Poa, 146

Reeves, 141

Reseda luteola, 94, 96

Reserve celluloses, 65

materials, $9,55,58,71,80,118$

Resorcinol, 68, 87

Respiration, 5, 71, 114
Respiration pigments, 114

Reversible reactions, 18

Reynolds Green, 84, 86

Rhamnaceae, 145, 150

Rhamnose, 96, 144

Rhamnns, 96

Rhizophora, 91

$$
\text { Frangula, } 146
$$

Rhodophyceae, 13,49

Rhubarb, 63

Rhus, 91, 97

- Coriaria, 92

- Cotinus, 93

- vernicifera, 113

Ribes Grossularia, 146

- nigrum, 146

_ rubrum, 146

- sanguineum, 93

Ribośe, 43

Ribwort Plantain, 95

Rice, 127

Ricin, 124, 135

Ricinoleic acid, 80

Ricinus, 81, 83, 85, 136

- communis, 80, 84, 124, 125, 127, 135,139

Robertson, 71, 76, 78

Robinia, 144

Robinin, 144

Rosa, 144 gallica, 102, 104

Rosaceae, $61,80.144,145,150$

Rose, 93, 99

Rosemary, 2

Rubiaceae, 60, 81, 113, 145, 157, 162

Rumex obtusifolius, 95

Ruscus, 59

Russula nigricans, 113

Ruta, 144

Rutaceae, 145, 150, 164

Rutin, 144

Rye, 124, 127, 132

Saccharonyces, 20

St Ignatius' Bean, 163

Salicin, $48,88,143,148,152$

Salicylic acid, 89

- alcohol, 48, 88, 148, 152

- aldehyde, 88

Saligenin, 88, 143, 148, 152

Salix, 88, 143, 152

Salkowski, 53, 78

Salvia pratensis, 156

Sambucus, 137, 144

$$
\text { nigra, } 68,95,146
$$

Sambunigrin, 144, 146

Saponaria, 150

Saponification, 82

Saponins, 11, 150

Sawdust, 45,54

Sawyer, $42,55,70,71,72,76,77$

Saxifragaceae, 145,150

Scarlct Geranium, 93, 102, 103, 138

__ Runner, 138, 139 
Schenckia blumenaviana, 113

Schryver, $38,39,40,63,78$

Schulze, 60, 78

Schweizer's reagent, 66

Scilla, 58, 62, 70

Scopolia japonica, 161

Scorzonera, 143

Scotch Fir, 136 hispanica, 156,160

Secale cereale, 124, 127, 132

Seliwanoff's test, 51

Serine, 120

Shibata, 93, 116

Silicic acid, 13

Silver Fir, 136

Silver sol, 12, 16

Sinalbin, 141, 149

Sinapin acid sulphate, 144, 149

Sinapis alba, 80, 149

- nigra, 80

Sinigrin, 142, 144, 149

Skatol, 68

Smedley, 86

Snapdragon, 95, 96, 99

Snowdrop, 55, 70, 95

Soap, 11, 12, 16, 82, 83

$$
\text { tests for, } 83
$$$$
\text { -wort, } 150
$$

Sodium picrate test, 146

Solanaceae, 157, 161

Solanum, 75

Sorghum, 143

uberosum, 70, 113, 126

- vulgare, 148

Soy-bean, 126, 156

Spanish (Sweet) Chestnut, 91, 92, 93, 126

Sparteïne, 162

Spartium scoparium, 162

Spatzier, 149, 153

Spinach, 138

Spinacia, 138

Spiraea, 144

Spruce Fir, 136

Squash, 127

Stachydrine, 157, 161

Stuchys sylvatica, 32 tuberifera, 160, 161

Stareh, 12, 16, 55, 69)

— soluble, 56, 74

tests for, 56

Stearic acid, 79

Steiger, 60, 78

Sterculiaceae, 81

Stereoisomerism, $43,46,143$

Stiles, 27, 40

Stock, 95, 108

Stoll, 27, 40, 110, 117

Straw, 45, 53, 54, 68

Strawberry, 63, 65

Strophanthidin, 144

Strophanthin, 144

Strophanthus, 144, 156

hispidus, 160
Strychnine, 163

Strychnos Ignatii, 163

Nux-vomica, 163

toxifera, 163

Substrate, 18

Sucrose, 41, 52, 70, 76

- tests for, 52

Sulphur reaction (for proteins), 123

Sumac, 91, 92, 97

Sunflower, 55, 75, 81, 127, 135, 136, 156

Suspensions, 11, 12

Suspensoids, 11

Sweet Flag, 155

Sycamore, 166

Synthesis by condensation, 3

- of aromatics, 6

- of carbohydrates, 5, 26

of fats, 6,85

Syringa, 143

of proteins, 6,119

- vulgaris, $65,74,95$

Syringenin, 143

Syringin, 143

Talose, 47

Tannic acid, 75, 92, 123, 158

Tannin, 73, 74, 89, 90, 111

- reactions of, 91

Taraxacum, 60 officinale, 58, 95, 108

Tautomerism, 48

Taylor, 16

Tea, 89, 92, 165

- plant, 165, 166

Teasel, 113

Terpenes, 2

Thalictrum uquilegifolium, 146

Thea, 144 sinensis, 165,166

Thebaine, 164

Theine (see Caffeine)

Theobroma Cacao, 81, 166

Theobromine, 166

Thorn Apple, 155, 161

Thyme, 2

Thymelaeaceae, 150

'Thymol, 68

Tiglic acid, 79

Tiliaceae, 145

Tobacco, 155, 156, 159

Tomato, 138

Tragacanth, 61

Trier, 167

Trifolium, 59, 137

- ochroleucum, 74

- prutense, $65,74,75,166$ repens, $\mathbf{1 6 6}$

Trigonella Foenum-graecum, 156, 160

Trigonelline, 157,160

Trimethylamine, 155

Trisaccharides, 41

Tristeariu, 82

Triticum, 113

- vulgare, $124,127,130,139$ 
Trommer's test, 49

Tropacocaine, 162

Tropaeolum, 60, 75, 136, 137, 144 138

Tropane, 159, 161

Trypsin, 139

Tryptophane, 23, 121, 122, 137, 138

Tuberin, 126 trimethyl, 157

Tulip, 138, 139

Tulipa, 138

Turnip, 63, 65, 75, 136, 137, 138

Tyrosinase, 113, 114

Tyrosine, 113, 121, 122, 137

Ultramicroscope, 14

Umbelliferue, 60, 108

Urtica, 28

Urticaceae, 145

Usher, 36,40

Vaccinium, 151

$$
\text { —_ } \quad \begin{aligned}
& \text { Myrtillus, } 102 \\
& \text { Vitis-Idaea, 88, } 102
\end{aligned}
$$

Valine, 120, 136

Van Rijn, 153

Vanilla plunifolia, 89

Vanillin, 67, 89

Vegetable ivory, 60

Vernon, 24

Vetch, 124, 126, 133, 134, 136, 148

- common, 146,166

- hairy, 146

Vicia, 136, 137, 144

- angustifolia, 148

— Faba, 124, 126, 133, 138, 139, 156

- hirsuta, 74, 146

- sativa, $74,124,126,133,136,137$, 146,166

Vicianin, 144,148

Vicianose, 144, 148

Vicilin, 126, 133

Vigna sinensis, 126

Vignin, 126

Vine, 70

Vines, 138, 139, 141

Viola, 108

- odorata, 55, 95, 99
Viola tricolor, 96, 102

Violaceae, 58

Violanin, 102

Violet, 55, 95, 99, 108

Virginian Creeper, 102

Viscum album, 62

Vitis, 144

vinifera, 70,102

Voorhees, 130, 141

Waage, 88, 116

Wallilower, 96, 97, 99, 100, 101, 107, 108

Walnut, 53, 80, 92, 126

- American, 126

Walther, 113, 116

Water Ranunculus, 136

Wax, 69

Weil, 117

Wheat, 56, 113, 124, 127, 130, 139, 156

Wheldale, 94, 95, 96, 98, 104, 115, 116

Whitley, 115

Wig Tree, 93

Wilkinson, 97, 116

Willow, 48, 88, 152

Willstätter, 27, 40,98, 101, 102, 106, 110, 116,117

Wine, 89

Winterstein, 153, 167

Woad, 113, 152

Wohlgemuth, 24

Wood Gum, 53

Xanthine, 165

Xanthone, 87

Xanthophyll, 27, 28, 29, 39

Xanthoproteic reaction, 122

Xylan, $45,53,54,55,60,67$

Xylonic acid, 45,54

Xylose, 41, 43, 45, 53, 54, 60, 61, 62, 63

Yeast, 20

Zea Mays, 80, 126, 127, 132, 138

Zechmeister, 102, 117

Zein, 127, 132

Zilva, 22, 23, 24, 25

Zollinger, 117

Zymase, 20, 21, 22

Zymin, 21, 22

Zymogen, 84

\section{PROPERTY LIBRARY N. C. State College}






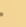




North

QK861.046

PRACTICAL

CAL PLANT BIONiversity Libraries

II 1 IIIIIIIIIIIISTAY

$\mathrm{S} 02778164 \mathrm{~K}$.|I
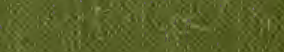

\%.

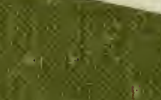

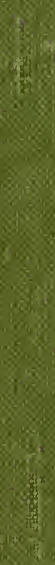

48 